Lara Schrijver

Oswald Mathias Ungers

and Rem Koolhaas

Recalibrating Architecture

in the $1970 \mathrm{~s}$

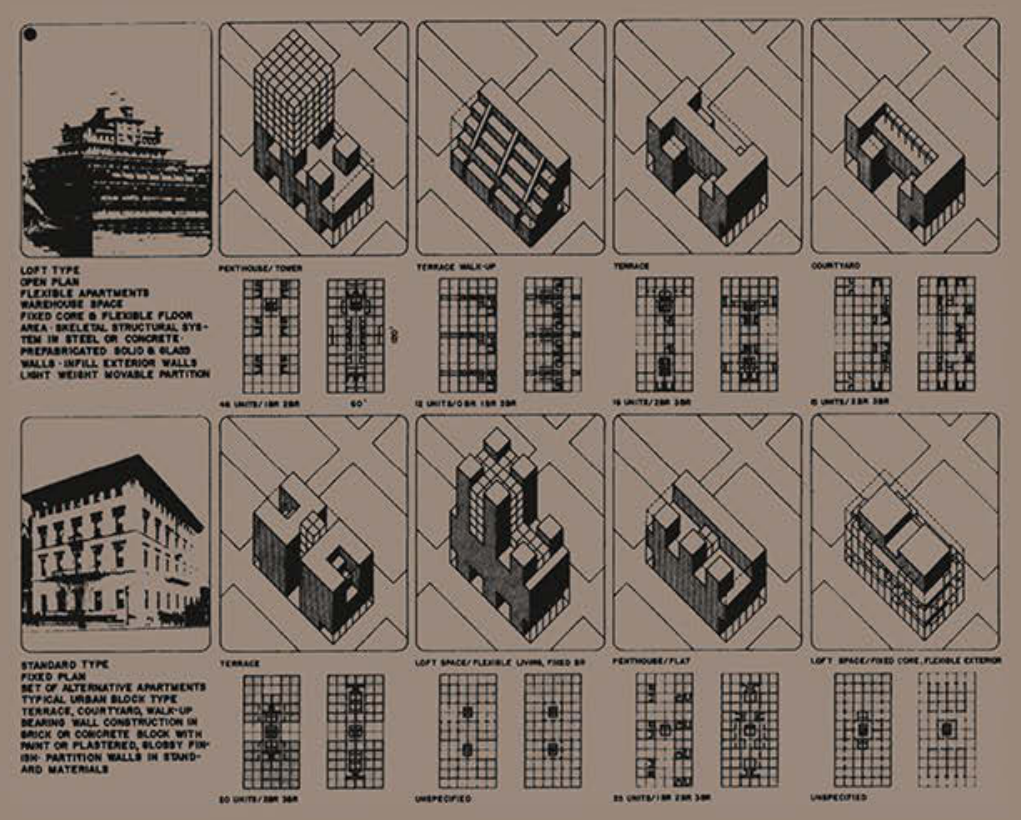

[transcript] 
Lara Schrijver

Oswald Mathias Ungers and Rem Koolhaas

Architecture | Volume 63 
Lara Schrijver is professor in architecture theory at the University of Antwerp Faculty of Design Sciences. She has served as editor for OASE journal for architecture and is editor for the KNOB Bulletin. She is the author of Radical Games (2009) and has published and lectured widely on twentieth-century architecture and its theories. 
Lara Schrijver

Oswald Mathias Ungers and Rem Koolhaas

Recalibrating Architecture in the 1970s

[transcript] 
This publication was made possible by funding from the University Foundation of Belgium and from the University of Antwerp research group Henry van de Velde.

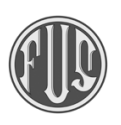

University of Antwerp

I Henry van de Velde

\section{Bibliographic information published by the Deutsche Nationalbibliothek}

The Deutsche Nationalbibliothek lists this publication in the Deutsche Nationalbibliografie; detailed bibliographic data are available in the Internet at http:// dnb.d-nb.de

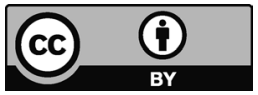

This work is licensed under the Creative Commons Attribution 4.0 (BY) license, which means that the text may be remixed, transformed and built upon and be copied and redistributed in any medium or format even commercially, provided credit is given to the author. For details go to http://creativecommons.org/licenses/by/4.o/

Creative Commons license terms for re-use do not apply to any content (such as graphs, figures, photos, excerpts, etc.) not original to the Open Access publication and further permission may be required from the rights holder. The obligation to research and clear permission lies solely with the party re-using the material.

\section{First published in 2021 by transcript Verlag, Bielefeld (๑) Lara Schrijver}

Cover layout: Maria Arndt, Bielefeld

Cover illustration: O.M. Ungers, Roosevelt Island housing competition, 1975, courtesy of Ungers Archiv für Architekturwissenschaft

Copy-editing: InOtherWords, D'Laine Camp

Printed by Majuskel Medienproduktion $\mathrm{GmbH}$, Wetzlar

Print-ISBN 978-3-8376-5759-3

PDF-ISBN 978-3-8394-5759-7

https://doi.org/10.14361/9783839457597

ISSN of series: $2702-8070$

eISSN of series: $2702-8089$

Printed on permanent acid-free text paper. 


\section{Contents}

Acknowledgments ............................................. 7

Preface: Architecture and Disciplinary Crises ...................... 9

Chapter 1. The 1970s: Reclaiming Autonomy for the Fait Social ............... 19

Facing Crisis: Rethinking the Agency of Architecture in the 1970 s .............. 22

Forming the Social in the Twentieth Century ........................... 28

Constructing a Contingent Autonomy: From Oppositions to Multiplicities .......... 33

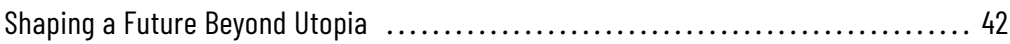

Chapter 2. From Delirium to Archipelago, the Postmodern Collective in the City ... 53

The Terrifying Beauty of the Twentieth Century .......................... 54

Situated Urbanism: The City of the 1970 s................................ 57

New Urban Concepts for the Fragmented City .........................6 61

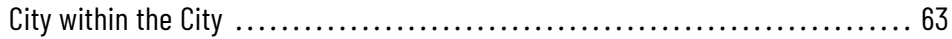

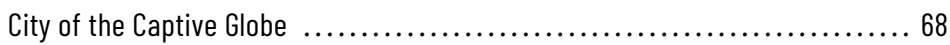

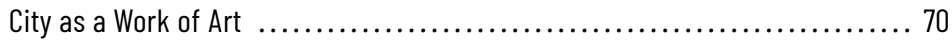

Grossform .................................................. 70

Looking Forward: Urban Notions for the Twenty-First Century ................ 75

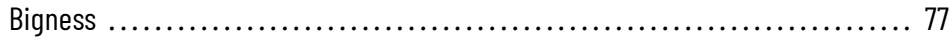

Generic City and Lagos: Escaping Architecture ..................... 78

Incorporating the Failure of Control.................................. 79

Chapter 3. The House: Crystallized Architecture Thinking $\ldots \ldots \ldots \ldots \ldots \ldots . \ldots 87$

Modern Domesticity in the Patio Dwelling ............................ 92

Iconography and the Gestalterische Idee ............................... 97

Purity and Autonomy, Capturing Reality in the Grid ....................... 100

Formal Gestures, Social Habitus: Constructing the Idea of Home ............... 108 
The House as Microcosm of Social Complexity ........................... 111

Small Projects, Big Ideas .......................................... 114

Poolside Stories..................................................... 119

\section{Chapter 4. Elements, Rules and Conventions:}

Architecture as Material Knowledge ............................... 121

Words and Things, Ideas and Realities ................................ 127

Knowing, Showing and Telling: Reincorporating Architecture's Tacit Dimension ...... 133

Transmitting Knowledge in Architecture: Studios, Apprenticeship,

Precedent ................................................ 137

Tactical Manoeuvres: Exercising Material Ideas ......................... 144

Collecting ................................................ 145

Coincidentia Oppositorum and the Oxymoron ....................... 145

Lobotomy ................................................... 146

Order ...................................................... 147

Architecture: Individual Experience and the Collective Dimension of Culture ....... 148

The Knowledge of Design Thinking, Contingent and Transformative .............. 151

Reconstructing a Vocabulary for Architecture .......................... 154

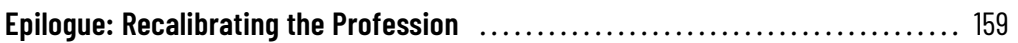

Shifting Architecture, from Visionary Projects to Entangled Approaches .......... 163

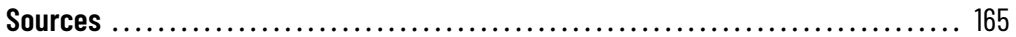




\section{Acknowledgments}

As with any long-term research project, more people have contributed to this book than can be named, whether it was through a chat over coffee or a thorough (and time-consuming) criticism of the text at various stages. To everyone who is not named here: my deepest thanks for each and every moment of hearing me out.

Work on this book has taken place at three institutions, each of which has played a role: Delft University of Technology, which granted me time, the Academy of Rotterdam, which allowed me to bring my research into the seminars I was teaching, and the University of Antwerp, where the broader context of this work became clear.

When I brought the research into my classes, the students in Delft, Rotterdam and Antwerp were valuable sounding boards. The students in my master's course on Theories on the City in particular contributed more than they were aware at the time. Their analyses of the projects I was studying helped shape my understanding of their relevance. A heartfelt thank you to those classes of 2010-2014. And to the reading group in Antwerp: thank you for your close reading of Chapter 1 - your thoughts helped me move forward with more clarity.

A number of specific contributions are too important to go unnamed. Early on in the research, Mary Ann Quinn of the Rockefeller Archive Center proved to be the type of archivist indispensable to academic discovery, adding a few additional documents to my request that proved crucial to a later stage in the research.

To Jean-Louis Cohen, Christine Boyer and Arie Graafland, who read the manuscript in earlier versions: thank you for giving your time so freely. I know how difficult it can be to find the time for a critical reading, and the encouragement you provided was heartening. 
To Françoise Fromonot: thank you for your words of support at a time when I was unsure what yet another book on OMA might contribute. I have often thought back on your comments when I was ready to give up. I hope its final form does not disappoint.

Over the years, the Ungers Archiv für Architekturwissenschaft has been thoroughly generous in answering my queries, offering me space and time at the archive. Anja Sieber-Albers and Sophia Ungers were most helpful in rounding out my studies of the work of OMU with their recollections and interpretations of the person Mathias.

To Peter Riemann: thank you for providing images I did not find elsewhere, and also for your kind words along the way.

To Ellis Woodman: when I had just about given up on completion, our cab-ride conversation from Mendrisio to Milan helped me to pick up the manuscript and finish it. I will be forever grateful.

Several colleagues played a key role in the final revisions. To Christophe Van Gerrewey: thank you for comments that were both critical and generous; I hope the final work does justice to your suggestions. To Roemer van Toorn: I did not expect for our paths to cross again on a work like this. Your lectures and writings were formative for me in earlier years, and I hope the ripples of those pebbles are legible in this final work. To the anonymous reviewers who took the time to read the final draft: thank you for giving a constructive nudge to my presentation of the central ideas in this book.

My closest circle of colleagues helped me stay the course: they were always there to listen, provide encouragement and direct my attention to the continuity of my ideas. To Tom Avermaete, Christoph Grafe and Eireen Schreurs, I owe my thanks for lending their ears to yet another stream of consciousness on Koolhaas and Ungers in the 1970s, whether it was in private conversation or in the space of a seminar.

To D'Laine Camp: you were crucial in ensuring my ideas were formulated clearly and consistently. Your precision and critical eye are paralleled only by your support; all of it is deeply appreciated.

And to Deborah Hauptmann, Lotte Haagsma and Bas van Beek, who know intimately the obstacles and challenges this manuscript has faced in its gestation period: thank you, each of you, for helping me not to give up.

Finally, to my children: you always see me typing. Now you can see the result! 


\section{Preface: Architecture and Disciplinary Crises}

In the past two decades, the public perception of architecture has gone through significant changes. In the early twenty-first century, several urgencies were already on the table, such as rapid urbanization and concerns for climate change and sustainability. Even as the realization grew that the building industry was responsible for a large share of existing and unsustainable (Western) habits, there was still a sense of optimism that the industry would evolve and that many issues would resolve themselves over time. Moreover, there was still a conviction (certainly in the Netherlands, but equally in its neighbouring Northern European countries) that architecture had quite a bit to contribute to the wellbeing of its users.

The global financial crisis of May 2008 (coincidentally the $40^{\text {th }}$ anniversary of the Parisian student revolts) upended many certainties about growth, capitalism and financial stability. Although building projects already underway were often completed, in 2011 Reinier de Graaf of OMA/AMO curated an exhibition in Rome aptly called 'On Hold', showing more than ten projects worldwide that had been postponed indefinitely due to the uncertain financial future of their clients, or in some cases simply their shifting priorities in the wake of the banking crisis. ${ }^{1}$ The exhibition itself garnered relatively little attention, but in hindsight it may have been a harbinger of more to come. More than anything, it demonstrated once again how intimately the forces of capital and the profession of architecture are intertwined.

While architecture has variously been positioned as a profession of building, an engineering-based discipline, an art or even a service industry, it continues to question itself. Rightfully so, no doubt, as it is dependent on multiple actors and contexts for its value and legitimacy: on its patrons, its users, its contractors and producers. In this perspective, it even seems odd that architects are so strongly educated in the myth of the singular genius at work in his office. Yet this myth has had a longstanding function, particularly 
in times when the architect was the primary interlocutor of the building process, with all its complexities.

The central question of this book revolves around repositioning the architect - not as a redeemer of, but as a contributor to society, helping to give material form to the values it wishes to uphold. In this repositioning, Oswald Mathias Ungers and Rem Koolhaas have played key instrumental roles in questioning the values of architecture in relation to its societal context, both in their writings and their projects. In the transitions that have taken place since the 1960s, the manner in which Ungers and Koolhaas address the autonomous features of the discipline of architecture in relation to its social context is situated primarily in the city as the formative condition for architecture. While they have both contributed significantly to urban thinking, their ideas are also manifest in their houses, as the intimate environment of the house provides a relatively small and simple program that can be entirely and individually designed to the last detail. Both of these lines of thinking, the urban and the domestic project, are addressed separately, in Chapters 2 and 3. Throughout the different projects and ideas examined here, a belief in the relevance (if not necessarily power) of architecture to do 'something' - even if it is not precisely as expected, or if it transforms over time - is apparent in their negotiation of disciplinary autonomy and societal context, which is discussed in Chapter 1. Finally, their teaching and writing shows how they navigate the material and intellectual aspects of the discipline, which is addressed in Chapter 4.

The primary distinction between the positions of Ungers and of Koolhaas seems to be one that might also be situated along a timeline. Where the writings and work of Ungers still fit a more traditional category of authority based on the classical uomo universalis, the work of Koolhaas aspires to a more editorial and observational position, akin to the 'curator' as part of the architect's identity. ${ }^{2}$ Both are manners of addressing the changing conditions of the discipline and its role in society, and also as a response to shifting networks of actors within the discipline. In so doing, they both address the relation between the social and the formal as a modern, emancipatory position. Here, I suggest that the idea of a 'plausible' architecture reconstitutes this relation between the social and the formal, offering a form of humbleness in the realization that architecture's agency may not be as straightforward as originally posited in modernist architecture.

There is a vast amount of information available on OMA, which makes a book like this somewhat daunting. ${ }^{3}$ What could possibly still be said after the 
thousands of articles and the books about one of the most prominent architecture firms of the last four decades? Not to mention the self-presentations of the office, which hold some middle ground between position statement, architectural provocations and office portfolio, currently driven mainly by AMO, the thinktank founded in 1999 as research department alongside and independently of OMA. The approach of OMA, and later AMO, to writing and building centres on the work of Rem Koolhaas, but has also transformed over the past decades through the work of many partners, research directors, colleagues and clients, not to mention the students, interns, modelmakers, and other less visible contributors to the design process.

Nevertheless, in this book I am going back to the roots of much of this work, as it is the intellectual inheritance of an approach that continues to inform a particular perception of the discipline. As Koolhaas seems to delight in thoughtful statements followed by mysterious provocations that have kept many critics busy interpreting, he also set the bar for a particular understanding of the starchitect. His love for manifestoes has been visible throughout his career, from Delirious New York (1978) to Generic City (1994) and 'Bigness' (1994) to Content (2004). ${ }^{4}$ At the same time, even as he wistfully refers to the former authority of architects, he constantly situates his practice in relation to the changing conditions of the world around him. ${ }^{5}$ From text to architecture and back, his intellectual flexibility and shifting provocations have kept the architecture debate moving. Refusing to be pinned down to one definite identity, he thrives on the contradictions that architecture operates within, and he uses them to continually test preconceptions.

As such, he has grown larger than life - a mythical figure in an everexpanding debate. His celebrity status has led to varying receptions, from hero worship to immediate antipathy. As the only architect to ever grace the cover of Time magazine, as editor for a special issue of Wired, having been listed in the 'Time 100', as creator of a new flag for the European Union, with the branding of Prada and his presence on CNN, he is perhaps one of the most broadly visible architects of the late twentieth century. With his most recent Guggenheim exhibition on the countryside (received ambivalently as, on the one hand, the 'indulgence of a starchitect', and on the other as an agenda-setting exhibition), he proves that even at 76 , he is still capable of commanding the spotlight. ${ }^{6}$ His work has been studied by French philosopher Bruno Latour - as a possible demonstration of a 'new' form of knowledge that moves from a former stasis in thinking that runs throughout modernism and postmodernism, to a fluid form of thinking more suitable to the twenty-first 
century. ${ }^{7}$ He made the 'Time 100 ' in 2008 , with particular reference to the fact that he does not see architecture as something that can change the world, but rather that he has looked at the messy facts on the ground to see how designers and planners can submit themselves most usefully to the realities all around them'. 8

Nevertheless, there are a few details that have not all been gathered, which are of significance in understanding a number of changes in architecture debates between 1968 and 1978, when Delirious New York was published and caused a stir in architecture circles. As I will argue in this book, this period is also crucial to the formation of how the role of the architect is seen today. As such, this book focuses primarily on Koolhaas's early years, prior to and just after the Office for Metropolitan Architecture was founded in 1975, reflecting on seminal ideas of this period through issues facing the discipline today. In particular, it examines the intellectual legacy of his collaboration and close contacts with his erstwhile mentor Oswald Mathias Ungers, the other protagonist of the book. While Ungers presents a similar problem to any author, with countless articles and books already devoted to his work, there is the slight advantage of many of these publications being in German, leaving him a little less well-known in the English-speaking world. ${ }^{9}$ Nevertheless, his presence at Team 10 meetings (and as organizer of the 1965 Team 10 meeting in Berlin and a seminar at Cornell in 1971-1972) as well as the Charlottesville meetings organized by Peter Eisenman, testifies to his wideranging influence and his transatlantic significance. ${ }^{10}$

The collaboration between the two has been studied somewhat, but this book presents aspects of their intellectual relationship that are fundamental to how we understand the profession of architecture and its broader cultural assumptions. It presents the entanglement of ideas and their material form in relation to social context as central to current debates on architecture. The main developments presented here were engendered between 1968 and 1978, when many conditions around architecture shifted radically, both in response to the legacy of the 1960s, and as a result of the changing global context. In order to understand the effects of this period, the work is bookended by two crucial concepts, Grossform (1966), in which Ungers explicitly situated architecture as a discipline of shaping the city; and 'Bigness' (1989), through which Koolhaas brought urban conditions directly into the architecture project. ${ }^{11}$ In between, the work and writings of these two architects set the stage for a rapidly changing profession. As will be discussed in detail in Chapter 2, Grossform begins the trajectory into what will eventually encompass 
Fig. 0.1: O.M. Ungers and R. Koolhaas at Charlottesville conference, 1982

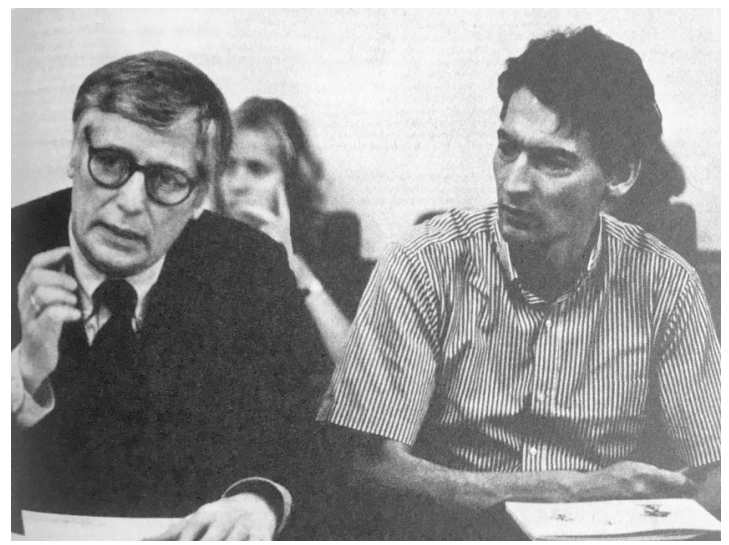

photo by Dan Grogan, in Jasper Cepl, Oswald Mathias Ungers

urban diversity in the notion of the City within the City (1977), and which arguably finds a temporary completion in 'Bigness'. As such, it is a precursor to a number of ideas that become central in the work of Koolhaas and OMA. Notable here is its primarily architectural character, which offers a formal and disciplinary perspective on urban transformation rather than a sociopolitical or economic perspective.

There are numerous interesting details to be found in the early years of Koolhaas's venture into architecture (after film school and journalism), particularly in the manner he shaped his studies and early career, and Ungers is a substantial presence in these years. At the founding of OMA in 1975, O.M. Ungers was listed as one of the founding members. While initially this might seem pure opportunism, simply making use of the authority of a professor at Cornell, the close ties between Koolhaas and Ungers are visible in early correspondence. Ungers may have been more of a mentor than an associate, but for institutions and potential clients he did provide some authority alongside the younger founding members of OMA. His position as professor at Cornell was explicitly named, and the work done by Koolhaas for Ungers was given a prominent position on his $\mathrm{CV} .{ }^{12}$ His status as some kind of associate was occasionally visible in correspondence and publications 
Fig. 0.2: Letter accompanying Funding application, Amsterdams Fonds Beeldende Kunst.

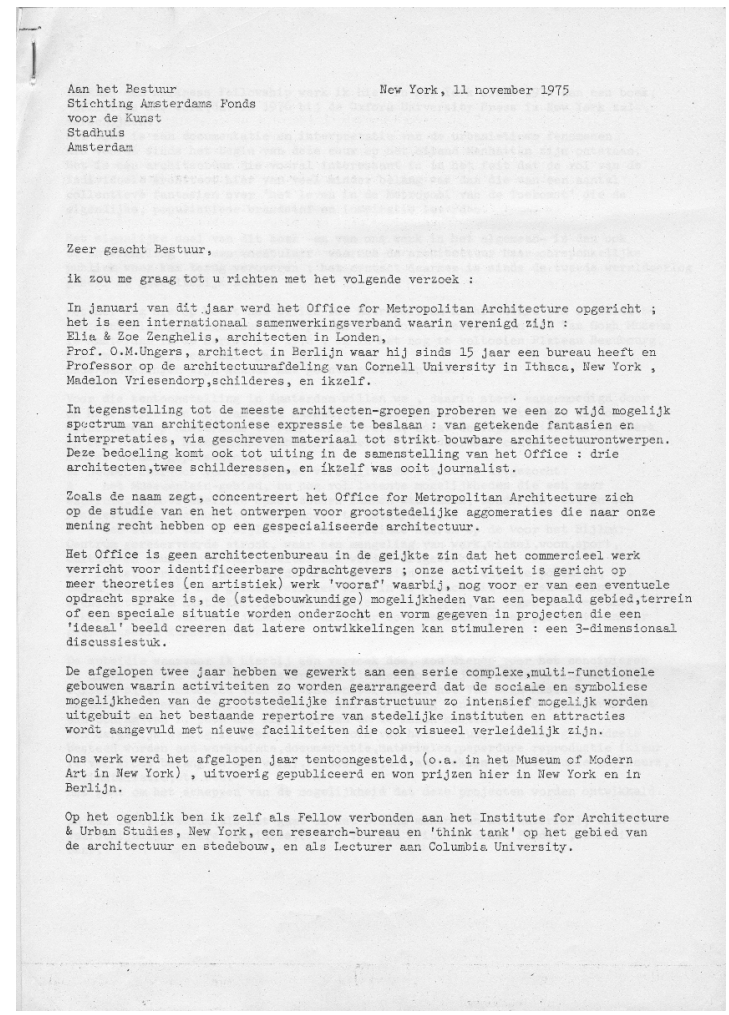

Het Nieuwe Instituut Rotterdam, OMA archive

until 1976, when the Roosevelt Island housing competition entries were published. ${ }^{13}$ The submissions to this competition by Ungers on the one hand, and Koolhaas and Zenghelis on the other, were listed as two submissions by OMA.

Much of this prehistory to the success story of OMA has faded away over time, but Koolhaas has rarely seemed to let an opportunity pass to recall the qualities of Ungers in interviews and conversations. ${ }^{14}$ Of all the architects and thinkers Koolhaas has chosen to refer to over time, it is Ungers who seems to have commanded the greatest respect - enough that it is worthwhile 
to explore the mutual influence of Koolhaas and Ungers, and position them within the late-twentieth-century architecture debate. I argue here that this early history of OMA in relation to OMU (the abbreviation often used to refer to Ungers) stands as a symbol for our time and the radical shifts that have taken place in the role and position of the architect in Europe and North America since the 1970s. These two architects hold strong convictions on the value of architecture, and express these convictions variously in their writings, projects, teaching and buildings. The work they developed in the 1970s and 1980s, both separately and in collaboration, contributed to a renewed sense of professional responsibility and responded to changing conditions in the urban context.

Fig. 0.3: OMA, Roosevelt Island housing competition, 1975, entry by O.M. Ungers

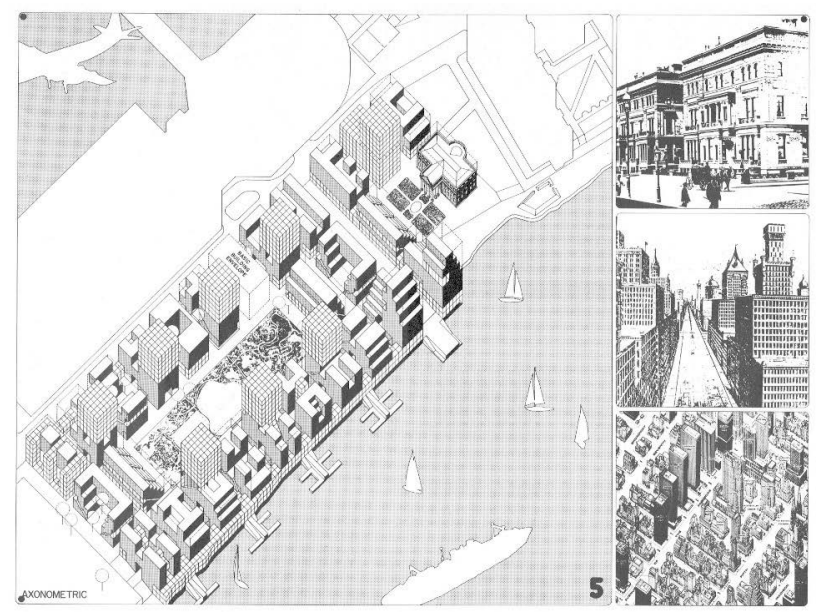

Lotus International 11 (1976)

Throughout their respective oeuvres, it is the oscillation between the social and the formal that circumscribes the agency of architecture, which is addressed both explicitly and implicitly. Over the years, Koolhaas has provided many variations on his statement that architecture is a mix of impotence and omnipotence. In a 1996 lecture at Rice University, he notes that 'the architect almost invariably harbors megalomaniacal dreams that depend 
Fig. 0.4: OMA, Roosevelt Island housing competition, 1975, entry by $R$. Koolhaas, E. and Z. Zenghelis

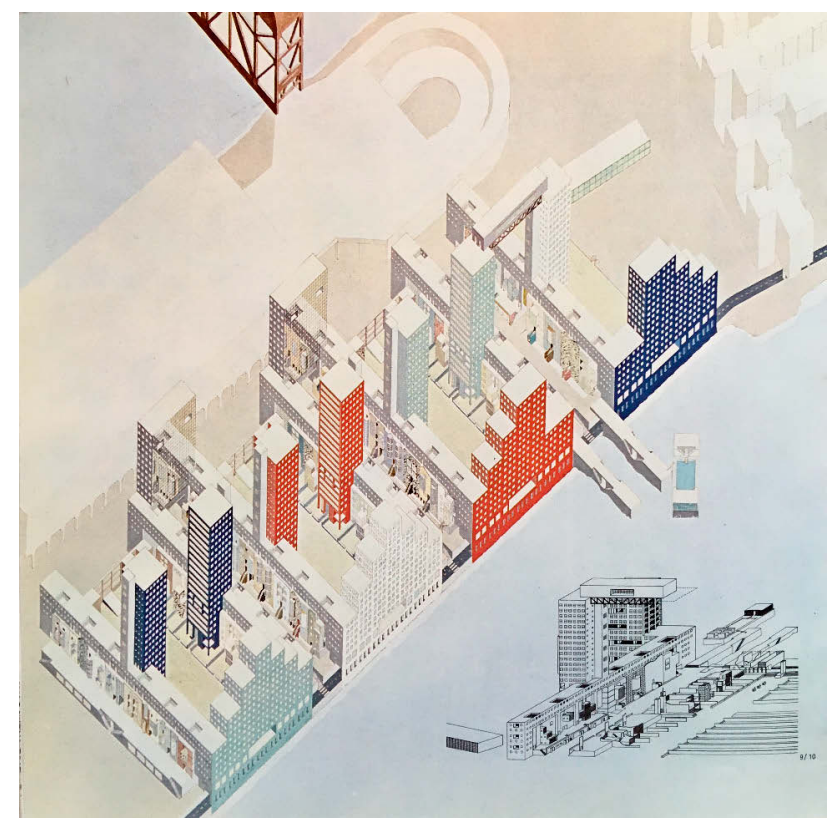

Lotus International 11 (1976)

upon others, and upon circumstances, to impose and to realize those fantasies and dreams'. ${ }^{15}$ Architecture is a profession that sits between disciplinary autonomy, which is articulated in artistic, spatial and technical developments, and a service to society, which is constrained by external conditions and cultural needs. The discourse of modernism and the ideas of post-war architecture maintained a belief in the fundamentally emancipatory drive of architecture. At the same time, this social calling needs to find material form, whether innovative, traditional, subtle, recognizable or challenging. This question is addressed in many historical manifestoes and is visible in many areas of the built environment. From the perspective of today, the values materialized in projects throughout the twentieth and twenty-first centuries have shaped the issues currently facing the profession of architecture. The work of the two main protagonists in this book conveys the particularly tricky 
conditions under which architecture comes to fruition in the late twentieth century. This tension and complexity lead to what Koolhaas refers to as a 'plausible' relation between the formal and the social in architecture, which in turn shapes the prominent position of form in the architecture discourse of the late twentieth century. 



\section{Chapter 1. The 1970s: Reclaiming Autonomy for the Fait Social}

To me, it is ironic that the - I would almost use the word innocent-core of our activity - to reinvent a plausible relationship between the formal and the social- is so invisible behind the assumption of our cynicism, my alleged lack of criticality, our apparently neverending surrender. . 1

Rem Koolhaas

In a conversation with Sarah Whiting in 1999, Rem Koolhaas reflects not only on the work of OMA but on its critical and public reception. His reference to the 'almost innocent' core of the office's work suggests a hesitation to align architecture with innocence, signalling his awareness of twentiethcentury history. Yet he also spins the conversation, accusing his critics of projecting their own assumptions on the work. Typical of Koolhaas, this small sentence is dense with issues facing contemporary architecture, drawing lines from the individual projects of the firm to broad cultural themes. Recuperating the position of the architect in this era of late capitalism (and its seemingly potential demise?), necessitates a reclaiming of architecture as a field of future promise while simultaneously acknowledging its limitations. Current architecture is marked by the historical trajectory of high-profile architecture from the 1970s, when OMA was founded, to today. In retrospect, the references to 'innocent activity' and 'lack of criticality' are significant. The 'innocent' optimism of architecture has, over the course of the twentieth century, led to untenable arrogance and totalitarianism in the form of Utopian proposals. A rising self-awareness of this hubris marks the second half of the twentieth century, yet this does not seem to have diminished 
the attraction of overstated social influence. Koolhaas's insertion of 'almost' reflects a postmodern sensibility that is aware of the critical fault lines in a comment such as this, yet underneath, his interests in the social ramifications of architectural gestures ring through. The reference to 'criticality' frames this comment within the legacy of the 1960s discourse on the critical role of architecture, against which the early works of the 1970s are positioned. ${ }^{2}$ The intricacies within this self-reflexive positioning of OMA will be unravelled in further detail, but first we need to rewind to nearly 20 years earlier, to the Venice Architecture Biennale of 1980 entitled 'The Presence of the Past', which included contributions by both OMA and Oswald Mathias Ungers.

In his essay for the exhibition catalogue, Ungers emphatically dismissed social concerns as a driving force in architectural design, arguing that other considerations are required to produce a building of lasting architectural significance. He made particular note of the contingency of behaviour and public opinion:

It is equally difficult to derive a formal structural project from mere social conditions, since one cannot trust sufficiently either in the behaviour and habits of a single person's life or in the general public's feelings. In most cases people's good sense has turned out to be a failure as an artistic metre. Social factors naturally influence architecture, but careful analysis of people's habits and customs does not necessarily lead to the choice of an architectural form as well. ${ }^{3}$

With this statement, he goes against the grain of dominant themes and approaches in the 1960s, which increasingly focused on vernacular architecture as an expression of 'people's good sense' and resisted approaches that incorporated an obvious formalism.

The statements by Koolhaas and Ungers, made nearly 20 years apart, emphasize the distinction between the social content and the formal expression of architecture. While the social context and the material form of the resulting building are understood to have a relation, they are neither derivative nor directly correlated. Both positions, the desire to reinvent a plausible relation between the formal and the social (implying if not the absence of such a relationship, at least its troubled nature), and the absolute denial of utilizing the social as foundation for architectural form, rise to prominence in the 1970s. This decade was marked by the failure of the social agenda of the 1960s to produce a lasting transformation in the discipline of architecture. Additionally, the perception of architecture as the repository of 
a materialized collective history, identity and desire drove a turn towards the language of architecture and symbolic form in the 1970s. In their approach, and particularly their shared concern for architecture's formal qualities, Ungers and Koolhaas stand testimony to their time and their generation seeking a more balanced relation between the emancipatory role attributed to architecture in the twentieth century, and the formal traditions and expertise embodied within its material objects. In this transformative period, the specific oeuvres of Ungers and Koolhaas illuminate a timeless issue that continues to be relevant today: the role of the architect, and the influence of architecture on the various domains of (urban) life. While their work engages with this question in different manners - if only in the obliqueness of Koolhaas's literary approach versus the directness of Ungers's didactic writings - a resonance between their interests became clear in the mid-1970s, coalescing around a shared interest in the European metropolis. Moreover, their paths crossed at a number of crucial junctions in the architecture debates of the 1970s, particularly in the United States, and mainly connected to the Cornell School of Architecture and the Institute for Architecture and Urban Studies.

It has often been suggested that Koolhaas relegates architectural form to a secondary status, or that he almost 'forgets' to address it. With the overwhelming attention to cultural issues and the city in particularly the writings of Koolhaas (and by extension those of OMA), it is easy to overlook the importance of the material object. Yet the many design proposals and the notes made on project documentation - even as a design goes to construction - belie this interpretation. At the same time, while Ungers may be more directly focused on architecture both as a discipline and as built form, his work is at times so directed at idealizations that the finalized project seems almost secondary. Nevertheless, the resulting materialization of ideas is crucial to the work of both architects. Their ideas must be understood in relation to their built work - and the houses show precisely this painstaking attention to detail in giving form to abstract ideas. The very notion that Koolhaas might forget about form rests on the misconception that being interested in the formal qualities of architecture amounts to being knowledgeable about or reverential towards the tradition of architecture or its exemplars. Although Koolhaas consciously departs from tradition, in writing as well as building, sometimes even going so far as to suggest a disregard for the tools of architecture, this is not the same as being uninterested in the material articulation of his ideas. ${ }^{4}$ I argue here that it is precisely because of 
the historical legacy of architecture as a social agent, from the late nineteenth century to its optimistic portrayal in the 1960s, that the particular position of Koolhaas towards formal autonomy and social agency has remained less visible. Moreover, I argue that the explicit self-positioning of Ungers reveals implicit ramifications in the ideas of Koolhaas, which may be understood as reconceptualizing architecture's social effect through its material presence.

\section{Facing Crisis: Rethinking the Agency of Architecture in the 1970s}

This tension between the social dimension of architecture and its formal language shaped the work of the 1970s, which was marked by the disillusionment that followed the heady optimism of the 1960s. One prominent response to the failure of architecture to radically change society was to retreat into a more self-contained discourse of architecture. ${ }^{5}$ In the work of Peter Eisenman, for example, the autonomy of architecture gained an increasingly prominent role, beginning with his 1963 dissertation on the formal foundations of modern architecture. ${ }^{6}$ In 1969, Manfredo Tafuri argued that architecture was in essence already compromised by virtue of being an integral part of the power structure of the capitalist system. ${ }^{7}$ This led some to conclude that architecture had no other recourse than to engage primarily with the internal logic of the discipline. These two figures are simply examples of a broader turn in art and architecture criticism. In 1960, art critic Clement Greenberg had already drawn attention to the importance of the canvas and the brush strokes for the evaluation of artistic quality. ${ }^{8}$ As early as the 1950s, Colin Rowe and John Hejduk, among others, were already experimenting with a didactic programme that encouraged students to explore an architectural problem primarily through formal and compositional elements of architecture, exemplified in John Hejduk's ninesquare-grid problem. ${ }^{9}$ Time and again, the reflections in this period run in opposition to the understanding of architecture as anchored in the social that had been foregrounded throughout the 1960s. ${ }^{10}$

Throughout the architecture discourse of the twentieth century, this spectrum from social field to architectural presence has been situated as an opposing choice: one cannot be a formalist and be political at the same time. ${ }^{11}$ Yet in the period between 1966 and 1978, the contours began to appear of a less definitive position, a mode in which we might begin to conceive of multiplicities that presume influence without direct correlation. It might 
open up the potential of thinking carefully about form, shape, symbols, and yet being conscious of the social fabric within which these aesthetic concerns are sited. This may be seen as the advent of postmodernity, yet it might also be seen as simply a recalibration of modernity in order to accommodate the complexity we are by now so familiar with. ${ }^{12}$ Without a doubt, the limitations of ideals and social agency became increasingly prominent in the post-war years. Colin Rowe took note of the constrictive features of Utopian thought in 1959, nevertheless concluding that 'as a reference (present even in Popper), as a heuristic device, as an imperfect image of the good society, Utopia will persist - but should persist as possible social metaphor rather than probable social prescription'. ${ }^{13}$ In some ways, this fits well with the recalibration of architecture's role - while the 1970s may have seemed rather bleak after the bubbly high hopes of the 1960s, the changing positions in the architecture debate also provided space for rethinking what architecture should do if it was not only an emancipatory gesture. Rowe would later be highly influential in reclaiming the importance of the formal in urbanism, both in his teaching and his writings, most notably in Collage City. ${ }^{14}$

While the cracks that began to manifest fully in the 1970s were in some seminal form already present in the 1960s, in hindsight the 1970s were a pressure cooker, showing the crisis of the social in architecture in stark detail. In the face of an economic recession on the heels of the 1973 oil crisis, building commissions steadily declined and much of the architectural production turned to speculations and dream images - not of the shining future just around the corner, but rather of the unseen implications of a society in crisis. Early projects and fictions by OMA such as the Welfare Palace Hotel (1976) and The Story of the Pool (1977) show this type of speculation, seeking a role for architectural imagery as polemic and as a collective subconscious. ${ }^{15}$ In hindsight, these early projects explored the less acknowledged aspects of modernity from the seductive to the intimidating, and instigated a new approach that not only basked in image culture, but perhaps even prefigured an irrelevance of architecture as material reality. At the same time, even within the complexity of today's profession, the desire remains to provide significance to the built environment beyond the immediate needs of the client. In today's discourse, this shows in the attempt to define architecture between its dependency on many distinct factors, ranging from urban regulations and policies to the quality of contractors and the engagement of its clients, and its autonomous production of future scenarios, in which current realities find speculative formal expressions for how we wish to live. ${ }^{16}$ 
In this recent history there are clues to the state of architecture today, and the personal trajectories - accidental or not - of Ungers and Koolhaas form a striking pair, crossing the Atlantic in both directions within a relatively short time. In the case of Ungers, one might argue that it was not just the mere coincidence of an invitation to come to Cornell, extended by Colin Rowe. His readiness to accept was also related to the context of university life at the time: while Ungers was trying to teach his students the deeply rooted cultural and historical values embodied in architecture, his students were preoccupied with the general sense of resistance spreading through universities, and questioned all teaching that seemed to align with the establishment. As the student uprisings reached Berlin, Ungers packed up his family to resettle in Ithaca. Immediate triggers for this emigration were the turmoil at his architecture theory conference of 1967, and possibly also the June 1967 shooting of student Benno Ohnesorg by the police, who were trying to contain student unrest. ${ }^{17}$ To Ungers, the further radicalization of the student movement may have signalled the moment to emigrate, as he had a difficult time connecting to a student debate that was turning to wideranging discussions of politics, while he continued to express the steadfast conviction that architecture was formative of culture, and thereby important in its own right.

Koolhaas enrolled at Cornell in the fall of 1972, having acquired a Harkness Fellowship for this course of study. In his application he made particular note of the presence of Ungers and Rowe at Cornell. Referring to a graduate course in Urban Design, Koolhaas wrote: 'The attraction of that course would be the active presence of Prof. O.M. Ungers, whose work in Urbanism at Berlin University I have found very sympathetic and highly relevant. Secondly, Prof. Colin Rowe is regarded very highly as a historian and theoretician of recent and historical architecture with special emphasis on Urban Design. ${ }^{18}$ Ungers had come to Cornell from the TU Berlin in 1968 at the instigation of Rowe, who later regretted his invitation. ${ }^{19}$ The animosity between Rowe and Ungers seems rather surprising in light of the similarities of their interests and ideas, in particular on the existing city, which led to Rowe's invitation in the first place. However, it appears that the architecture department at Cornell was too compact to accommodate their outspoken and often clashing personalities. ${ }^{20}$ Koolhaas had been following a course of study at the Architectural Association in London since 1968, and proposed to spend a year at Cornell towards his final degree at the AA. He had stumbled across the work of Ungers through Veröffentlichungen zur Architektur. ${ }^{21}$ His transfer to Cornell was informed by an 
irritation towards overly 'social' architecture, such as manifest in the Dutch architecture discourse (which was formally unsophisticated in the opinion of Koolhaas), as well as the 'rice-cooking hippies' at the AA. ${ }^{22}$ Koolhaas's interests ran to Soviet Constructivism and the outspoken architecture of Superstudio. Koolhaas found his space to think, write and design in the relative calm of Ithaca, where at least some questions of form were being made explicit in the work of Ungers and his colleague Colin Rowe.

Fig. 1.1: publication series Veröffentlichungen zur Architektur, issues 10, 12 and 19
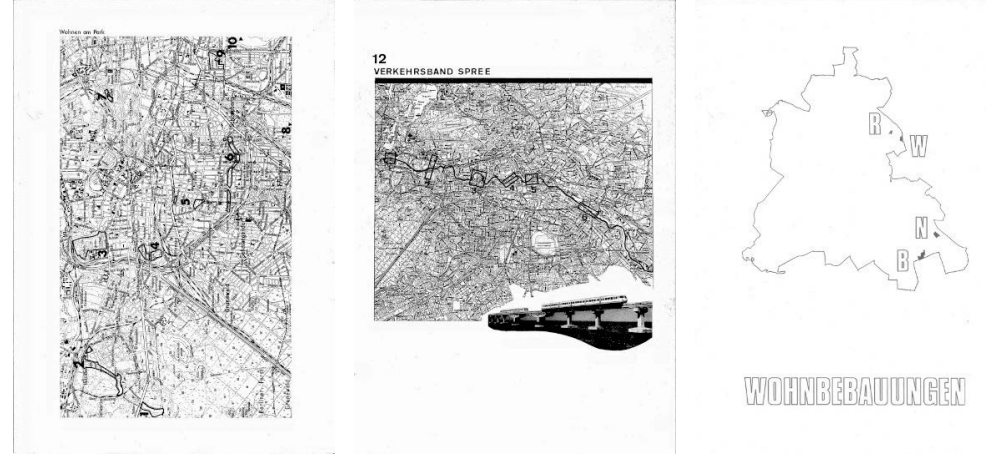

Ungers Archiv für Architekturwissenschaft

The work Koolhaas produced in resistance to his tutors at the AA, and later under the collegial tutelage of Ungers demonstrates precisely this complex need for formal production that is nevertheless also informed by the less tangible conditions surrounding each project. The difficulty in the ideological positions in the late 1960 s caused an increasing rift between the formal and the programmatic in architecture. This radical distinction between the social and the formal was particularly strong in the Netherlands, where ideological battle lines were drawn in the discourse of Team 10, in the professional journals, and at Delft University of Technology, not least by Aldo van Eyck. ${ }^{23}$ In the Netherlands this resulted in a strong focus on social programming, not only in the work of Van Eyck but also his younger acolytes, most notably Herman Hertzberger. In America, the highly autonomous architecture of Eisenman defined a different response by abstracting external influences in favour of a focus on the formal logic of architecture. While Koolhaas was explicitly sceptical of the revolutionary potential claimed for architecture in 
the 1960s, he remained interested in the social implications of architecture, referring to the work of the Soviet Constructivists as a touchstone for revolutionary projects with a clear formal dimension. Similarly, Ungers flatly refused a purely social agency of architecture, but his focus on the intrinsic qualities of architecture also extended to social and historical factors as formative of the life within.

It is against these shifting contexts of Europe and the United States that the resonance between Koolhaas and Ungers becomes clear. Indeed, one can argue that their migrations not only contributed to their personal affinity, but were a crucial component in their critical position on both social revolution and radical autonomy. In this particular aspect of the debate, the EuropeanAmerican axis holds a specific importance. ${ }^{24}$ Even the student unrest of the period was distinctive - the European ones more aligned with the working class, the American ones set out along racial distinctions and anti-war demonstrations. ${ }^{25}$ From the culture analysis of Adorno, in which Hollywood films epitomized an affirmative cultural position, to the transatlantic wanderings of modernism, poststructuralist thought and postmodernism, the intricate relationship between formal and political ideologies has been tinged with specific positions depending on which side of the Atlantic they resided. ${ }^{26}$ This makes the traveling trajectories of Koolhaas and Ungers of particular interest, with perhaps still a speculative line to be drawn towards the developing economies that held Koolhaas's interest in the early years of the twenty-first century, such as Lagos, Nigeria. In America, it is the freedom from politically entrenched positions and the social engineering of high modernism that led to the cynicism of late deconstructivism, but also allowed for the sheer joy of California modernism. In Europe, the politically laden ideas of architecture have at times encouraged a questionably anti-aesthetic participatory planning, yet have also led to more care in the design of public spaces, particularly in countries with a strong welfare state. ${ }^{27}$ The distinct sociopolitical histories of architecture in Europe and North America reveal differences in the treatment of architecture at the crucial junction between modernity and postmodernity. In this light, it becomes evident that Mary McLeod's precise and careful analysis of the interrelation of form and politics in the late 1980 s is focused more on the carefree formal allusions of American postmodernism. Although she makes distinct note of the complexity of the relation between form and politics, she emphasizes the overestimation of form to the detriment of a social conscience. When viewed from the perspective of the exaggerated social conscience of European architecture, 
one might equally read in it the unexpected effects (and thus importance) of the formal explorations of architecture. ${ }^{28}$ As such, the urban ideas of Koolhaas and Ungers can hardly be understood without the underlayment of American urbanization and its toned-down political consciousness. ${ }^{29}$ Interestingly, as such the work also shows the complexity of the relations it argues: the influence of the sociocultural context from Europe to the United States becomes manifest in new perceptions of the city.

In 1975, Denise Scott Brown already signalled this reductive duality in the architecture debate and tried to correct it with a reference to the multiple factors that influence architecture. She suggests that social concern and formalist analyses should be perceived as elements within the larger domain of architecture. She identifies the opposition between the two as coinciding with the rise of the Modern Movement. 'Persons concerned with the analysis of form were ipso facto irresponsible toward the other aspects of architecture and particularly toward the social duties of architecture. ${ }^{30}$ Instead, she notes that issues of social concern and of form are simply variables, which can be isolated for the purposes of analysis and research, but both still pertain to the architectural project at hand and must be resynthesized for the purposes of design. It is in this process of synthesis that Scott Brown situates the primary responsibility of the architect: Allegations of social and architectural irresponsibility can, indeed, be made if the architect does not resynthesize all factors to the greatest extent possible in design. ${ }^{31}$

All in all, the balancing act between social awareness and architectural articulation entered a new phase in the 1970s. This found particularly fertile ground in America. The introduction to Five Architects documents this perceptible shift away from social concern:

But the concern for reform has flavored all discussion and criticism of anything that claims to be architecture first and social reform second. That architecture is the least likely instrument with which to accomplish the revolution has not yet been noticed by the younger Europeans, and in America is a fact like a convenient stone wall against which architectural journalism can bang heads. An alternative to political romance is to be an architect, for those who actually have the necessary talent for architecture. The young men represented here have that talent (along with a social conscience and a considerable awareness of what is going on in the world around them) and their work makes a modest claim: it is only architecture, 
not the salvation of man and the redemption of the earth. For those who like architecture that is no mean thing. ${ }^{32}$

This was received as radical at the time: to be 'only' architecture. We may do well to wonder why this was so radical - and the answer must address the continual expansion of the agency and responsibility of architecture over the course of the twentieth century, until it indeed was seen as the 'redemption of the earth'. The inescapability of architecture as a large part of the everyday environment may well require more attention and care, but it does not necessarily mean that architecture is omnipotent in the way early twentiethcentury architects seemed to suggest.

One of the challenges that architecture faced in the 1970s was how to reclaim agency for the discipline without assuming that it could impact and transform all domains of life. Focusing on 'only' architecture provided the opportunity to explore architecture's particular internal language typological variations, morphological studies, analyses of composition - and to suggest that spatial quality itself was a worthy aim. The modernist tendency towards novelty and innovation in architecture was countered with historical precedent and the study of its logical underpinnings in order to provide legitimacy, as for example in Rowe's comparison of the proportional systems of Renaissance and modernist architecture. ${ }^{33}$ With the publication of Delirious New York in 1978, Koolhaas contributed a new approach to autonomy with his fictional manifesto that described the logic of Manhattan. In this book, he took on the existing urban fabric and described its architecture with a nontraditional vocabulary, using metaphors and ideas rather than architecturally descriptive words. ${ }^{34}$ In the same year, Colin Rowe and Fred Koetter's Collage City made use of historical precedents and compositional approaches to counteract totalizing urban strategies, instead providing a structure for multiple Utopian projects. ${ }^{35}$

\section{Forming the Social in the Twentieth Century}

While the architecture debate and work of the 1970s puts the contrast between formal exploration and social engagement into stark contrast, the story of twentieth-century architecture as a whole shows an increasing belief in the ability of architecture to transform everyday life, until at least the late 1960 s. This history of architecture as a primarily social construct finds a starting 
point in the Utopian writings and experiments of the nineteenth century, such as the overbearing morality of John Ruskin's Seven Lamps of Architecture (1849) and early industrial towns such as Robert Owen's New Lanark Mills (1825). This optimistic and paternalistic approach expands in the early twentieth century to enlighten the masses, and as it began to celebrate what Koolhaas would later call the 'terrifying beauty of the twentieth century', it became (at least in its own perception) an inescapable saviour, leading the way to a life more in tune with the inevitable spread of modernity. A substantial part of the narrative of the twentieth century, whether it concerns the experiments of Soviet Constructivist architecture, of the Bauhaus or the CIAM and Team 10, revolves around recasting architecture as an agent of social transformation. Ironically, precisely through its self-proclaimed importance, the discipline may now have fallen prey to both a diminished agency and an increased culpability - an unfortunate combination for the public image of the discipline as a whole. The historical trajectory preceding this ultimate downfall, however, contains possible avenues of escape, if only by virtue of a more careful reading.

Underlying the opposition between the autonomy of architecture and its status as fait social is the relation between form and its (social) content. Until the twentieth century, the strength of tradition was solid enough that social content was seen as having a naturalized relation with form. Questions of social transformation and morality were at times present but less explicit until the nineteenth century, when Augustus Welby Pugin argued a direct correlation between architecture and moral guidance in his book Contrasts. ${ }^{36}$ It is in the tradition of Utopian plans and social progressives such as Owen, Fourier and the like, that architectural form gains a strong connection to the social content it is meant to imbue. As delicate a field as this is to explore, it remains nearly irresistible to many architects. The notion of having a profound impact not only on the manner in which everyday habits take shape, but also on the very social being of its inhabitants, is heady. Koolhaas finds it a seductive thought, as is not only evidenced by his deep-seated interest in the Soviet Constructivists, but also in his repeatedly outspoken desire to transform life through architecture. However, his wish to influence seems tempered by an acknowledgment of the inadequacy of architecture, while Ungers's refusal of influence beyond the aesthetic seems to build on a general human interest.

At heart, one of the concerns revolves around the role of architecture as cultural production: does it engender social transformation quietly, as a 
slow cultural initiator that secretly inserts new insights, or is it an agent of revolution, following Le Corbusier's statement of 1923? Or is architecture limited to the replication of the social order by virtue of its ties to capital and power? These questions go to the heart of what architecture is, and the role of the architect within society. The twentieth century holds a unique position in this debate. It is in the twentieth century that three main themes, 'pure' art as opposed to applied art, Utopian plans aimed at social transformation, and the relation between autonomy and engagement take centre stage. In 1980, Ungers brings forward the longstanding historical discussion on architecture as the art of building that sits between the symbolic content of pure art, and the functional requirements of the applied arts. ${ }^{37}$ Framing the question of autonomy in architecture within the categories of functional design and aesthetic expression, his ideas not only explicitly build on the work of Kant, but also pay tribute to the distinctions between pure aesthetics and architectural aesthetics made by Sörgel at the beginning of the twentieth century. ${ }^{38}$

The work of Koolhaas and Ungers - whether in writing, drawing or building - addresses a longstanding polemic in architecture, revolving around its status as pure or applied art, or as artistic or technical discipline. This came to a particular convergence in the twentieth century, where its functional imperatives (its nature as applied art) were elevated to a status of essential qualities. The famous notion of 'form follows function' became a manner of transforming architecture into a vanguard venture, running out ahead of the troops to lead the way to a brave new world. While the relationship between the social and the formal is seemingly inevitable, there have been moments in history when it has been particularly central to the (self-)perception of architecture. This is visible in a variety of nineteenth-century Utopian projects such as Charles Fourier's phalanstère, Robert Owens' New Lanark Mills, and Ebenezer Howard's Garden City, as well as early twentieth-century experiments such as the ambitious projects of the Soviet Constructivists, a long-time favourite of Koolhaas's. Within this, the twentieth century is marked by an increasingly instrumental view of architecture as a means of societal revolution, followed by a distinctive retreat from this instrumental view in the late 1970s.

Modernist architecture holds a special position in this question of social agency and formal expression. Based on a relatively circumscribed connection between physical space and its impact on life - deriving from nineteenth-century Utopian projects - the visions of the future involved in 
high modernism included a formal specificity of the future that was deemed to encourage a progressive mode of living. This approach remained embedded in many architecture practices throughout the twentieth century, including that of OMA, which Kim Dovey and Scott Dickson note as having the 'early modernist imperative toward an architecture that would remake the habitat and habitus of everyday life'. ${ }^{39}$ Modernism shared with the early avantgardes a desire to influence all spheres of life, although it tended to operate more within (aesthetic) convention and typically presented itself as an end condition. ${ }^{40}$ The optimism of the 1960 s and its aftermath also form a key moment in this timeline, when the happy ideals of the generation of 1968 seemed to flounder in the face of cultural disillusion and economic crisis. The perceived agency of architecture in social transformation thus seems a particularly modern phenomenon, or at least to hold exaggerated significance in most of the twentieth century. While the relation between the material object and its social influence has often remained implicit, it underpins many considerations of architecture. Vitruvius, for example, provides a self-evident guide for spatial needs in accordance with the social role and standing of the patron, while Ruskin's Lamps of Truth and Life draw direct analogies between social habits and architectural expression..$^{41}$ All the same, the very beginning of the twentieth century does seem particularly alert to the transformative potential of spatial composition and aesthetic expression. ${ }^{42}$ The 1960 , while undermining many of the aesthetic notions of high modernism, maintained a reasonably steadfast belief in the social engagement of architecture, conceiving of near-future worlds in which societal reconfigurations would be pre-empted or triggered by new spatial forms.

There is an intimate relation between the idealized construction of form and the social construction of Utopia..$^{43}$ Especially the abstraction of the modern city has seemed to elude specific contexts of time and space, and thereby remain solidly entrenched in the discourse of social agency in architecture. The idealization of form and its presumed correlation to social virtue, however, has a long history, with particular prominence in the Renaissance and the Enlightenment. According to Rowe, this begins to become problematic with Romanticism, due to its emphasis on the subjective and the individual, which leads to the dissipation of a shared social fabric. Yet one might wonder whether Romanticism attempts to continue the undertones of Utopia in a different form. Certainly one might suggest that the undertones of Utopianism are present throughout many documents that simultaneously breathe the romantic subjectivity of individualism, Delirious 
New York not least among them. Koolhaas's turn to the surreal may be delving into subjective experiences, but it seems at the same time to presume a shared understanding of symbolic content, thereby restructuring the very concept of Utopia.

The problem of what architecture is and what it does sits at the centre of the twentieth-century self-image of the architect. With Le Corbusier as a prominent figurehead in proclaiming the revolutionary qualities of architecture ('Architecture or revolution? Revolution can be avoided'), a large number of architects have found themselves becoming social workers with bricks and mortar as their primary tools. The countermovement turns to pure formalism, disavowing any impact of architecture on everyday life and allowing some architects to show a complete disregard for the environment designed for real inhabitants. Neither position in the extreme - the architect as social revolutionary or the architect as creative artist - does justice to the breadth and complexity of the field and the profession. The everyday practice of architecture cannot be subsumed in the mythology put forward in the discourse, and yet the singular authority of the architect remains a powerful narrative within the discourse. This is built in part on the many facets of life meant to be gathered within the space of architecture and the city, which may easily lead to overstating the influence of the architect. While architectural projects and urban designs can provide a frame for the life within - and perhaps even inform social habits through their spatial interventions - the mythical dimensions of twentieth-century rhetoric in architecture do not do justice to the multifaceted, long-term reality of architecture as a changing profession. ${ }^{44}$

It is in this context of rethinking the limits of architecture's agency that a number of similarities in the ideas of Koolhaas and Ungers become notable. What sets their work apart is the renewed relevance of these ideas in the contemporary city. As early as the 1970s, they shared a willingness to look at the existing urban fabric in a different manner, using a specifically architectural approach to reconceptualize the issues of the city. They both proposed ideas that addressed the tenuous yet still extant relationship between form and meaning, such as Grossform and 'Bigness'. These two notions rethink the role of architecture in relation to the city, while the Stadt in der Stadt already incorporates the shrinking city in its urban principles. In each case, the metropolitan field is the primary focus, in which the complexity of architecture and urbanism is prominent. As such, their ideas take shape in a fundamentally heterogeneous field, determined by not only 
the social domain, but also the everyday labyrinth of regulations and bodies of bureaucratic intervention, as well as the many different perspectives manifest in the city. In this sense, Koolhaas and Ungers early on begin to grapple with conditions of postmodernity such as discontinuity and heterogeneity, although the notions they launch to address these conditions typically derive from reflections on architecture and the city. The notion of a plausible relation between the formal and the social allows for the potential to address new conditions such as the increasing heterogeneity of the city through the material realizations of architecture and urban design, without presupposing that a project is either universal or permanent.

In their approach, and the concern for architecture's formal significance in particular, they signal their time and their generation. ${ }^{45}$ Their nearly 20-year age difference is somehow effaced by a shared distaste for the underestimation of the power of architecture, which they saw in the student movements and in many of the teaching staff at the AA. Their time was situated uncomfortably between the failure of social ideals and an uncertain future. After the demise of the 1960s came the gold crisis (1971), the Club of Rome report (1972), and the oil crisis (1973). The economic downturn in the United States in the wake of the oil crisis in particular had far-reaching effects on the profession of architecture and on the construction industry, with staff being cut by 30 to 50 per cent in architecture firms by the late $1970{ }^{46}{ }^{4}$ Yet Koolhaas and Ungers, as many of their colleagues, remained convinced of the significance of architecture in everyday life. Their high hopes are perhaps characteristic of the twentieth century in general (beginning in the late nineteenth century), when architecture became seen as a means for social improvement and less as an aesthetic expression of the existing social order. ${ }^{47}$ At the same time, their ideas from the late 1960 s on also addressed the increasingly complex conditions that came with the rise of postmodernity a more fluid and fragmented social field, the loss of an overarching narrative, the rise of the digital age (or in the early days the 'network society'), and the loss of a traditional sense of Gemeinschaft.

\section{Constructing a Contingent Autonomy: From Oppositions to Multiplicities}

Perhaps the most fundamental intervention that can be attributed to Ungers and Koolhaas is a recalibrated awareness of the ambiguity of architecture. 
Flying in the face of 1960 s discourse that, for all its self-proclaimed openness, followed the constrictive logic of Utopia, Ungers and Koolhaas introduced alternative interpretations that appealed to both the classical tradition of edification, tradition and precedent (Ungers), and to the modern legacy of 'terrifying beauty', social transformation and multiplicity (Koolhaas).

Koolhaas's last project at the Architectural Association in 1972, 'Exodus, or the Voluntary Prisoners of Architecture' plays out this dilemma between social engagement and brute form. ${ }^{48}$ In the context of the AA it was a more or less direct confrontation with the dominant culture. Zenghelis, his tutor, was perhaps more forgiving of the severe references incorporated in Exodus, but many of the teachers and students at the AA appeared to be more inclined towards architecture with an explicit social agenda. The Exodus project undermines the conventional use of political references by using images that are targeted at achieving freedom through surrender. The Berlin watchtowers and uniformed guards require the new inhabitants to surrender to the conditions of the project, brute form that is beyond good or evil. The naked entry into paradise - or hell as it may be - and the implied rebirth into an environment of architectural domination all suggest a surrendering to the terrifying beauty of the twentieth century. It is a complete reversal of the comforting notions of 'I'm OK - You're OK' of the 1960s scene at the AA. ${ }^{49}$ Ironically, in the retrospective gaze of Koolhaas, Peter Cook seems to have been one of the most difficult tutors to convince of the value of this monumental intervention, while the influence of Archigram is often seen as introducing a structural mode of irreverence. Perhaps not quite aligned with the hippies in their love for consumer culture, the members of Archigram showed a strong distaste for authority in their work, which perhaps explains their resistance to the totalitarian designs of Superstudio. Nevertheless, these seemingly open approaches of the 1960s generation are also dogmatic in their demand that everyone conform to the logic of this apparent flexibility. ${ }^{50}$ The Exodus project inverts this principle, offering a conscious intervention of highly formal architecture - the references formed by Superstudio and Soviet Constructivism, where formal and aesthetic experiment were part of the forward-looking approaches. Yet they are also imbued with the idea that sociopolitical progress can be configured by the spatial form they are given. The programmatic compositions of the Constructivists, reminiscent also of the phalansteries of the nineteenth century, reorganize collective life by reorganizing the family and elements of what is otherwise considered the private domain. Rather than the nuclear family as the basic cell of society, 
the individual elements of the family are reorganized. Women are set to work, their reproductive functions a necessary element but not the focus of their being, and children are put together to be raised by specifically allotted domestics.

Fig. 1.2:. R. Koolhaas, Exodus project, 1972, reception area

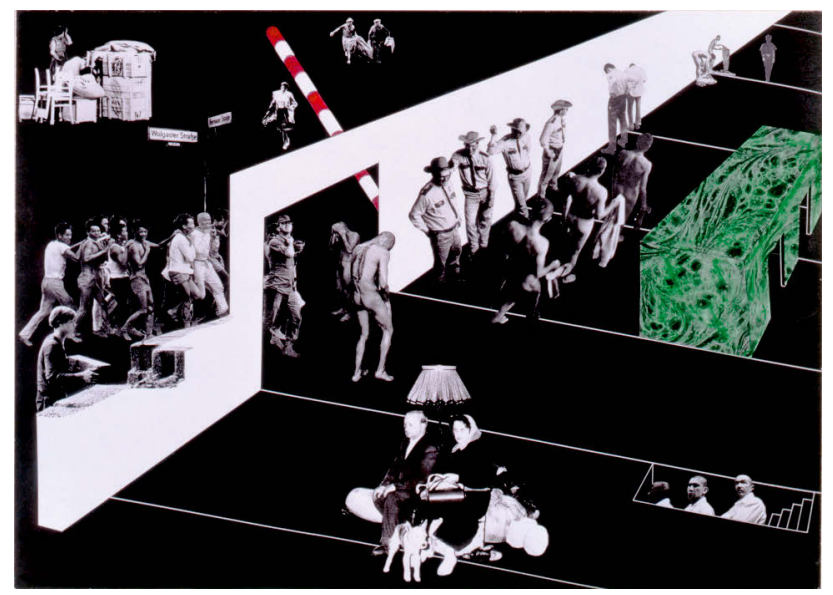

Image Courtesy of OMA

The Exodus project thus embodies ambiguity: architecture is something to surrender to, but willingly so. It is breathtakingly important, which is why the project also provides the banal allotments as an escape. It resonates with the impact of the social condensor, with overtones of reconfiguring the social habitus in its formal severity. The project includes a series of pure forms that might even call to mind some of Ungers's projects. The squares that make up the baths, for example, might easily be situated in the Hotel Berlin, if the film stills were absent and it was pure form. At the same time, the provocative narrative that accompanies the project is at odds with the more rational and architectural descriptions that Ungers provides in his work.

It is only if we see the relation between the formal and the social as founded on opposition that these ambiguities become problematic. The oppositional narrative that has been construed over the course of the twentieth century has become unforgiving. Every formal gesture without immediate social referent correlates to a suspect motivation, while every 
Fig. 1.3: R. Koolhaas, Exodus project, 1972, baths

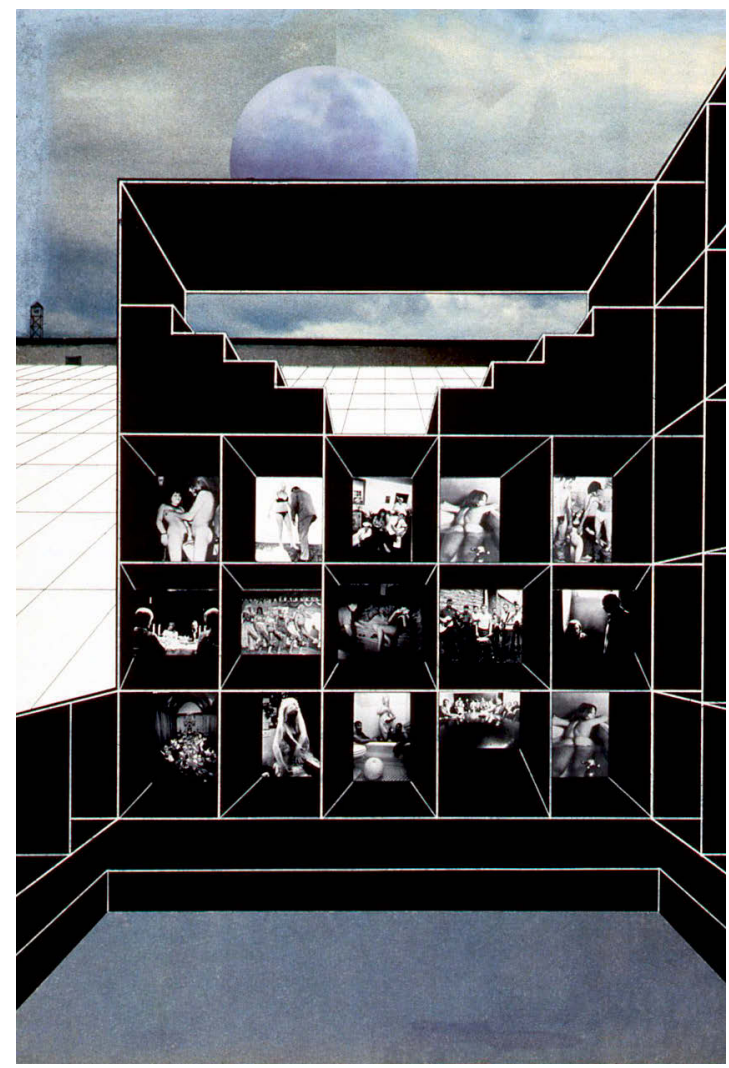

Image Courtesy of OMA

explicit social gesture is construed as a sign of architectural inadequacy. Dovey and Dickson suggest that the potentially most transformative moment of Koolhaas's work lies in the transformation of architecture from a more or less linear narrative to architecture as a 'field' implying freedom of choice in the use and appropriation of space. ${ }^{51}$ The habitat is less definitive of the habitus within it, as will be discussed further in Chapter 3, which examines a number of houses by Ungers and Koolhaas. This freedom in shaping the habitus is a liability within a discourse focused on transformative qualities of 
Fig. 1.4: O.M. Ungers, Hotel Berlin, Lützowplatz competition, 1977

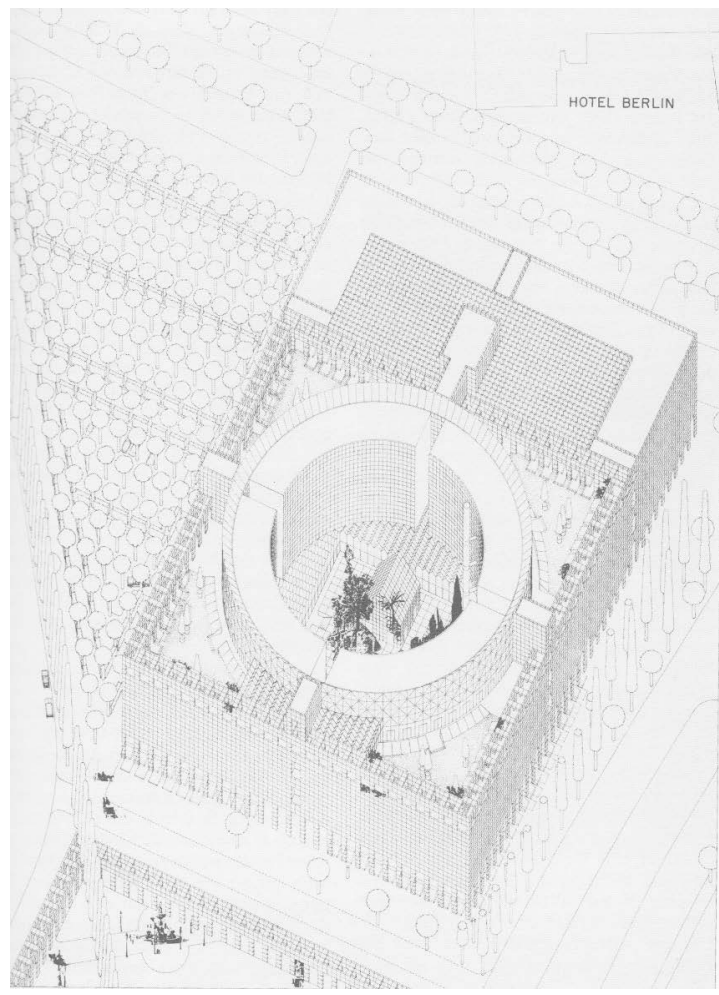

Ungers Archiv für Architekturwissenschaft

architecture: because OMA is perceived as not shaping the habitus, there is a kneejerk perception of the firm as cynical and uncritical. This follows in part from the Dutch architecture discourse, from the dominance of Team 10 and Van Eyck, with very particular views on the responsibility of the architect. ${ }^{52}$ This criticism deserves some rethinking, as it rests on the notion that there are singular directions in which architecture can engage the inhabitant, indeed that architecture can perform a vanguard social function.

In this notion of architecture as a 'field' with freedom of choice, the failure of architecture as social reform does not correspond directly to 
a lack of influence. The work of Koolhaas and Ungers is in some ways incommensurate with their time. They both seem acutely aware of the failure of architecture as a social agent, perhaps more so than their immediate contemporaries. In the case of Ungers, this involved a turn to historical conditions and timeless considerations, for example by introducing Grossform as a formal notion at the Team 10 meetings, or by taking into account the city developments, while in the case of Koolhaas it was perhaps more apparent in his interest in alternative topics and narratives, whether it was the Berlin Wall as architecture, or the spatial qualities of Rockefeller Center. At the same time, neither architect seems to suggest that architecture has no influence whatsoever.

The problem with the discourse is that it presents as a choice what is in reality a spectrum, or even a field of relations between 'purely' architectural concerns (composition, order, symmetry, material) and the sociocultural fabric they engage with. Moreover, the evident confusion between political action and the agency of architecture as a legacy of the 1960s has made it difficult to see the more subtle modulations of sociological concerns, which are transmitted through and transformed by cultural expressions. ${ }^{53}$ The strong ties between political action and the formal articulation of architecture have clouded the view of the specificity of each project. The pronounced disillusionment of the late 1970s resulted in two high-profile responses: an interest in tradition and in autonomy. The turn to the traditional underestimates the influence of innovation, while the turn to autonomy does the same for long-term cultural impact. The continued search for a Utopian impetus shows more of a nostalgic desire for clean ways forward than a sensitivity to the complex field in which architecture navigates. The vastness of a globalized world, with an abstract 'system' that leaves its inhabitants at a loss, is nevertheless counterbalanced by small pockets of community. There is a conceptual space residing in the various scales of the environment where architecture can make a difference, or so some of the projects suggest.

Nevertheless, while architecture has a social impact, architecture's right to an autonomous language is a manner of resisting the external constraints of architecture being made into its theme and content. In his essay for the 1980 Venice Biennale, Ungers refers to ecological, sociological and technological functions that take over the proper functions of architecture. ${ }^{54}$ This begs the question: What then is the proper content of architecture? In essence, it is this complicated reconstruction of architectural content that Koolhaas and Ungers bring to the table in the 1970s, as do the New York Five and the Texas Rangers 
with their explorations of grids, forms and compositions. What they share is a focus on identifying the most salient features of architectural design. Various hints are present throughout the writings and projects of Ungers, showing what he deems the appropriate internal content of architecture. It is elaborated through formal reiterations of ideal proportions, such as his beloved square, and it is an explicitly legible, clearly categorized series of alternatives. As such, architecture does not comprise a single perfect solution, but must go through multiple iterations to show the breadth of possibilities, as long as the overall sense of logical patterns and forms remains tangible. Architecture contains an appeal to the ideal and transcends the merely rational satisfaction of existing requirements. The Biennale essay shows the complexity with which Ungers addresses the question of the social content of architecture and the autonomy of the discipline. ${ }^{55}$ Although he concedes that social factors influence architecture, the role he attributes to architecture can only be fulfilled if it transcends the everyday social content. ${ }^{56}$ Koolhaas similarly attributes a transcendent role to architecture, but his is filled with the provocative speculations of the unconscious. It should be noted here that the richness of his conceptual approach at the time might have been easily overlooked, were it not for the drawings by Madelon Vriesendorp and Zoe Zenghelis that accompanied some of the most important articles. The City of the Captive Globe (Zenghelis) and the Flagrant Délit (Vriesendorp), embody precisely this embrace of the surreal within everyday reality.

This is one of the great differences between Ungers and Koolhaas: while Koolhaas is fascinated by surrealism, Ungers seeks the logic of architecture within the rational. While Koolhaas easily allows for the unexpected wanderings of the surrealist mind, even the spiritual content of Ungers's architecture is constrained by rationality, anecdotally evident in his incessant use of graph paper for drawing on. Ungers's interpretation of social content is however not a one-to-one translation, but rather a sensibility that appeals to spiritual content - it is no guideline for ethical behaviour, or for architecture that will become more than simply the material form of temporary needs. Ungers notes:

Over and above the laws of construction, the consideration of human necessities and the effective usefulness is the imperative requirement of formal shape, and this is where the architect's spiritual responsibility resides. The total failure of modern architecture in transmitting the cultural models of 
our times into formal symbols is proof of the lack of spiritual values and contents. ${ }^{57}$

Fig. 1.5: M. Vriesendorp, Flagrant Délit, 1975

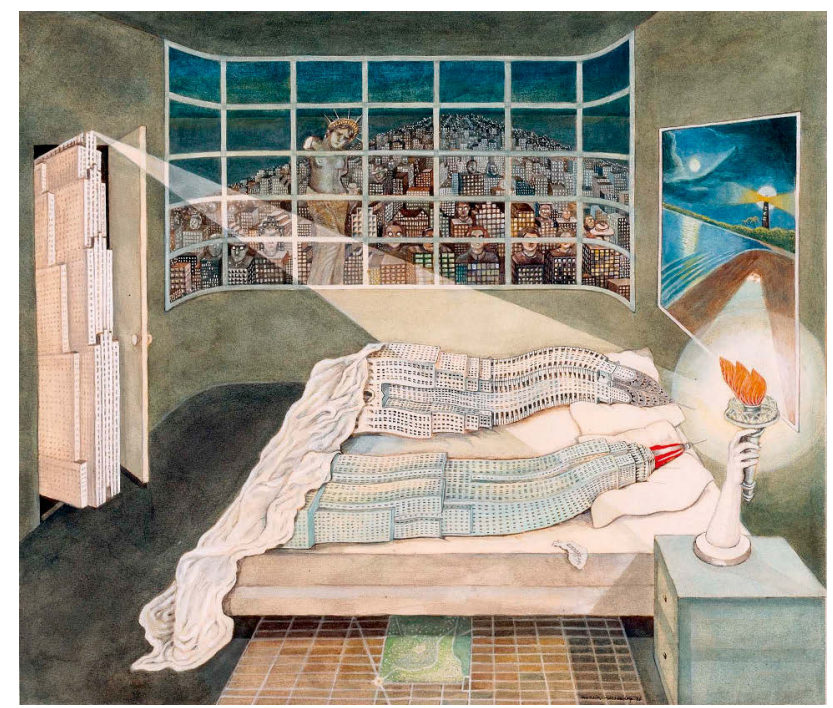

courtesy of M. Vriesendorp

As early as 1960, Ungers together with Reinhard Gieselmann presents the idea that form must somehow express a spiritual content. ${ }^{58}$ However, the difficulty in this position at the time is due to the apparent arbitrariness of formal and symbolic languages. Recuperating these languages is the project postmodernity set itself, which has not yet been completed: as will be argued in Chapter 4, architecture is currently still aiming at the possibility to discuss form while also acknowledging variations in perception and underlying conceptual frameworks. How do we talk about a shared meaning in form when cultural foundations are so diverse and individuated? One solution is to unravel the logic and history of form in architecture, as Ungers does in his teaching and writing. ${ }^{59}$ Another is to embrace the irrational underbelly, as Koolhaas begins to do in Delirious New York.

Ungers sees form as one of architecture's central features: 'The communication of ideas and experiences by way of the language of form is one of 
architecture's basic premises. ${ }^{60}$ In this quest for the meaning of form, Ungers is not alone. His position echoes a number of German scholars from the late nineteenth and early twentieth centuries, most particularly Sörgel, but it also shares a sensibility to be found in the work of, for example, Joseph Rykwert, who suggests that there are timeless foundations for architectural form. His book On Adam's House in Paradise presents the two archetypes of the tent and the cave as the first architectural gestures in history. ${ }^{61}$ Against those who find architecture lacking in artistic qualities because it is dependent on external constraints, Ungers argues that it has its own logic that includes these constraints, which sometimes even engender new formal qualities. Referring to its 'true social mission' and its 'humanist responsibility', Ungers puts forward the need for spiritual and cultural content in architectural form. For Ungers, this is a logical conclusion based on his study of architecture history, which is:

... full of examples of social and religious institutions being established in existing spaces ... of functions other than those originally planned ... adapting to the predetermined form. The validity of a spatial sequence therefore does not depend solely on its function. The type of building obviously takes precedence over the function. Functions adapt to the building type. ${ }^{62}$

This position shares its premises with Koolhaas's approach to Manhattan in Delirious New York. Examining the buildings of Manhattan from the perspective of an architectural novelist constructing a retroactive narrative, Koolhaas tries to isolate significant architectural features that subconsciously stand witness to a cultural logic. One feature that returns throughout the later projects of OMA both as argument and as architectural gesture, is what he identifies as the 'lobotomy' between the façade and the life within, noting that the scale of the modern city has destroyed the possibility of modernist honesty between floor plan and façade: 'Less and less surface has to represent more and more interior activity. ${ }^{63}$ In his appraisal of Rockefeller Center, he then presents 'the Great Lobotomy's indispensable complement: the Vertical Schism, which creates the freedom to stack such disparate activities directly on top of each other without any concern for their symbolic compatibility'. ${ }^{64}$ To Koolhaas, this reveals how functional or economic requirements may result in the transformation of formal articulation. This interpretation seems to be presaged by Ungers in his focus on the complex junction of structure and façade in modern architecture, which Kieren identifies as the 'real architectural debate' since the nineteenth century: '[T]he relation between 
the construction technique and the form of the facade and the building as a whole. ${ }^{65}$ If indeed, as Kieren suggests, Semper already identified the basic problem in this relation, then we might conclude that Koolhaas has been reworking this nineteenth-century debate since his identification of the Vertical Schism. Similarly, the 'honesty' put forward by the moderns leads Ungers to turn towards form as a 'whole', and to historical concepts that demonstrate the interconnectedness of architectural form and the construction that enables it.

Delirious New York makes use of the difference in modes of practice and thinking on either side of the Atlantic. Koolhaas perceives a freedom in the creation of Manhattan that he believes would be impossible on the mainland of Europe, yet he also positions himself as the best (or only?) candidate to write the retroactive manifesto that is Delirious New York. The apolitical pragmatism of a city produced by capitalist principles expresses itself as a delirium, a plot where the traditional categories of aesthetic value are discarded, but new and exciting modes of building prevail. Koolhaas himself attributes his receptiveness to new perceptions to his own global upbringing (from an early youth in Asia to the years in Europe and North America). ${ }^{66}$ As such, he has positioned himself as rethinking his own preconceptions in confrontation with alternate visions. His approach here suggests a contingent autonomy of the object - it is a thing unto itself, material and tangible, and therefore open to interpretation from various perspectives, and it also embodies a cultural context, with all of its implied habits and values.

\section{Shaping a Future Beyond Utopia}

The significant contribution by these two architects in the early 1970s rests, however, not on their ascertaining of the flaws of socially engaged architecture, but rather on their construction of an autonomy of architecture that does not fully retreat from social concern. In this, Koolhaas, Ungers, and a handful of other architects make the tension between the social and the formal particularly obvious. There is a striking parallel between Denise Scott Brown's complaint that her work on Las Vegas with Robert Venturi was seen as socially irresponsible by virtue of the populist qualities of their topic and their approach of formal analysis, and Koolhaas's comment that the work of OMA is seen as cynical and a-critical. The choice of study objects by Venturi and Scott Brown indeed parallel the choices of Koolhaas, in their 'inappropriateness' to 
the dominant discourse. ${ }^{67}$ Koolhaas's study of the Berlin Wall falls into this category, as does his interest in large gestures such as those of Superstudio, which are present in the Exodus project. Similarly, the interest of Ungers in the work of Sörgel and in Gestalt theory runs counter to the programmatic, political and social interests of his colleagues in Team 10.

In an interview, Koolhaas notes an undertone of political issues in the work of Ungers, that nevertheless remains only that: 'And in fact, you reiterate in every work, that there are solutions to these issues on a formal and morphological level, but not on a social one. ${ }^{68}$ In reply, Ungers confirms a position towards that of the autonomy of art and architecture: 'I believe that the social problems of architecture cannot be resolved. We do not have the means to do so. Our tools can only solve architectural problems. In the same manner, art cannot resolve societal issues.' Ungers refuses a social agency for architecture, insofar as it is seen as salvation. Nevertheless, he does see architecture as something that has an effect. In most of his writings, he discusses this as a cultural effect, something that cannot be predetermined but can at most offer an acceptable platform for unexpected life within.

Koolhaas resists this, questioning whether there is not some moral position embedded in the architecture itself. Although Ungers concurs that he has a personal moral principle, he describes it as separate from the architectural. This is to Koolhaas's dismay, in the sense that his hopes for the architectural manifesto seem to remain even today. Alongside his own appeal for an increased realism, remains a hope that his work has an indelible impact on human life, even if only in potential. Ungers seems less ambitious for the particular impact of his own work, yet all the more emphatic about the importance of architecture as part of a general cultural sensibility. This may refuse a moral or social position, but by no means diminishes the importance of each project in the grand historical trajectory of architecture as cultural expression.

In City Metaphors, Ungers also suggests that architecture may intimate specific actions, or set certain goals: 'Not the least the model is an intellectual structure setting targets for our creative activities, just like the design of model-buildings, model-cities, model-communities, and other model conditions supposedly are setting directions for subsequent actions. ${ }^{69}$ In other words, the artifact itself embodies an appeal (which may be ignored) more than a command. This echoes the plausibility thesis of the social and the formal: the response to a design is not predetermined, but it may be open to suggestions. Hinting at the expanding agency of things as is currently 
present in contemporary discourses of architecture, art and the humanities, which all show a heightened awareness of non-human agency, the suggestion here is that carefully designed spaces with high-quality materials may suggest more care in interaction, appealing to a sense of gentleness, but they cannot prevent destruction. ${ }^{70}$ Designs with evident traces of recycling may appeal to a consciousness of environmental sensitivity or sobriety, but they cannot enforce a culture of recycling. In this sense, our models, our buildings, our ideas set targets, but they do not demand compliance. Moreover, the more complicated culturally embedded symbolism may fade over time, leaving primarily the most obvious aesthetic dimensions of proportion, scale and symmetry to be read in accordance with (or in opposition to) altered connotations. It is here that the 'spiritual content' that Ungers recognizes in architecture ensures the continued relevance of building, transcending the merely functional.

As such, the autonomy that Ungers considers central to design - that architecture is - does not imply that architecture does nothing. It is by virtue of its intricate and multifaceted being that it does something. Ungers simply acknowledges that this cannot be predicted with accuracy, as the conditions around it shift as well. While in the 1960s these changing conditions led to incorporating flexibility and indeterminacy in the design, Ungers counters this approach, arguing that this leads to meaningless form, which in turn destroys the potential for any significant relation with architecture. In particular, Ungers notes that:

Function is - in terms of the language of architecture - of secondary importance; it is merely a means to an end and not the end itself. Architecture is highly formulated; it does not have a specified function, which does not mean that it is use-less, but rather that it manifests its true dimension free of external constraints. ${ }^{71}$

Construing a new significance in this age does, however, pose a distinct problem for architecture. While the hope to contribute to a society more amenable to its inhabitants grew, the available vocabulary to do so diminished throughout the 1970s. The increasing complexity and individualization of contemporary society had eaten away at the shared sociocultural symbols that founded earlier art and architecture. These symbols were increasingly replaced with expressions of global culture and a desire to define items structurally rather than through the myriad collections of artifacts that together comprised a coherent set - albeit unwittingly - of longstanding 
cultural production. Altogether, these objects form a fabric that engages with social reality, but they are not sociopolitical phenomena in themselves. More than anything, the architecture debate of the 1970s is in negotiation with its own limitations. The ideas resonating in a project may be transformed or even become obsolete in the face of changing realities. This is one of the reasons that Ungers turns to building types as a fundamental concern of architecture. He holds that type can offer a significance beyond social change, or beyond change in function. These are ideas he explores in his Berlin studios, published in the Veröffentlichungen zur Architektur, with topics structured around spatial types and architectural elements, such as squares and streets, motorways and buildings, or firewalls. ${ }^{72}$ Architecture is a slow process, particularly in the context of public spaces, which require extensive decision-making processes. ${ }^{73}$ While Ungers disavows the social responsibility of architecture beyond the creation of an environment that appeals to a sense of 'good form', Koolhaas periodically reiterates his own interest in 'reshaping society' through architecture: 'Without ever having been communist or knowingly Marxist . . . one influence that certainly led me to architecture was a confrontation with Soviet Constructivism, and with that moment where you could really speculate about how society could be reshaped, architecturally. ${ }^{74}$ Although his ironic and self-critical position precludes his making the same kind of radical statements as his modernist forebears, he is nevertheless enticed by the notion that his building will continue to shape the relations within.

In Delirious New York, the section on the Downtown Athletic Club is steeped in Koolhaas's interest in Soviet Constructivism, in the potential to transform life through architectural space, together with a kind of wonder that it exists already in New York, in a most naive, non-Utopian form. Koolhaas repositions the pragmatism of the Downtown Athletic Club as

... the complete conquest - floor by floor - of the Skyscraper by social activity; with the Downtown Athletic Club the American way of life, know-how and initiative definitively overtakes the theoretical lifestyle modifications that the various $20^{\text {th }}$-century European avant-gardes have been proposing, without ever managing to impose them. In the Downtown Athletic Club the Skyscraper is used as a Constructivist Social Condensor: a machine to generate and intensify desirable forms of human intercourse. ${ }^{75}$

Here, the fascination for the possibility to intervene in and transform the habitus of individuals, in the end transforming society at large, collides with 
a reality that already seems to have transformed these individuals without a predetermined goal.

While Koolhaas has been accused of negating or denying social responsibility, and Ungers has been seen as too rational or heavy-handed, they both seek to recalibrate the role of architecture, and in so doing, realign the public perception of the architect to the value they feel architecture holds. This is connected to the notion of a 'plausible' architecture that is able to express the social in form yet maintains the understanding that it is neither universal nor definitive. Both architects certainly share a strong sense of the discipline but where Koolhaas tempers his faith in the omnipotence of architecture by at least verbally acknowledging its impotence, Ungers seems to posit social impotence yet offer much stronger cultural significance. For both, there is a belief that architecture has something to contribute to society at large - but while Koolhaas remains fascinated by the hope for full-scale transformation as a potential, if not realistic, ambition, Ungers seems to act within a smaller circle of influence while expanding it to the longer-term cultural horizon. Their respective articulations of a future beyond Utopia both seek a lasting influence, but Koolhaas does so through radical gestures, while Ungers seems to seek timeless forms.

If form is no longer a 'vessel for meaning' - or perhaps the proliferation of various forms has disrupted the well-understood rhetoric of formal communication - then what might the role of form be? Should we re-examine the role of symbolic form in weaving a sense of community, as Alan Colquhoun suggests ${ }^{76}$ This would imply that material form impacts the idea equally to the other way around. As such, addressing architecture as an applied art (which includes, as Ungers notes in reference to Kant, the idea that it is 'impure' or contaminated), would open the door to considering both its internalized, disciplinary language of form and its cultural expression as dependent on external constraints and coincidence. ${ }^{77}$

Given that the projects of architecture as such - whether articulated in drawings, models, or buildings - have both a form and an implicit content (of cultural meaning, aesthetic values, societal preconceptions), the desire to reinvent a plausible relation between the formal and the social is notable for a number of reasons. First, this is not a full-blown dismissal of social concern in favour of 'pure' form. It presupposes the possibility of a relation between a thing and its reception. Second, it implies the recognition of an object as multivalent, as something that can be imbued with different interpretations or modes of significance, depending on context. This implies that the field 
of possible interpretations is also open to transformation, as the object outlasts its original context or intention. Third, it does propose that artificial interpretations may be introduced - hence the potential for reinventing a relationship. Finally, it offers two crucial operations: it intimates the need for specificity (as abstractions remain primarily in the realm of ideas), and it de facto engages with history in reclaiming some form of connection between form and content.

This does not make the problem any easier to unravel today. In the 1990s, the notion of 'shaping' arose as a manner to restate the value of architectural expression, without the heavily laden discourse of 'form', which was seen as too deeply entrenched in modernist rhetoric. ${ }^{78}$ 'Shaping' appealed to a more value-free, postmodern understanding that allowed for multiple interpretations of an architectural form, which in turn suggested an identifiable building (a 'logo') that still offered a liberating neutrality. ${ }^{79}$ This perspective honours Colquhoun's idea of 'figure' as appealing to the social content of form or symbols, but severs them from their determination by (longstanding) convention. ${ }^{80}$ The problematic here is that the resulting indiscriminate use in the heyday of postmodernism precludes them from becoming embedded in the social fabric.

What this also suggests is a renewed relationship between form and agency, which is simultaneously altered from correlation to plausibility. Although it is necessary to maintain some type of relationship between the material object that both resides in existing culture and indeed also constructs and alters it, the facility with which one can identify correlative concepts is waning. The backdrops have perhaps become too fragmented, the foreground perhaps too defined by fickle individuality. One approach is to remain tied to the material articulations of reality, taking even the accidental ones at face value. This is one part of Koolhaas's attraction to Salvador Dalí's Paranoid Critical Method. ${ }^{81}$ While the consistent questioning that marks the state of paranoia shows a sceptical approach to the perceived inevitabilities of reality, the aim of creating previously unimagined forms contains an equal appeal to a heightened sense of individuality. In so doing, the interests of Koolhaas often circumvent the more obvious elements of social engineering in the work of Le Corbusier, for example. There is a fascination for the underbelly of modernity, and for the sensibility of materials that keeps the architecture tied to a bodily experience rather than the intellectual abstractions more prominent in the writings of Le Corbusier. 
Fig. 1.6: Ideas competition Landwehrkanal-

Tiergartenviertel, 1973, sketch by Ungers

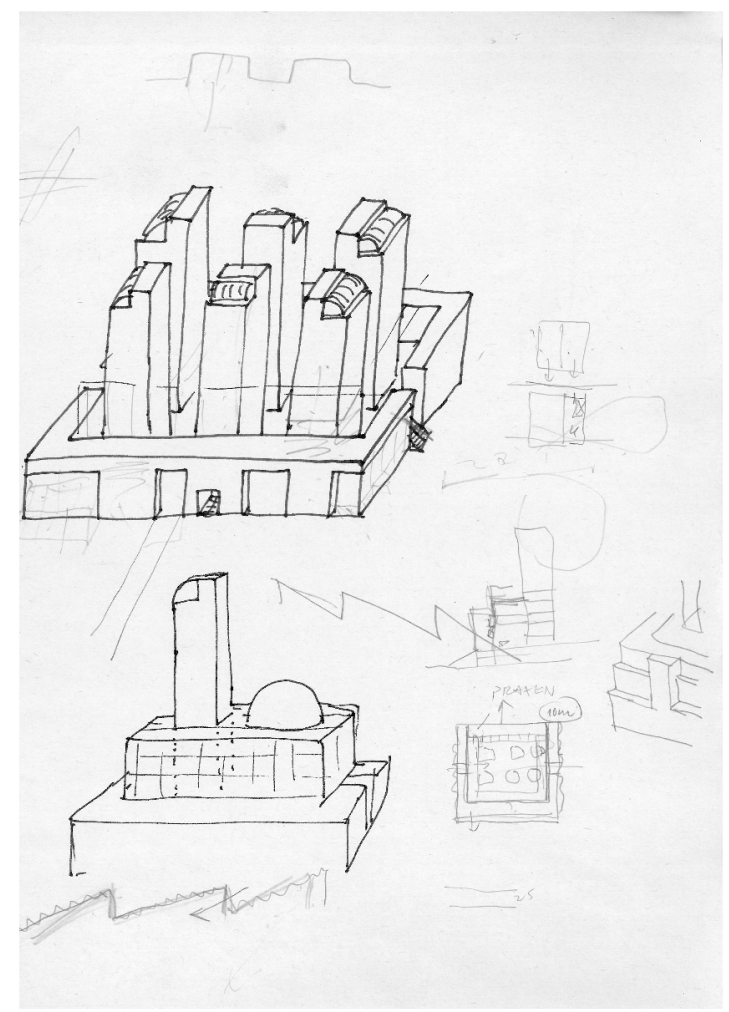

Ungers Archiv für Architekturwissenschaft

Koolhaas's quality is perhaps also his ability to shift between various perspectives and to include the unexpected, low-culture domains, as well as to compel the client to take a clear position. As such, he already makes use of the logic of 'no-brow', where each cultural artifact is taken for its features as such, and not for its standing in either high or low culture. ${ }^{82}$ Ungers's strength is his didactic clarity combined with his demanding ideas; he has no patience for the inadequate while he does appear to have a forgiving sense of what cannot be changed. By placing incommensurate images and references alongside a reality that will inevitably follow a course of its own, this work 
Fig. 1.7: Ideas competition Landwehrkanal-

Tiergartenviertel, 1973, sketch by Koolhaas

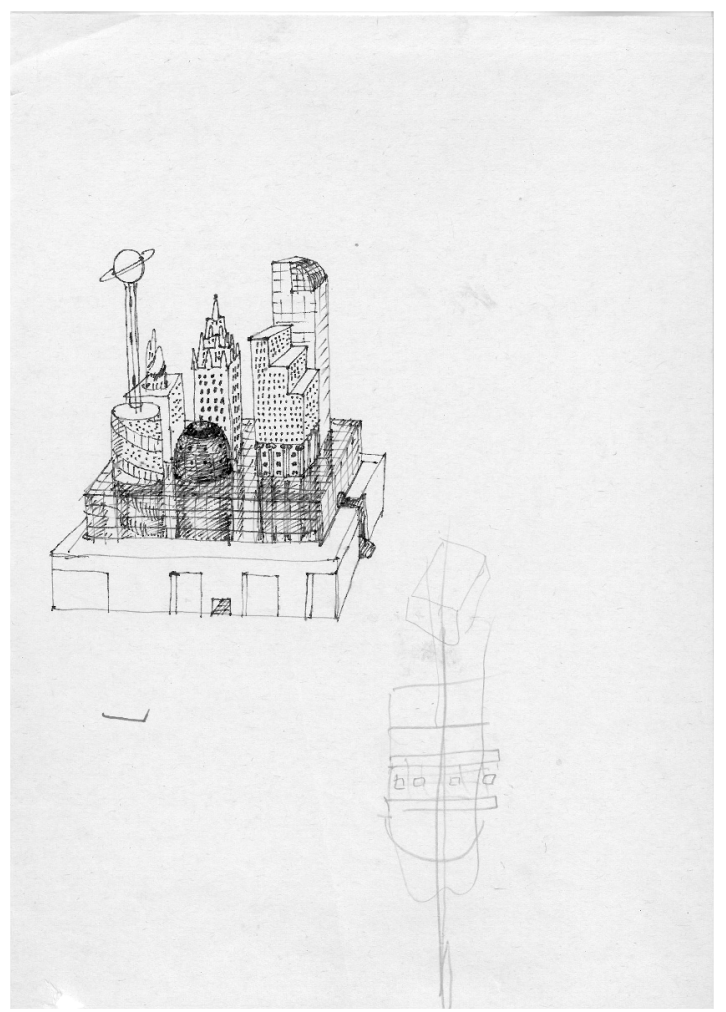

Ungers Archiv für Architekturwissenschaft

tones down the overstated power of architecture to enter into all spheres of life and transform it in its entirety. It retains the evocative power of architecture through a variety of idealized images, yet also calls attention to the fault lines between this ideal and its reality.

Thus the mythologies around architecture are realigned: Ungers carefully explicates them, appealing to the domain of spiritual content, but approaching it in a rationalized manner. He picks apart the elements of architecture in order to excavate the potential for creating a significant space in the city. Koolhaas, on the other hand, uses these mythologies to his advantage, 
oscillating between the relatively dry, factual description of conditions, such as the Generic City or the studies of Lagos, and the provocative speculations on the underlying narratives of form, as in Delirious New York, or Bigness. Then perhaps this is what drives the need for a plausible relationship between the social and the formal. The journal Radical Philosophy returns to this question in the early years of the twenty-first century, questioning what this relationship might be. ${ }^{83}$ A striking reference Koolhaas names here for his work on Delirious New York is Roland Barthes' Mythologies. ${ }^{84}$ The approach taken by Barthes incorporates the meticulous description of situations or objects as well as sociocultural associations and a plausible fiction written on the cultural significance of the objects he describes. This illuminates the synthesis in Delirious New York of the quite factual, journalistic descriptions Koolhaas had developed during his time at the Haagse Post, and the surreal stories he weaves throughout, which are illustrated by the sensual art of his wife, Madelon Vriesendorp. Here, the social content of the work is present, less as an activist agenda than as offering an imaginary life of objects that reflects the dream images of our culture. In a sense, Mythologies clarifies the imaginary life of objects presented in Delirious New York. It constructs a new relationship between things and ideas by incorporating Barthes' strategy of contextdependent speech. In other words, these images may carry messages, but the context influences, and is indeed necessary for, the interpretation. This approach maintains a certain fluidity that is absent from the more semiotic constructions underpinning the work of, for example, Peter Eisenman.

The plausible relationship between the social and the formal should then perhaps be seen more as analogous to the Mythologies of Barthes, in which the language of cultural expression and social conditions sometimes simply states its meaning, and at other times runs parallel to intention and significance, constructing its own fictions alongside the facts of its existence. Barthes' readings of the signs and symbols of everyday popular culture (Marilyn Monroe), of unexpected sports (wrestling), his understanding of cultural symbols, his excavation of the significance of each piece, of the various elements, all contribute to a 'plausible relation between the formal and the social'. Barthes performs a reading of our culture that not only describes its simple facts, but incorporates the likely dreams and fears attached to them. Koolhaas's statement that he might not have written Delirious New York without having read Barthes is perhaps exaggerated (Koolhaas's appetite for interesting thoughts, stories, ideas and objects would no doubt have found other touchstones), but the influence of Mythologies is nevertheless 
strong. The similarities between the hidden life of Manhattan skyscrapers and Barthes's Mythologies are striking. Whether he is writing about the spectacle of a wrestling match, in which an eternal storyline of Justice is carried out, or about the cultural and psychological implications of laundry detergents, Barthes uncovers the secret life of everyday objects that makes us consider these things in a new manner. Similarly, Koolhaas describes the underlying logic and backgrounds of New York architecture, mining not only the traditional literature of architecture, but also their portrayals on postcards, in literature on urban development and in his own imagination of the stories that construed their histories. Likewise, Barthes focuses on a variety of artifacts in contemporary existence, opening his essay 'Myth Today' with the statement that myth means speech while adding a footnote to explain that many other meanings of myth can be cited against this, but that he has 'tried to define things, not words'. ${ }^{85}$

Is architecture to be held responsible for the activities within? Koolhaas argues that this cannot be true, given that evil takes place in so many different kinds of surroundings. ${ }^{86}$ Yet if a system, an environment, can influence preexisting tendencies, then why should architecture - the total environment be absolved from any influence whatsoever? The wish for care, for civility, for restraint, for thoughtfulness - what Lampugnani suggests as a tolerant normality' present in the built environment - seems to hold out hope simply by virtue of analogy. ${ }^{87}$ While it is immediately obvious that beauty and the good are not by necessity correlated, there has been a renewed interest in the appeal that a well-designed object makes to its user or observer. This also suggests the inverse, that a poverty of the built environment provokes a disregard for environment, and as such a disregard for civility.

Yet it is not in the initial intention, but rather in the resulting stories, objects, drawings and buildings that the potential for new insights lies. Kieren sees the tension between idea and reality - the Utopian dimension of Ungers - as central:

And now, in the 1990s, we see Ungers move down the path towards 'pure form' - towards the provisional completion of an idea which is so autonomous, so absolute, that it is bound to fail when set against reality. This element of utopia is what is so deceiving, yet simultaneously pleasing, about Ungers' work, for ideas are always subversive - once they have been voiced, they can never be silenced: long after their first appearance, they retain the power to enrich the world, to cause unrest. ${ }^{88}$ 
This takes note of the material, tangible impact of implicit ideas. Whether they are read in their original intent or not, they may still cause 'unrest'. I would rather suggest that the 'pragmatic' visions of Koolhaas and Ungers function as smaller idealizations - the storytelling and imaginative speculations of Koolhaas, and the didactic expositions and clarifications in Ungers pushing us to rethink the relation between architecture and the urban. In the urban domain, reality perhaps takes the lead. The city is defined explicitly by its social field, it is a conglomerate of all the complexities that make up the practice of architecture, from regulations and infrastructure to individual spaces and monumental buildings. The ideal cities of the past notwithstanding, the heterogeneous field of the contemporary city is defined more by its multiplicities than by a coherent image or a clear social identity. In contrast, the architecture of the house at times allows the idea to be expressed with more purity and precision by virtue of its limited scale and programme, and the single client involved. These issues take particular shape in two distinct domains of work in both firms - the metropolitan projects, engaging with urban conditions and the social field they are interlaced with, and the more self-contained architecture of the house, in which the limitations of scale allow the full breadth of a concept to be developed unfettered by the inevitable compromise of complex programmes and infrastructures. Finally, in considering the underlying aims of Koolhaas's and Ungers's work, these two types of projects - the urban or metropolitan, and the individual house might be complemented by examining their writings and their teachings. While the city projects demonstrate their ability to navigate complexity, and the houses provide the strongest material articulation of their ideas, it is in their teaching and writing that a recalibration of the role of the architect and a conviction on the relevance of architectural expertise is to be found. 


\section{Chapter 2. From Delirium to Archipelago, the Postmodern Collective in the City}

Confusion in her eyes that says it all She's lost control.

Joy Division

So what happens if architecture can no longer engender the social ideals it saw as its raison d'etre? What is left when the city becomes a collection of phenomena that only sometimes congeals into something comprehensible at the scale of the building? What does one do when the forces of the metropolis have become overwhelmingly diffuse? In hindsight, Ungers and Koolhaas's urban experiments already seem to indicate a turning point in the treatment of the city. In fact, a small reflection on the problem of 1960 s urbanism is hidden within their 1977 summer studio on Berlin. Presenting the proposal of the archipelago city, the authors situate it in relation to the urban planning ideas of the time: "The pluralistic project for a city within the city is in this respect in antithesis to the current planning theory which stems from a definition of the city as a single whole.' This may well be one of the most crucial insights of the city studios that Ungers organized during his time at Cornell. The renewed engagement with the city picks up on the social commitment of the 1960s, but resists the unifying stories of urbanism - the seeds of postmodernity clearly taking hold, many projects on the city become a balancing act between the exercise of control (specific, architectural projects as urban catalysts) and 'letting go': acknowledging the limitations of the design intervention in the face of cultural and economic transformations. Or, as Koolhaas would later note: 'Architecture is a desperate attempt to exercise control and urbanism is the failure of that attempt. ${ }^{2}$ 


\section{The Terrifying Beauty of the Twentieth Century}

The modern metropolis, or Georg Simmel's Großstadt, stands as the emblem of modernity throughout the twentieth century. ${ }^{3}$ As such, it has taken on many guises within architecture writing. Ranging from the functionalist idiom of the CIAM to the 1960s cluster cities meant to encourage new forms of community, or the recent studies on the informal and self-organization, the city figures prominently as design question and as ground for architectural interventions. The past 30 years have seen a striking interest in the disorderly aspects of the city, in the qualities of tradition and in the network. In retrospect, we might see these stories - besides the city branding aspects - as manners of confronting the postmodern condition within the fabric of urban development. Ungers addresses the question of plurality and divergence by focusing on the structures that allow for life and vitality to develop independently within, while Koolhaas focuses more on introducing singular points of recognition amid the chaos of the city.

Both are seeking a way to escape the unity that is implied in the city of modernity. As it failed, and Team 10 began to rethink the project from within, the conditions Ungers explored in Berlin, and the cities that Koolhaas addressed, share a certain resistance to traditional aesthetic or functional understanding. A far cry from the city as a work of art (one of Ungers's earlier essays), the clinical view they bring to the table through their various urban explorations aids in addressing the type of urban spaces that seem to make many critics of the modern city uncomfortable: emptiness, banal buildings, anonymous spaces and large infrastructures. In this, they are heirs to the early modern thinkers on the city, such as Georg Simmel, who observed a new sensibility arising with the metropolis, and Robert Park, who suggested that the modern crowd had an unmistakable power that should not be underestimated. Both expressed a sense of liberation in the conditions that were changing at the turn of the century. ${ }^{4}$ In 'The Terrifying Beauty of the Twentieth Century', Koolhaas notes that he may simply have an affinity for what exists, for the modern experience. He ends the essay, an extended riff on the qualities of the strange, disjointed cities of Berlin and Rotterdam, with the observation: 'But maybe all these arguments are in the end mere rationalization for the primitive fact of simply liking asphalt, traffic, neon, crowds, tension, the architecture of others, even. ${ }^{5}$ His attraction to what exists leads to a pragmatic handling of conditions, yet it seems not to have limited his affinity for constructing potential mythologies around 
these existing objects. This continues to inform his writings on the city in subsequent years, which show a recurring negotiation between the ideal and the conditions at hand. "The great originality of the Generic City is simply to abandon what doesn't work - what has outlived its use - to break up the blacktop of idealism with the jackhammers of realism and to accept whatever grows in its place. ${ }^{6}$

The shared affinities of Koolhaas and Ungers for the shaping of the city through the life within it, and the role of architecture in this, are explicitly addressed in a number of their ideas on the city. Those of Koolhaas are most immediately traced through the work he did from 1972 to 1978 on Delirious New York, which sets up a conceptual framework that returns throughout many of his metropolitan writings. Ungers's early city thinking can be traced primarily through an appeal to transcendent ideas from 1960 to 1966 in 'The City as a Work of Art' and the notion of Grossform as a framing mechanism for the uncontrollable life in the city.

Alongside Yona Friedman's Ville Spatiale, Constant's New Babylon, Alison and Peter Smithsons' Cluster Cities, and other 'mountains and molehills' published in Archigram 5, there were more growing interests in the organic city, and the significance of the city as a palimpsest of collective memory, of architectural intervention, of slowly developing urban fabric. Combining concerns of functionality and representation into a conglomerate material memory of the city, Rossi explored the Città Analoga (1966), while Ungers sought an underlying logic of architectural approaches - the city that was no different from a house, from the point of view of designing it. The focus on what made the existing city work had already begun to figure in many post-war writings, as a recuperation of the comfortably worn old city fabric that had been swept aside by the modernist drive for progress. Jane Jacobs had alerted the public to the value of existing city neighbourhoods, while the Smithsons had proposed that the city be approached as a group of neighbourhoods akin to a village. Yet there did not yet seem to be a language for 'the terrifying beauty' that Koolhaas was to identify as part and parcel of the twentieth century. ${ }^{7}$ Ungers and the Tendenza group were aligned in this exploration, more so than the architects involved in Team 10, and the various 1960s groups focused on the more sociopolitical dimension of the city. Italian architecture journals were some of the first to publish Ungers's early work, and in Vittorio Gregotti he found one of his staunchest supporters. ${ }^{8}$

A key feature here is the collective and its role in relation to the built form of the city. Koolhaas and Ungers's projects and writings investigate 
the role that architecture may play in the city, and implicitly in how it may contribute to forming a collective. Can it offer a space of significance that somehow mediates between a pluralistic and fragmented public space, and a purely individuated private space? Can it create a collective space that situates itself in between the two? Can this collective space help negotiate the seemingly inevitable oppositions of the contemporary metropolis? What are the respective positions of architecture and urbanism - is the urban configured purely by urban design, with architecture simply as infill, or can architecture play a pivotal role as a punctual intervention within the larger urban field, or can it truly redefine a collective?

Without presuming a direct causal link, the physical manifestations of the 'maelstrom of modernity' are explored as counterparts to a cultural sensibility. ${ }^{9}$ The complicated relation between the public, the collective and the individual has been a theme throughout the architecture discourse of the twentieth century. Crucial to the modern avant-gardes, but also to the development of modernist architecture and the International Style, there are seminal texts such as Georg Simmel's 'Die Großstädte und das Geistesleben' (1903) and Ferdinand Tönnies's Gemeinschaft und Gesellschaft (1887), which study how the public and the collective is formed or affected when natural social relations have been severed or undeniably altered. ${ }^{10}$ Through a mutual interest in the collective, Koolhaas and Ungers address the problems of 1960 s city planning, which still treat the city as a unified whole. ${ }^{11}$ Koolhaas's interest in Leonidov is immediately evident in this domain (also forming visual/architectural references in Exodus). Koolhaas and Ungers in particular navigate many ambiguities inherent in a thinking practice of architecture, exemplified in their writings and projects when set next to one another. Their city studies in general are less unified and definitive than the typical plans of the 1960s. In the case of Ungers, the city plans were rarely realized, whereas Koolhaas has had the opportunity to realize some large-scale projects. ${ }^{12}$ During the years they were in close contact, from 1971 to 1978 , a number of themes arose that alluded to a transition between modernity and postmodernity, as well as the role of architecture in the contemporary European metropolis. They shared an interest in oppositions and contradictions as a way to reconfigure existing approaches to the city. 


\section{Situated Urbanism: The City of the 1970s}

In 1971, an issue of Casabella addressed 'The City as an Artefact'. This issue illuminated a number of the urban issues of the time, including articles by Peter Eisenman and Joseph Rykwert, and one by Thomas Schumacher on 'contextualism', which would soon become prominent in the debates on the city. ${ }^{13}$ This issue illustrates the spectrum of urban thinking in the 1970s, which engages with the problems of context and tradition, but also of modernity. It presents the duality of the contemporary city as an organic development of the vernacular and traditional, interspersed throughout with modern anomalies. By necessity, it implies the impossibility of returning to previous histories. This forms the background for the later notion of the archipelago city. This idea, launched in 1977 during the Cornell Summer Academy in Berlin, provides a new theoretical model that is based on the existing city, using empirical observations on the particularity of Berlin, such as its clearly defined boundary of the Wall and its shrinking population, to inform new models of interpretation such as the City within the City.

The notion was recalled later by Koolhaas as one of the most powerful notions in urban thinking: a blueprint for the new European metropolis. ${ }^{14}$ The history of the archipelago city incorporates a number of crucial transformations in the approach to the city. It seeks a manner to adequately address existing urban fabric and explores a system that allows both for individualization and comprehension as a coherent whole. This approach to the city does not stand alone. It shares characteristics with the Collage City by Colin Rowe and Fred Koetter, and with Aldo Rossi's Città Analoga. Each addresses the city as an amalgam of collective history, individual perceptions, architectural and urban interventions. Nevertheless, the close collaboration between Ungers and Koolhaas seems to have added a conceptual dimension founded both in history and in the observation of different urban conditions that they encountered in the United States. ${ }^{15}$

The contribution of Koolhaas to thinking about the city is evident throughout his work, from Delirious New York as his 'retroactive manifesto for Manhattan' to contemporary studies of African and Asian cities as selforganizing systems or as the materialization of a global economy. These projects address the larger field of architecture, the conditions within which it takes form. Many of the architectural concepts Koolhaas introduces are based precisely on the urban conditions he sees as underlying the practice of architecture. The Vertical Schism (and the 'lobotomy') introduces a solid 
Fig. 2.1: Berlin as archipelago city, Cornell summer studio 'The city in the city', 1977

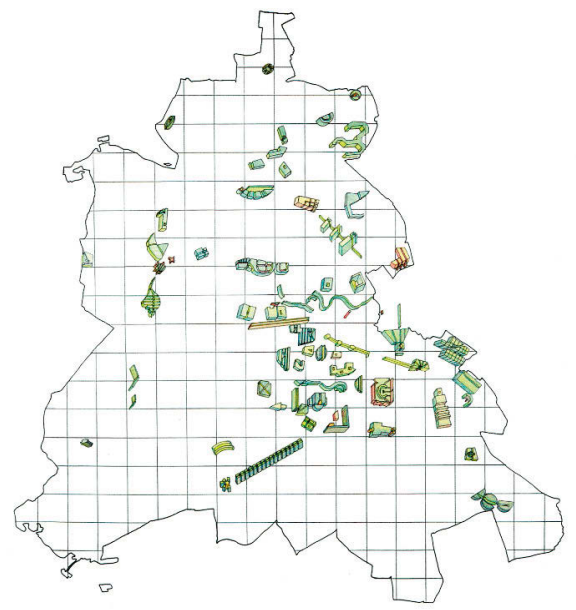

drawing by Peter Riemann, courtesy of artist

division between inside and outside, calling into question such modern notions as 'honesty' or 'form follows function'. ${ }^{16}$ The Generic City postulates an urban condition that is similar to the typical floor plan, but expanded to the urban field. One could argue, in this sense, that for Koolhaas there are no distinctions between 'architectural' and 'urban' thinking. To Ungers, too, the city is the primary situation of architecture. Even when the 'shrinking city' is acknowledged in the text 'Cities within the City', the transformation of this urban condition into something new still aims at preserving urban qualities: "The future task is going to be not only to plan the growth of cities but also to develop new proposals and concepts for dealing with this exodus by protecting the better aspects of cities. ${ }^{17}$ Despite alternative proposals of semi-urbanization, and in this text, even the assessment that cities the world over are suffering from population drops, the city remains the prime example of collective dwelling throughout the twentieth century. While both 
Ungers and Koolhaas clearly underwrite the archipelago city as an appropriate urban model for the time, some difference is visible in the details of the text and in the archive, which can be traced back to Ungers's interest in an overall architectural coherence, versus Koolhaas's interest in the maelstrom of modernity. ${ }^{18}$

There is, however, a crucial distinction between architecture and urbanism. In the early twentieth century, architects approached the challenge of the city as a design problem, enforcing a modern architectural programme on the city as a whole. In the 1970s, a renewed interest in the existing fabric of the city, and the recognition of the qualities of the city as a cultural artifact developed over long periods of time, contributed to a distinction between architecture and urbanism. This begins in the late 1950s, when a marked resistance arises - particularly in the work of Team 10 - against overbearing modernization. The modern project is not fully dismissed, but rather the major problems with full-scale modernization are addressed, such as the loss of neighbourhood and habitat. Ungers is central to this shift in the debate; while his introduction of Grossform is met with interest, his rationalist tendencies later lead to a clash with the structuralists. ${ }^{19}$

The approaches of Koolhaas and Ungers are strikingly unsentimental, ranging from studios taught by Ungers on urban issues in Berlin to Koolhaas's speculations on the architectural qualities of Manhattan in Delirious New York, to the variations on urban archetypes in the 1975 competition entry for Roosevelt Island. The many contradictions they explore within their work create the space to acknowledge the potential of the 'realism' that Generic City refers to. For Koolhaas, this is a manner of envisioning alternatives to an extreme sociospatial determinism as visible in Dutch architecture. At the 1990 symposium 'Hoe modern is de Nederlandse architectuur?', Koolhaas notes that Dutch cities suffer from the mythological status of the 'sympathetic' historical core, and that everything beyond this core is left to its own devices. $^{20}$ The strained approach to city centres leads to the neglect of everything outside of the centre. In this perspective, the cluttered landscape arises not despite, but rather due to the resistance against the maelstrom of modernization.

Koolhaas's approach to the existing urban condition is already present in his 1971 study of the Berlin Wall, which he approached as an architectural object rather than addressing its sociopolitical significance. His resulting study, compiled in photographs, collected images and a reconstructed narrative of the architectural impact of the Wall, lists numerous architectural insights 
deriving from his observations. Not unlike the later structure of Delirious New York, he offers a series of themes, derived by a process of induction from observations and images. The most significant comment in light of the later urban work is perhaps his consciousness of the 'heroic scale' and the 'tension between its totality and the separate elements that create it', which seems to predict the structure of the City within the City. ${ }^{21}$ Additionally, his appreciation of the Wall as 'an object without program' is a harbinger of the programmatic instability that will later become so central to the work of OMA.

Fig. 2.2: R. Koolhaas, Summer Study, The Berlin Wall, 1971
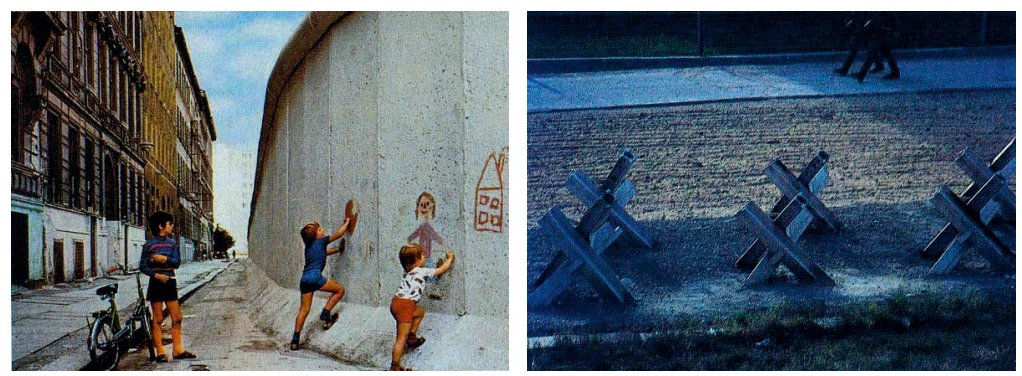

in R. Koolhaas et al., SMLXL

While Koolhaas was there, he may have picked up a few copies of the Veröffentlichungen zur Architektur, a publication series edited by Ungers. ${ }^{22}$ In 1963, Ungers was appointed professor at the TU Berlin, where he developed a number of studio exercises on the unique urban conditions of Berlin. The clearly limited urban boundary already suggested the laboratory setting of the city, which was explored in thematic clusters such as 'roads and buildings', 'living along the park', or 'traffic strip Spree'. The studio results were published in the Veröffentlichungen zur Architektur. ${ }^{23}$ As Koolhaas studied the Berlin Wall and sought to exacerbate the tension between architectural intervention and existing conditions, so the studios of Ungers explored the possibilities of architectural intervention in an artificial enclave, treating Berlin as an urban laboratory, in which aspects of design could be isolated and studied.

As noted in Chapter 1, Koolhaas's affinity for the studies of Ungers informed his 1971 application for a Harkness fellowship to follow the graduate programme in Urban Design at Cornell, where Ungers was then teaching. Ar- 
riving in the United States in September 1972, he spent his first year at Cornell with a varied programme of studies including a course in elementary Russian, presumably to be able to further study the Constructivists whose work he admired so much. ${ }^{24}$ After the first year, he took his work to the Institute for Architecture and Urban Studies as a research fellow. Manhattan opened up yet another vista of modernity, with an endless grid of pragmatic buildings in need of a retroactive manifesto - the early stages of Delirious New York. He discovered the work of Wallace K. Harrison, explored the naive and optimistic presence of Radio City Music Hall, and reinterpreted the Downtown Athletic Club as a social condensor of Constructivist proportions - without the underlying ideological intentions. In this approach, Coney Island became a site for urban fantasies that paralleled the metropolitan speculations of the European modernists, but without a comparative socialist programme. Rockefeller Center showed the potential of private investment with a bottomline of quality, directed at profit - an inverse of the European policies aimed at the welfare state. Certainly the 'Romance of Rockefeller Center' must have been attractive to Koolhaas during his research on Manhattan. ${ }^{25}$ This construction of an a posteriori narrative of a building process, while largely based in fact, suggests the more provocative manner in which Delirious New York is built up. At the time, the differences between the work on the European mainland and that in the United States were already visible in their finance base. In the United States private enterprise has played a more significant role in determining the public face of architecture than in Europe, which was more defined by the development of the post-war welfare state.

What Manhattan made obvious, is that there are concepts with which to address the unexpectedly titillating sense of the city without a plan - and that the urban manifestoes of European modern architecture had not created the cities that Koolhaas could admire. It is in this gap, between the built reality of Manhattan and the idealized failure of Europe, that the new urban concepts of Ungers and Koolhaas began to take shape.

\section{New Urban Concepts for the Fragmented City}

Two of the most striking ideas of this period are the City of the Captive Globe and the City within the City, or the urban archipelago, both deriving from an analysis of actual cities (Manhattan and Berlin). ${ }^{26}$ One of the most salient issues here is that both Koolhaas and Ungers (although differently) approach 
the issue of difference and fragmentation as a key question, undermining the unity that is central to earlier twentieth-century urban thought. These concepts must be viewed in relation to Colin Rowe and Fred Koetter's Collage City and Aldo Rossi's Città Analoga, in the sense that these also address the condition of fragmentation, and postulate an explicit relation with the existing city, as fragments or as fabric. While Rossi presents the urban fabric as signifying a continuous repository of collective memory, his fragments in the Città Analoga suggest a contemporary mode of addressing the presence of history, which also returns throughout the Collage City, and the 1978 competition Roma Interrotta. ${ }^{27}$

The City within the City and the City of the Captive Globe both represent concepts that are instrumental in addressing a changing European metropolis. Both derive from an existing city, an actual city, and model the traits they see as most valuable or striking. The City within the City derives from the condition of Berlin as it was in the late 1960s, early 1970s: with individual areas and neighbourhoods showing pronounced and different identities, all embedded in a larger metropolitan field. The City of the Captive Globe derives from a study of Manhattan, where, according to Koolhaas, the grid is such a rigorous ordering system that each plot itself can manifest a completely unique identity without destroying the conceptual coherence of the gridded city. Thus both concepts are distilled out of the unique and specific conditions of Manhattan and Berlin, and employed as tools to reflect upon the European metropolis of the 1970s with its increasingly fragmented multiple centres. The remains of the historical city are still present, yet embedded in a newer field of urban expansion. The concepts evolved both from within the discourse of the late 1960s and from within the work itself of Ungers and Koolhaas.

The various urban concepts put forward by Ungers and Koolhaas both take into account the inevitable conditions of modernization, and selectively pick out earlier historical ideas that may retain some use in the contemporary urban domain. As such, they weave a small tapestry of interrelated ideas on the late twentieth-century city that addresses the specific contemporary conditions through historical pearl-diving and cultural contemporaneity.

More than anything, the work of Ungers and Koolhaas at this time offers a departure from the perception of the city as a cohesive whole. What they share is the idea that even in a fragmented city, the connections within it and the role of architecture can remain vital. For Ungers, unity is created in a strong form (Grossform) or by virtue of the intense individuality of city 'islands'. For Koolhaas, the grid itself is such a neutral yet omnipresent condition that 
Fig. 2.3: R. Koolhaas and Z. Zenghelis, City of the Captive Globe, 1972

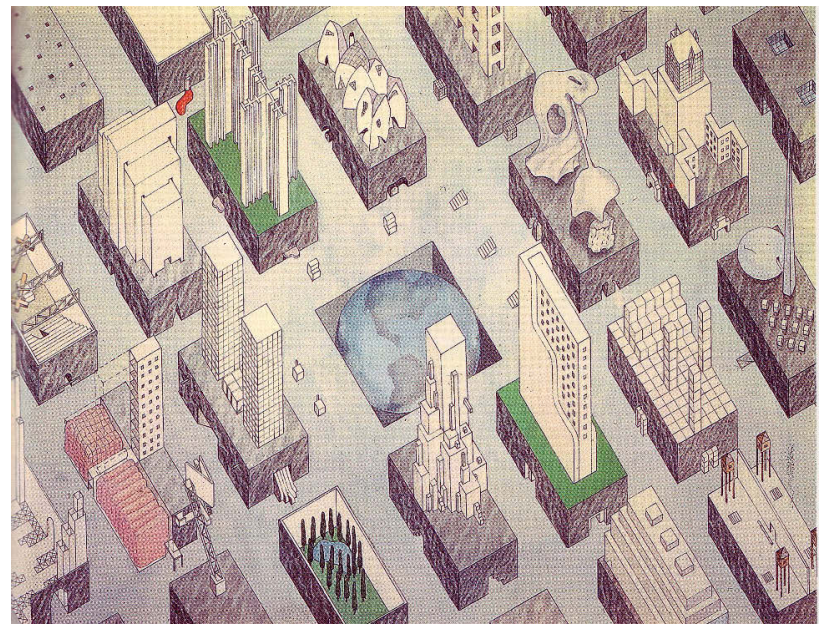

Image Courtesy of OMA

it encompasses a lack of unification. As a strong urban condition, the grid allows maximum freedom for each individual condition within it. In fact, the individuality of each plot reinforces the unity of the grid. This attention for the individual condition offers a strong position to architecture in the urban fabric: it may reinforce the larger field of the urban simply by being specific. Is it possible that the archipelago city offers a suggestion towards encompassing a collective within the heterogeneous urban realm?

\section{City within the City}

In his 1985 essay 'Imagining Nothingness', Rem Koolhaas notes the introduction of an important urban concept, the archipelago city, in a 1977 studio by Oswald Mathias Ungers 'with as yet unrecognized implications':

'A Creen Archipelago' proposed a theoretical Berlin whose future was conceived through two diametrically opposed actions - the reinforcement of those parts of the city that deserved it and the destruction of those parts that did not. This hypothesis contained the blueprint for a theory of the 
European metropolis; it addressed its central ambiguity: that many of its historic centers float in larger metropolitan fields, that the historic facades of the cities merely mask the pervasive reality of the un-city. ${ }^{28}$

The notion of the archipelago city, consisting of various cities within the city, is relevant for a specific view of the role of architecture in the city as both formal and formative. ${ }^{29}$ The role of Ungers in the development of these ideas, as an architect and a teacher, is essential to understanding the simultaneous internal coherence and overall interest in difference. These are crucial features that continue to be relevant to the current debate. The many urban ideas put forward such as the City as a Work of Art and Grossform (Ungers), the City of the Captive Globe and Bigness (Koolhaas), build on suppositions that revise an earlier approach to the city. These include the acknowledgment of a collective symbolic role of architecture, positioned as dream-images more than social engineering, and the discontinuity of formal expression and social 'content' or reception. They also include a fascination for the 'maelstrom of modernity' that is at odds with the return to primitive archetypes, the ordinary and the village in the late 1960s.

To Koolhaas, the archipelago concept addresses the tension between the historical centres, typically seen as the stronghold of traditional public spaces, and the larger, more fragmented metropolitan fields surrounding them. The archipelago concept, in folding both conditions into a general theory, illustrates the attempts by both Koolhaas and Ungers to address the potential of architecture to create pockets of meaning and significance within the urban. They both note a tension in the contemporary city in its inability to combine a traditional form of public space, offering cohesion and a sense of community, with the extensive desire for individuation that is also part of contemporary society. While neither architect presumes a direct relation between the social field and built form, they do identify projects and ideas that are more receptive to the collective imagination. Although the city concepts of both architects address specifically architectural and urban questions, an underlying concern with a broader cultural significance is discernible. Reconsidering this early work in relation to questions raised today, it shows an implicit yet seminal concern for the idea of 'collectivity' - something in between the traditional idea of the public and the private, acknowledging the pluralism of an individualized society without giving up the idea that a larger cohesive framework is possible.

In his essay, Koolhaas notes that in the archipelago model: 
. . . the desire for stability and the need for instability are no longer incompatible... such a city becomes an archipelago of architectural islands floating in a post-architectural landscape of erasure where what was once city is now a highly charged nothingness. ${ }^{30}$

This raises questions about the relation between architecture and the city: Does architecture now become the city, while the city becomes a highly charged nothingness'? Is architecture simply relinquished in favour of a 'post-architectural' form of urban practice? Does architecture 'erase' the city by incorporating its urban functions? The continual negotiation between architecture and the city is central to the reconsideration of the metropolis and how to define and create space for collective meaning. The archipelago concept is a 'system of fragments', an interpretation that Ungers had been working on for many years, which negotiates the problem of forming a sense of community that can transcend the purely individual without destroying the potential for individuation. This is perhaps the most crucial feature of late twentieth-century urban thinking, as a unifying view becomes increasingly difficult and a plausible logic to connect formal interventions to the undercurrents of a fragmented city seems untenable. As an interpretation of Berlin, the archipelago city is based on a 'natural grid' of green interspaces that allow a full range of life to grow in between, not unlike the rigorous New York grid as described by Koolhaas in 'The City of the Captive Globe'. ${ }^{31}$

The summer studio 'Die Stadt in der Stadt' was taught in parallel with another studio on the Urban Villa, exposing a deepening interest in the urban condition and architecture's relation to it. ${ }^{32}$ It follows in the tradition Ungers had built of approaching Berlin as a laboratory to experiment with urban ideas. The City within the City seems a natural fit to the context of Berlin. As Neumeyer and Rogier argue, the city of Berlin is crucial to the development of the archipelago concept, as the Berlin conditions already suggested a presence of Utopia and a defined enclosure. ${ }^{33}$ Important here is the approach, examining the existing for durable cultural features that become embodied in the urban artifacts, much as Rossi suggested in the city of collective memory. ${ }^{34}$ As such, the most important features of the City within the City are the systematic approach to difference, and the attempt to facilitate collectivity in the fragmented city. The City within the City forms a bridge from the analysis of the existing city (Berlin in this case) to derive 'urban rules', to the projection of critical urban qualities for the future. It seeks to comprehend the underlying logic of the city as an indication of general 
urban conditions, which may hold true in other situations. Both Koolhaas and Hans Kollhoff were involved in the conceptualization and the publication of the material after the studio. The final publication puts forward 11 'theses' that form a chronological sequence of steps in analysing and working with the specific conditions of Berlin. The theses follow a simple structure of 'thesis', 'comment' and 'conclusion', which together form an argument within the larger framework. Each initial thesis contains a general position (such as the predicted population decline in Berlin, or the differentiated structure of large cities), which it follows up with a commentary that focuses on the specific situation at hand, and a conclusion that prescribes a potential urban intervention.

The main body of morphological work is situated in theses 6 and 8 . Thesis 6 describes the identification of urban islands, which is an exercise in describing programmatic, formal and urban qualities, in order to acquire 'design knowledge that can be utilized in a typological sense'. ${ }^{35}$ Here, the images show the study of areas of the city through aerial photos and plans, with a figure-ground diagram to isolate the most important morphological features, an application of Gestalt theory that recurs throughout the work of Ungers. This urban structure is then compared with an exemplary project of a similar composition. In thesis 8 , the focus is shifted to the smaller, but still collective, scale of the urban villa, which would accommodate multiple families in a volume smaller than the apartment block and larger than the detached house. The urban villa accommodates the desire for social infrastructure and the 'need for individuality'. The images following this show a series of urban villas ranging from the nineteenth-century version to Berlin vernacular and new propositions, followed up by the concrete and situated proposition of clusters of these urban villas.

A particular focus in the archipelago city is the accommodation of new forms of collectivity. This focus reoccurs throughout the theses as a counterpoint to the diversity of the metropolis. Thesis 5 notes the importance of an overarching collective structure that also acknowledges the primacy of the individual, identifying the whole of the city as a 'federation' of distinct city areas given 'consciously antithetical' forms. These antithetical forms are a natural conclusion to thesis 4 , which explains the metropolis as 'characterized by the overlapping of many distinct, mutually exclusive and divergent principles. This is what distinguishes it from the village, the town, the city district and from smaller and medium-size cities. ${ }^{36}$ This inherent quality of the city is reinforced through the 'selective reduction of urban 
Fig. 2.4: Berlin islands: Friedrichstadt, Kreuzberg, Lichterfelde. Left to right: aerial photo, urban plan, figure-ground drawing, and reference project.
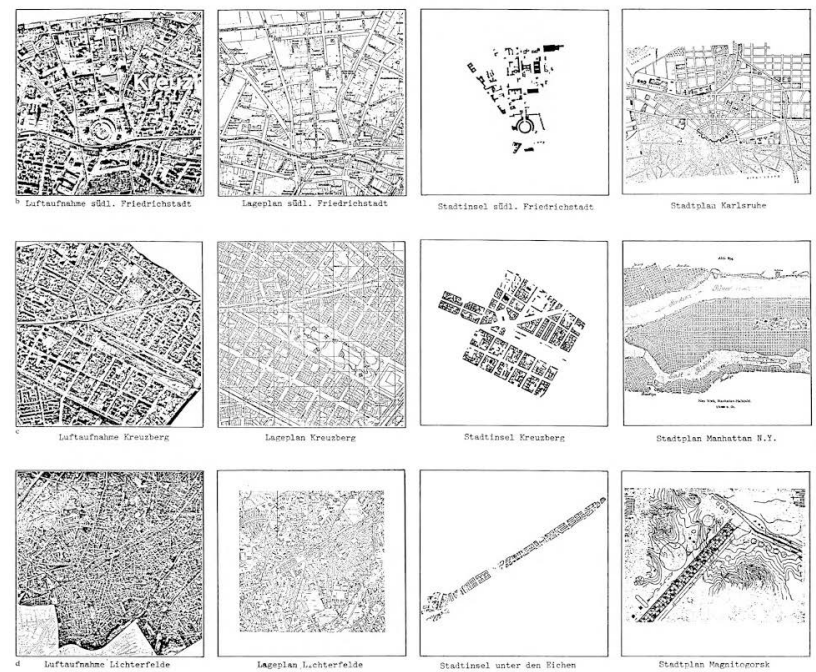

Lotus 19 (1977)

pressure'. This entails the elimination of superfluous areas of the city and the amplification of the distinct qualities of functioning areas. As a whole, this exercise creates the archipelago city: "The enclaves thus released from a general urban anonymity will then create, as it were, liberated city islands, an urban archipelago in a natural green lagoon. ${ }^{37}$ The green zones function as an amorphous field surrounding the city islands, through which they become distinct and clearly defined.

The resulting notion of the City within the City now forms the basis for a future urban spatial plan for Berlin. The image of Berlin as a green archipelago city is seen to offer a 'pluralistic urban concept' that is 'the antithesis of urban design theories until now, which are based on the definition of a unified city'. ${ }^{38}$ The position of the collective is still seen as relevant to the urban condition, but it is premised on the individualized society of the contemporary metropolis. Therefore it maintains a different relationship with the traditional understanding of the public and mediates between the 
totality of unconditionally accessible public space and the pure privacy of individual experience. The idea of the City within the City 'accommodates the contemporary structure of society, which has developed ever more towards an individualized society with different needs, desires and ideas. The concept also incorporates the individualization of the city and thus a dislike for the typical and for unification. ${ }^{39}$ By individualizing the city, there is space for the inhabitant to identify with something specific (as opposed to the depersonalization encountered in the anonymous city).

If one major shift can be identified in the work of Ungers and Koolhaas both, it is from the city as a unified whole to a city that is embedded with various pluralities, and various heterogeneous spaces, that nevertheless still construct an overarching whole. ${ }^{40}$ The images of Ungers, his geometries and various fragments are each a distinct and clear unit, always emphasizing individual moments and the coherence of each City within a City. These beg reference to the City of the Captive Globe, with the grid that is so strong as a framework that it allows each individual plot the maximum freedom to expand in the vertical dimension in terms of scale and in an infinite variety of forms.

\section{City of the Captive Globe}

While the City of the Captive Globe is structurally similar, its visual language is distinct, as is its approach. The City within the City arose from the work of the studios, following a traceable process of analysis that is explicitly laid out in the theses of the publication. The City of the Captive Globe rather appeals to the mythical narrative of the city and its foundations in radical architectural proposals. Its visual language is central to its symbolic power, with its colourful renderings of iconic architectural projects such as Le Corbusier's Plan Voisin and Malevich's Suprematist models. It is hard to imagine its impact being quite as strong without the paintings by Madelon Vriesendorp and Zoe Zenghelis accompanying the text. In early reviews of the work of OMA, the images were often addressed first, with reviewers being in equal parts enthralled and puzzled by the visual language. ${ }^{41}$

Both notions make use of historical precedent, with the City within the City extracting historical forms from the urban fabric, and the City of the Captive Globe placing them on pedestals as symbols of different possibilities. Both ideas approach the city as consisting of isolated islands being able to maximize their own individual traits. ${ }^{42}$ It is clear that this work takes a 
new direction in defining the role of architecture in the city as punctual, as one of specificity rather than abstraction and totality. Both the ideas of Ungers (archipelago, Grossform) and Koolhaas (City of the Captive Globe, Bigness) show a transition in how the city is handled from the perspective of architecture. They attempt to grapple with a continually transforming condition of the metropolis, incorporating plurality and dissension even in its foundations, yet in their work this struggle is always resolved through architecture.

The City of the Captive Globe also makes note of the importance of a framework if the diverse forms of urban life are to thrive, but here it is based on the Manhattan grid. This material was developed from 1972, when Koolhaas landed in Ithaca to take classes with Ungers, through his stay in Manhattan with the Institute for Architecture and Urban Studies in 19731974. ${ }^{43}$ The pragmatism of American architecture and the varied sites of Manhattan formed his ideas on urbanism. It enabled Koolhaas to look for what there already was, to explore the endless potential of the city as it stood, in a material presence, much as he did with the Berlin Wall. ${ }^{44}$ In its final form, Delirious New York gave a form to this inductive approach, which openly appreciated varied and incongruous aspects of the city: it became a 'retroactive manifesto' for Manhattan. The apparently simple material fact of its presence became the starting point for a process of discovery, inductive reasoning and fictional speculation on the underlying rationale and desire that constituted its current shape. The identifiable characteristics of architectural form - composition, detailing, massing, materialization were no longer treated as the inevitable result of an abstract ideology, but as archaeological finds that help to reconstruct a possible narrative.

This leads to specific concepts such as the 'lobotomy' and the 'vertical schism', which Koolhaas posits as describing the distinct realities and potential opposites enclosed within the same skin. He uses non-architectural notions (like the lobotomy) as descriptive analogies, making his perceptions intuitively understandable, yet also somewhat mystifying in comparison to drier architectural descriptions. In the condition of the skyscraper, when the form disengages itself from the programme and manifests itself as an undeniable presence of architecture, it creates a new condition that is strong enough to encompass the complexity of everyday reality.

In 1976, Lotus published a shorter version of 'City of the Captive Globe' than published in Delirious New York in 1978, which refers to the grid as 'an archipelago of "Cities within Cities". ${ }^{45}$ In this publication, the original work 
on the 'City of the Captive Globe' is dated to $1972 .{ }^{46}$ Both ideas remain focused on diversity and the construction of potential futures out of what is found in the existing urban fabric. In this, they show their affinity with Rossi's Città Analoga, combining pieces to create new meanings, and with Colin Rowe, even though his work seems to remain somewhat more nostalgic or historical.

\section{City as a Work of Art}

Earlier work of Ungers and Koolhaas illuminates the specificity of their ideas at this time. The strong focus on form, composition and morphology is visible in Ungers's work as early as 1963, when his publication 'Die Stadt als Kunstwerk' drew parallels between the rules of composition in architecture and urban design. The article is an early manifestation of his steadily increasing interest in morphology. ${ }^{47}$ Moreover, it demonstrates the clear foundation of his thinking in a design logic that builds on the tools of architecture. Earlier, in 1960, even when he was appealing to a 'new spirit' in architecture, the centrality of architectural composition is central. The new spirit is a question of material articulation, a matter of finding the right architectural composition. ${ }^{48}$ The notion that a material articulation may evoke a 'spirit' places this work closely to high modernist claims for architecture. Nevertheless, the manner in which Ungers appeals to the city as a work of art also is founded on a rationalist approach to architecture - that the logic and principles of design are transcendent, and scalable. This stands in contradiction to Koolhaas's later propositions on Bigness, which claim that beyond a certain scale, traditional architectural tools are useless.

\section{Grossform}

While Ungers was perhaps less interested in the immediate urban condition, he similarly had a deep-seated fascination for the unexpected aspects of the city; in the life that grew within it, and how architecture might facilitate this type of growth. Ungers was looking for the logic that would allow difference and transformation to occur - a conceptual model that would go against the unified thinking of both the modernist city plans and CIAM's rebellious progeny, Team 10. He seemed to have found a solid model for this approach to the city in the notion of Grossform, which was put forward in 1957 by Otto Schweizer. ${ }^{49}$ This notion took note of a new condition 
arising with the scale of the modern city that required a new approach to architecture and the city. The concept as such is picked up by Ungers in his 1966 lecture 'Grossformen im Wohnungsbau', and similarly addresses the question of how to give humanly comprehensible form to the modern city shaped by forces of economy and technology. ${ }^{50}$ In this sense, the concept of Grossform offers an architectural approach to the city - it revolves around the Gestaltung, or form-giving, of urban space. Following earlier modern ideas, it approaches the city architecturally. There is a striking similarity between Ungers's position on architecture's autonomous language, and what his erstwhile teacher Schweizer proposes in his book on the architectural Grossform, which similarly argues that architecture has a responsibility to transcend mere considerations of function. ${ }^{51}$ For Schweizer, this amounts to a combination of the Baroque and the Gothic, in which the structuring of architecture and urban space addresses both formal and spatial aspects. For Ungers, the Grossform performs a similar function, but is more oriented on his later interests in the visual ordering of our environment. ${ }^{52}$ Where Schweizer avails himself of the language of modern architecture, and illustrates his ideas with his own work, Ungers begins to gather various examples, from various time periods, fabricating a thematically oriented history of architecture as the facilitator of urban life.

Schweizer's proposition of an architectural Grossform takes into account the fundamental problem of a new scale of experience in the modern metropolis, and the challenge that architecture and urbanism face in addressing it. Calling to mind the principles of Gestalt theory, he writes of the shift from the architectural significance of the single building to the larger structure of the built environment. ${ }^{53}$ The primary feature here is a holistic approach: 'Die Voraussetzung für das Werden der Großform ist eine veränderte Blickeinstellung: eine Ausweiterung des Sehens, eine Wendung des Blickes vom Einzelnen auf das Ganze. ${ }^{54}$ This comment incorporates the 'tipping point' in perception that was part of Gestalt psychology - the moment in which individual elements are no longer perceived individually, but as subsidiary contributions to the whole. This prefigures the later work of Ungers, specifically on the human need for visual ordering in the 'Man TransForms' exhibition of 1978. Schweizer concludes that the modern metropolis has brought new considerations of form and spatiality to the foreground: 'Das differenzierter Leben eines modernen Großstadt hat neue Gestaltungskomponenten in Erscheinung treten lassen. ${ }^{55} \mathrm{He}$ particularly refers to the increased mixing of landscape (growth) and the modern 
metropolis (built), which seems to hint at the contrasting conditions present in the later proposition of a future Berlin as a green archipelago.

The 1966 essay by Ungers on 'Grossformen im Wohnungsbau' explores the potential for architecture to have a morphological impact on the city. As such, Grossform is defined more by form than by scale. The essay begins with an observation of quantity and scale: 500,000 dwellings had been built per year in the German federation since 1950, resulting in 8 million new dwellings by 1966. This is used to argue the need for quality, which resides in formal articulation. Ungers notes that the increased need for dwellings, the limitations of space, and a poor relation between expenditure and yield results in 'a concentration of building volume, rationalization of construction methods, and densification'. ${ }^{56}$ He follows with a criticism of the quantified nature of this construction, noting that people speak of 'units' but mean 'numbers': 'Man spricht von Wohneinheiten und meint die Anzahl der Räume, von Wohnblocks und meint die Anzahl der Wohneinheiten.' This passage echoes Gestalt theory; Grossform is defined more by the relation of the parts in apprehending the whole, than by the mere response to scale and number. This allows the idea of Grossform to incorporate an extra dimension that is strictly architectural, not instrumental, social or functional. It is not a metaphorical expression of the interior function but a formal 'added value', much as the 'iconography' of Bigness, which presents the building envelope and the façade as an independent entity, founded on the 'lobotomy' stipulated in Delirious New York. ${ }^{57}$

Grossform responds to the metropolis, as do the later urban notions of City within the City and the City of the Captive Globe: it is set up to resolve a specifically urban problematic of containing diversity. On the one hand then, scale is highly relevant: the large scale requires a careful consideration of the form that will both encompass diversity yet offer a distinct framework. On the other, Grossform is almost solely dependent on form: if the form is powerful enough, even 'a small house' can be a Grossform. This encapsulates the tension between form and scale that will later resurface in the proposition of Bigness by Koolhaas. In Bigness however, once the scale becomes large enough, the problem of form becomes something entirely different. Where Grossform offers a mode of apprehending something larger, Bigness shows the obsolescence of traditional architectural tools and ideas.

In contrast, Grossform sets out to identify specific architectural approaches in the examples that accompany it. From these projects, which include the work of Le Corbusier, Frank Lloyd Wright and the Smithsons, Ungers derives 
four criteria that may construe a Grossform: an (over)accentuated element, a connecting element, the principle of figure and theme, and a specific ordering principle. In a further categorization of these architectural interventions, he groups them into two 'perspectives' on urban space: the formal (walls and towers: visual anchors in the environment) and the functional (streets and plateaus: spaces of gathering and interaction). Even in the functional perspective, the interest in typology is dominant. The streets and plateaus form the urban spaces and thus become available for appropriation.

Fig. 2.5: The four criteria of Grossform: overaccentuated element, connective element, figure-ground, ordering principle.
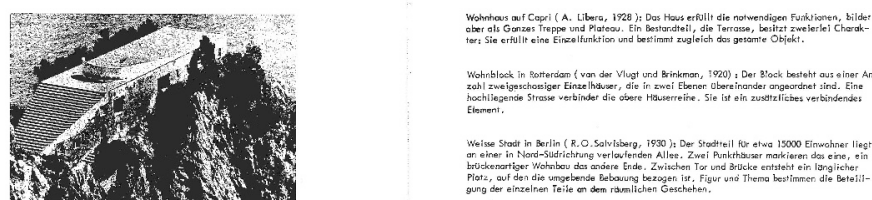

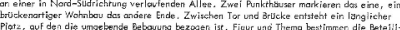

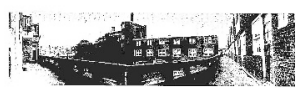

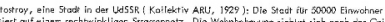

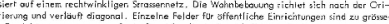

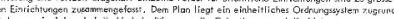
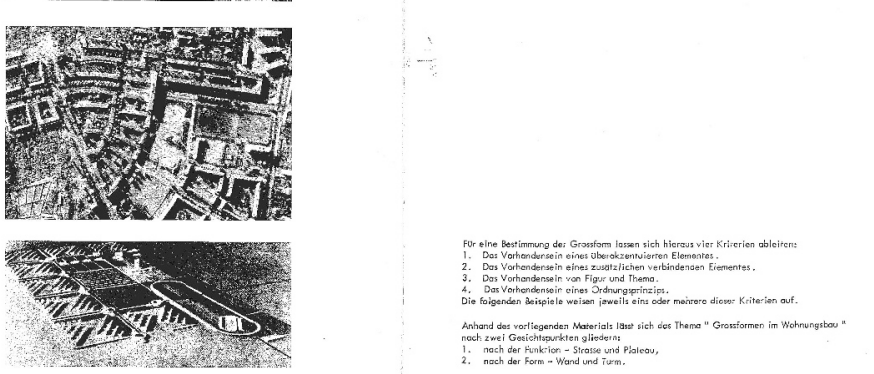

Veröffentlichungen zur Architektur 5

In retrospect, the closing comments of 'Grossformen im Wohnungsbau' are a prelude to the 'archipelago city'. 'Warum Grossform? . . Die Antwort: Die Grossform schafft den Rahmen, die Ordnung und den geplanten Raum für einen unvorhersehbaren, nicht planbaren, lebendigen Prozess, für eine parasitäre Architektur. Ohne diese Komponente bleibt jede Planung starr und leblos.' This introduces the condition that will be exacerbated in the notion of a City within the City: the maximum freedom for individual elements to be 
uniquely defined within a larger scheme that holds these individual elements in place. Koolhaas interprets the effect of the Manhattan grid in a similar fashion, arguing that its horizontal restriction (the plot boundaries defined by the grid) creates a space of ultimate freedom along the vertical plane and within the blocks of the grid.

In all of these ideas, the continuing importance of some form of zeitgeist that underpins the original relation between the social and the formal is tangible, even as in the discourse today: Schweizer's proposition of Grossform aims at a conscious relation to the conditions of our time, which will found an approach that leads to modern architectural unity. ${ }^{58}$ As an approach to the role of architecture in the city, Grossform arises out of the conditions of the twentieth century. It spans the modern and the postmodern condition in its explicit appeal to contemporary conditions, its incorporation of an everincreasing expansion of scale, its invocation of historical precedent, and its role in bringing order to the new urban condition that appears chaotic but is implied to be a new ordering system that we cannot as yet comprehend. While Grossform is founded on the importance of formal composition in the perception of our built environment, it does not presume to be able to predict the nature of public reception. In this, we can see the rise of postmodernity, which questions the direct and inevitable correlation between intention and result. Similarly, the images accompanying Delirious New York express a fascination with the crystallization of these conditions into concrete and specific architectural forms, as well as with the explosion of different forms not governed by architectural coherence, which is reminiscent of the diversity that Schweizer sees as arising within a rigorous architectural frame. ${ }^{59}$

The most important conceptual propositions for the city put forward by Koolhaas and Ungers approach the issue of difference by formulating a space between what is made and how it is used. Their respective studies of Berlin and New York City show how they find a way to utilize empirical observations to discern patterns in the city, which will return in Ungers's 1982 publication City Metaphors. The City within the City, as well as Grossform and the City of the Captive Globe and the later notion of Bigness all incorporate a distinction between the thing itself and the events within. In this, these ideas are related to the work of their contemporaries - from Tschumi and Eisenman's interest in the event to the postmodern focus on alternate narratives. Nevertheless, there are important differences as well. The lessons Ungers turns to are those of history, emphasizing an underlying condition humaine that we share across various cultural boundaries. The affinities of 
Koolhaas span a broader spectrum of cultural production, although they too are used to draw comparisons between various historical and geographical contexts, from the European city to the African megacity of Lagos.

\section{Looking Forward: Urban Notions for the Twenty-First Century}

The City within the City proposes a relation between architecture and the city based on fragments. Suggesting similarities to the Foucauldian idea of heterotopias, the City within the City uses Berlin to help define what tactics would be useful for a diverse and vibrant city. ${ }^{60}$ Returning to Berlin from the suburban context of Ithaca and the culture of congestion in Manhattan, the urban concepts altogether congealed into a more robust conception of the city. The urban notions of the twenty-first century continue this balancing act between control and freedom. The crucial feature now becomes the locus of control: where the tangible dimensions of twentieth-century urban design form explicit limitations, there is now a perceptible shift towards underlying and invisible mechanisms.

In a broad sense, the role of collective and symbolic form is central to the three Berlin summer academies held in 1977 and 1978. The two themes for 1977 were the Urban Villa and the City within the City, and for 1978 the Urban Garden. ${ }^{61}$ The summer academies continued along the lines of earlier projects undertaken by Ungers, where specific ideas were given a systematic framework to be worked through as design projects. In these projects, a fundamental connection between the work of Ungers and of Koolhaas becomes visible: the interest in the various conflicting conditions that make up our world as we know it, and the desire to not smooth that over with a single architectural gesture. The summer academies begin to explore the potential of multiplicity, particularly through the notion of the City within the City, which allows for the juxtaposition of fundamentally different areas within a larger whole. As a design proposition, it is not dependent on a single architectural or urban gesture, but rather offers a framework within which differences can exist and be cultivated. ${ }^{62}$ This concern for difference makes Ungers and Koolhaas's work timely as the rise of postmodernity emphasized the importance of distinct individuality. Nevertheless, the need for an overarching logic remains tangible. Postmodern architecture made reference to collective symbolism, but its nostalgic and image-bound nature neglected to offer contemporary alternatives for collective desires. The balance between 
control and freedom, the underlying logic of extrapolating continuities between the historical fabric and contemporary concerns, and the explicit articulation of distinct forms contribute to the robustness of these ideas.

The projects of OMA are driven by ambivalence and opposition. ${ }^{63}$ This may be interpreted as an extreme form of 'realism' in its acknowledgment of contradictory requirements. Yet it may also be seen as a series of small ideologies, or ideals expressed purely through a form of specificity. The provocations against politicized architecture that are present in the work of Koolhaas were also present in that of Ungers, who generally identified more with the cultural and intellectual role of the architect. Both rethink the role of architecture in the contemporary city. Building on the importance of the formal in its broadest sense (the composition of a building, the image it evokes, the sensibility of a detail), both Koolhaas and Ungers imply that ideas must be assessed in their material forms. Ungers uses the formal as a structural principle, which is materialized in multiple reiterations of concretized ideas. ${ }^{64}$ Through the lens of Ungers's direct focus on formal principles, it becomes easier to revaluate the role of form in the work of OMA: it is not about the autonomy of form as an experimental drive within the limits of the discipline, taking no account of possible external realities. Rather, it is in the relation between idea and form that the work of architecture is situated, in the materialization of ideas and the confrontation with external constraints.

Ungers and Koolhaas explicitly resisted the politicized architecture of the 1960s. Using the shortcomings they perceived in this sociopolitical focus, they countered with an alternate direction for architecture. Particular to their work is the appreciation of historical examples without nostalgia. They explored the formal autonomy of architecture, yet maintained an interest in cultural ramifications. This explains the interest in divergent forms of collectivity, even in a project such as Exodus, strongly marked by references to autonomous architecture. ${ }^{65}$ The insistence on collectivity remains present throughout the texts and drawings of both Koolhaas and Ungers. They attempt to envision the collective without expanding it to a smooth or allencompassing reality. Koolhaas seeks a strategy of flexibility that remains architecturally specific. His use of the oxymoron as a design tool - the clash of inherent contradictions - clears out a space of architectural specificity that stands its ground because it does not offer a direct link between form and meaning. Form is present, as is significance, but they are autonomous conditions, suspended within the space of architectural experience. 
The work is thus about collisions, not about finding a unified whole, but about creating tiny momentary utopias. The collective may be temporary, liquid even, but it inserts itself between the ever-expanding global public and the increasingly small manoeuvring space of the individual. This space is a hopeful one, despite the fact that the ideals of the 1960 s failed to materialize. Within an individualized collective there may yet be a potential for architecture that embodies neither a mechanical utopia nor an idealized perception of the creative individual. Explicit and materialized contradictions are instrumental in this understanding of a contemporary collective simply because they present alternative perceptions.

\section{Bigness}

The 1994 essay 'Bigness' looks ahead to a new role of architecture in the urban domain based on the ever-increasing size of buildings. While the observations founding this category of Bigness are similar to the conditions Ungers notes about his contemporary city in the mid-1960s, the small step in scale here is a giant conceptual leap in the role of architecture. Bigness is situated simply as the result of an increase in scale ('Beyond a certain scale, architecture acquires the properties of Bigness'), which then becomes a condition that transcends traditional comprehension of form and the common strategies of architecture. ${ }^{66}$ Here, scale instigates a completely different appreciation of aesthetic value:

The only drastic explanation is that beyond a certain scale almost all buildings are beautiful, from their sheer overwhelming presence. Ethically that is very difficult to admit for an architect, believing that beauty is something that you create, not something that comes from the outside or simply because of a certain scale. ${ }^{67}$

In a departure from the writings of Ungers, Koolhaas here makes a conceptual leap: he simply discards the traditional techniques of architecture. Traditional tools such as composition and ornamentation are useless, or: "The "art" of architecture is useless.' The city cannot be seen as a work of art, governed by accepted rules of composition, nor does Grossform, as a formal sense of coherence, offer a solution. Grossform is to some extent derived from scale, but is defined primarily through its formal qualities. Bigness derives from a scale that transcends form entirely. This becomes the key to a new problem in architecture: Bigness may be derived from quantity (the 'numbers' discarded 
by Ungers in his essay on Grossform), but it becomes a new quality. This quality then has the capacity to 'reinvent the collective'. Where Grossform maintains a tenuous balance between scale and form, the scale of Bigness allows it to transcend form. Grossform still somehow frames the collective, or makes the collective appropriation of space possible. Bigness, on the other hand, is meant to entirely reinvent the collective - it does not offer the framing mechanism of a strong form but demands a full-scale rethinking.

Bigness 'instigates a regime of complexity': it engenders the conditions we typically consider 'urban', which cannot be addressed merely by a coherent totality of architectural form. Yet this regime of complexity, precisely like the archipelago, and even as framed by Grossform, is not positioned as pure fragmentation. Rather, in Bigness, the 'parts remain committed to the whole'. The congruence between the writings of Ungers and Koolhaas remains visible: neither denies the possibility of coherence, but both try to accommodate the complexity and plurality of the contemporary metropolis. It is within this regime of complexity that new forms of collectivity are to be formulated.

\section{Generic City and Lagos: Escaping Architecture}

Despite its claims to discarding traditional techniques of architecture, Bigness is still framed within a discourse on architecture. The notion of the Generic City and the studies of alternate forms of urbanization found in Lagos approach this question from the other direction. They study the expanding networks of the global city and their consequences for urban architecture. The operation itself is founded on the earlier work of studying existing conditions, but the object has transformed from a clearly circumscribed area to a diffuse condition of networked reality. This focus is no longer evidently related to the work of Ungers as it moves forward into a posthuman condition of contingency and precarity. Here, the traditional tools of architecture and urban design become truly useless, as the architect is forced to deal with networks, an expanding global field, and a swarm-like logic of objects that have begun to act as agents. The exponential increase in urban complexity, on the other hand, demands new insights and new approaches, which Koolhaas hopes to furnish with the generic and his studies of African and Asian cities. ${ }^{68}$

It is here that the question of the loss of control, or the failure of control, acquires its most poignant characteristics. Our cities are becoming organisms that we feel no longer capable of grasping - whether it concerns the millions of inhabitants in a highly dense Asian city like Seoul or the 
inhabitants of a sprawling American city like Los Angeles - there are factors that now contribute to an increasingly unsettled habitus in the metropolis. Simultaneously, one might also argue that the digital realm has opened up new possibilities while also demonstrating the significance of physical space.

In 2011, Koolhaas notes in an interview that the idea of the generic resulted from his specific urban studies: Delirious New York, Lagos, and Singapore are all different conditions, but once you re-examine them, their similarities are what is most striking. Koolhaas claims that the Generic City suits the twentyfirst-century urban condition. The specific identity of contemporary (and branded) spaces essentially thwarts its users. Instead, it is the non-identity of the typical and the generic that better facilitates use. ${ }^{69}$

Coming full circle, back to the freedom inherent in 'urban nothingness' and the spaces of the green archipelago, the Venice Biennale exhibition 'Cronocaos' recalls the lesson of the City within the City and injects it with the current need for the generic. In 1977, the notion of preservation was implicitly addressed in the realization that the population of Berlin was shrinking but the city itself was not, implying that the needs of the future would not require new construction. 'Cronocaos' offers a parallel proposition that architecture is being preserved more quickly, turning back to Berlin's original proposition, which states that what is exceptionally good should be maintained, and the rest left to disappear - selective preservation:

There's something more important than the design of cities (which will become more so in the immediate future), namely the design of their decomposition. Only a revolutionary erasing process and the establishment of 'zones of freedom', a conceptual Nevada in which all the laws of architecture are suspended, will be able to put an end to the tortures inherent to urban life - the friction between the programme and its hindrances. ${ }^{70}$

\section{Incorporating the Failure of Control}

The proposition of selective preservation plays out the inevitable struggle between control and its failure. It elevates architectural design to an utmost determinant in the preserved spaces, yet the naturalization of the system as a whole allows no room for articulation.

Like his colleagues of Team 10, as well as many others of the same generation, Ungers maintains an interest in shaping the spaces that would 
allow a sense of cohesion, something that might connect the extremely individualized beings sharing the space of the late twentieth-century city. In contrast to ideas such as the megastructure and network cities from this period, however, to Ungers it is primarily the formal definition of architecture (as a self-contained whole) that leads to its function in the collective. Architecture must not turn to other disciplines such as sociology to begin to understand how collective spaces are formed. By offering a strong form, it grounds the unpredictable and fleeting condition of life within it. Ungers (and later, Koolhaas) places architecture at the centre of creating a collective, but leaves its mechanisms within only the discipline. This is not architecture as social engineering, but architecture as architecture.

In the publication series Veröffentlichungen zur Architektur (1965-1972), Ungers shows a tendency to argue for the collective, or the larger frame the coherent formwork that is more than just the individual pieces. A strong role is allotted to the architectural object, both as trigger in the urban fabric and as (after)effect of societal conditions. Furthermore, a crucial position is given to collective spaces, though not always identified with a broader notion of the collective domain. These spaces do not follow the European tradition of the town square, but that of 'strong form' as counterpoint to voids and the surrounding amorphousness of a dissipating city. Perhaps this is also precisely the distinction between the City within the City, or the City of the Captive Globe, and their precursors in the form of Team 10 or the principle of megastructures. Rather than seek a new collective totality, a new public domain that will embrace all, the work of both Ungers and Koolhaas allows a tension to remain between the configuration of a collective and the freedom of individual agency. The idea of a grid with freedom inside the grid, the archipelago city that offers a totality of a conglomerate of islands, yet the full freedom for individual development per 'island', is perhaps the most relevant aspect of this work in regard to the questions arising within the contemporary urban condition. The archipelago city incorporates the failure of control as an initial parameter, yet it refuses the complete disintegration of the public realm by proposing a format for 'loose' collectives that transcends the merely individual, yet allows for individuation. The unremitting desire to address the problem of a collective space in the face of a pluralistic society is what strikes a chord in the work of Koolhaas and Ungers. Whether it is the freedom to produce an unpredictable infill of the larger frame of a Grossform, or the potential to reinvent a collective through the condition of Bigness, there is a continuous oscillation between clearly defined architectural form and the 
space for unprogrammed, undefined and unpredictable interventions. This suggests that focusing on form rather than programme may create space for individual agency. In this way, the archipelago city, as a 'blueprint for the theory of a European metropolis', offers something distinct and new: the potential for small-scale interventions based on architectural form, which have the potential to create collective spaces. This holds a key to a pluralistic yet cohesive urban space, with collective spaces forming an intermediate condition between the public and the private.

Fig. 2.6: O.M. Ungers, competition entry $4^{\text {th }}$ ring, BerlinLichterfelde, 1974, with Koolhaas listed in the project team

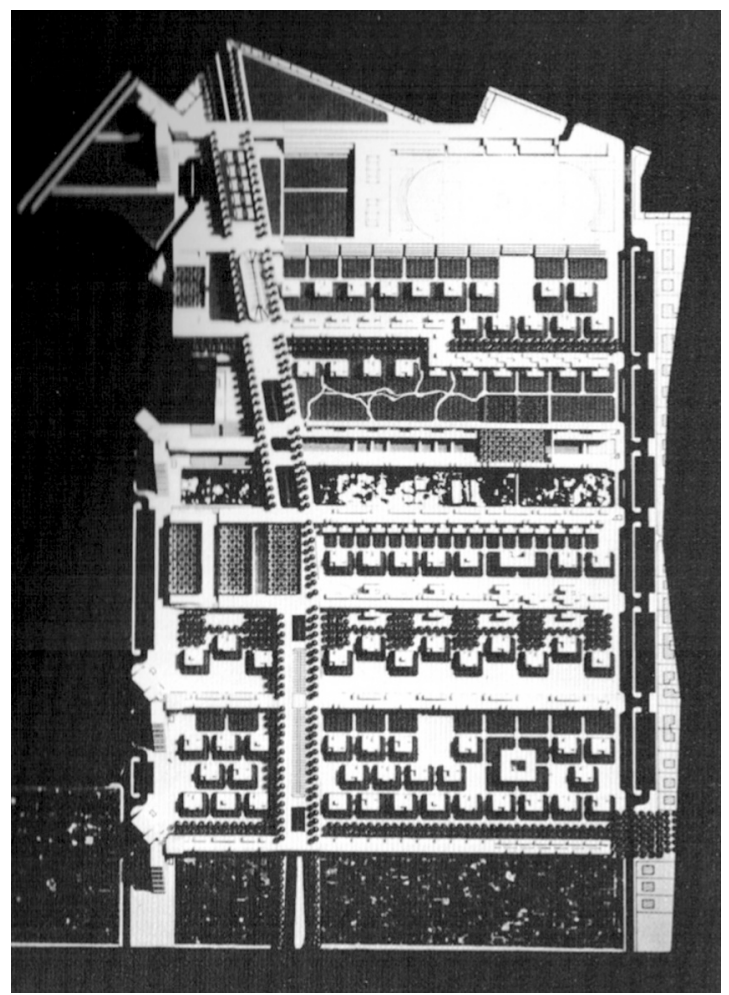

Ungers Archiv für Architekturwissenschaft 
Fig. 2.7: OMA, competition entry Parc de la Villette, 1982

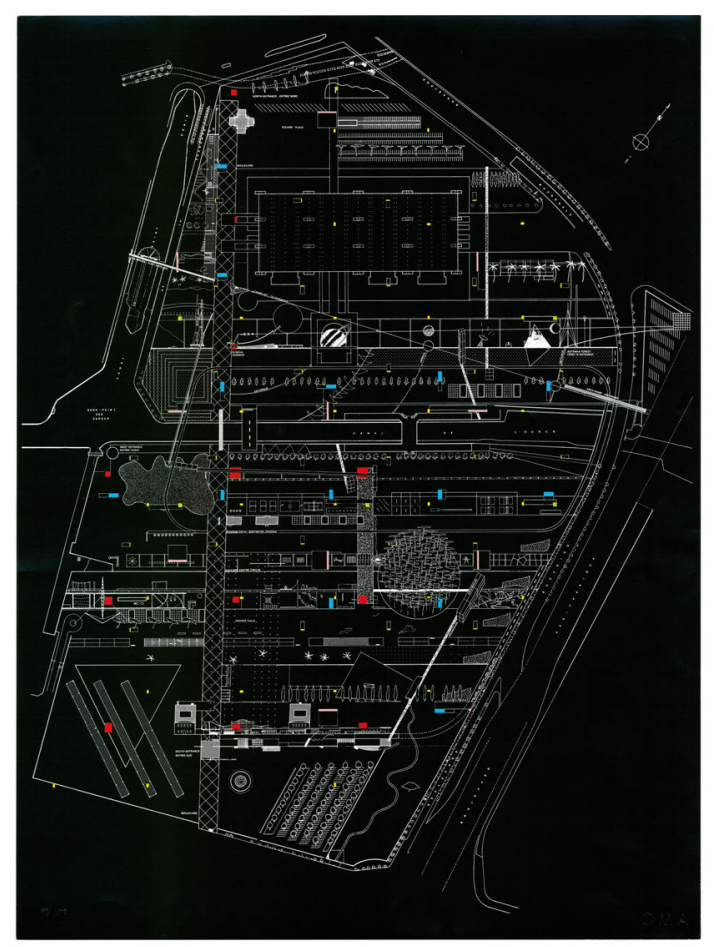

Het Nieuwe Instituut Rotterdam, OMA archive

The city concepts put forward in the 1970s reveal the inadequacy of a purely architectural approach, yet also leave space for architectural articulation within the larger domain of the city. They reveal the inadequacy of modernist theories in addressing specificities, and show that the legacy of Utopia engenders a more restrictive and idealized approach, while the reality of architecture is more mundane, navigating compromise and complexity. Maintaining a strong cultural idea (an image in the abstract sense: an unformed image that is allowed to be reinvested with new cultural tendencies) is one of the hallmarks of a longstanding architectural project - one that transcends the immediate context to evoke an element of timelessness. There is a strength in deriving logic from specific cases through the process of 
induction, which addresses material reality and seeks patterns from within. In this sense, the object itself allows multiple relations to it - yet is not so 'unformed' that it denies any relation. Somehow it provokes or elicits responses while remaining somewhat flexible in reception.

Perhaps the most immediate, pressing issue underlying the urban work of Koolhaas and Ungers is precisely the inadequacy of our theoretical models to 'surf the waves' of reality. As far back in history as Thomas More's Utopia, there are examples of ideal cities meant to facilitate or engender ideal societies. These propositions typically fail by virtue of their articulated perfection. ${ }^{71}$ Ungers had the opportunity to examine the aspirations and realities of Utopian communes up close while he was in the United States. One summer, he took a family road trip along various American communes, which resulted in the 1972 publication of Kommunen in der Neuen Welt 1740-1972. ${ }^{72}$ In this book, which was a collaboration with his wife Liselotte, a variety of features of each commune is analysed, including the family and social structure, the organization of labour and farming, and its town planning and housing principles. The notion of Grossform is to some degree an architectural answer that provides both a materialized ideal and an openness to long-term questions in the urban domain, which are inherently unstable. The archipelago city offers a postmodern approach to this instability: it incorporates vast differences within the total urban fabric of the city at any given moment. Following Fredric Jameson, the question may be posed whether this full embrace of diversity does not result in an overall indistinguishable field of 'difference', but at the time, they provided a generous framework that allowed for aberrations. ${ }^{73}$ Fashioning a communal sense of responsibility within this diversity is difficult at best. While the desire to transcend individual difference remains, the question of how to approach this is unanswered. What is more than evident in the current time, is that a renewed sense of collectivity and social justice will be required to face the economic and ecological challenges of the near future, as well as the question of distribution of wealth. We are far beyond an era in which we can draw lines between the various areas (nation-states) of our world, and the global impact of economic and ecological crises is now clear. A communal sense of responsibility will be necessary for the direct future. In this sense, the 1970s provide interesting lessons for the future - it was a decade in which various crises took hold, and when the human influence on the climate became increasingly clear. The 1972 Club of Rome report provided dramatic predictions for the future, the economic crisis of the 1970s had a strong impact, and population drops were 
plaguing various urban centres. While this history may have fallen a little below the radar of current reflections, there are some hopeful developments in response to the multiple economic, ecological and urban crises that suggest new approaches.

Fig. 2.8: L. and O.M. Ungers, Kommunen in der Neuen Welt, 1972

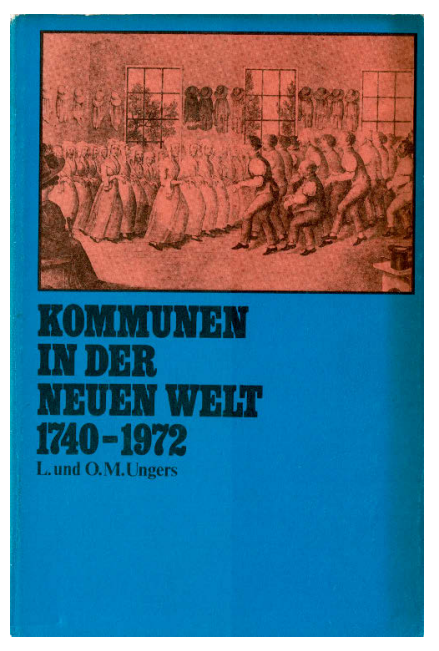

What is important to keep in mind is the oscillation between an ideal type and the social context. If it is indeed true that the formal may not be reduced to an illustration of social intervention, nor that the two are causally related, it is nevertheless crucial to examine the relationship we perceive between the things in themselves - in their material manifestation - and the social and psychological responses they elicit. It may well be that there is a quality in things that allows for a continual reconfiguration of this relation; that it is not an invested intention, or a circumscribed understanding, but that transformations in this relationship are enabled (and that the relation is therefore continually reactivated). The plausibility thesis between the social and the formal reserves a central role for architecture in determining the urban condition, but also maintains a place for collective desire and the attribution of significance with regard for aesthetic qualities but without 
preconceived style. As such, the quality of the object-user relationship became a more important element. The initial steps of the 1970s discourse introduce a renewed space for interpretation and reception that aid in individuation, but remain tied to the material conditions of the built environment.

This position bridges the transatlantic crossings of architecture thinking. Koolhaas notes that his return to Europe in 1975 was informed by the developing rationalism he found there. ${ }^{74} \mathrm{He}$ further explicitly rejects the exclusion of social programme:

Colin Rowe's modernism . . . was completely stripped from its social programme. The social for him being the height of ridiculousness. There is in his book, Collage City, a very revealing phrase: 'In the way we can enjoy the aesthetic of the Utopia without suffering from the annoyance of the political Utopia.' It was the first time that I was confronted with this tendency, typically Anglo-Saxon, which later became more and more dominant. ${ }^{75}$

The coherence and continuity between the social and the formal seems more typical in the European debates. The Anglo-Saxon debate was somewhat marked by the aesthetic attitude Koolhaas here alludes to, while the American side of the debate included a pragmatic approach that again transforms the approach to the city and its relation to the domain of architecture.

The city remains strongly circumscribed by the sociopolitical sphere, on which architecture has some, but limited influence. Where the twentieth century began with an exaggerated sense of the influence of architecture, it seemed to hit a note of despair in the late 1970s, with the question of what architecture might do beyond window dressing. The urban concepts of Koolhaas and Ungers navigate the tricky domain of social justice and architectural production by allowing for a role of city form that recalls the mythologies of Barthes, or the dream images of Baudelaire - they show potential, open up vistas, but leave the infill to be determined. Precisely by concentrating on the salient features of urbanism and architecture themselves, they allow for the possibility that its value may exceed the immediate situation. The early twentieth-century hopes for urbanism as 'fait social' may have failed, but a hopeful window is opened on a less rigidly determined, but nevertheless influential role, in which the collective dreams are given material form. This does require rescinding the modern belief in the architect/urbanist as social engineer, and the belief that modern forms will help initiate the modern sensibility. One tangent problem arises here: the discipline remains somehow dependent on an interpretation of architecture 
that sees it as embodying a Hegelian zeitgeist. While the new urban ideas of the 1970s allow for disjunctions and heterotopias, they are still framed as inextricably linked to the contemporary. It becomes difficult to speak of timeless or shared ideas, if the production of architecture is defined by its contemporaneity.

If the city is the domain in which we experience both the collective dimension of humanity and a sense of exacerbated individuality and aloneness (still, in a sense, following the lines set out by Simmel), it is the role of architecture to give space and form to the collective sensibilities in the city. For Ungers, this encompasses a more classical view of architecture, which amounts to a symbolic value beyond direct representation, and a structure that can supersede the immediate (Grossform); for Koolhaas, this amounts to an organizing of the structures of modernity, and above all leaving space for the unknown. Both thus position the architect as relevant to the built form of society (in contrast perhaps also to the Lagos studies), yet as the Exodus project shows, in a special position: the wall that demarcates the project of modernity - the voluntary prisoners of architecture - to which one must willingly surrender. 


\section{Chapter 3. The House: Crystallized Architecture Thinking}

We've always liked doing houses because they're just as complex as buildings: they often take as much time and you always work with one single individual, as opposed to a state institution or a business conglomerate. ${ }^{1}$

Rem Koolhaas

Throughout the history of architecture, individual houses have held a privileged position. Alan Colquhoun suggests that this is a sign of the elitist character of architecture, which becomes notably clear in the oeuvres of modernist architects, who succeed in their technological aspirations more in single villas than in the social housing projects they argue are their main objective. ${ }^{2}$ Michael Müller supports this provocation with his study of villas as a form of hegemonic architecture. ${ }^{3}$ At the same time, Colquhoun does demonstrate that individual houses drive forward the discourse by their exemplary and often experimental designs. Elitist or not, single-family houses and villas have played an important role in the development of architecture. While this may be self-evident in the longer history of architecture, with Renaissance villas such as Palladio's Rotonda or the Villa Borghese remaining noteworthy examples of the architecture of the time, modern architecture would also be inconceivable without a number of key houses, such as Frank Lloyd Wright's Robie House, Mies van der Rohe's Farnsworth House, or Le Corbusier's Villa Savoye. A space for experimentation, especially when the architect was fortunate enough to find a patron willing to fund an often provocative search for the ultimate architectural expression, these iconic houses can themselves provide a palette of dominant themes in architecture for many periods in history. 
The houses designed by OMA form a counterpoint to their evident interest in urbanity (or 'metropolitan form' as Koolhaas labels it in the late 1970s). They occupy the other end of the spectrum from the large-scale urban visions, exposing the nature of a clearly circumscribed project. In $S M L X L$, these are the projects that constitute the category 'Small' in terms of actual size. What is specific to these commissions is that they maintain the complexity inherent in a design process, but offer a relative purity in their materialization of an architectural idea. Less constrained by conditions surrounding the project - whether that concerns urban regulations or zoning districts, multiple stakeholders or institutional conventions - they occupy a field of architectural ideas and personal preoccupations of the architect and the single client. While the house may be more idea-driven than a larger commission, this does not necessarily correspond to an explicit theoretical discourse, but may simply be manifest in its physical presence. In fact, Koolhaas has devoted few words to them, yet they are shown extensively in plans, images, models and photographs. ${ }^{4}$ The reticence of Koolhaas on the private homes may simply indicate his discretion on behalf of his clients. Yet it also testifies to a primary interest in the architectural object itself, in its material presence. The clients' motivations are left more or less private, the background of these houses remains framed in a purely architectural manner, and the photographs and plans are left to speak for themselves. This is precisely what makes these projects interesting, as the speculative yet tangibly concrete counterpart of the larger ideas we find at the (abstract) scale of the city. Where their ideas on urbanism by necessity take into account the social, the houses are allowed some leeway. It is in this relation between the material form and the abstract phenomena, and more than anything perhaps that which escapes direct correlation, that we find the most striking similarities between Koolhaas and Ungers. Both architects have outspoken ideas, and have regularly voiced their thoughts on daily practice in relation to the larger issues of architecture as a discipline. Their work spans the entire range from written manifestoes or reflections to completed buildings, and all the material forms of thinking in between. Discovering a more coherent relation between ideas and their material forms is more conceivable in the private home, if only by scale.

Thus, while one history of twentieth-century architecture is to be written through its major public institutions and its relation with the city, the question of the dwelling encapsulates another history, no less important to the development of architectural ideas. The private home stands model 
for individual preferences and collective notions of home. The connection between archetypal cultural notions of dwelling and innovative architectural forms is particularly strong in this type of commission. As such, villas have held a prominent place in the history of architecture, and particularly that of modernist architecture. ${ }^{5}$ Numerous versions of this history have been written, emphasizing the centrality of our domestic spaces in our understanding of architectural developments. ${ }^{6}$ This domestic space, the space of the dwelling, is seen as a touchstone for the ideas of architecture because of its primal connections - the first human shelter, the first architectural gesture. It comprises origins that traverse so far back in time that they acquire authority merely due to their age.

As a commission, the house is distinct from the larger institutional projects not only by virtue of its scale but also because of the architectclient relationship, which holds a privileged position. The personal relation with the client is more intimate (and thus often more volatile) than with a professional client. ${ }^{7}$ The commission itself requires that the client be candid about needs and desires in the most personal space: the home. These small commissions may be part of a semi-public vanguard, but they are also a private retreat, the embodiment of personal ideas of comfort, shelter and identity. Over the course of the twentieth century, as the home became a focal point of architectural design ideas, it superseded the practical necessities of a functional household. Rather than organizing the daily life of the household, it became increasingly tied to who the client is (or would like to be). The most prominent commissions for private homes have often involved outspoken clients. In the description of the commission for the Villa dall'Ava, Koolhaas emphasizes the deep-seated convictions of his clients throughout. ${ }^{8}$ Both archetype and prototype, the house may be determined by practical constraints, be they regulations, context or financing. Yet its scale and its limitations allow more emphasis to be placed on ideas than on constraints. These projects show a concrete idealization of the architectural concept.

In potential, the limited scope of the programme combined with a client who will also be the occupant allows for a more coherent and ideadriven design. Houses and villas - as archetypal shelter or prototypical innovation - offer the opportunity for thoroughness in their treatment from idea to materialization. In contrast to large institutional commissions, the programmatic demands are in principle less complicated and less situated in a network of dependencies. Of course, that does not necessarily mean it is easier to design a house, because it simultaneously lends more weight to the 
idea that the house affords the ultimate realization of an architectural idea, worked through from programme to detail. It suggests a perfectly coherent concept, self-contained and elaborated down to the last screw.

This idea-driven design does, however, lend credence to the central position of the house - or at least the villa - to the development of new ideas in architecture. The work of Le Corbusier found radical expression in projects such as the Villa Savoye, but even in its less immediately innovative expressions was systematically developed in projects such as the Villa Stein at Garches. It is in terms of the materialized idea that the houses in this chapter are examined. As a temporary relief from the complexity of large-scale urban or institutional plans, a return to something that can be grasped more easily (and thereby offers more depth?) the houses set the stage for an exploration of architectural form and how it can frame or transform the approach to the social. Each of the houses described here features specific qualities related to site, client, events or other contingencies. The architectural concerns of the house are more immediate, being directly informed by a specific client, site and moment. ${ }^{9}$ Yet each is systematic in its relation between the architectural fact and the intellectual idea. Each shows how deeply the conceptual work can be embedded in a material object. ${ }^{10}$ At the same time, it is important to note an element of historical contingency: the catalogue Five Architects shows that the work of the New York Five at the time comprised only relatively small projects. While this might be considered as a sign of the purity of their ideas, it also begs the question of whether there are moments in history that houses take centre stage as the place for architectural experimentation. When public money dries up as it did in the economic situation of the mid-1970s, the smaller commissions of houses may be the obvious medium to continue articulating ideas on architecture. Moreover, when the economic situation turns as it did in the 1970s, and after the financial crisis of 2008 , societal and economic conditions also suggest new constraints to address.

The respective oeuvres of Koolhaas and Ungers contain a number of these 'small' projects that exemplify a manner of thinking. ${ }^{11}$ Ungers not only designed a number of private homes throughout his career, but also built three houses for himself. He was both architect and client for these houses, two in Cologne (1958 and 1996) and one in the Eifel (1988), which in many ways illustrate and magnify his convictions about architecture at the time of realization. These houses did not, however, include the kind of dialogue with the client that a typical commission would have. In the case of Koolhaas, a few of the villas show specific interests that are magnified, such as the void, 
both in the Patio Houses of 1988 and the Dutch House of 1995, and the notion of architectural specificity coupled with programmatic indeterminacy, as in the Villa dall'Ava.

In SMLXL, the section on 'small' includes the Patio Houses in Rotterdam (1988), Nexus World Housing in Fukuoka (1991) and the Villa dall'Ava (1991). ${ }^{12}$ It also includes the installation for the Milan Triennale (1985), the renovation of Hotel Furka Blick (1991) and the Video Bus Stop in Groningen (1991). These small projects reveal a different dimension in architecture. In the urban proposals, the existing city is scrutinized for the material articulations that testify to unspoken ideas. In the houses, the relation between architect and client negotiates general ideas on architecture and individual needs. Where in the city social conditions reveal formal logic, in the houses, architectural preoccupations and a formal logic define the social habitus. The drawings, the photographs, the detailing serve to show specific architectural considerations, where sometimes the immediacy of the object may transform the idea as well: these projects show that the realization of architecture is not a linear process from idea to material reality. 'The Terrifying Beauty of the Twentieth Century' is included in this section, making note of 'systematic idealization': an overestimation of what exists. This stands as criticism of the theoretical framing of every (even accidental) element. In contrast to the incessant idealization of every last corner of our material environment, Koolhaas here offers the strategy of 'clinical inventory', an architectural counterpart to his approach as a journalist for the Haagse Post, which was based on factual description rather than personal interpretation. ${ }^{13}$ As Koolhaas writes, approaching the 'objective potential' of each project without presupposition allows the imagination to be triggered by what is found, no matter how trivial or banal it seems. This valuation of the trivial stands in contrast to the approach of Ungers; while both architects appreciate contingency and the unexpected, Ungers sees architecture as having 'the ability to free our environment and existence from the everyday and the banal, from the trivial nature of reality, and to overcome material constraints by artistic means' ${ }^{14}$ Ungers sees architecture as a way of transcending the trivial, whereas Koolhaas sees value in precisely these trivialities.

The private houses of Ungers embody this aim at transcendence through a rigorous spatial order. They form an architectural biography, tracing out a trajectory of his ideas and their development. The Koolhaas houses are a different issue - they are built for clients, not for himself - and show his experimentation with ideas. The house is regarded as a microcosm, 
as a particular exploration of architectural interests, such as the patio, indeterminate spaces, or archetypes. While Ungers is typically explanatory in his publications, reiterating and clarifying the ideas found in his architecture, the publications of Koolhaas experiment with different kinds of texts, treating the work as exploration rather than clarification.

The houses by OMA discussed in this chapter comprise four commissions spanning 20 years, beginning with the patio villas. They form two pairs: the Villa dall'Ava and the Maison à Bordeaux (1998) are related in terms of their structure, arrangement and overall articulation. The Dutch House and the patio villas in Rotterdam form an equally complementary pair of subtle explorations of an archetypal form. The houses by Ungers presented here are his own, which together document nearly 40 years of his design experience and architecture thinking. Although he notes in an interview that he has done three times what an architect should never do - build a house for himself - they have proven to be exemplary projects in his oeuvre, showing the development of his work over time as well as specific concerns in each case. ${ }^{15}$ All of the houses in this chapter appeal to modern sensibilities yet incorporate timeless archetypes.

Both Koolhaas and Ungers show specific preoccupations in their built work. Those of Ungers are directed more towards specific architectural ideas, some rooted in architecture history, others appealing to the most essential interpretation of architecture. Those of Koolhaas seem more scattered, sometimes responding to contextual issues, other times deriving from historical preferences. They are less rigorously organized around a comprehensive understanding of architecture, but they still play a pivotal role in defining the work as it is realized. These ideas, and their manifest forms, enjoy a mutual relationship that cannot be reduced to a physical illustration of an idea, or to an essence of intuitive design. The continual reworking of ideas, of forms, of architectural approaches, shows a literal manifestation of the preoccupations that engage these two architects. These preoccupations at times are magnified in the houses, because there are no additional requirements to tone them down.

\section{Modern Domesticity in the Patio Dwelling}

The patio dwelling has become an important urban dwelling type in the past 20 years, with its enclosed exterior space safely tucked away at the heart of 
the house. This type of dwelling refers to the Mediterranean house, centred on a courtyard or atrium, but also builds on the late modern patio house, as perhaps first truly explored by the Smithsons. In the famous 1956 London exhibition 'This is Tomorrow' at the Whitechapel Gallery, the Smithsons, together with Eduardo Paolozzi and Nigel Henderson, put together an installation that confronted two housing types with one another: the patio house and the modern pavilion. ${ }^{16}$ The patio house offered a view of the sky in high-density situations, and, in the Smithsons' own terms at the time, a 'vertical tube of unbreathed air'. While the tube of unbreathed air has not been an overriding concern, certainly the proliferation of patio dwellings in the 1990 s is related to the potential for high-density dwelling with a comfortably enclosed private exterior space.

The patio houses in Rotterdam, completed in 1988, combine references to modernist architecture and the prototypes of American coastal modernism with a reinterpretation of the Dutch dike house. This is emblematic of much of the work of OMA - while the programme may also be seen as a driving force, there is an underlying iconic symbol (the dike house) that provides a base for architectural experimentation. Not unlike the earlier studios of Ungers (in which Koolhaas was deeply involved), the specific local type is used as a Grundform or a basic formal premise, from which to depart in an architectural exploration of the quintessential Dutch house.

The Patio Houses were initially conceived in a row of three, combining the typical Dutch serial dwellings with the section of the dike house. The project was 'half-commissioned': one of the houses was for the mayor of Rotterdam, while the others were initially commissioned by the developer Geerlings to be sold upon completion, but only one of these was realized. The houses remained quite similar, but incorporated some small distinctions, such as the paving treatments. Situated along a dike, the section of the house is derived from a typical Dutch dike house, but inverts it. Typically, the dike road forms the access to the house, which makes its top floor (accessible from the road) the public level: an entry, a living room, a kitchen. The lower floor, nestled up against the dike, is the private floor, where the bedrooms are located. In this case, the typology is inverted: the access road is below, while the back garden is above. Rather than the private spaces being nestled downstairs against the protective wall of earth, these houses use the downstairs floor as an entry, with the private space of the home opening out towards the view over the backyard. While the traditional dike house would have a single-storey front 
Fig. 3.1: OMA, Patio dwellings Rotterdam, original proposal of three houses in a row.

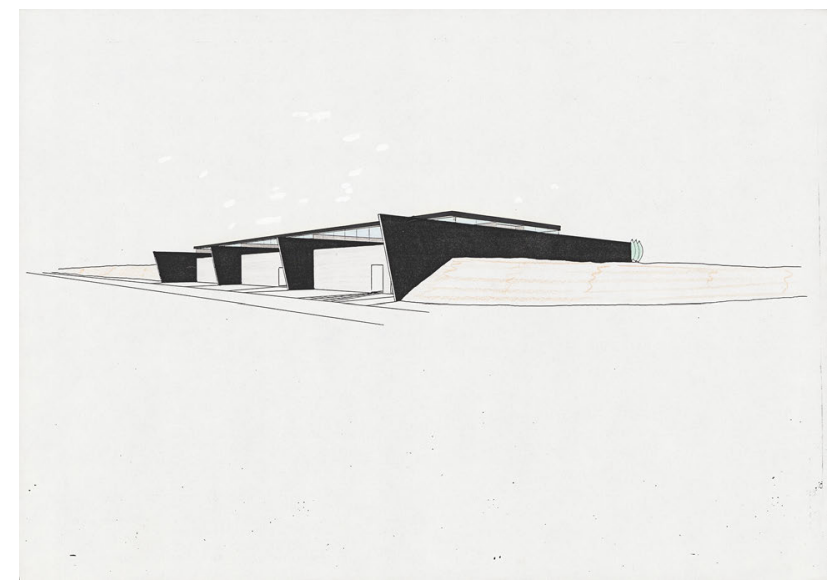

HNI Rotterdam, OMA Archive

façade, the patio villas present two full stories to the access road, with the garage and entry leading up to the living floor.

One might argue that these houses are eminently postmodern in their incorporation of both modern and archetypal references, and with their more light-hearted gestures of the façade painting, which are both abstract and figural - referring to the asphalt drive, but abstracting that to planes of colour and grey. Touching upon iconic gestures without overly expressing them, these houses appeal to very basic archetypes of the home. At the same time, the architectural language of the house refers more to the modern tradition. Koolhaas's affinity for the architecture of Mies van der Rohe is visible in the columns, in the walls between the bathroom and the bedroom. Early versions of the plans show a continual reiteration of a series of courtyard houses in various arrangements, including a reference to Mies van der Rohe's House with Three Courts (1938). ${ }^{17}$ Inside, an added internal patio provides an interior focus. When lit, the patio calls to mind Bachelard's archetype of the 'house in the woods' with a lantern lighting the way to the safety inside. Although the entire back wall is glazed, opening up towards the woods, it is the gravitational pull of the patio that defines the sense of enclosure, that 
Fig. 3.2: OMA, Preliminary studies patio dwellings, Mies van der Rohe's House with Three Courts

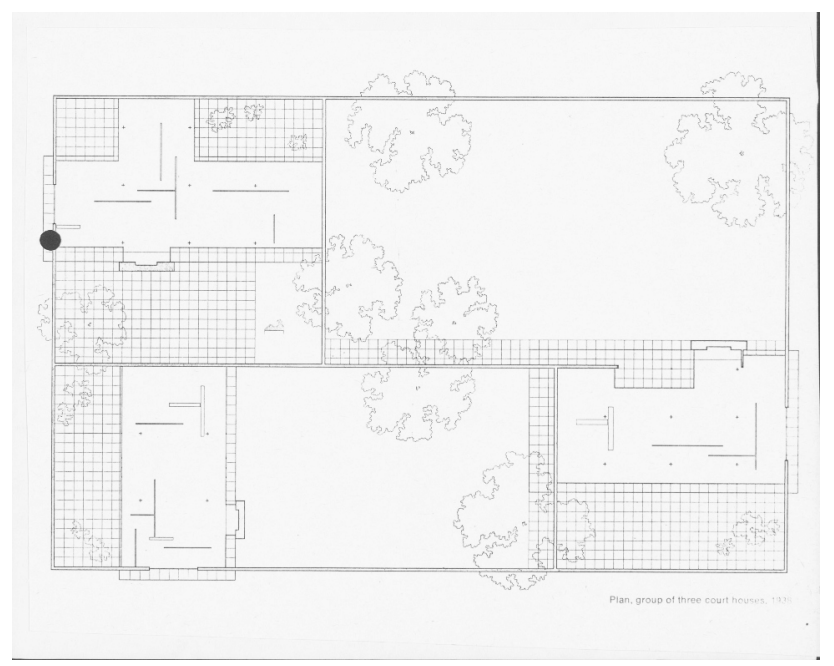

Het Nieuwe Instituut Rotterdam, OMA archive

draws the observer inside. Although the Miesian references in the house are prominent (the chip walls instead of marble, the glazed back wall that calls to mind the openness of the Farnsworth House), the traditional Dutch housing references are no less present. ${ }^{18}$ The dike house typology calls to mind the house that is lodged up against the dike, settled against the safety of the wall against the water, while at the same time sitting on the edge of danger - if the dike breaks, these houses are the first to suffer damage.

The use of various types of glass in the patio houses has been discussed extensively, referring specifically to the interplay of reflections, refractions and transparencies. Yet the quintessentially modern nature of glass as a material is also tempered by the tactile qualities of the wire glass and glass bricks. Its various modulations belie the smooth perfection that caused Walter Benjamin to refer to it as the material that leaves no traces. ${ }^{19}$ Instead, this articulation of the rear façade calls to mind the notion of 'phenomenal transparency' introduced by Colin Rowe and painter Robert Slutzky when they were still working together in Texas. More significant, however, seems the 'lantern' inside the house: the void of the patio that glows when the gym 
Fig. 3.3: OMA, Preliminary studies patio dwellings, interior

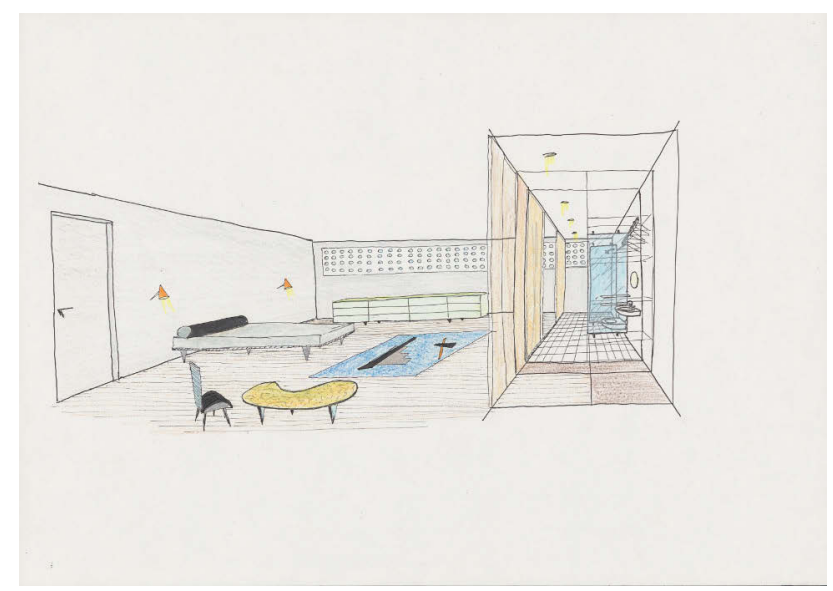

Het Nieuwe Instituut Rotterdam, OMA archive

below is in use. A snapshot of the Downtown Athletic Club in miniature, the workout of the body is implicitly present in the patio. Here, the American modern becomes manifest - the architectural language of the sketches that evokes a California or Miami modern (both open, for warm climates and for the display of the well-trained bodies inhabiting them).

In contrast to the eminently modern modes of dwelling in the patio houses in Rotterdam stands the patio interpretation of the Dutch house, where it forms a hermetically sealed light well at the core of the house. Completed in 1995, the Dutch House is an enclosed fortress, with the master bedroom at its centre, cut off by a drawbridge access. As open as the Rotterdam houses are with their references to Mies van der Rohe and the iconography of California modern, so archetypal is the Dutch House in its refusal of the exterior. Yet here, too, the house references an exemplary modernist project: the fireplace in the bedroom allows a view through to the patio, an echo of the fireplace overlooking the sea in the Casa Malaparte.

These houses are distinct in their organization. Both have a patio hidden inside, but the Rotterdam patio is expressive, a focal point, making note of the bodies working out underneath, and glowing at the heart of the otherwise flowing modern domestic space. The patio in the Dutch House offers a little 
patch of sky to the master bedroom, which seems more akin to a panic room. The successive spaces of enclosure bring everything back to this little 'tube of unbreathed air' in the patio, which is an ironic gesture on this secluded site in the woods. Both projects avail themselves of modernist precedent in their composition and materialization. Indeed, the explicit attention for the material is also evidenced in a project memo that states that the project should mostly be made as cheaply as possible, with specific details wellconstructed and by implication, more expensive. ${ }^{20}$ Clear priorities are thus given within the budget constraints of the project. Throughout, specific and subtle references are made to the archaic, which are folded into the explicit appellations to modernity.

\section{Iconography and the Gestalterische Idee}

If the patio dwellings in Rotterdam and the Dutch House represent a modern type of living that incorporates the afterimage of archetypes, Ungers's Glashütte in the Eifel speaks more to a longstanding tradition of architecture. The house was completed in 1988, the same year as OMA's patio dwellings. As a whole, the Glashütte is composed of iconic references to the Renaissance and Classical Antiquity. Its square plan with staircases on all four sides immediately call to mind the Villa Rotonda by Palladio, while the typical photograph also contains undertones of the Parthenon. The design development of the Glashütte shows the referencing of archetypal dwelling structures, with a particular focus on the rural courtyard farm. The transition from this rural courtyard farm to the classical villa it became suggests that the ideas take precedence over contingency. The context suggests a different type, while the resulting building references the history of architecture more than its surroundings. The reductive language of the stone exterior forms a dialogue with modern dwellings. No ornamentation is added to the exterior, the expressive features of the façade are limited to the punctures of windows and doors. The design drawings of the Glashütte recall the Roman villa and the courtyard farm, and each historical reference is transformed and resituated in a modern context.

The basic form of the house oscillates between the perfect square of the floor plan, and the iconographic pitched roof of the classic house. The pitched roof implies a rectangular plan, while the square plan calls to mind the dome of the Villa Rotonda. The pitched roof emphasizes the axis of the site (also 
Fig. 3.4: O.M. Ungers, Glashütte, Eifel, 1988

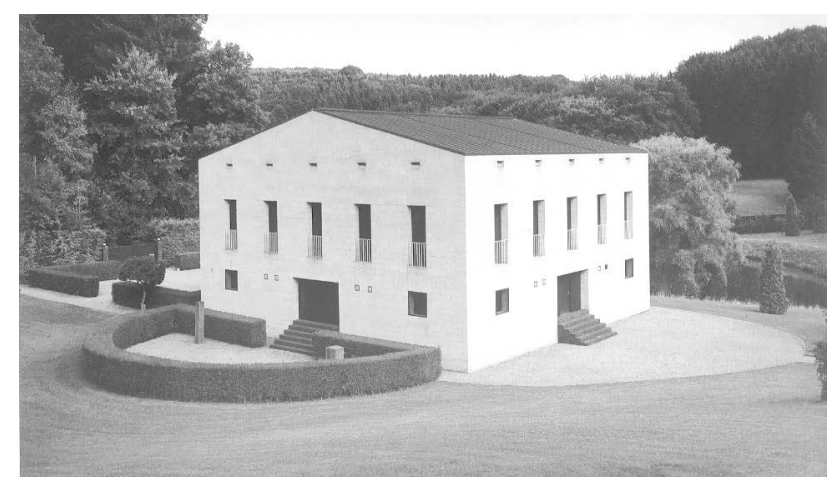

Ungers Archiv für Architekturwissenschaft

present within the house), while the square plan reinforces the centrality of the villa in the landscape. The equality of the two elements brings the oscillation between two equal figures into play that Ungers borrows from Gestalt psychology. The house retains both these figures, the contemporary archetype of the Monopoly house and the historical prototype of the Villa Rotonda. The Glashütte's cleanness of form and clarity of line significantly contrast the sculptural qualities of the Belvederestrasse house. The Glashütte is a stripped-down version of a house, but seeks to find an essence in remaining both archetypal and iconographic.

The Gestalterische Idee, a 'form-giving idea' that appeals to transcendence within the material form it takes, is eminently visible in the houses. While the difference in scale between the architectural and the urban is distinct, the understanding of both can be treated as the same. This is how the structural condition of the City as a Work of Art can be seen as no different from a house. In his later work such as the 1989 library addition of the Quadratherstrasse, which is very strictly organized along a grid, and the Glashütte, even with its appeal to the simple structure of Laugier's primitive hut, the importance of proportion and measure are more prominent. ${ }^{21}$ As such, the Gestalterische Idee appeals to what transcends immediate material reality. It is in the need to define space and to give form to it that architecture distinguishes itself from the other art forms, or so Ungers reminds us in reference to Hermann Sörgel. ${ }^{22}$ 
Fig. 3.5: O.M. Ungers, preliminary study Glashütte, based on European courtyard farmhouse

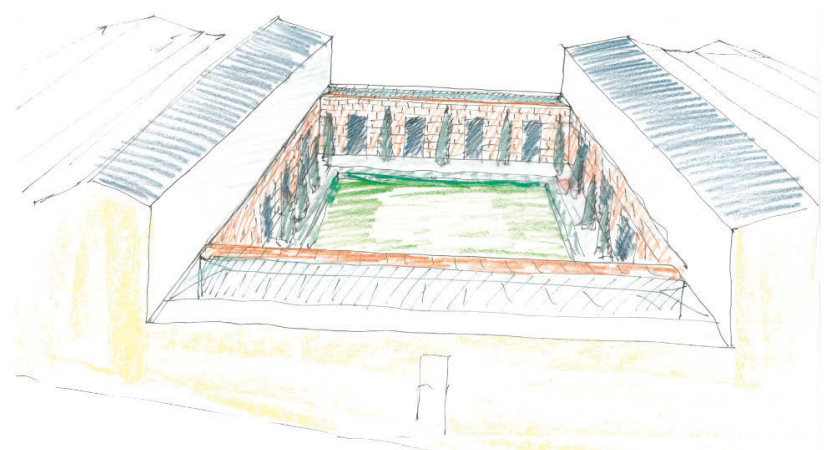

Ungers Archiv für Architekturwissenschaft

In retrospect, Ungers identifies the Glashütte as a Grundform, as might be expected from its abstraction of a historical type. ${ }^{23}$ While it appeals to a rational approach, it is more easily understood through his essay on city metaphors than his earlier work. City Metaphors opens with an essay on the cultural significance of architecture and our individual understanding of the world through visual pattern recognition, or systems of order. It sees the need for order as a fundamental human condition, a manner of making sense of a world borne of chaos. This is why the definition and form-giving of space is so crucial; the autonomous language of architecture serves to structure the world around us. Ungers articulates his affinity with timeless architecture in which cultural significance can accrue, given that the forms are strong enough to remain relevant throughout the transformations of life over time. This is, in essence, what Ungers is aiming at with the proportions that can be found throughout time and cultures, which contain a plethora of cultural references yet can be also simply internalized as a formal element.

In the book Sieben Variationen, Ungers addresses this question directly. ${ }^{24}$ The spaces are interpreted through their formal articulation - so whether we are studying the 'street, hallway, corridor, arcade or gallery', each particular 
instance concerns the general Gestalterische Idee of a linear space. Each type of space appeals to a specific principle that is legible in, or embodied by, its material presence.

The seven variations of space are analogies to seven spatial types or seven form-giving principles. The shell directs us to the principle of nested enclosures, the labyrinth to the principle of intertwining, the gallery to the principle of structuring, the octagon to the principle of gathering, the poché to the principle of hollowing out, the object to the principle of elementarization and finally the enfilade to the principle of lining up. ${ }^{25}$

Ungers uses this systematic identification of spatial arrangements and their implications to organize his lectures at the TU Berlin in the winter of 1964-1965. In this lecture series, the spatial paradigms form the main theme, by which historical and contemporary examples are compared and explained. From this systematic study of space, Ungers elicits the essential characteristics, not only as formal arrangement but as underlying conceptual frame.

In this manner, the Gestalterische Idee is tangibly present in the forms around us - not unlike Rossi's approach to collective memory as being embedded in our urban environment - yet because it appeals to an idea beyond the immediate response to programmatic need, it affects us in a more profound manner. For architecture, the means to achieve this Gestalterische Idee is to be found within the discipline. The tools of architecture are not only a means of solving spatial needs, but they are a physical iteration of how we think', as well as a means to express the quintessential character of a specific commission, such as the private space of the home. ${ }^{26}$ The private home transcends the merely functional and trivial conditions of everyday life by having this Gestalterische Idee incorporated in its material presence.

\section{Purity and Autonomy, Capturing Reality in the Grid}

The Gestalterische Idee contains a metaphysical reference that is easy to dismiss, as it requires a belief in the referential values of stone and glass beyond their simple, material presence. As such, it requires either an eye trained in historical references or a willingness to engage in idealization. Without requiring an article of faith, however, the rigorous ordering system of Ungers's house on the Kämpchensweg, completed in 1996, speaks immediately to the purity 
Fig. 3.6: O.M. Ungers, winter lectures TU Berlin, 1964-65. Lecture 2, single-room buildings, and lecture 8 , simple and complex systems.

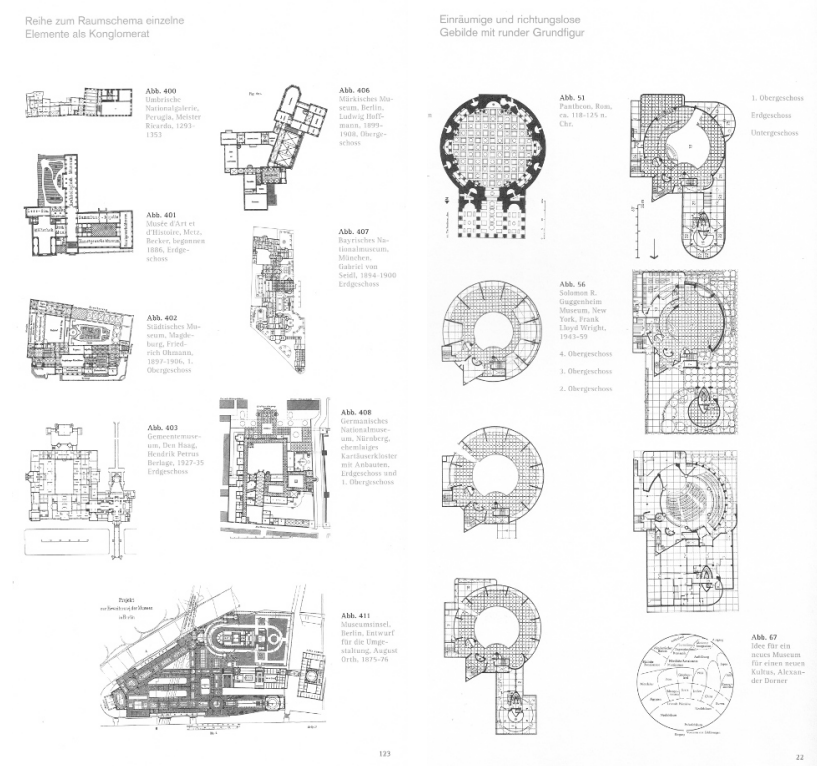

Arch +179

of an architectural system, regardless of the life that plays out within. The attention to simplicity and reduction to bring order to things is taken to an extreme. The house's proportional system and mathematical exactitude are immediately evident. This purity requires that we engage with the ideal. Kieren has noted that reality can only disappoint in the face of such rigour, but the house seems to tend more towards the zero-degree presence of precision: it requires more of its occupant. The inhabitant must surrender to the totality of the system - it is a matter of total deliverance. While the Exodus project by Koolhaas provides a (limited) space that is free from the severity of the architectural system, and the material presence of the Berlin wall included some variations throughout, the Haus ohne Eigenschaften forces everything into the grid. While Ungers does ensure that everything fits in accordance with its functional requirements, the house on Kämpchensweg does seem 
Fig. 3.7: O.M. Ungers, Kämpchensweg, 1996, plan

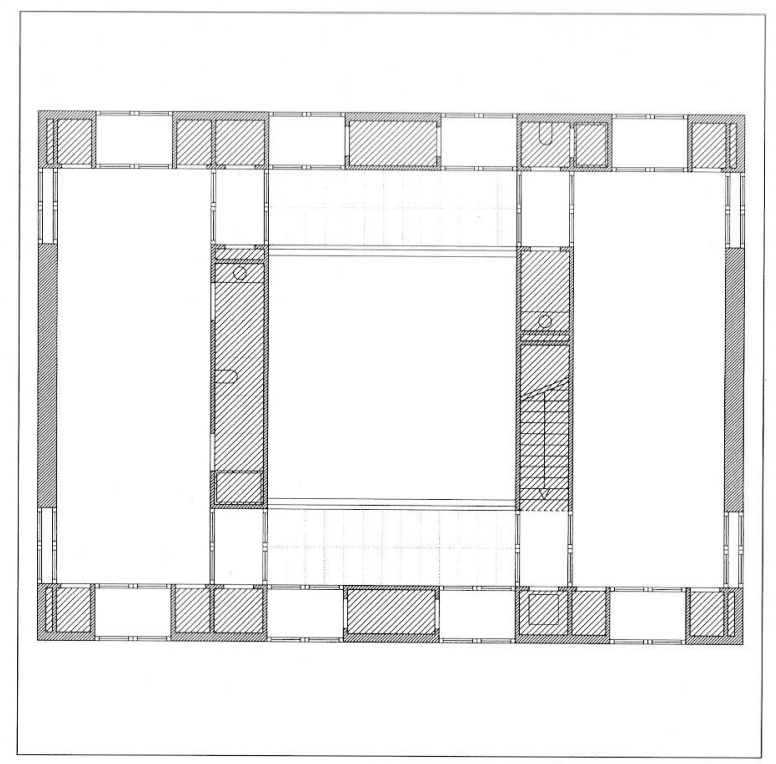

Ungers Archiv für Architekturwissenschaft

to preclude the kind of 'vitality within' that Ungers typically hoped that the autonomy of architecture form would give rise to. He may not have gone as far in conceptualizing the grid and its permutations as Eisenman did in projects such as House VI - where the idea of the house sometimes consciously and directly contradicts its functionality - but in this house he did bring the rational order to its most rigorous conclusion.

Ungers suggests that 'perfect realization characterizes both the best architecture and the best painting'. It is no secret that he admires the most uncompromising examples of systematic architecture and thinking. In the Kämpchensweg house, the spaces are organized in a systematic grid. Here, the very premise of the house is situated in its ordering system. The organization of the plans and the punctured windows in the façade, each individual element of the home is subjugated to the grid. In this case, the 
Fig. 3.8: O.M. Ungers, Kämpchensweg, 1996

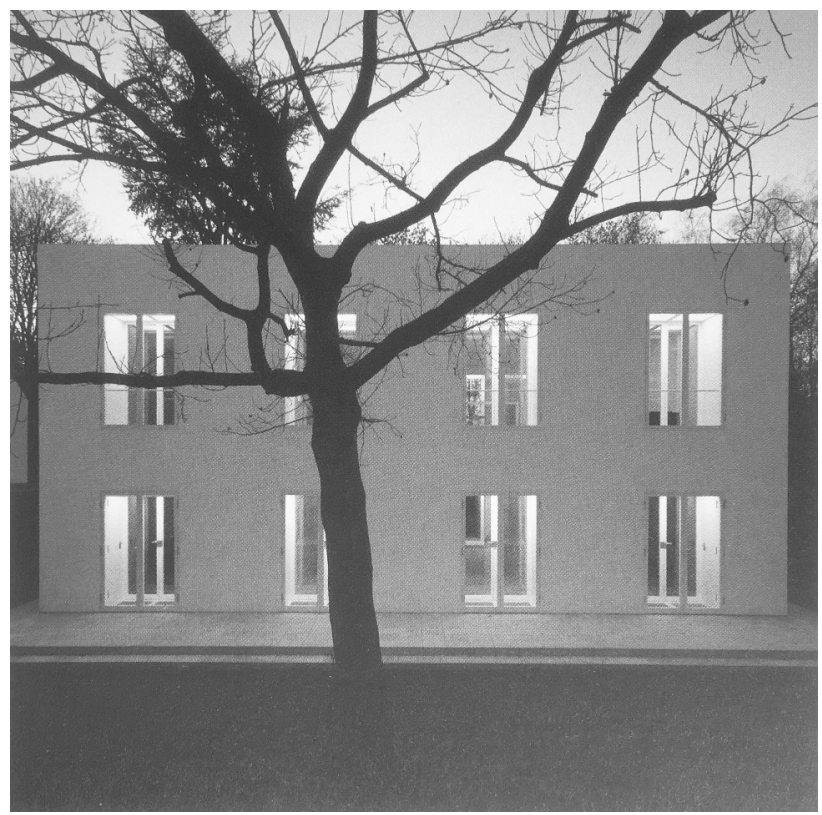

Ungers Archiv für Architekturwissenschaft

grid operates not so much as a harbinger of the freedom to move within, but rather as a constant presence throughout the house from plan to detail.

While the Kämpchensweg house embodies the purity of its ordering system both as essence and as symbol, Ungers's desire for the systematic at times struggles with the realities it faces. His academic explorations of order, proportion and symmetry may help clarify why certain dimensions elicit a more favourable response, but the sketches demonstrate the confrontations that arise between the rules he has constrained himself to and the reality they are meant to accommodate. In the design for the library expansion on the Quadratherstrasse, the initial premise of building a cube based on a clear grid is worked through in an extensive series of drawings, in which the ninesquare division of the library guides and constrains each design supposition. In a real-life version of Hejduk's nine-square exercise, Ungers here goes through endless iterations of spatial ordering. Early on in the design process, 
Fig. 3.9: O.M. Ungers, library expansion Quadratherstrasse, 1989, design studies

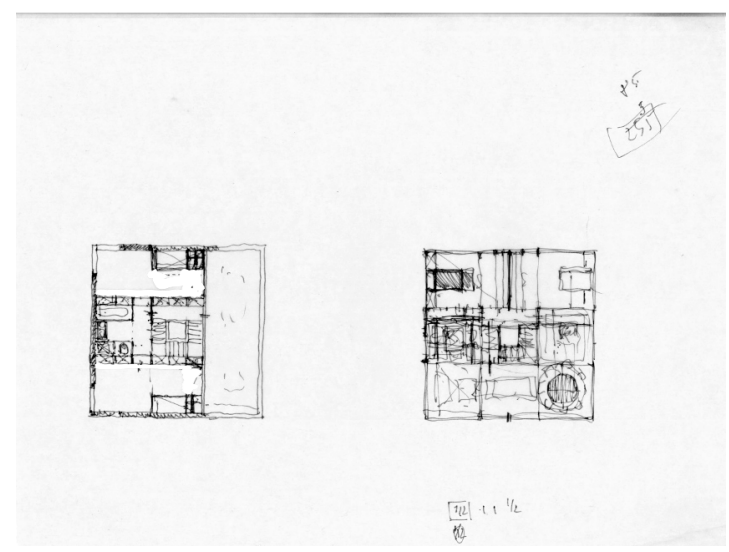

Ungers Archiv für Architekturwissenschaft

the cube seems to have been envisioned as including a living space as well: there are drawings with a living room on the top floor, lined with windows. This stage of the design includes a roof terrace and reiterates the Marburg design studies in how it tries to squeeze the living spaces into the purity of the cube. The design sketches show many attempts to fit the banalities of day-to-day living into his geometrical schemes. There are drawings of toilets squeezed into corners of the grid, stairs that are extended or compressed to fit the gridlines. The stair is in fact cause for endless studies, some situated within the squares of the grid, others positioned in line or perpendicular to it. Many of these phases speak directly to 'the failure of the idea in face of reality', showing the limits of pure ideas when confronted with imperfect material conditions. $^{27}$

As a design figure, the square is present throughout the work of Ungers. In the 1980s, he publishes a collection of square houses that run in parallel to a text and series of images on the square by Bruno Munari. ${ }^{28}$ In this book, Munari gathers the most diverse instances of the square, from Chinese characters to the computer boards of the time (still called the 'electronic brain'), from game boards to architectural examples, and even esoteric ideas such as the physiognomically 'square' type of person (who 'indicates an 
Fig. 3.10: O.M. Ungers, library expansion Quadratherstrasse, 1989, design studies
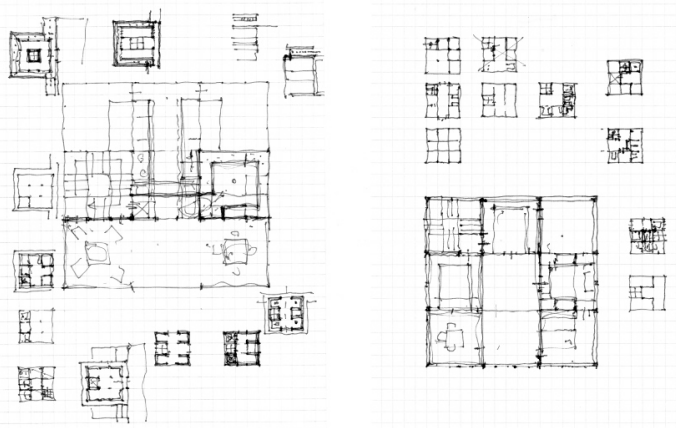

Ungers Archiv für Architekturwissenschaft

energetic blunt nature, a firmness of character to the point of inflexibility, that may easily degenerate into stubbornness'). ${ }^{29}$ The book forms a visual archive, exploring the square in all of its manifestations (including pinwheels, various compositions, and the proportions that derive from the square), but not solely as form. Its cultural significance is not explored in a systematic chronological inquiry, but rather arranged alphabetically. This gives rise to various unexpected juxtapositions, offering a spectrum of significant (and less so) examples of the use of squares (logos, area of the square, Nicaea, musical notes). ${ }^{30}$ Munari's exercise is graphically beautiful and shows the rich variety that can arise from a simple formal premise such as seeking out squares. At the same time, transforming these purely visual analogies is not necessarily an easy translational shift. The spatial implications bring other factors into play, which Hejduk's square and diamond houses address, for example. Nevertheless, these different iterations of basic form and its possible variations do bring it back into the centre of an architectural vocabulary after the endless proliferation of networks and diffusion of the 1960 s.

The square is intended to function as might the Manhattan grid, as a frame within which differences can be cultivated, connecting the social 
and the formal. Departing from the shape of the square, the Marburg (Ritterstrasse) project of 1976 becomes an exemplary project, showing the full potential of the system developed by Ungers, combining a morphological range of models with ideas on variety within unity and the city in miniature. ${ }^{31}$ This approach incorporated individual distinctions that nevertheless contribute to a coherent overall design. In the Marburg design, 13 variants were developed that each had a similar envelope, a five-storey house that was a 6,5-m square in plan. The three middle floors contained the basic living functions (kitchen and dining on the first floor, bedrooms on the third and living spaces in between), while the ground and top floors varied in their use. The images include variations on the clustering, and variations within the houses to accommodate different needs, depending on the future inhabitants and the conditions of the site.

The Quadratherstrasse project, the 1989-1990 library addition to the Belvederestrasse house, is equally based on a mathematical system yet is tempered by its relation to the existing house. The combination forms a more careful balance between an organizing system and its contextual embedding. The expressive nature of the house - which is simultaneously turned inwards, as a fortress, and expressive in its many elements - is brought into balance by the library extension. The new addition is an exercise in restraint, forming a contrast to the house with its very dark exterior, almost as a shadow sitting next to it. The attention for geometry and composition is immediately evident, producing a quietude that derives from mathematical precision. When Ungers designed his library, he did so as a place of retreat. Cepl recalls his reference to the library in Hadrian's villa as the 'most central place, filled with the knowledge of Classical Antiquity'. ${ }^{32}$ Ungers treats the expansion of the library as antithesis to the earlier expressive form of the house itself. ${ }^{33}$ Yet he comments on the unity of the two pieces of the house: 'Darin liegt eben der humanistische oder auch enzyklopädische Ansatz, der keine Ausschliesslichkeit, keine Exklusivität anstrebt. Die Gegensätze bedingen sich vielmehr gegenseitig. In der ganzen Spanne liegt erst das Eigentliche. Das will ich zeigen. ${ }^{34}$ His idea on the Coincidentia Oppositorum derived from Nicholas of Cusa, in which multiplicity is gathered into a whole that transcends its parts, shines through in this comment, also recalling his early manifesto with Reinhard Gieselmann on the spiritual content of architecture.

Koolhaas seems to depart more fundamentally from the premise of difference. Taking the system too far squeezes the life out of it - in a fully 
unintentional demonstration of the limits of conceptualizing architecture, the house on Kämpchensweg cannot tolerate the life that does not adhere to its rules. While Ungers characterizes the house as one in which he has managed to leave out all that he knew about architecture (in contrast to the Belvederestrasse house), it is perhaps more accurate to say that he let the system overtake the architectural dimension here. Koolhaas arguably claims a different space for the autonomy of architecture. Rather than reducing his articulations to their bare minimum, he turns to the notion of 'architectural specificity', through which the houses acquire an agency, as it were. Here, the specific articulations of materials, details, columniation, all serve to contribute to an overall distinctive language. The spaces are less programmatically defined than as architecturally distinct elements, not unlike the gestalterische spaces that Ungers describes and applies in his work. At the same time, in the projects such as Villa dall'Ava and Maison à Bordeaux, the different areas have a distinct spatial sense (flowing, ensconced, horizontal, vertical, connected or isolated) more than as functions of living ('living room', 'bedroom', 'hallway') or as classic compositional elements.

Is it when the tools or instruments (such as a grid) call attention to themselves that they fail as system? The intent of the nine-square exercises presented by Hejduk or the systematic grids used by Ungers, is to allow for spatial definition. The quintessentially centred nature of the square facilitates the surrounding space. Almost as if they are not visible themselves, but only as a shadow, present in the formation of the spaces. Autonomy, as it became manifest in the 1970s, occasionally transcended the rigour of the system. Yet sometimes it only remained within itself. Purity as such is a modern wish - the denial of contamination, of the imperfections of the everyday. It is only when purity allows for the imperfections to be accepted that it seems to work. This goes to the influence of the habitus. When the system is eminently manifest as system, it can no longer influence the habitus as it elicits resistance - the object in itself that counters the subject. When it is more subtly present, it can influence the life within yet not dominate it. 


\section{Formal Gestures, Social Habitus: Constructing the Idea of Home}

The house is a space for living, a workplace, a way of conceiving the world, and at the same time an opportunity for experimentation. ${ }^{35}$

Oswald Mathias Ungers

The relation between ideas and their material presence is precisely what marks these various houses. They sit along a spectrum of architectural innovation and idealization, combined with the necessity of facilitating daily domestic activities. These houses can be approached from the perspective of the idea that is manifest in the material, or from the formal experiment that transforms the idea. They show the mutual influence between aspects such as the material, the social and the formal. The houses discussed here show different approaches, with those designed by Koolhaas tending more towards provocation of preconceived notions, and those by Ungers tending more towards an excavation of deep-seated archetypes. Nevertheless, each house shows its own negotiation between the formal gesture and the social habitus.

The most extreme example of an idealization that impacts every aspect of realization is perhaps the Kämpchensweg house, otherwise known as the Haus ohne Eigenschaften. It idealizes the ordering system and proportion to an extreme, incorporating symmetry and a rigorous grid, while trying to reduce all non-essential elements to a bare minimum. Each view of the house is marked by cleanliness and order, and even the photographs virtually recall the original grid-lined drawings composing the spaces. The system underlies every space, seeking to elevate daily existence. At times one might consider whether this does not demand too much of an occupant, whether the overbearing rigour might not be at odds with the life within, rather than facilitating it. Is the Kämpchensweg house meant to reside more on the plane of Platonic ideas than be situated in reality? Can it age well, or does each crack in the stucco, each stain on the floor, detract from the overall?

In the end, it is in the formal innovations that one sees triggers to a new habitus. This is explicitly activated in the Villa dall'Ava, where the architectural specificity of the spaces is seen as a counterbalance to a purely functional engagement with the residential programme. The composition of the house allows for architectural daring - with the heavy, enclosed box 
sitting lightly on top of the glazed ground-floor space. The Maison à Bordeaux includes a similar gesture, but its overall composition is more complex, which leaves the glass-and-concrete arrangement less central. Moreover, its elevator core - a moving platform of $2 \mathrm{~m}^{2}$ - eclipses the more refined elements while also anchoring the surrounding spaces. The overall composition of the Villa dall'Ava is a negotiation between its site and its internal programme. Its materialization consists of a compilation of various industrial materials, going against the grain of the typical dwelling. Ungers's Glashütte is an explicit recall of a country house archetype, its ideal of a country home accentuated by its centrality in the landscape and its nods to the existing sightlines. OMA's design for the Maison à Bordeaux equally incorporates two archetypes, one more public, another more discipline-related: the glass box holds every reference to the classic modern home, which dissolves into the environment, each threshold dissipated, as little resistance as possible between interior and exterior. Yet the cave appeals to the other extreme, the safety of the enclosed space, the solidity of rock to retreat into.

These houses offer a palette of negotiations between the ideal and its material presence, and their relations with the everyday. They are not only formed by architectural ideals, but also influence the habitus of those within. In his writings, Ungers often makes note of transcendent ideals, but they are always embodied in form. He may disavow the political and social ramifications of architecture, but he maintains a firm belief in the metaphysical appeals of architectural form, in the 'spirit' of architecture. Its agency lies within this, not in its ability to function as moral or sociopolitical guide. It is an ability to awaken a deeper consciousness, which is what he shares with Rossi, particularly as the rationalist and scientific approach remains part of this aim. Yet it also appears that what the consequences may be of this awakening is left to the recipient, is not to be determined by the architect. At the same time, this does not mean that the habitus or the social implications are irrelevant or merely illustrative, simply that architecture is formative in a different manner.

In terms of the social habitus, a striking feature of the houses by OMA shown here is the self-sufficiency of the individual elements of the home. In these villas, parents and children typically occupy autonomous sections of the house. In the Villa dall'Ava, the daughter has her own 'box', while in the Maison à Bordeaux, the children have their own 'cave'. In the Dutch House, the lower level is the children's domain. In these houses, the children's bedrooms are not arranged as a series of spaces dependent on those of the parents, but rather show a sensitivity to the autonomous life of children, encouraging 
a social habitus that fosters their independence and privacy. ${ }^{36}$ In the house the tangible, physical, material presence becomes important not only as the embodiment of an idea, but also as a daily interaction with the habits of the client. ${ }^{37}$ In the Maison à Bordeaux, the idea centred on the client in a wheelchair being placed at the heart of the house: not as a handicap, but rather with the wheelchair becoming a departure point for making the elevator platform the dominant element in the house. After the death of the owner, there came the need to reconfigure the habitus of the house - the elevator platform needed to be rethought in order to not create a pure absence at the heart of the home. Here, the architectural specificity of the gesture arguably helps to provoke renewal: the platform becomes a space that needs a new infill, rather than fading into the background. ${ }^{38}$

In the houses, there are two primary relations at work: between idea and form, and between form and habitus. The first is a matter more situated within the discipline, a more conceptual or intellectual relation between what is intended and what is constructed. The second is a matter of architecture's agency in the world, its (necessary) contamination by everyday interaction. These designs are interesting precisely because of the friction or slippage between the ideal and its reality. In the original designs for the Quadratherstrasse extension, the system seems to have preceded the infill. Sketches show many failed attempts to fit functional elements such as toilets and staircases into the idealized system of the cube. Reducing the programme to library and study allowed the grid and the space to avoid contamination by mechanical systems or everyday necessities. Conversely, in the Maison à Bordeaux, the envisioned use of the home generated an idea of the mechanical heart - the condition of the wheelchair, a contingency, reconceives the idea of this home. 


\section{The House as Microcosm of Social Complexity}

Each of the three houses is a place, each a microcosm, a mini-universe. Belvederestrasse: a small, living, spirited city, always changing. Kämpchensweg: abstraction to pure form, number and geometry, architecture reduced to its barest terms. Glashütte: constructed memory, a sum of experiences. Three places, three concepts, three attempts to get a grip on the phenomenon of architecture and find a solution. ${ }^{39}$

Oswald Mathias Ungers

While the purity of the system is an appeal to underlying universal characteristics of architecture, some of the houses walk a fine line between the opposing demands of their ordering system and facilitating the life within. The first house that Ungers built for himself, on the Belvederestrasse in Cologne in 1958, has been compared to the Soane House, suggesting that the 'cosmos' Ungers created with his architecture, his models and his references to art and architecture is only comparable to the self-enclosed world at the heart of the Soane House; that the variety and depth of its architectural gestures also compare only to this. ${ }^{40}$ Lepik calls it a 'physical manifesto/tractatus', making the house the core of the person's position in the world ${ }^{41}$ In this case, the ordering system is a highly idiosyncratic one, congruent with the person at the centre of it, which results in odd categorizations. In some ways, this compares to OMA's Maison à Bordeaux, which was equally centred on its owner and created a world around him. At the same time, the 'world-building' in the case of the Maison à Bordeaux was proposed as a necessity: since the physical world of the owner had been limited by his disability, it was crucial that his intellectual and perceptual world was expanded. In the case of the Soane House and Ungers's houses, it was more of an intellectual and disciplinary exercise in constructing an expansive world that was facilitated by architects building their own homes. In the history of architecture, this approach is not unusual for the design of a house: it may be a relatively small commission but it encompasses the 
collective desires of the dwelling, the archetype of the home and, particularly in the twentieth century, the desire for expressing individual identity.

The house on the Belvederestrasse is a material document on composition and materialization with a complex programme. Its composition was envisioned as a 'small city', organizing the different and autonomous elements within, and its expressive, carefully articulated brick façades attracted the attention of Reyner Banham, who put it forward as an example of the New Brutalism. ${ }^{42}$ Ungers's determination to 'show that architecture can elevate any situation artistically, ennobling it and rendering it sublime - however trivial it may be' figures throughout the house. ${ }^{43}$ Nevertheless, the spaces themselves offer a quiet dignity, in accordance with the intellectual ambitions of the work. ${ }^{44}$

Originally built as a three-family home, the house has a complex floor plan with two independent dwellings enclosed within it. Built to accommodate more than one family, the programme indeed constitutes a 'small city', with office space for Ungers, the family home, and two apartments to be rented out in order to cover the costs of the house. ${ }^{45}$ The Belvederestrasse house originally did not have a separate library. When Ungers moved back to Cologne from Ithaca, this 'small city' was reconfigured into a single-family home. The apartments were cleared out to accommodate a library in the two rooms of the upstairs apartment, and the downstairs rooms became a studio. ${ }^{46}$ In the street façade, the house is remarkably unassuming, while inside it unfolds. It initially appears more of a fortress, with little external information, and a sober entry. Inside, its complicated combination of office space, the family home, and an apartment gives rise to a sense of an urban composition, emphasized by its materialization, with stone flooring between the major sections of the house.

The complexity of OMA's Villa dall'Ava is less immediately apparent. It begins to construct the narrative of programmatic indeterminacy and architectural specificity. It is in the distinct delineation of spaces that an appeal to architectural qualities becomes manifest. The concrete box resting on the glass box, aside from being a marvel of construction technology, recalls the Miesian glass house but maintains a level of privacy for the bedrooms. The cheapness of the construction materials and the unusual organization of the house speak to the house as an experiment. The composition of the boxes and the expansion of dwelling space on what is essentially a small plot of land also intimate a complexity of organization. 
The presentation of the Villa dall'Ava in SMLXL comprises a brief story about the client, and pages upon pages of (amended) drawings, plans and photographs. ${ }^{47}$ Overall, the house revolves around structural complexity that is presented as a formal simplicity - a closed box on a transparent base and its programmatic fluidity. The Maison à Bordeaux explicitly positions the house as a microcosm, playing off of the physical limitations of its owner in order to appeal to a much broader sense of the world through the architecture. The commission for the Maison à Bordeaux had been explored as early as 1988 when the Lemoine family was considering moving out of their home in the centre of Bordeaux. Plans were delayed for a number of reasons, until $\mathrm{Mr}$ Lemoine was in an accident that confined him to a wheelchair. The home they were living in was unsuitable for a wheelchair, making the need for a new home more pressing. In this new situation, Lemoine was searching for an architect who would not deny his handicap, or estheticize it. ${ }^{48}$ In fact, Lemoine stated that he was in need of a complex house, as that would become his world. ${ }^{49}$

In essence, the complexity of these houses is therefore not about the complexity of the programme, nor about the intricate dependencies one finds in bigger commissions. Instead, it is about triggering the spatial imagination, about world-building, and about providing the occupant with a sense of grounding in the world at large. The sense of depth resides in the presence of ideas in the material - in the inevitable slippage between idea and form and the space that leaves for interpretation and speculation. These are not ideas that remain rigid, as unassailable ideologies, but rather ideas that remain an accompaniment to everyday life, free to be ignored, but nevertheless influential, and at their best, influenced by the conceptual generosity of the spaces within. 


\section{Small Projects, Big Ideas}

If utility were the principal aim of those who build houses, then Farnsworth House, Falling Water, Villa Rocca Pisana, and Maison Savoye would never have been built. The house is a copy of our idea of the world, life, and existence. It is a passage from our existence. ${ }^{50}$

Oswald Mathias Ungers

Constructing the ideal home relates to everyday experience, but seeks to elevate it beyond the mundane. In some cases, these houses have sought our archetypal expressions of 'home', in others they present alternative modes of domesticity. The Dutch House is rendered throughout with notions of 'safety' - the fortress, the privacy of the master bedroom - combining the modern need for privacy and retreat with archetypal notions of safety. The house on Belvederestrasse picks up an intellectual proposition of the house as a small city, and combines the various programmatic elements with explicit material references to city squares and streets.

By positioning the house as a 'passage from our existence', and as an embodiment of our 'ideas of the world, life, and existence', Ungers anchors far-reaching implications of the Gestalterische Idee in the house itself. Because the commission for a house is small, it enables the architect to be precise, to approach it in-depth. It does not reach the level of abstraction that the urban environment does. Instead, we are familiar with every step in the house, and its peculiarities become embodied in our own trajectories. This is its most far-reaching influence, a tacit one, difficult to identify but embodied in our very movements. There have been moments in the twentieth century when houses formed a solid core of architects' work. The modernist repertoire of architectural design is inconceivable without the Weissenhof Siedlung, or the various villas by Le Corbusier, Mies van der Rohe, Gropius and others. ${ }^{51}$ Some of the prime examples of postmodernism are relatively small but precisely designed houses, such as the Vanna Venturi house or Botta's home in Ticino. The work of John Hejduk explored the simplest forms of inhabitation, with the most evocative narratives of inhabitation. 'Houseness' becomes an exemplar of the (metaphysical) sense of shelter from outside, of warmth and safety. 
The houses are ideas, yet they are given tangible material form. They are a personal world, which encompasses an intimate microcosm.

This essentialism runs throughout the publication Quadratische Häuser, where Ungers's fascination with the square as a form that taps into transcendence is combined with the texts of Bruno Munari on 'the discovery of the square', and a constellation of projects by Ungers and various contemporary and historical architects, all somehow premised on the square. ${ }^{52}$ The texts convey a universalist theme that indicates a foundation within architecture. Many qualities are contextual, or so it seems to suggest, but some resonate throughout different cultural and historical contexts. The fascination with the multi-symmetrical shapes of the circle and the square is one of these stable undercurrents in architecture. Ungers has a clear preference for the historical continuities in architecture such as proportion and geometry, for architectural instruments that he considers intimately connected to the metaphysical spirit of architecture. 'Denn im Menschenleib fanden sie die beiden Hauptfiguren, ohne welche kein Kunstwerk gelingen kann, nämlich den vollkommenen Kreis und das Quadrat. ${ }^{53}$ The introduction notes that the homo circularis and homo quadratus came from antiquity and remained throughout the Middle Ages as an abbreviation of the Christian universe. These forms were seen as significant and became directly connected to architecture. The Christian metaphysics were not given up, but rather were given a stronger neo-platonic orientation. The image of man inscribed in a circle and a square could re-establish or repair a connection between God and the physical, visible world. To Ungers, this simply proves the universal importance of these figures.

His recurrent iteration of platonic forms presents a continual awareness of the ideas that guide everyday life by organizing spaces around classical proportions and measurements, a theme explored further in City Metaphors as a human need to bring order. At the same time, the overall composition and formal references of houses like the Belvederestrasse house and the Glashütte accommodate an underlying sensitivity to patterns, images and metaphors that help to structure the everyday environment.

The Marburg project offers a spectrum of typological variations primarily in the overall composition. The series could be imagined as a larger series, as the simplicity of the frame makes it easy to imagine its extension. While larger building programmes might offer more complex challenges, these small projects, when given sufficient attention, can bring us back to the essential ideas of the architects designing them. Their logic embodies an analogy 
that draws its lines from the immediate and material to the conceptual and transcendent. ${ }^{54}$ Their questions are brought back to a few central issues, instead of being confronted with layer upon layer of requirements and regulations. As such, the houses go to the heart of these architects' interests.

The irony of seeking a 'primitive hut' on the eve of the twenty-first century is not lost on Koolhaas and Ungers. To Ungers, it is a human condition - as we understand our world not only through functions but also through symbols and ideas, the house represents our position within that. The primary quality of the primitive hut is not its nostalgic implication of a return to a simpler life, but rather its embodiment of the Gestalterische Idee, something that remains valid throughout the societal transformations we have undergone. His three houses represent a life's trajectory of positions, as a person and as an architect. The exploration of these ideas not only becomes evident in the presence of the houses, and the understanding of their background, but also through their differences in having been given form. The main distinction between the work of these two architects is perhaps the kind of ideas being injected - where Ungers typically appeals to ideals as a manner of framing or bringing order to messy reality, Koolhaas typically adds new, personal narratives, offering 'possible stories' rather than seeking out essential, underlying truths. Ungers offers a systematic exploration of these systems, and the tools of the architect such as the square, the grid and symmetry, while Koolhaas builds on the contingencies he encounters, the patio housing as a dike-house or the Villa dall'Ava's requirement of a small footprint. Koolhaas tends to bring together more fragments, in materials, precedents and sensibilities, while Ungers gathers the contingencies into a system.

The notion of the house as cosmos and as a passage from our everyday existence naturally begs the question of how to understand apartment dwellings, which since the rise of modernism have provided simple types, the machines à habiter, cookie-cutter homes that supply adequate space but offer little more. Ungers seeks out an interim scale between the house and the apartment: the Urban Villa, which provides some of the benefits of a private home, in its scale, its more or less direct connection to outside and a situation in open greenery. Yet it also introduces the comfort of a small community.

In the commission for a private house, two moments of individuality become prominent. The first is the simple intimacy that arises from designing the private home for a client. The programme typically derives from a deeply personal sense of how one wants to live, as on the one hand an 
experiment in architectural expression, and on the other a moral appeal to 'good living', both of which are present throughout the history of modern architecture. The private home has been central to many transformations in twentieth-century architecture. Some of the homes that were central to the development of new architectural forms are easily identifiable: the Farnsworth House, Fallingwater, the Villa Savoye, the Eames House, House $\mathrm{X}$, the Maison à Bordeaux. But even the homes that figure less prominently in architecture history are often a fond reminder of the ambitions and hopes that can be enclosed in the smaller commission, such as Peter Blake's Pinwheel House, or John Lautner's Chemosphere. ${ }^{55}$ In these commissions, the home truly becomes the cosmos. This comprises the other moment of individuality: the home becomes a jewellery box that represents the individual cosmos - it becomes the beginning and end of the architect's work. As a small commission, it receives an attention that must seem relatively lavish compared with larger commissions. There may be fewer regulations, the building may be smaller, but often the private homes hint at the vast design work that goes into them.

Bachelard writes that our understanding of space and our sense of the home is deeply formed by the archetype of the house with its cellar, main floors and attic. ${ }^{56}$ The houses of OMA and Ungers show how the specific dimensions of dwelling - whether that is the rigorous mathematical purity of Ungers's house on the Kämpchensweg or the unexpected inversion of a classic Dutch dwelling type in OMA's Patio Houses - can shape ideas as well. They are built on precedent, on classical language, yet they refer to (and reconfigure) an ideal. These positions refer less to constantly shifting societal conditions than they do to archetypal concerns such as grounding, home, shelter or meaning. In the end it is the balance between idea and material reality that shows this work to be more than a simple addressing of the programme - the houses are not a fulfilment of the clients' desires, but an intellectual exercise, played out between the idea of the house - from Adam's house in paradise to Bachelard's hut in the woods - and the everyday reality of a space for living in.

While the houses by Ungers shown here were all designed for his own family - and they can very well be organized along the autobiographical lines he himself suggests, from his youthful hubris ('everything I knew, I put into the house') to the calm sobriety of the Glashütte and the mathematical precision of the library addition - they also contain, on a smaller scale, various ideas that remained with him throughout his career. Their infill may transform over time, but not their formal coherence or underlying principles. These, 
by and large, have remained the same. The great transformation is in how Ungers feels his ideas are best made manifest in the architectural form of the house. The houses show the continuity of his concerns, emphasizing the idealized aspects of his work, manifest in the basic tools of architecture such as geometry and mathematical rigour. The concerns of Koolhaas as such seem more fluid and responsive to context, though their continuity is to be seen in the constant provocations of accepted truths.

Although they represent different scales of inhabitation and design, the themes embodied in the house and the city are not necessarily opposed. As Michel Jacques notes, 'the theme of the house participates in OMA's meditation on the contemporary city. Houses may even work as a smallscale laboratory, a site for experimenting with the most intimate aspects of living space. ${ }^{57}$ In contrast with the mathematical precision and symmetrical organization of the houses of Ungers, the houses of OMA may be seen as 'games in dissymmetry', making them dynamic rather than inert. ${ }^{58}$ If we are to treat these houses as constructing a cosmos, those of Ungers appeal to a sense of coming home, the stable centre from which to enter the world, while those of OMA appeal to a reaching out, always keeping their occupants slightly off balance while constructing a kaleidoscopic environment around them, full of new surprises.

The distinction between the material form and the intellectual presuppositions has been noted by François Chaslin in a somewhat counterintuitive fashion, when he says that critics in particular have a difficult time seeing the lighter side of Koolhaas.

[Critics] don't understand the connection that exists between Koolhaas's intellectual stance, his lucidity, his refusal of idealism, nostalgia or sentimentalism, his rejection of the taboos and classical values of architecture (usually more or less dependent on other theories and even moral codes), and the undeniable elegance, lightness and virtuosity of his buildings. They are suspicious a priori, because they live in perpetual fear of being seduced. $^{59}$

Here, the elegance and virtuosity of his buildings is seen as connected but not causally linked to his intellectual principles. More than anything, what Chaslin puts his finger on here is the inadequacy of architecture criticism that tries to find logical relations between intellectual principles and material form, or the intelligent engagement of classical values and the resulting architecture. The essay is generally insightful, referring to Koolhaas's search for the sublime 
and his refusal of 'intellectual comfort' as well as his celebration of 'terrifying beauty'. Chaslin suggests that the fragments of modern architecture's legacy that are present in the work of OMA (such as Le Corbusier, Mies and Leonidov) have been stripped and destabilized, reinvested with other associations and meanings. ${ }^{60} \mathrm{He}$ positions these references as less naive than the original icons, with an incorporation of disquietude, and constant bringing together of contradictions by seeking a permanent dynamic imbalance between a harshness and bruteness in the spaces that is complemented by sensuousness and common materials. ${ }^{61}$

\section{Poolside Stories}

There is a small epilogue to this story of the house, which relates to the pool. The personal preoccupation with swimming runs as a red line through the work of Koolhaas, from his story of the pool in the appendix of Delirious New York, to the various private pools accompanying the houses he designed. The floating pool of the Villa dall'Ava is perhaps the most direct articulation of the story of the pool, with its orientation towards the Eiffel Tower (an inversion of the Soviet swimmers, continually swimming away from the Statue of Liberty - another one of Eiffel's constructions). ${ }^{62}$ Yet each pool shows a particular instance of this idea and its material articulation, again constructing a personal narrative based more in a possible (retroactive even?) fiction.

At the Villa dall'Ava it is part of the recklessness and exuberance of the villa - the heaviness of the pool on the roof, balanced ever so tenuously over the glass volume. It shows the exhilaration of swimming towards the Eiffel Tower, the dramatic end of the swimming pool which also ends the house (not quite as luxuriously decadent as the infinity pool alongside John Lautner's 1969 Elrod House, which figured in the film Diamonds are Forever). In the Maison à Bordeaux, the pool is a later addition, part of the reconfiguration of the house after its central occupant passed away. The heart of the house, the elevator platform, was given a new function, and the remaining occupant, Hélène Lemoine, now has a swimming pool quietly set in the hillside, surrounded by trees. A self-cleaning natural pool ensconced in greenery, with a view to swim towards as yet another reiteration of the story of the swimming pool. In the Maison à Bordeaux, the proportions recall the original elongated pool in Delirious New York, meant for swimming laps. 
As a counterpoint to the pool as a sense of escape then, is Ungers's pool at the Kämpchensweg house, which is trapped in the grid. The pool sits at the core of the house, where the sheer luxury of swimming within one's own premises recalls the long-gone days of the central hearth. But here the fluidity of water is contained in the house, constrained within the rigorous order of the grid, demonstrating the power of architecture to maintain order. 


\title{
Chapter 4. Elements, Rules and Conventions: Architecture as Material Knowledge
}

\author{
The reality of the drawing board and \\ the model is not the same as that of \\ materials and volumes. ${ }^{1}$ \\ Oswald Mathias Ungers
}

As noted in Chapter 1, the 1970s overall form a period of self-reflection in architecture. The oil crisis of 1973 and the pessimistic projections of the Club of Rome report have their impact on the field. Yet within the profession there is also a conviction of the value of architecture. The converging lines of internal legitimacy and external transformations lead to a period of heightened selfconsciousness. As the world begins to transform in the 1970s, and as architects increasingly seek a logic in architecture that is less susceptible to external conditions, the turn to autonomy is crucial. Ideas on the city are transforming in response to the differentiation in our cities, and to the collapse of a unified understanding of the city. In the meantime, the projects for houses are used as testing grounds, explorations of the limits - not of industrial fabrication or other modern exploits - but of the internal language and the undeniable logic of architecture.

What this then revolves around is rules and conventions, elements and compositions, techniques and materials. The approach to architecture is self-focused, without the very large themes such as Utopia, but with a particular aim at understanding key features of architecture. These are architecture explorations that focus on constituent elements rather than on architecture as a whole. They train particular skills and focus on specific features and allow for freedom in reconstituting the subsequent whole. Studio programmes and experiments such as John Hejduk's Diamond Houses and Ungers's Wochenaufgaben follow this structure, with the assignment 
focusing on particular aspects of design such as materialization and spatial composition.

In essence, there is a return to the internal drives of architecture, though this is also in response to the externalization of demands. This focus can be related both to the historical continuum of architecture as a whole, and to the societal conditions it resides within. ${ }^{2}$ The condition of crisis triggers a reconsideration of the legitimacy of architecture, a field that is in many senses a luxury. ${ }^{3}$ Yet within the discipline, a clear move towards autonomy is already visible in the work of the Texas Rangers, in Analogue Architecture, in the Flemish generation of 1974 and in the work of the New York Five. These developments dovetail, with the lower number of commissions requiring a search for alternate forms of practice, or offering the time to rethink the conventions of the discipline. More architects involved in education and fewer in building, which also drives internal innovations. Portoghesi's 1980 Biennale 'The Presence of the Past' might be said to definitively usher in a postmodern position in architecture, with use of historical references and a semantic approach to architecture determining the face of architecture in its first Venice Biennale. ${ }^{4}$

Fig. 4.1: Strada Novissima, Venice Biennale, 1981. Facades by Ungers (4th from left), OMA (right) in bottom row. Others include Bofill, Venturi and Scott Brown, Graves.

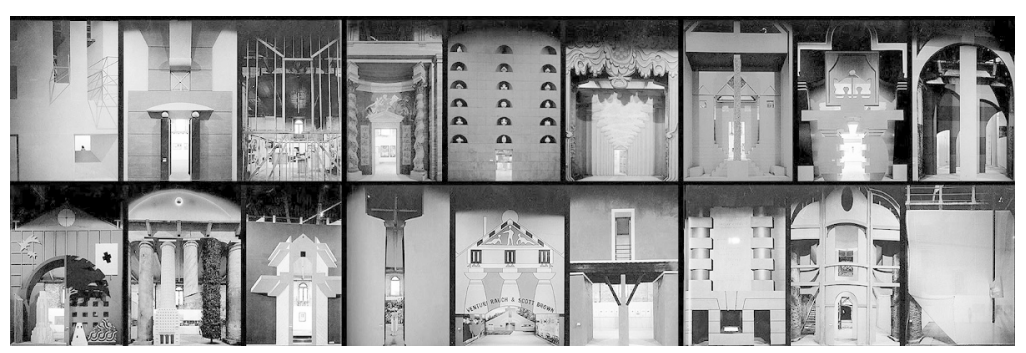

All this simply goes to show the dependency of architecture on external influences, and at the same time the fact that there is a 'hard core' of the discipline. ${ }^{5}$ Koolhaas is exceptionally attuned to external conditions, observing concerns such as scale, density and traffic flow, from which he derives ideas such as Bigness, Generic City, Junkspace and the self-organizing logic of slums. In so doing, he seeks out the elements that can be folded into a repositioning of architecture. Architecture, in this approach, remains the 
Vitruvian Mother of the Arts, where the features of the external world become material to work with.

Ideological positions notwithstanding, the architecture of the (late) twentieth century continues to wrestle with the conditions of modernity. As early twentieth-century architecture found its new élan in references to immediate and visible developments (industrialization) and at the same time claimed techniques of the avant-garde, it shattered quite a number of conventions. This took decades, if not nearly half a century, to show its full impact in the built environment. The shaking off of traditions, and the seeking out of new logic and vocabularies also necessitated a dispelling of the charm of the historical. And as the scientific enlightenment of modernism expanded, the enchantment of the world as it is faded further from our view. It could be argued that for some decades now, we have been seeking this sense of enchantment again as a counterweight to the disenchantment of pure rationality. Yet it is also a pendulum movement from the building booms of the 1950s and 1960s (or later, the 1990s and 2000s) to the moments of crisis that not only bring the field to a standstill but also require reflection as conditions are changing and will not return to the previous status quo. Each time, the question arises as to what shape these new transitions will take, and architecture, as a field engaging both with rapidly shifting social contexts and with longstanding traditional building methods, sits squarely at the junction of tradition and innovation.

This chapter springboards from the more contained transformations in urban thinking and in the architectural articulation of ideas in the houses to seek out the lines running underneath the changes in approach and what this means to the discipline as a whole. The legitimacy sought in the 1970s is perhaps not what is needed today, but the two are related. As the discipline formerly known as a 'minor profession', architecture has become institutionalized, causing unexpected side effects in teaching and research. ${ }^{6}$ Architecture theory has become all but separated from the practice and reflection on architecture, holding its own in the academic world. At the same time, there is a growing interest in design methods and in design research. And to continue the question posed by Kazys Varnelis in 2004, 'Is there research in the studio?', we now might ask: 'What kind of research is there in the studio?'7 The Harvard studios run by Koolhaas, taking their cue from the Las Vegas and Levittown studios by Robert Venturi and Denise Scott Brown, introduced an expansion of research approaches in architecture. 
It is questions such as these that underlie this book. If the assumption is that architecture still offers a valuable contribution to society today, then what does this consist of? Is it the 'tolerant normality' identified by Vittorio Lampugnani as an essential feature of European architecture? ${ }^{8}$ Is it the 'spiritual content' once suggested by Ungers as central to architecture? ${ }^{9}$ Or is it rather an oscillation between cultural convention and autonomy, as Hays proposed in his seminal essay on 'critical architecture'? ${ }^{10}$ The irony is that we often see particular strengths yet equally often have a difficult time identifying them.

This is what I am trying to get at here - architecture is multiple. It has more than one interpretation and it can last (often significantly) longer than the moment and aim it is realized for. It is situated in a time yet appeals to timeless principles. And as such it is a complicated object, with cultural evaluations that are similar to objects of 'pure' art, yet with the additional constraints of construction, convention and function. As such, it is a messy discipline, dependent on many conditions outside of its grasp (gravity, regulations, patronage), and at the same time an overconfident discipline, convinced of its own internal logic.

The hopes of the early moderns notwithstanding, architecture cannot adhere solely to the rules of scientific analysis, because it is involved in less rigorous domains of life. It cannot appeal to a pure autonomy, because it is too dependent, but it is also a discipline that aims at more than simply solving problems. As such, one might identify architecture as a discipline of situated autonomy. Its core revolves around a self-propelling autonomous trajectory of disciplinary inquiry and development, while each individual project and indeed the discipline as a whole is tied by its very nature to an intricate web of dependencies that cannot be dismissed as 'mere' constraints. ${ }^{11}$

Setting aside the distinctions between modernity and postmodernity, throughout these transformations in the field of architecture there is a notable struggle with an underlying sense of alienation: the structures that comprise the built environment may answer to minimal requirements of space and light, but the abstract systems and structures somehow do not align with a self-evident presence in the world. ${ }^{12}$ As such, some of the developments discussed in this chapter will show an exploration of the rationality of architecture, while others are attuned precisely to the underlying desires. Ungers remains in this division more aligned with principles of rationality, while Koolhaas consciously seeks out enchantment and the surreal. Both, however, seem to be strongly rooted in some form of humanism, and presume 
an agency for the architect: the ability to create conditions that might lead to new habits. The question is what their approaches might have to offer in a time of posthuman agency.

In this chapter, I trace out a few particular approaches that negotiate the sticky terrain of what philosopher Gilbert Ryle once identified as 'knowing that' versus 'knowing how'. In his 1946 lecture, he identified the philosophical dilemma that there are modes of knowledge we cannot convey or learn purely in theory. ${ }^{13}$ In essence, one can learn the physical laws and calculations pertaining to gravity, force and trajectory, but this will not guarantee that one can hit a home run in a baseball game. Cookbooks may offer an aid in learning how to cook, but truly knowing how cannot be conveyed in abstract theories or rules. This dilemma was further refined by Michael Polanyi in distinguishing 'tacit knowledge' from 'explicit knowledge', where acquiring 'tacit knowledge' requires a leap from the student. ${ }^{14}$ It can be explained to some degree, but it is in the embodiment of this knowledge and the act of actually trying it that it becomes more solid than the mere abstract understanding of principles.

Both Koolhaas and Ungers typically relate their projects to fundamental ideas, working through them in texts, drawings, models and buildings. It is the irreducibility of one medium to the other that makes these oeuvres worth studying, particularly as they navigate all of them with an agenda for the current status of architecture. ${ }^{15}$ In the retrospective gaze of Nikolaus Kuhnert, editor of Archt, the 'discursive design' of Ungers situated architecture as a collective exchange of ideas and design principles, while the 'conceptual architecture' of Koolhaas pushed the boundaries of design. ${ }^{16}$ Overall, their work has an explicit relation to architecture's body of knowledge, addressing issues of the underlying information being incorporated in designs, or of methodological interests. Koolhaas identifies the nature of architecture as complicated and ambivalent, which allows him to set aside what he cannot influence in order to have a stronger impact with his work. This negotiation of the limitations of architecture while exploring alternative avenues of influence is perhaps one of the most characteristic aspects of the work of OMA. The work of Ungers takes the inverse approach, not explicitly staking out which societal forces he is dependent on as an architect, but rather exploring the expanse of the intellectual and visual universe encompassed within architecture. Nevertheless, his depth and breadth of knowledge of architecture as a field of intellectual and design discipline forms a basis on which Koolhaas could build his tactical manoeuvres. In neither case can 
we speak of purely intellectual interests, in which the design or building is reduced to an illustration of intellectual concerns.

The distinction between the resulting form of ideas, whether that lies in two-dimensional representations, linguistic explications or the larger built form of a house or even the abstracted infrastructure of an urban design, is what this work is concerned with. Each manifestation finds its roots in the ideas, but it is not until its specific execution that new insights arise. Each idea may be easily supported, but the realization of that idea leads its own life. Thus it is in the specific iteration of an idea that a qualitative assessment can be formulated.

So what if the current challenge for architecture is to offer a plausible relation between the social and the formal? This would suggest a contingency to the epistemological status of architecture - it is not about definitive evidence, but about the 'right idea at the right time'. In addition, it would suggest that this 'right idea' may be rethought over time, that architecture is loosely defined: as it is a long-term project, it remains open to reinterpretation after the immediate spatial needs have perhaps disappeared. Think, for example, of the many empty churches around the European continent that are currently finding new uses, from residential apartments to bookstores. The material presence remains, while the surrounding context transforms. Moreover, by emphasizing the relation between the social and the formal, the suggestion arises that these domains are able to relate, thereby countering the underlying schism that has been exacerbated over the course of the twentieth century. In this field, 'plausibility' between the social and the formal then suggests that there may be some sense to and pattern in why buildings are reappropriated that support the legitimacy of architecture. It suggests that architecture provides more than simply shelter, but on a more modest scale than Utopia.

What becomes apparent in the urban ideas and the work on the houses is the volatile status of the implicit values of architecture, such as in the domains of ethics and aesthetics, as well as its lack of explicit vocabulary and clear standards of evaluation. The meaning of architecture is at once both carved in stone (or concrete) and dependent on the shifting sands of cultural sensibilities. This unstable status is partially tempered by the actual buildings, as they remain open to multiple interpretations and revaluations. It is within the objects of architectural production (whether projected, drawn or built) that this multivalent nature becomes most clear. Yet it all revolves around the ideas put forward, regardless of the vessel they are presented in. 
Ungers does both [write and make things]. His immense written body of work proves his ability to make seminal contributions to both disciplines, enriching the world of architecture with artefacts while building a conceptual world out of words. The foundations for both lie in the world of ideas. ${ }^{17}$

\section{Words and Things, Ideas and Realities}

If the old saying that 'a picture is worth a thousand words' is true, then why do architects write ${ }^{18}$ For one, there is a tension between words and things: they are not entirely commensurate. ${ }^{19}$ They may be able to get quite close, as an evocative literary description might adequately identify a city, or as a building might evoke a particular style of description. Yet it remains difficult to collapse one medium into the other.

Most architecture is primarily public in nature. While the fiction writer might be able to keep a novel in their desk drawer, and the painter may be able to turn their paintings to the wall, architecture is bound to a complex interrelation of patronage, execution and reception. Buildings are typically funded by the client (who may or may not be the occupant). The financial risks are with the client. Execution is typically given to a contractor (who may employ numerous subcontractors). The final building, in this sense, stands at arm's length from the architect's direct intervention. It is the interpretation of the design. And in this age many buildings - even some private homes are so eminently present in public space that the public may often feel the need to evaluate the results.

In the era of the starchitect, these developments have fundamentally complicated the Renaissance rhetoric of disegno. The classical 'genius' of artistic inspiration has been modernized and globalized in the contemporary notion of the starchitect. As such, writing fulfils a wide variety of functions for the architect, from the mundane to the highly theoretical. It can help to convey the ideas in a building to the client. It may help to explain irregularities in relation to zoning requirements. It can help clarify the main ideas in the design process, and it can identify the most important constraints for a contractor. In the history of architecture, however, writing has also had a privileged status. It constructs theories around the built oeuvre and it builds up legitimacy for architecture as an intellectual endeavour, requiring more than a simple instruction manual. ${ }^{20}$ 
In other words, by its very public nature, the material results of an architectural idea are examined, evaluated and written about, by architects, critics and the general public. Koolhaas and Ungers show a productive slippage between words and architectural tools in their work. They show the tension between 'just words' or 'learning in theory' and what it means to 'know how'. This knowing how is eminently present in the houses, and perhaps a little more hidden in the urban proposals, because these are dependent on large structures and systems. But what we can see in the projects is a material reality of testing boundaries, of elegance, of precision and of reconsideration. In recent years, much attention has been given to the writing on architecture; to architects' words and their intents. But has equal time been given to the material presence of architecture?

Koolhaas is a paradoxical figure in this spectrum of words and things he produces endless amounts of writing, while at the same time proclaiming the impossibility of speaking about architecture. He dismisses the possibility of explanation, yet constantly seeks to define what it is he does. His writing can be oblique in terms of the particular effects or features of a building, yet it also contains remarkably clear observations on the work of the architect in a globalized world, documenting the cultural misunderstandings in project meetings on Fukuoka, even if hidden in what is designated as a poem. ${ }^{21}$ In contrast, the writing of Ungers is more controlled on particular topics and far more straightforward. It typically situates the historical context and explores specific ideas in architecture such as proportion or precedents, or a general cultural context such as the autonomous language question. The rogue perspective of Koolhaas is well-known and often seen in the ambivalent reviews of his work. ${ }^{22}$

The importance of Ungers is indisputable in terms of his combination of practice and theory, and his systematic approach to both. ${ }^{23} \mathrm{He}$ is perhaps best known for his didactic influence, which has been emphasized in recent years with the republication of some of his teaching material in Arch+. ${ }^{24}$ As a whole, his fundamental rethinking of and writing on architecture, combined with his continuing practice, seems more akin to the thinkers of the nineteenth century such as Viollet-le-Duc and Ruskin, than to his contemporaries such as the members of Team 10. Ungers's lectures for the TU Berlin are testimony to his intellectual approach, which is grounded in architecture history but oriented towards the derivation of systematic principles. In concurrence with his teaching, from 1963 to 1978, Ungers spent most of his time thinking rather than building. Beginning with his 
Fig. 4.2: O.M. Ungers, Systems of the body, the city, and the car. Contribution to Man TransFORMS, 1978

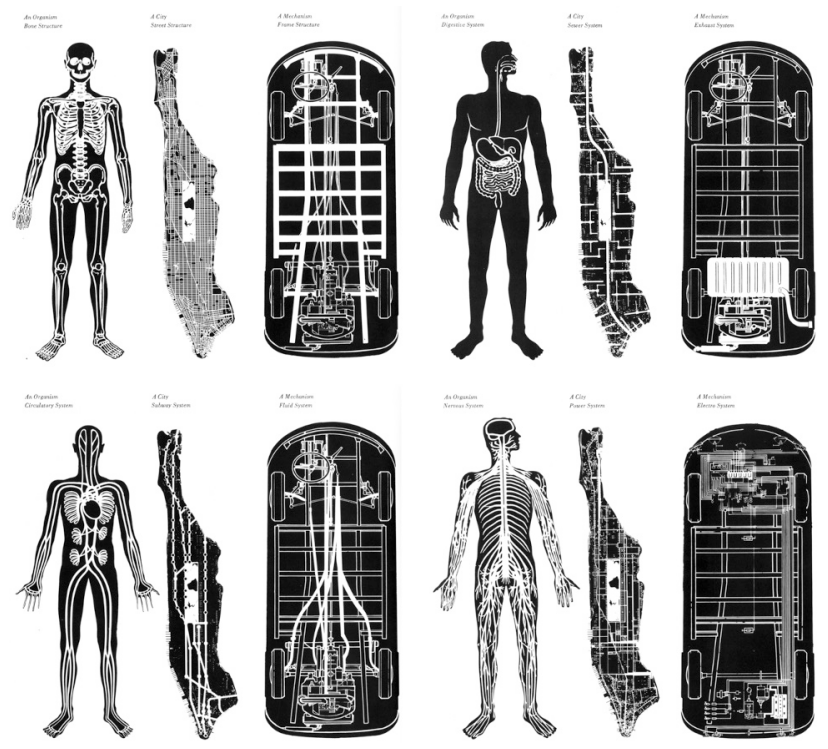

exhibition catalogue Man TransFORMS

appointment at the TU Berlin, his practice slowed down, and his focus shifted to teaching and systematically disseminating his ideas on architecture. According to Kieren, from the perspective of the mid-1990s, 'this was precisely the period when the foundations of his present international fame were laid, as he began a cathartic pursuit of a purely intellectual, conceptual, programmatic architecture. ${ }^{25}$ It may well have been the time invested in picking through architectural principles and their exemplars that allowed him to delve further into this intellectual architecture. Throughout however, it remained founded on the material objects of architecture. Even at its most conceptual, as a reflection on human modes of perception, the writing of Ungers remained fundamentally tied to architecture, never becoming a pure thought experiment. In the context of the Cornell years, Sébastien Marot also makes note of the striking contrast between Ungers and Rowe. He identifies Rowe as above all a historian, despite his love of and interest in architectural practice and techniques. While Ungers is presented as the inverse: despite 

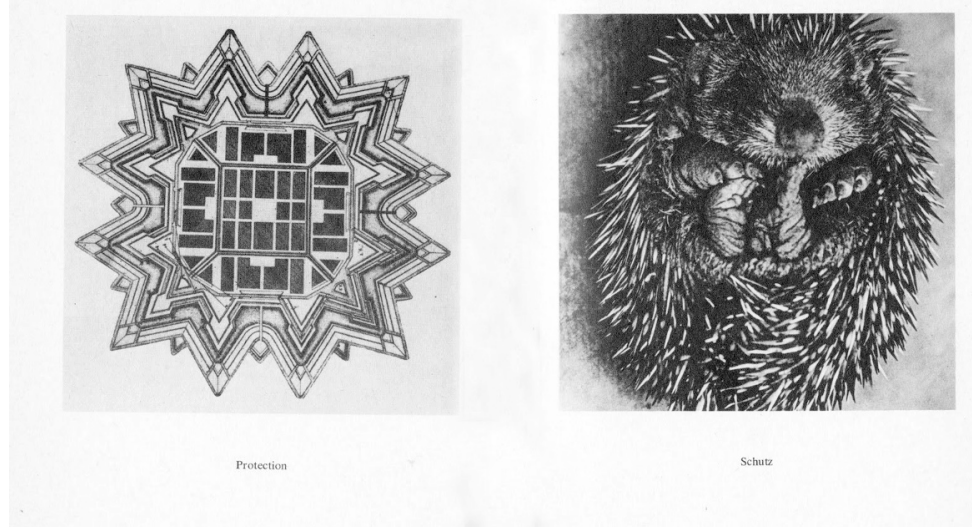

O.M. Ungers, City Metaphors

his love of and interest in research, use of models, precedents and systematic thought, he is above all an architect. He needs to make buildings, to intervene in cities and to add new realities to the world as it is. ${ }^{26}$

This then draws the boundaries between the analytic nature of natural sciences and the synthetic nature of the sciences of the artificial. ${ }^{27}$ The pejorative identification of the 'muddled' domain of architecture as not pure, and as operative, could here make way for a view to its singular qualities, shared among the domains of engineering, city planning and computer programming. In these domains, as Marot notes in relation to the work of Ungers, 'it is important not so much to have an abstract definition of conditions, but to find an operative manner of dealing with things'. ${ }^{28}$ It is in the operative (in 'knowing how') that the tacit dimension of architecture is apparent. In fact, it is the unexpected dimension raised by reality, by material phenomena, impossible to preconceive in systems, that discloses alternate, singular perceptions. This may even be where the ideas of Ungers converge with Koolhaas's predilection for the surreal: not in how the underlying desires are expressed, but in the fact that there are hidden dimensions of life that find their way into the project, either explicitly or as spiritual content. 
Fig. 4.4: O.M. Ungers, 'Similarity': Magnitogorsk (Leonidov, 1930) and chessboard
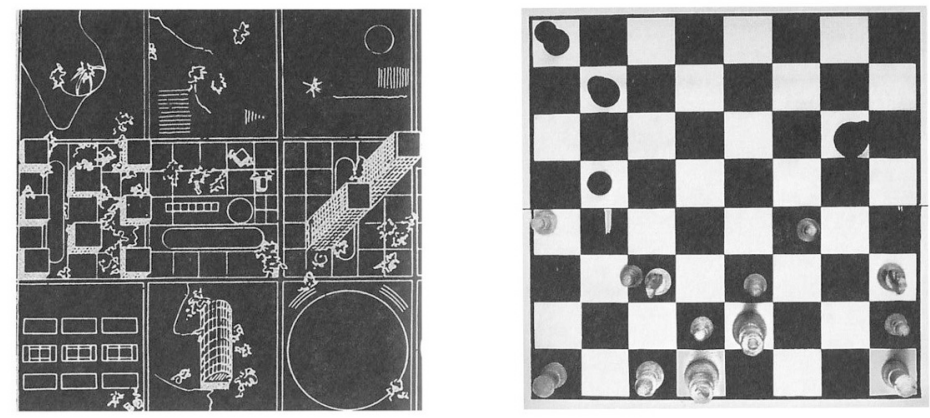

Similarity

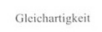

O.M. Ungers, City Metaphors

Koolhaas in fact seems to generate many of his ideas from this operative dimension, gathering his energy from the constraints on architecture. In reflecting on the Milan Triennale of 1986, he implies that the purity of abstract ideas is less interesting than built architecture: 'Because real work was rare, these occasions were invaded by mini-, sub- and quasi-architectures that, liberated from issues like clients, use, money, and technique, could become "pure". ${ }^{29}$ Criticizing the dry, irrelevant nature of this pure architecture, Koolhaas shows in his work that he is more interested in the underbelly and the rough edges. It is the underlying discomfort that he seeks out in order to feed his understanding of architecture.

For Ungers, much of the identifiable knowledge of architecture is based in pattern seeking and categorizing objects. This forms the heart of the 1976 exhibition 'Man TransForms' at the Cooper Hewitt, which was reworked for the 1982 book City Metaphors. ${ }^{30}$ The book consists of two sections, an essay and a series of images and plans that were presented in the 1976 exhibition. The central premise of the essay revolves around designing with analogies and metaphors, emphasizing the importance of formal articulation. It suggests that visual thinking and pattern seeking are the most fundamental human traits in conceptualizing the world. The analogy, the metaphor and other 
Fig. 4.5: O.M. Ungers, 'Reduction': Plan for Victoria (Buckingham, 1848) and infinity image.
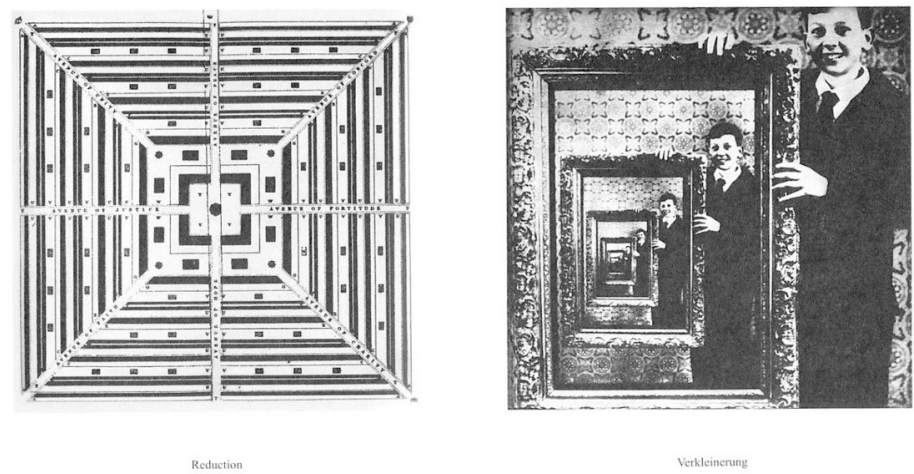

O.M. Ungers, City Metaphors

forms of (visual) structuring are the most important connection between ideas and material reality. Here, the ideas of architecture, arranged in parallel with historical developments but according to essentialist categories of architectural form, are aligned with specifically intellectual interests. Historical context, formal autonomy and intellectual inquiry: these ingredients combine to intuit an alternative epistemology of architecture, combining city plans, associative imagery and words denoting ideas. This approach acknowledges external forces and disciplines, while maintaining a firm grip on the specific expertise of the architect, which consists of composing space and building forms. His interest in a rational approach to architecture led him to categorize these objects, not only in their historical situations, but also - importantly at the time - according to their architectural elements and structures. ${ }^{31}$ Many years later, in reflecting on specific themes in architecture, he also notes that the spatial interrelations have been central to defining a number of themes. For example, on the figure of the doll-within-a-doll, Ungers writes:

It is possible to ascribe a series of spatial interrelations to architecture which may be epitomized by this concept. In the broadest sense any urban 
structure that is separated by a city wall from the surrounding countryside, is phenomenologically an object within an object. The city wall is like a shell inside which buildings and squares are arranged. These in their turn contain internal courts and spaces, that are divided up into ever smaller units. Thus the image of a doll inside a doll fits the mediaeval city from a spatial point of view. ${ }^{32}$

As such, Ungers suggests that there is 'solid' knowledge in architecture, although it may not be quantifiable in a traditional scientific manner. He shows his conviction that there are spatial relations that can be studied, that historical precedents are not mere interesting objects of study but that they hold some kind of truth within, about the way we prefer to live, to organize our cities. His early work and lectures, and his great efforts of categorization both in his teaching and in his writing, show the intuitions behind his later identification of pattern seeking as central.

\section{Knowing, Showing and Telling: Reincorporating Architecture's Tacit Dimension}

Twentieth-century architecture, particularly in the second half, is marked by an eminently intellectual approach. This includes an emphasis on discourse and ideas rather than buildings and the everyday conditions of practice. There are a few identifiable moments that mark the increasing interest in a theoretical approach. For one, as the schools of the 'minor professions' (architecture among them) became steadily more integrated in university settings, they began to seek out a legitimation of their own methods and discourses. Additionally, there have been moments (such as the late 1970s) when economic conditions slowed down the industry, leaving architects little recourse but drawing and speculation. It is during one such time that the Institute for Architecture and Urban Studies was founded in New York. Although it was initially seen as an experimental platform for exploring real-life case studies, it rapidly developed into one of the most important proponents of theoretical discourse. ${ }^{33}$ At the same time, the legitimacy and nature of research in architecture have been an integral part of the discourse for a long time. ${ }^{34}$ As Gutman convincingly argues, self-reflection and the quest for legitimacy is part and parcel of the profession. ${ }^{35}$ Many debates have played out on this topic, and it is by no means settled. However, one of the 
interesting turns in the early twenty-first-century debate that continues to hold sway, is the revaluation of craftsmanship combined with a questioning of whether scientific methods are the only avenue of exploration in some fields.

In the intellectual history of architecture, it is the ideas that are paramount, and the categories imposed on architectural production imply a cleanness and identifiable movements that are never as clear in reality. Koolhaas, with his prolific writing, has often been identified more with his written positions on architecture than with his buildings. Yet his own relation to this has at times been ambivalent. In looking back at the Milan Triennale, he notes: 'Architecture, with all its messy complexities, is notoriously resistant to explanation, hostile to revelation. Corralled together, we now had to "think" our presentations. ${ }^{36}$ The implied ending to this sentence, of course, is rather than 'make' their presentations. This distinction between thinking and making runs through the twentieth century and taps into a fundamental division often held between intellectual activity and the physical and creative activities of the craftsman, of design, or of writing - in short, any domain that produces things (or events) beyond analysis. The tangible difficulties in bridging the domains of art academies and university faculties of art and architecture are still present, but there are many experiments revolving around the need to set a new direction. ${ }^{37}$ This is founded on the acknowledgment, however intuitive, that both aspects, reflection and making, are necessary to a full understanding of the field.

Despite Koolhaas's observation on architecture being resistant to explanation, he has built much of his reputation on writing. In this, he acknowledges the need to try to explain, to explore in words ideas that are similar to those that underpin the building proposals. The development of his ideas has equally taken form in publications like Delirious New York and in buildings such as the Kunsthal. In the early years of OMA, the importance of writing far exceeded the few realized buildings, or even the competitions. The built work did not catch up until the early 1990s, with the Kunsthal arguably forming the turning point from written to built work. In fact, in the mid1990s, the public reception had been so founded on the written material, that it led OMA partner (and erstwhile tutor) Elia Zenghelis to comment: 'In the end it is a pity that in this historical process, everybody has been concentrating on Rem Koolhaas for his smartness and not for his ability as a good architect. ${ }^{38}$ Here, however, one might also interject that the texts not only explore new territories, but also offer shelter, a place where the essential 
features of the project are cloaked in speculations and fictions (as a lightning rod for criticism, even).

One might argue that Ungers was bolder in addressing the implicit values of architecture. His professional career followed the more traditional trajectory of building small commissions first (including his own house) and being recognized for these early projects. At the same time, his intellectual development also took place in written work completed in parallel to his buildings, through which he articulated his architectural position, but also analysed and explained the implicit values of architecture. His 1960 manifesto with Reinhard Gieselmann on the spiritual in architecture (apparently completed in the house on Belvederestrasse) precisely tries to negotiate this possibility of explanation despite the complexity of architecture. ${ }^{39}$

In recent years, the centrality of the visual and the associative have become increasingly important, recalling the position articulated in City Metaphors. In 2006, for example, Koolhaas makes note of the importance of 'visual language' in a brief comment on the life of buildings after realization. ${ }^{40}$ His refusal to speak of certain qualities of architecture sometimes tends to posturing - in a 1992 lecture he notes:

It's becoming increasingly difficult for me to talk about the architecture my office has built. I think that is because as we get slightly more competent, as we know more about what we're doing and as some of the ambitions that we have are becoming more or less realized, it has become impossible, or intolerable, to try to express these events in words. It is really necessary to see the buildings. Therefore I will absolutely not talk about the buildings, but I will talk about urbanism. ${ }^{41}$

This seems a somewhat strange conclusion, as it implies that urbanism lacks the ineffable qualities that buildings have. Why would one be able to talk about urbanism more accurately than about architecture? Nevertheless, the mere fact of identifying a 'need to see the buildings' is a common thread in the lectures and analyses of many thinkers today. From Bruno Latour in 2004 to Willem Jan Neutelings in 2006, to Aaron Betsky in 2008, each addresses the qualities that cannot be captured in numbers, can only be approached in words, and are manifest in buildings. The central question now is: How close can we get to articulating the knowledge between these different mediations?

Even as Koolhaas regularly proclaims the failure of words, he also seeks alternate words, alternate vocabularies, in order to achieve a more accurate depiction of buildings. His irritation at the inadequacy of words is matched 
by an interest in the power of words: recently, he faulted architects for no longer writing. ${ }^{42}$ In the meantime, Koolhaas seems to combine the activity of building with writing exceptionally well, perhaps because he treats the two activities separately. His texts are not simply explanations of the projects, nor do the projects merely illustrate the texts. His projects (like the Kunsthal) are full of architectural concerns: layering, circulation, the combination and the collision of different materials. His texts are eminently quotable, full of short and provocative statements, exploring the underlying conditions for his architecture, or sometimes veering off on tangents relating to the design process, such as cultural miscommunications during his projects in Asia. At the same time, in his own assessment, his persona as a writer is crucial because it allows him the freedom to take on different voices. As an architect, he feels more constrained to live up to expectations and to a seriousness of the discipline. ${ }^{43}$ Ungers's texts take less freedom with their subject matter, exploring questions of architecture, the city and form in direct and often didactic form. At the same time, the texts are no more explanations of his projects than those of Koolhaas are. Instead, they explore themes and ideas that are related to the discipline of architecture, from proportion and order to visual metaphors and analogies. ${ }^{44}$

The history of distinguishing between the intellectual operations of thinking and writing and the creative operations of architectural practice feeds this perceived distance between the abstract idea and its material form. This stands in contradiction to the (historical) evidence of developing typologies or formal innovation, which requires an understanding of architecture history and a positioning within it. Ungers is aware of the distinction between the immaterial ideas in drawing and writing, and their realization, when made tangible and concrete, yet he tries to bridge this gap by explaining as clearly as possible the design, from its spatial structure to its cultural implications. Koolhaas, in identifying the same problem in explaining architecture, resists didactic explanations in favour of provocative texts that reiterate or reinforce the ineffable qualities he sees in architecture.

As such, writing about and around architecture also helps to explore to what extent the tacit dimension might be approached, how much of it might be disclosed, and perhaps also to foster an understanding of the limitations of words. In our time of design blogs and retweeting a 'liked' building, this may be more than just a trivial matter. As the contemporary reception of buildings becomes more aware of the limitations of academic reflection and scientific standardization, yet also more mediated by various layers of electronic and 
visual representation, we may well need to remind ourselves to go see the architecture itself before passing final judgment. In other words, what we seem to need most right now is an acknowledgment of the explicit and the tacit dimensions of the discipline. While for credible academic study we may be more dependent on explicating principles and conventions, clarifying hypotheses and analysing hidden conditions, the domain of architecture cannot do without the tacit dimension. And while this may be resistant to classic explanation and analysis, this does not necessarily mean it cannot be shown, and thereby understood.

\section{Transmitting Knowledge in Architecture: Studios, Apprenticeship, Precedent}

The problem facing a discipline with such a strong tacit component is therefore one of credibility. While apprenticeship was a common mode of learning in the past, now a university degree is typically also required. ${ }^{45}$ We may accept the idea of learning by apprenticeship when it comes to ostensibly simple crafts such as carpentry or even the type of skill it takes to be a musician, but when it comes to a discipline like architecture, we also require the study of codified knowledge, an understanding of principles. Nevertheless, one could still argue that the central place of studio projects in most architecture curricula contains the idea of apprenticeship, albeit in a form that provides more space to experiment (for lack of clients and financial concerns).

The explicit components of architecture lend themselves to more traditional teaching - issues that have clearly identifiable constraints and parameters such as structural stability or building regulations. The activity of design as an act of synthesis of both explicit and tacit knowledge, based in the skills of drawing and spatial composition, may be partially conveyed as an abstract principle, but in essence requires doing. The role of the teacher here becomes a matter of coaching the self-taught skills found through practice and reiteration. ${ }^{46}$ Indeed, there are those who suggest that 'teaching' architecture is at best an oxymoron. 'The best an architecture school can accomplish is to foster its students as autodidacts. This requires the encouragement to work autonomously towards foundations, to exert critical skepticism, to research intensely, and formulate their own hypotheses and work towards syntheses. ${ }^{47}$ Nevertheless, there are contributing forms 
of knowledge that help develop design-oriented skills. Studying historical precedent is a common form of design teaching in which the qualitative analysis of design is central. Describing the specific qualities of the historical precedent thus does not offer a design guide, but does offer identifiable design themes that are evaluated. These historical precedents become part of the body of knowledge of architecture, which architects then transform to address new and unforeseen problems.

Ungers experimented with various teaching modes, such as the thesis studios on Berlin, the Wochenaufgaben as introduction to design tools, and the lecture series to share his knowledge of historical precedent. In recent years, three particular models of the teaching of Ungers have been published in abbreviated form. The winter lectures of 1964-1965 show his approach to the Gebäudelehre, bringing order to architecture history through a categorization of projects, forms and compositions. All historical examples are categorized in a way that trains inductive reasoning, deriving general rules from specific examples. Not only does this offer a spectrum of historical precedent, but it is built on the supposition that there is a knowledge to be culled from the building itself. The Wochenaufgaben are coherent brief design exercises directed at training design skills, while in the process developing the tacit knowledge founded in particular aspects of architecture: function, composition or material, to name a few. They require the students to propose specific solutions based on general constraints and conditions. Each particular study addresses one type of problem (materialization, composition, volume). By retaining the same programme throughout the course (a house, with the same components and spaces), the Wochenaufgaben as a whole embodies the understanding of variation within a limited set of parameters. Precisely because the attention is limited to a smaller number of (practical) issues, the care with which the assignment is articulated is stronger. Exercising just one design component or skill each week thus develops design as an idea-driven activity rather than a list of conditions to fulfil. In this sense, the work shares quite a bit with the design exercises of John Hejduk (both at Cooper Union and in the Texas Rangers period). The external narrative that often accompanies larger design projects is here superseded by constrictions and specificity. In contrast, the summer academies (such as the Urban Villa, the Urban Garden, and the 1976 academy on the Urban Block, in Ithaca) are more akin to the final-year laboratories Ungers led while at the TU Berlin, in which specific problems are confronted from different perspectives by a group of students. 
In all of the studios, the practice of looking, analysing, drawing and designing are prominent components.

Fig. 4.6: O.M. Ungers, Wochenaufgaben 1966, topics week 1 (form) and 3 (theme)

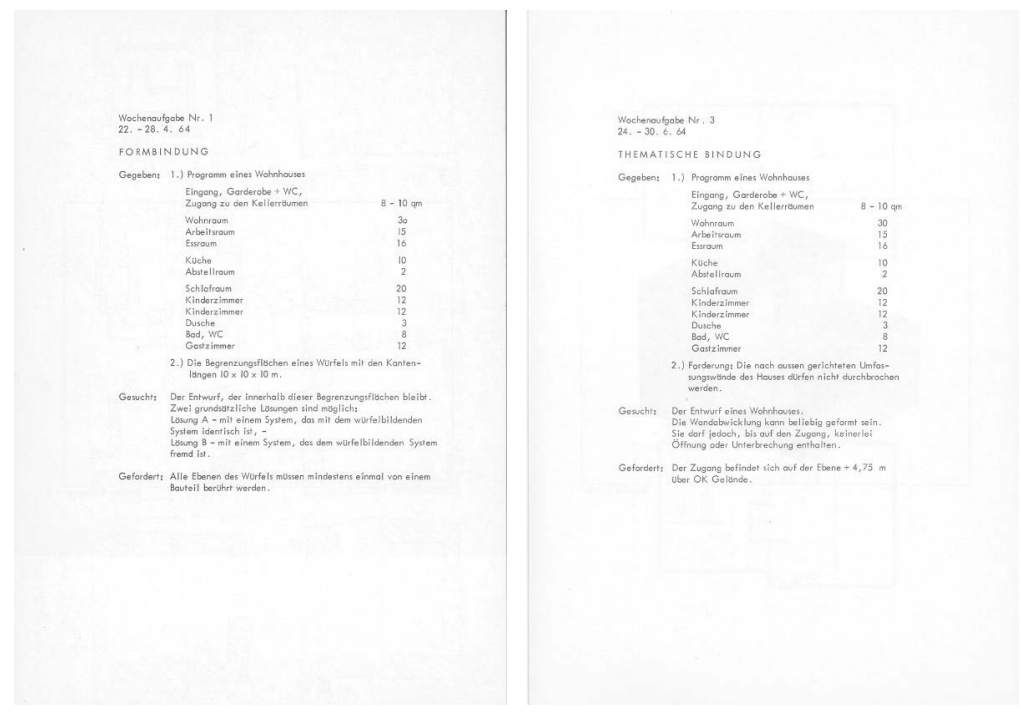

Veröffentlichungen zur Architektur 1

Koolhaas has also published the results of his teaching at Harvard, which were often aimed at analysing in a 'designerly' manner the conditions to be found (on shopping, or in Lagos, for example). While these studios are not directed at the development of design skills as the Wochenaufgaben are, they are organized around an implicit mode of examination, analysis and synthesis. In a sense, many of the studios replicate the structure of Delirious New York, in which Koolhaas took the existing condition of Manhattan to unravel various (sometimes speculative) storylines that contributed to the existence of Manhattan. Koolhaas's studios are focused more on information gathering. This approach is based on inductive reasoning - seeking out the logic, the patterns, from a vast spectrum of material, not from a preconceived notion of architectural principles. It makes use of both speculations by projecting possible scenarios, and systematic categorization in organizing the material found. In addition, analogies are drawn between architecture and everyday ideas in order to explain phenomena by association rather than 
explanation. The use of literary principles and narratives thus help sensitize the student (or in practice, the client) to more specific architectural issues.

The distinction between the approaches forms perhaps the most striking difference: the explicit considerations on the discourse by Ungers stand in contrast to the oblique explorations of ideas in the work of Koolhaas. In this, Koolhaas seems to be a product of his time, refusing to speak of what cannot be discussed. The work itself shows the carefully considered steps in the design process, turning over the work and reassessing it, taking nothing for granted, exploring the physical material of it as well as the sociocultural conditions and constraints. Yet there is a refusal to engage with a direct vocabulary on the work beyond description, while at the same time his oeuvre is a quest for new definitions, for words not yet tainted by obsolete theories. Is this indeed the personal preference for a paranoid critical method, or is it rather a response to a state of discourse in which value and quality have somehow been relegated to personal preference? Either way, the era of 'truthiness' and 'alternative facts' seem to have blurred the line between expert evaluation and subjective opinion. Reconstituting a plausible relation between architecture and its social context - something that finds a middle ground between knowledge and expertise on the one hand, and the acknowledgement of diverse values and perspectives on the other - has become a key challenge today.

For both Koolhaas and Ungers, teaching studios becomes a valuable tool in producing research and exploring the very status of knowledge within architecture. ${ }^{48}$ The 'laboratories' of Ungers (as Koolhaas later dubbed the thesis studios on conditions of Berlin) seem more constrained, more focused on the discipline-based tools and instruments such as historical precedent and design experimentation. The Harvard studios draw on many different examples, not only the design-based seminars of Ungers, but also the many perspectives of analysis used by Venturi and Scott Brown in the Las Vegas and Levittown studios. ${ }^{49}$ As such, the teaching of Koolhaas is extended further outward, gathering as much material as possible in order to synthesize later. Ungers addresses the relation between clearly identifiable explicit domains of architectural research, and the tacit components involving practice more directly as a topic of inquiry. In contrast, Koolhaas leaves the epistemic states of architecture aside, instead provoking self-education, breaking rules as much as teaching them. Although Koolhaas 'gathers' more information from distinct domains, he shares a tendency towards structuring, towards bringing order to the information collected. 
Additionally, for Koolhaas, the office is perhaps as much a knowledge exchange as his teaching is. Within the halls of academia, he may be able to explore more personal interests than within the constraints of client demands, but the office seems to work very much as a high-pressure research studio. While Ungers separated his practice from his teaching more - perhaps as much by necessity of time constraints and the move from Germany to the United States as by intention - Koolhaas operates in many distinct spheres simultaneously. This is facilitated by his drive to collaborate and to enter into new networks of people. Some of the differences between the office structures of Ungers and Koolhaas are striking, most notably the compactness of the Ungers office and its hierarchy. ${ }^{50}$ It was a more or less traditional small office structure, with work and intellectual discussion, learning and doing intertwined. OMA has a more flattened office structure, and at times used internal competition as a way to encourage new ideas. ${ }^{51}$ This structure facilitates autonomy for the project directors, where Koolhaas takes on the role of 'editor' within a large group of people who are working diversely on a number of projects. ${ }^{52}$ In this sense, the structure of OMA recalls the way Warhol organized the Factory, and raises similar ambiguities: on the one hand, authorship is seen as less important than the work itself, while on the other, the role of the 'editor' becomes crucial - the group seems to exist by the grace of the intellectual leadership of its founder.

For Ungers, theory plays a key role in understanding architecture, and the years in Berlin allowed him to explore various ideas. In 1967 he organized a conference on architecture theory in Berlin that eventually led to his position at Cornell..$^{53}$ At this conference, there were contributions by Colin Rowe, Julius Posener and Kenneth Frampton, among others. Many of them still fell to either side of the division between practice and theory, while Ungers's own contribution focused on the knowledge that was situated between practice and theory. In general, his approach is more focused on explication and he works through successive definitions and arguments thoroughly. In contrast to the enigmatic statements of Koolhaas, these arguments are didactically structured, sometimes to the point that they lose some of their poetic potential. In this manner, Ungers departs more from the position of classical education in terms of Bildung, while Koolhaas follows a more empirical approach, fed by the observation of various social and visual phenomena. This informs Delirious New York as well in its attempt to avoid any traditional architectural terms, aiming to redefine how we speak and think about architecture. ${ }^{54}$ Ungers instead focuses more on clarifying architectural form, 
using precedent and systematic categories to do so. ${ }^{55}$ The contribution of Ungers in design approaches thus resides in the explication of the knowledge of architecture, sifting through various projects and synthesizing them

Fig. 4.7: O.M. Ungers, patterns and morphological studies: square, circle, and triangle in multiple variations

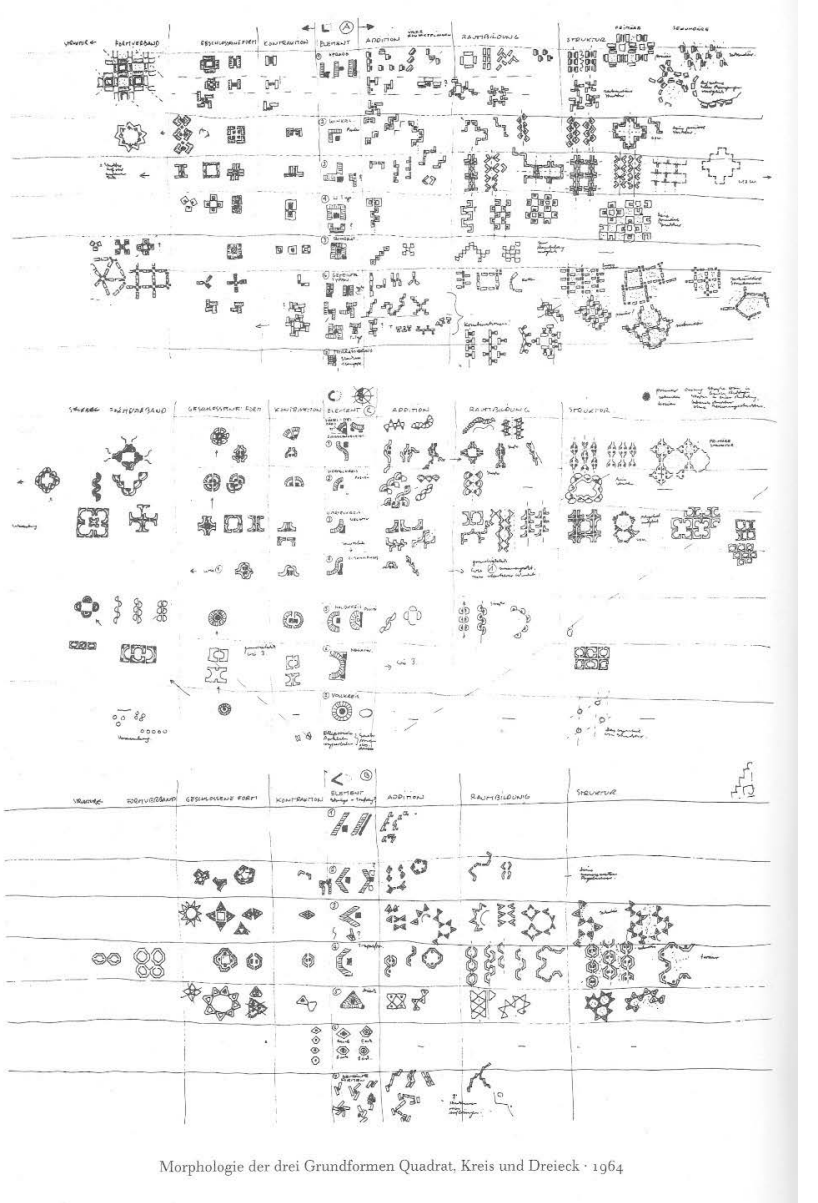

O.M. Ungers, Sieben Variationen 
into logical families as an encyclopaedic quest in architecture, reminiscent of Viollet-le-Duc's nineteenth-century Dictionnaire Raisonnée. The texts of Koolhaas are different, not explanatory but provocative and suggestive, making use of other vocabularies than those of canonized architecture. Yet he has also contributed to the formal language of architecture with architectural elements, such as the slanted columns in the Kunsthal and the floor that curls into wall and ceiling in the Educatorium, identified in Content as 'copyrights' of OMA's innovations, which derive from their constantly generating models and prototypes. ${ }^{56}$

A further notable distinction between Ungers and Koolhaas lies in their sources. Where Ungers turns to traditional, weighty, disciplinary sources, Koolhaas often makes use of the not-yet-incorporated, the alternative. Where Ungers makes use of Renaissance treatises on architecture, Koolhaas refers to postcards and Japanese pornography. ${ }^{57}$ Unsurprisingly, Ungers comments in an interview on his library as a space of 'dignified knowledge. ${ }^{58}$ While Ungers is acutely aware of the material realities of architecture, he sets his sights on humanist tradition, emphasizing the rational and the spiritual. The endorsement of the civil society, even with the visually humorous interventions of City Metaphors, remains a primary characteristic of the writings and projects of Ungers. In contrast, Koolhaas operates more on the principles of Pop, opening up the visual language of architecture by using references from various sources, preferably with multiple associations. ${ }^{59}$ In addition, there is a marked presence of the sensual in the work of Koolhaas, perhaps as a counterpoint to the coolly intellectual approach of architecture discourse. As such, he makes use of the new style of drawing by Madelon Vriesendorp, which plays off the raw aspects of the symbolic, the Freudian 'underbelly of modernism', proposing entirely fictional constructions of alternate worlds. ${ }^{60}$

This navigation of both the abstract, intellectual properties of architecture, and the subtle presence of a tangible sensuality mark the instinctive ambivalence of Koolhaas. He has an appreciation of both the primitive and the modern, the temporal and the timeless. Ungers's teaching is directed at reducing the tacit dimension of architecture, by explaining and rationally approaching as much as possible. The Wochenaufgaben is exemplary of this approach - by limiting the space for invention, the contributing skills of design are thoroughly trained. Only later in the course of education is the synthesis of a larger design project required. Koolhaas's teaching is based more in a mode of speculation that embodies the tacit dimension. The 
suggestive nature of the writings and studio results triggers personalized associations.

\section{Tactical Manoeuvres: Exercising Material Ideas}

Koolhaas and Ungers's oeuvres, particularly in the late 1970s, seem to be oriented towards a reconstruction of an architectural vocabulary. This is immediately evident in the work of Ungers, who explicitly uses historical forms and types in order to construct a legible series of architectural gestures. The 1970s projects such as Roosevelt Island (1975) and Berlin Lichterfelde (1974), but also the summer academies (Urban Garden, Urban Villa, City within the City) identify essential features of historical types in each area. They then use these essential features to construct series of new buildings, each a modulation of the essential type. As such, these projects offer us a history-based series of potential transformations. This didactic and explanatory approach is not in evidence in the work of Koolhaas. Nevertheless, there is a similar attention for the existing vocabulary of building types and their derivations, though Koolhaas gravitates more towards the language of modern architecture. Making use of a more intuitive series of resemblances, or at times even an idiosyncratic selection, the most essential features are isolated and magnified, as a material document of ideas.

In order to reconstruct (or in the case of Koolhaas, reinvent) an architectural vocabulary, Ungers turns back to history for continuity and universal underpinnings of architecture. Koolhaas instead expands out to engulf the world within his logic, or the logic of design. The teaching studios and the office are both organized along this principle of expansion, lending credibility to Yaneva's comment that 'OMA and Koolhaas treat the studio as the world, a world that is to be re-enacted in practice, a world that is to be reinvented by design'. ${ }^{61}$ Instead, Ungers sees particular themes as giving voice to the spiritual content of architecture. ${ }^{62}$ Despite the individuation of the contemporary, these themes appeal to general ideas, to cultural resonance. In the projects and writings, a number of themes and approaches together construct a position on architecture and its epistemological concerns, such as 'order', 'analogies' and the 'oxymoron'.

This section briefly recapitulates a number of these operational ideas in order to illustrate where these notions take shape and how they construct a plausibility between building and idea. 


\section{Collecting}

The very notion of the collection allows for idiosyncrasies, while also suggesting the mass culture of modernity, premised on serialization and industrial production. Collections, as a general condition, or as an architectural project, justify themselves by virtue of their mass. In the work of Ungers and Koolhaas, whether it concerns multiple iterations of the urban dwelling (Ungers's Roosevelt Island, 1975), or the many possible shapes for an alternative skyscraper (OMA's CCTV project, 2012) there is a pattern seeking that becomes manifest in the collections. It shows a manner of bringing order by categorizing, that speaks to how architecture is to approach the endless potential of gestures without predefined rules.

Das Sammeln als 'Ausdruck einer Auswahl, die immer auf Reduktion abzielt' (Wilfried Kühn) is eine geistige Haltung, die sich im Konkreten erfüllt. So präzis die Kriterien der Reduktion in Ungers's Architektur und Theorie auch sind, so scheint durch die materielle Akkumulation der Bücher, Modelle und Kunstwerke in seiner Sammlung dann eben doch auch das Prinzip der Vielheit, der Mannigfaltigkeit deutlich hindurch. ${ }^{63}$

As a whole, the collection shows a multiplicity and plurality, while its individual components emphasize individuality, subjectivity and the occasional detour. The ambiguity of Ungers's quest for purity and the embrace of multiple possibilities is visible in the library and the collections in the house.

\section{Coincidentia Oppositorum and the Oxymoron}

Contradictions run throughout the work of both Ungers and Koolhaas, which may simply be a particular feature of the twentieth century; Robert Venturi, after all, elevated contradiction to an essential feature of architecture. ${ }^{64}$ Certainly throughout the 1970s, a wealth of writings address issues of contradiction, opposition and the impossibility of reducing vitality to rules. ${ }^{65}$

Both Koolhaas and Ungers have their own specific concept to instrumentalize these contradictions. For Koolhaas, it is the oxymoron, while for Ungers it is the Coincidentia Oppositorum. Ungers borrows this notion from medieval philosopher Nicholas of Cusa, to identify a 'coincidence of antitheses and not their overcoming', where 'these contradictions do not shut themselves up in their antithetical nature, but are integrated into an all-inclusive image'. This is at the heart of the theme of fragmentation and its architectural counterpart, 
assemblage. To Ungers, this allows a new vision for architecture, one that releases itself from the obligation of unity. 'A new dimension of thought is opened up if the world is experienced in all its contradictions, that is in all its multiplicity and variety, if it is not forced into the concept of homogeneity that shapes everything to itself. ${ }^{66}$ While many of his colleagues were still seeking to draw out the possibility of architectural unity, this concept gave him a way to conceptualize plurality and use it in a formal sense. This does not deny a resonance or shared sensibility, but repositions it within the collective rather than the individual: 'Only collectivized thought can aspire to unity: the free, individual spirit seeks contradictions, antitheses, heterogeneity.' This all to address the problem that architecture and the city are typically judged by how well they form a unified whole - while to Ungers it may be worthwhile if 'the unresolved contradiction, was placed at the centre of the conception and of the plan and hence of architectural studies?', yet he follows this directly with the question: 'Is it possible - or even necessary to produce artificially, and therefore consciously, the contradiction that is usually determined by chance?' 67 Ungers clarifies that the idea of unity within the city is a myth - the growth process of a city is discontinuous, and therefore it is fragmented and contradictory. Here also the early formulation: 'Different epochs have left their traces on the city are different times. Theses are followed by antitheses, so that the city turns out to be a dialectical structure as far as its essence and image are concerned. ${ }^{68}$ Similarly, the oxymoron, as any combination of contradictory words, allows a simultaneous presence of incongruous realities. Koolhaas introduces the oxymoron as a way to address the inconsistencies he encounters in - and sees as integral to - what would later be called 'Manhattanism'. As F. Scott Fitzgerald notes: 'The test of a firstrate intelligence is the ability to hold two opposed ideas in the mind at the same time, and still retain the ability to function. ${ }^{69}$

\section{Lobotomy}

This notion is highly suggestive, one way that Koolhaas uses a non-architectural vocabulary to describe an architectural condition that immediately gives rise to associations in the mind of the reader. The descriptive quality of the words thus becomes more important than their historical use for architecture. The lobotomy describes the separation between the inside and outside of buildings - severing a connection that was formerly considered necessary. In direct contradiction to the modern imperative of honesty in 
the façade, the lobotomy describes the liberation of not knowing what is going on inside. It frees architecture from the need to represent internal functions, and it frees it from the constriction of authenticity - of being true to the programmatic infill. As a non-architectural concept, the notion of the lobotomy is suggestive in a directly physical sense, offering an analogy for what may be apprehended in the building. In Delirious New York, the goal was to use a non-architectural vocabulary, yet these words have made their mark on the architecture discourse, simply by their evocation of a condition. The psychological undertones of the lobotomy and the vertical schism reinforce the surreal images of buildings as living entities produced by Vriesendorp and Zoe Zenghelis. The Freudian connotations, intentional or not, have become part of the vocabulary of architecture. ${ }^{70}$

\section{Order}

The idea of a 'mental order' is crucial to Ungers - it is not only present in his texts as an explicit touchstone for architectural design, but it runs through his built work. In the house on the Kämpchensweg, this is translated into a mathematical ordering system, but the library on the Quadratherstrasse also creates a tangible form of order. ${ }^{71}$ It is founded on the systematic dimensions of human thought, presupposing the ability to categorize and arrange according to similarities.

The very notion of order has its architectural expressions in symmetry, grids, proportion and hierarchy, but it is also a theme unto itself, as exemplified in City Metaphors. In this essay, analogies and metaphors are not only human tools with which to understand the world, but also to transform it. This manner of conceptualizing illustrates the 'pattern-seeking' nature of people. As such, order exemplifies a way of thinking about architecture that bridges individual perception and the general human condition. Based on Gestalt theories on the apprehension of the whole and individual composing elements, it is strikingly resonant with contemporary insights on human thought (in particular the dominance of associative leaps and pattern recognition, as distinct from computer processing), and the literature on design thinking as an activity of synthesis based on apprehension of similarities.

These different themes and approaches do not so much explicate how architecture works, as that they give a presence to its tacit dimensions, formulating it by example and analogy. The loss of an architectural language is not to be remedied by semiology, but by understanding historical precedent 
and by delving into the tacit knowledge of architecture. This exercise may take place within the intellectual discourse of architecture, seeking out ideas such as 'order' and 'collection', or it may equally be the excavation of a symbolic value underpinning the places and objects of everyday life, as found in Delirious New York.

These explorations are about reconstituting a vocabulary for architecture that does justice to both its material and intellectual dimensions. Memory plays a central role, as does variation. These ideas are markers for the issues facing architecture in the 1970 in its rethinking of modernist architecture's legacy. Ungers notes, for example: 'Memory as a bearer of cultural and historical values has been consciously denied and ignored by the Neue Bauen. The anonymity of the functionally correct organization of the environment has asserted itself over collective memory. ${ }^{, 72}$ Moreover, he uses the modern Siedlung as an example of how all differentiation and distinction has been replaced with homogenous building, 'the monotony of built boredom'. ${ }^{73} \mathrm{He}$ attributes the loss of an architectural language and meaning to this enforced uniformity, since its placelessness and universality makes it no more than an 'empty gesture'.

\section{Architecture: Individual Experience and the Collective Dimension of Culture}

While the sources and results of Koolhaas and Ungers may be different, they share an underlying approach that intimates a similar structure of thinking. Ungers uses a limited range of sources in order to construct a general conceptual system. Koolhaas uses general references and associations, but brings them into architecture. In this sense, the rise of AMO as compliment to the work of OMA is significant. While AMO notes that it was founded to generate ideas outside the typical field of building, it may equally be seen as a manner of organizing or legitimizing the disparate topics of research in OMA. AMO expands the expertise of the architect to other issues. It utilizes the synthetic nature of design thinking in order to generate unexpected scenarios. ${ }^{74}$

As such, architecture is placed at the interface between the individual and the collective - where the architect is positioned as an individual, but also the experience of the architectural object mediates between individual experience and a larger domain of cultural sensibility. It is the negotiation of 
this individual moment and the traditions and rules that construct a collective experience that delineates the work of the architect.

The architect operates in much the same way, drawing on his or her own limited experience of perception, appropriation, recollection. But at the same time he refers to the history and traditions of the discipline, formulating models, which he then transforms and modifies. In this way he contributes to the environment that conditions us, to the barrage of ciphers and symbols of what we call 'history'. This is not a question of imitation, for 'that would mean', according to Ungers, 'that one consider[ed] history not as an existential problem but as a series of episodes. ${ }^{75}$

The salient feature of thinking in architecture is, in other words, inductive: proceeding from the specific, individual and contingent to attain general insight and propose broadly coherent models.

The material expression of ideas is key to articulating the project. While Ungers follows the traditional role of the Renaissance architect, with 'sound ideals, lofty judgment, vast knowledge' (as Leon Battista Alberti would have it), Koolhaas is more aligned with the postmodern intellectual, shifting between different modes of thinking. Both appeal to a highly disciplinary approach to architecture, but while Ungers draws his way through architecture and writes his way through concepts, Koolhaas fluctuates more. Sometimes the conceptual frame for a project is delineated in a simple written note, as in the clear instructions to use the best materials where crucial and the cheapest wherever necessary for the Patio Houses in Rotterdam, making budget constraints form a conceptual directive for material expression. At other times a simple sketch may suggest the fundamental idea behind a project, as in the Tiergarten sketch, in which the six towers are each articulated so distinctly that the basic premise of individual expression of the parts is unmistakable. Ungers more clearly maintains a connection between approach and intent. To determine the place of the staircase in the Quadratherstrasse library, Ungers draws every possible position in plan, and when it seems promising, in section and perspective as well. No notes accompany the drawings beyond the precise dimensions of the grid and the staircase.

In the work of Koolhaas, the role of architecture is grounded in a diffuse society. The 'elegance, lightness and virtuosity of his buildings' emphasizes a positive role for architecture: 
The intimidating severity of his dogmatic side not only does not exclude the provocative, playful and truly extraordinary nature of his architecture, it is actually bound up with it. Both stem from an attitude and poetics without illusions (but without any distress), adapted to societies whose horizons have collapsed, which are drifting uncontrollably in time and whose very geographical foundations have become unstable. In these societies, new reasons to act must be formulated - among them, pleasure, inquiry, mental speculation and artistic experience. ${ }^{76}$

Its role is set as continually 'other': not as guideline but as pinpricks, unsettling convention. The many faces of the work, from severe to playful, nourish the ambivalent reception, often swinging between acclaim and denunciation. Meanwhile, the figure of Koolhaas remains at the centre of these claims - more than the office, the collaborators, the students.

The persona of the architect now increasingly clouds the question of the role of architecture. There is a complaint - reiterated by so many these days that we are currently unable to clarify what the expertise of an architect encompasses. While this may be true in a general sense, the historical reflection that shows architecture to have once laid claim to an authority it no longer has is also coloured by the legacy of what has remained standing over time. If one carefully rereads Vitruvius or Alberti, there are equally strong admonitions to architects to hold high their reputations (as not all do). Ruskin equally chides his contemporaries for falseness of material, trying to maintain the standards of architecture, yet implying that they are not (yet). Public opinion and its relation to that of the expert is equally at play in various manifestoes. It is quite possible that this general logic has been exacerbated through the cultural impetus of legislation and regulations (in professional ethics), and by the stronger need for a public persona - often coinciding with a 'branding' or the mythology of the 'starchitect' - yet this does not mean that architects once had the ability to prove themselves valuable and have now lost it. There is a stubborn continuity of the myth of the architect - the Roarkian figure who knows best, or can see beyond the immediate to what is yet to come. This myth of the visionary has enabled a mystique that at times can contribute to getting ideas built, but it also entails a backlash of seeing the architect as a volatile and intuitive trendsetter. This has been exacerbated by the current fixation on celebrity, reinforcing the centrality of the architect as persona to the detriment of a discussion of urban conditions, realized buildings or architectural representations. Refocusing on the architectural 
object rather than its maker may contribute to a more distanced evaluation of architecture in society.

\section{The Knowledge of Design Thinking, Contingent and Transformative}

In the 1960s, the interest in explicating architecture knowledge focused on design methodology and the identifiable decision-making steps. ${ }^{77}$ This remained inadequate to describe and guide the range of choices that are in essence normative decisions (particularly the domains of ethics and aesthetics). This currently remains one of the strongest arguments against computerized design methods. Even if we can accept the idea of parameters generating a neutral design model, the orientation on design process merely sets parameters within which choices must still be made. Denise Scott Brown already noted this problem in 1975: design methodology does not solve the design problem. ${ }^{78}$

The profession is in part a matter of (explicit) knowledge - some solutions are more adequate than others, especially when it concerns clearly delimited issues such as traffic flow, structure or durable finishing. Yet because most of the issues are some version of wicked problems - which are typically poorly defined, insoluble and non-optimizable, within the realm of the adequate there are still choices to be made, based on values, on moral viewpoints or on aesthetic preferences. These are not 'knowledge' as such, but they contain a component of normative decision making. The issue of parameters being set is important, however, as they constrain the spectrum of possible solutions and this is in some sense the role of vocabulary: that a series of instruments and descriptions are shared, limiting the otherwise infinite possibilities.

Delirious New York shows a narrative that is attuned to the stories within objects. These stories are a notable combination of the clinical writing from the journalist days of Koolhaas at de Haagse Post, and the speculative narratives that Barthes discusses in his mythologies. ${ }^{79}$ It combines a matterof-fact descriptive style with an almost archaeological approach that uncovers the suggestive dimensions of these objects. As such, this approach hovers between the linguistic approach that accommodates rationalism, and a visual approach that accommodates the associative. Neither is sufficient in itself: the linguistic/semiotic is not sufficient to understand the implicit components of architecture knowledge, yet the 'purely' visual is equally inadequate. The 'spatial' offers a further correction, inasmuch as it requires 
a multidimensional approach. However, the tools for showing the spatial are still limited - it requires a projection of the plans, drawings and models that intimate a future built reality. Envisioning the consequences of a scenario that is yet to be realized is part of what constructs architectural expertise.

Koolhaas also makes note of the current absence of the semiotic:

As a student, I was soaked in the language of semiotics - later on, Deleuze effectively ended that. This is hardly ever mentioned any more in architectural discourse, but, to me, it is actually crucial, and, as an absent force, increasingly important. ${ }^{80}$

The domains of architecture knowledge are constructed out of these separate domains, yet the crucial component of an architectural expertise is founded on the ability to synthesize these different areas into a coherent project. The linguistic, the visual, the spatial and all the contributing facets of technical knowledge, awareness of regulations, sensitivity to contextual concerns. As contributing components, each can be analysed, (partially) explicated and approached as a body of knowledge. ${ }^{81}$ As a whole, design thinking is then founded on explicit domains of knowledge and the tacit dimension of contingency and synthesis.

Formal considerations play a crucial role in the definition and articulation of ideas in architecture. Yet according to Ungers it is precisely the ability to formally articulate these ideas that modernist architecture removed from the vocabulary of architecture:

While the theorists of late historicism argued over fundamental concepts of architectural form, the modernists who followed them (with their reformist mania) in the end even sidetracked the last formal elements and replaced architectural notions with the concepts of engineers. With the instruments of constructive thinking, with the principles of utility and functionalist logic, the primacy of the architectural concepts of body and space lost its strength. Both the building as a symbolic form and space as an experiential envelope disappeared from the architect's vocabulary. ${ }^{82}$

Is this indeed a question of knowledge? Is the body of knowledge in architecture to be derived from, or distilled out of, the objects of study? In other words, does the vocabulary as such contain the knowledge of architecture? The question revolves, again, around what constitutes the expertise of architecture - what is it that the architect knows, or can do, 
that others cannot? For Koolhaas, the erosion of competence is equally clear, though he attributes this to a different cause than modernist architecture:

Displayed to the public like the fat lady in a freak show, architecture's 'discovery' - by the media, developers, museums - became a Faustian gambit in reverse: a drastic erosion of its competences, a progressive dismantling of its ambitions; the only 'heroism' allowed was that of the tragic white clown injecting a tear of emotion. ${ }^{83}$

In light of the discomfort voiced here, it is ironic that Koolhaas has not only benefited from architecture's discovery by the media, developers and museums, but also contributed to it. Particularly in terms of the media, not only Delirious New York made a splash, but also SMLXL, an experiment precisely in the conditions of publishing and media. He has proven to be exceptionally adept at manoeuvring through the various media within which he has positioned his architecture.

For Ungers, the best direction forward is relatively clear: it is about the Gestaltung of architecture, or the knowledge and ideas that are materially embodied in form. City Metaphors in particular addresses this Gestaltung, both as an approach and as a topic of study. The book begins with an essay on the role of metaphors in our thinking, and the strongly visual element in our thinking. The essay is followed by a series of composite images, consisting of a city plan, a referential image and a concept articulated by a single word, exploiting the gaps between intellectual comprehension and visual correlation. While the images suggest a naturalized connection between the idea and its formal articulation, they are not necessarily more than correlative. As such, they would be difficult to transfer to contemporary design principles such as those of parametric design, which exploit structural rather than visual similarities. Koolhaas does not go into issues of Gestaltung as such, but he does suggest the importance of 'slippage' between media, when he speaks of representation: 'Representing the building (Seattle and Universal, for example) in seemingly incompatible ways. The images do not tell the same story and hopefully the same would be true for the building. ${ }^{84}$ In this, he similarly utilizes the gaps between different media and forms of expression. Overall, these seemingly incompatible perspectives knit together a larger narrative of the tacit knowledge embedded in cultural forms. Of course, these multiple narratives do take on different guises between the two: where Koolhaas builds more on multiple media, Ungers more directly addresses the individual articulation and reception of collectively shared ideas. 
The publications of Ungers on his teaching show his attention to the knowledge that is specific to architectural design in its various articulations - taken as a whole, they show an approach to design thinking. The Wochenaufgaben taught in 1966-1967 articulate a number of specific design areas that Ungers sees as crucial: the functional arrangement of spaces, the materialization of the building, and spatial or volumetric delineation, to name a few. As preliminary design exercises, they train specific aspects of design that will later contribute to the composite expertise of the architect. The City within the City makes use of figure-ground schemes of urban areas, followed by visual analogy. It also contains the gathering of photographic reference material to illustrate a local building typology. These elements combine with the quantifiable data of Berlin's shrinking population and predetermined surface area to sketch out the scenario of the archipelago city.

Overall, the work of Ungers and Koolhaas stands against the dissipation of a shared vocabulary, and against the focus on explicating only design decision steps rather than design principles. In different ways, they both seek a manner of communicating the implicit knowledge of architecture. With Koolhaas, this is more in the realm of suggestive narrative coupled with multiple models of architectural schemes, while Ungers is oriented more on the rational underpinnings of design, particularly as trained through longterm practice (both in the studio and in the office). It is particularly this tacit dimension that also does justice to the contingency of knowledge, with its dependence on cultural and social context that allows for subtle but farreaching transformations.

\section{Reconstructing a Vocabulary for Architecture}

If architecture as a discipline indeed contains a tacit dimension (which may be explicated at some point - by increasing insight, and developments in science, from cognitive research on design decisions to research on reception and understanding, as well as increasing the understanding of the epistemic status of images and the spatial), how does one treat this domain? First, accepting that there is a tacit component is not a release from the responsibility to clarify and make explicit what we do know. In this sense, the statements of architects need to be approached with some suspicion - as there is a distinction between what we do (and our motivations) and what we say or think we do. In other words, even if the post-facto legitimation of 
the architect is an honest statement on the design motivations, this does not necessarily disclose the actual design motivations. The explicit dimension of intellectual analysis is important in contributing to the traditional scientific dimension of architecture.

Reconstructing a vocabulary for architecture in a sense sits between these activities. On the one hand, the range of potential forms, types, approaches and materials appeals to explicit and identifiable qualities. Yet it is also dependent on an interpretation, based on seeing the family resemblance between different things. ${ }^{85}$ Ungers's belief in the value of a rational approach is present throughout the clear explorations of form, brought into a larger taxonomy that shows many options and identifies them all as it were within families and categories. These families may have unusual mutations, some of which will remain eccentricities and disappear, while others will influence a new subset or continue to evolve into new lines of descent. ${ }^{86}$ The inductive reasoning needed to reveal the patterns within these associative clusters may potentially contribute to the construction of a tacit knowledge base.

The very notion of reconstructing an architectural vocabulary goes against the grain of increasing individualization and of total contingency. As such, it moves beyond the postmodern tendency towards relativity, in order to seek out connections and similarities - it builds on a shared vocabulary rather than deconstructing it. The bridge between the individual and the collective resides in this plausible relation between the formal and the social. Its plausibility indicates that it is a shared sensibility but not universal. It holds no truth claims, but it does offer a suggestive narrative. It may make it conceivable to construct an epistemology that is both particularist and contingent, but that also partakes in the collective. Might this be the key to the tacit dimension? A shared sensibility that is not explicable, yet does withstand scrutiny?

The renewed sense of urgency in practice - what, if any, might be the added value of architecture - is related to the economic crisis, but also to a twentieth-century history of focusing on the new, to the detriment of continuity, consensus and the collective. In addressing this problem, Ungers follows the more traditional role of the intellectual architect who uses his understanding of history and a broad palette of references in order to excavate the meaning of architecture in its buildings, manifestoes, drawings and handbooks. In contrast, Koolhaas tends more towards the 'Homme de Lettres' that Le Corbusier fashioned himself. ${ }^{87}$ Each work and concept (Delirious New York, Bigness, Generic City) questions and refashions existing architectural principles, bringing together a range of societal conditions 
and architecture histories into a narrative of transformation, in which the architect is positioned as uniquely suited to the task.

Both architects hold to a specificity of architecture knowledge. This is immediately clear in the work of Ungers, whose projects give tangible presence to abstract and ideal concepts, almost as an admonition not to get lost in the mundane. All of this is presented through a weighty history of architectural exemplars, of ideal types, and a didactic approach that make it difficult to escape the lessons presented. The work of Koolhaas is less explicit about its architectural focus, yet historical precedent and contextual information directs the development of design ideas, constructing a durable spatial condition out of these contingencies. The specificity of the architect's knowledge does not preclude a shared or general relevance, however. Ungers typically formulates this in relation to a 'human condition', speaking of general underlying structures in thought and perception that guide human behaviour. Koolhaas typically relates it to specific spatial issues derived from observation, whether that concerns the various types of global cities, or the effects of widespread historical preservation in Cronocaos.

Moving forward in the field requires a shared vocabulary. It is this vocabulary that was deconstructed by the moderns and the avant-garde, and it is this vocabulary that Ungers and Koolhaas, each in their own way, attempts to reconstruct. While Ungers draws more on the classical approach to architecture, with a more clear-cut series of ordering principles, Koolhaas draws more on an approach that is near universal. It refuses hierarchical distinction and tries to look at everything as if it were entirely new. Both, however, try to articulate positions, ideas and approaches as a manner of reclaiming validity not only for the practice of architecture, but also for design thinking as an approach to complex problems.

And perhaps in all that, the treatises and manifestoes play a role again. Not as a blueprint for a future city, but as a guide in observation, an attempt to structure what we see, to heighten our sensibilities to space and light and form. Writing has been a form of explanation but also of legitimacy. It serves to articulate positions and to communicate with clients and the general public - but this can also be attempted with multiple forms of information, including the visual and the diagrammatic. In the IJ-plein project in Amsterdam, diagrams of canonical modernist projects with varying density, height and configurations were used in order to communicate with the future occupants of the neighbourhood - it became a crash course in architecture history, according to a retrospective text by Koolhaas. ${ }^{88}$ 
Importantly, however, architecture is also a profession of complexity. Viollet-le-Duc notes that it is more difficult to see disharmony in a façade than to hear it in a musical chord. ${ }^{89}$ The tension between art and science is played out in the field of architecture: after the progressive separation of architecture as the result of artistic inspiration in the Renaissance versus the structural expertise of the engineer, the 1970s also began to face a more hybrid construction of knowledge. No longer art or craft, engineering or architecture, the increased academic rigour of the 'minor professions' echoes the optimistic tones of Bauhaus education as the synthesis of many artistic endeavours. With the difference that in the Bauhaus there is a confidence in human intuition, and in the 1970s this shifts to scientific study. Perhaps what we are seeing today is the need for a convergence between what we believe is the rationality of Enlightenment thought, and the intuition that accompanies artistic practice.

To understand the undercurrent of architectural form that is embedded in the exploration of ideas (both urban and architectural), the work of Ungers is helpful, since he explicitly addresses many of the concerns that we can find implicitly present in the work of Koolhaas. Rather than obscuring these questions, Ungers addresses them directly and tries to explore them very specifically in both text and object. From investigating the City as a Work of Art in 1963 to his installation in the exhibition 'Man transForms' in 1976, Ungers reflected directly on the techniques and instruments of architecture itself. ${ }^{90}$ In other words: exploring the work of Ungers and Koolhaas as complementary oeuvres, we can reveal a position that neither equates architecture with the political (as the more 'engaged' architecture of the 1960 did), nor denies any possibility of social impact for architecture (as the debates on 'autonomy' centring around the work of Eisenman did). Instead, both Ungers and Koolhaas are aware of the societal constraints that architecture operates within, and both demonstrate interests in social issues (such as the promise of the collective, the contemporary condition of the metropolis, the simply factual need for housing), yet they operate within the discipline of architecture and the tools that are available to it (which here I $\mathrm{am}$, for the sake of argument, allowing to be encompassed under the larger category of 'form'). Regardless of personal ideas, they remain aware of the limits of architecture. ${ }^{91}$

And perhaps it is precisely a recalling of these types of convictions that is suggested by the Venice Biennale of 2014. With the challenges of the twentyfirst century and the steady demise of the starchitect, it makes sense that 
Koolhaas emphasized 'architecture, not architects' in his introduction to the Biennale. While one must remain a little wary of his sweeping statements, given his penchant for some level of paradox (so this biennale was somehow also about architects), it does suggest some modesty entering the debate. Although the architecture of the twentieth century began to revolve around a personality cult, many current architects are turning towards 'architecture'. Quiet interventions, tolerant normality, and humble pragmatism - they are the defining features of the now celebrated Flemish and Belgian architecture.

In 2014, in the Venice Biennale, a wall of the Arsenale was reserved for photographs by Charlie Koolhaas. A little over the top, with gold leaf framing the many details and views of the Biblioteca Laurenziana, it drew you in to examine the wall in extenso - and then notice the quote on the floor by Koolhaas, where he indicates that the confrontation with the Laurenziana showed him that all the rules he had learned in school were inadequate. In a funny parallel to his reinterpretation of the Berlin Wall, the object of brute force versus the sublime elegance of Michelangelo's library, he draws attention to the inadequacy of systems, models and reductions. Even in our absolute need to systematize knowledge in order to transmit it, what architecture, art, music, dance, medicine, computer programming and many other fields that intervene in a stubborn reality have to teach us, is that there is always an unexpected, undefinable glitch. And it is how we deal with these glitches that we prove our expertise, our craftsmanship. In the finest examples, the idea combines with the material resistance of reality to make something new and unexpected. 


\section{Epilogue: Recalibrating the Profession}

This book addresses a particular period in terms of architecture thinking, focusing mainly on societal transformations and the role of architecture from 1968 to 1989. At the same time, its intent is broader than historical documentation of the architecture debate in this period. The particular pattern-seeking of ideas here is aimed at appraising this work in terms of its continued conceptual and material significance to the challenges facing architecture today.

It is my hope that the very notion of a plausible relation between the social and the formal can reintroduce breathing room in a debate marked by utility and instrumentality, which are both eminently modern notions. Allowing ideas and buildings to be discussed both on their own merits and in relation to one another may provide a more entangled way of looking at architecture. Understanding architecture in terms of situated autonomy and embodied knowledge takes it out of the realm of modernist conviction and into a contemporary discourse on agency and limitations. I hope to have shown how deeply the 1970s resonate with the current time, offering valuable insights into the intended and the unforeseen effects of architecture in its complex negotiation of social intervention and formal articulation. There are additional examples throughout the 1970s that lend credence to this resonance, such as Bernard Tschumi's 1977 'Advertisements for Architecture' that call attention to the sensuous nature of buildings, showing the state of decay of the canonical modern villas and reinterpreting architecture through its unforeseen material effects. ${ }^{1}$

The main argument put forward in this book is that the work of Ungers and Koolhaas (both written and built) reveals particular features relevant to the changes facing architecture today. In order to do so, I have highlighted a number of core ideas in their work - written, drawn and built - that I believe hold potential for a more entangled reflection on and in the discipline. 
Both architects have been part of, or at least present for, significant changes in architecture over the past 40 to 50 years, engaging with the legacy of modernism and its critiques by Team 10, with the rise of postmodernism and with new ideas on the city, to name a few focal points. ${ }^{2}$ Their ideas have undergone various iterations over the past decades, but their key features are built on a shifting sensibility in the 1970s, when the globalizing economy increasingly became part of local concerns, and at the same time, the limitations of architecture as a redemptive force also became more apparent. Rather than a traditional history, this book attempts to provide a plausible theory of architectural ideas from the 1970s forward, that is conceptualized, materialized and entangled.

As the world transitions into a future that is increasingly difficult to predict, the built environment is relevant but not a determining force - it sits somewhere between innovative applied art and service profession. At the same time, the synthesis required of the architect - all the systems that need to be connected - is a type of expertise that is increasingly important. While many architecture manifestoes of the twentieth century have been alternately optimistic about the range and impact of architecture on society, or focused internally on the disciplinary ability to provide individual awareness of the logic of inhabitation and built form, the challenges of the twenty-first century do not allow for either position as exclusive approach.

In some ways, the public position of the architect has become more rather than less important, but not as the modernist genius with an internal motivation and highly individual drive. The field of architecture continues to require a strong internal drive, but adapted to a more pressing need for collaboration in the face of great challenges. Climate adaptation is clearly first and foremost: as the IPCC report of October 2018 unequivocally demonstrated in hard facts, the climate is heating up faster than any current measures can temper. ${ }^{3}$ At best, the world can hope to limit the temperature rise to 1,5 to 2 degrees Celsius, which will already require major adaptations in the built environment, from reconfiguring the coastline areas vulnerable to flooding, to the urban centres suffering from higher temperatures than the surrounding countryside. The contribution of the built environment to carbon emissions, currently around 40 per cent of total worldwide emissions, needs to be tempered. Experiments with different materials and reuse are small steps towards decreasing the impact. On a larger scale, addressing urban heat islands and 'greening' cities are being expanded. In many domains, the challenges are so large that they seem difficult to address in a single work, 
but the variety of engagements in material reuse and systemic approaches to resources and energy use are beginning to give rise to a number of interesting experiments.

The economy and the climate are demonstrably at odds, and architecture's strange hybrid self-identity between art, service, economic driver and future scenario suggests that a close self-examination could help reinvigorate the field, if it takes its social responsibility seriously. This is not to say that the future will be safeguarded by a more ethical profession, but the innovation that goes into current requests of developers for smaller apartments and higher profit margins might be put to better use in finding habitable and adequate dwellings in coastal areas, or tiny houses that provide sufficient spatial quality to house not just an urban elite. On this level, the effects of the 2020 pandemic have raised crucial questions on housing security, as well as shown the need for a healthy urban environment.

Beyond the urgency of climate change, there are also issues of social justice that have become increasingly present. While not everything falls within the responsibility of architecture, our built environment does project a portrait of how we wish to live. In essence, it expresses a cultural unconscious, but it is also self-conscious, allowing it to push forward with new ideas. And if Churchill was right, and our buildings shape us, then there is potential to transform society - although neither as widely as presumed by the Modern Movement, nor as radically as suggested in the 1960s. Instead, there is a subcutaneous, surgical potential to nudge inhabitants towards slightly better choices in relation to a living, breathing Gaia.

What Ungers and Koolhaas both show in their work is a wide-ranging intellectual and professional engagement with society at large. Their recurring refusal of social impact in their interviews is less an indication of cynicism or helplessness than it is a tempering of expectations. Counter to what is often understood, these two architects, like their many colleagues worldwide, are deeply serious about architecture, and put stock in its importance to society. They are impatient with the suggestion that architecture is mere window dressing and cannot abide by the notion that it is irrelevant. Yet they are equally marked by the unbridled optimism of the mid-century experiments: they are aware that their production is part of a greater economic and cultural cycle, and therefore limited in its range.

And their own work is limited as well, by their experience and their styles. While Koolhaas has often referred to the many contributors in his office, his presence is also sufficiently dominant to allow others to fade into the 
background. In the many shifts of the office over the period 1990 to the present, collaborators and partners have often founded their own office rather than remaining in the OMA constellation. This suggests that the narrative of the visionary architect is currently still too strong to allow equal and valued contributions to clearly rise to the surface. This is in part attributable to the forceful presence of Koolhaas in the office, and in part to the architecture media that still appeal to the notion of the solitary genius. Nevertheless, more recent experiments in the formation of architecture offices such as London's Assemble and the Belgian BC Architects show that the field is also evolving. Collaborations and new ways of working are systematically explored by a younger generation, and the current culture of building may catch up. Since the global financial crisis of 2008 , architects seem to be assuming a greater variety of roles, such as developer or founder of housing cooperatives, while project-based collaborations are also on the rise. Assemble is perhaps the most visible collaboration in the architecture media, but other collaborations are to be found in European countries, such as ROTOR in Belgium, and Superuse Studios in the Netherlands. These last two offices in particular, which both focus on circularity and reuse, demonstrate the need for a broader expertise, which is not necessarily part of the traditional organization of the architecture office. The images of many young designers clustered around 'the master' think, for example, of Frank Lloyd Wright or Le Corbusier - feel somewhat outdated in this day and age.

Moreover, the intertwined relation between architecture and society means that it is not easy to escape the restrictions of the cultural field and time. The collective unconscious seeps through, also affecting the public presence of the architect. For example, OMA's renovation of Rijnstraat 8, the 1992 building of the former Ministry of Housing, Spatial Planning and the Environment - now housing two ministries and two governmental organizations - has been criticized for failing to provide sufficient workspace. Yet the parameters for office space were provided by the client, based on a number of assumptions about remote work and flexible workweeks. As the building itself manifests these conditions, it seems natural to question the architect's design. Yet should we not also question the assumptions of the programme brief, and by extension, the culture that is transmitted in this manner? Questions such as these surface throughout Reinier de Graaf's book Four Walls and a Roof (2018), which collects various observations on the practice of architecture in a global economy that show how dependent the profession is on cultural contexts and assumptions. ${ }^{4}$ 


\section{Shifting Architecture, from Visionary Projects to Entangled Approaches}

Rather than retreating into its own boudoir, architecture as a whole may benefit by embracing a more complex approach. The challenges currently facing the profession are multiple. The high-profile production often assumed to be the final goal of studying architecture - a museum, a library, a large villa - is only a marginal part of the building stock. Instead, much of what is needed is a thoughtful manner of building what Willem Jan Neutelings has often called the 'bulk' of architecture. There is a vast need for considered renovation and transformation projects, to renew the existing building stock. In urban centres around the globe, there are infill projects that require a careful negotiation of their surroundings.

Around the world, housing security is shifting rapidly and asymmetrically, which also raises architectural concerns. As attractive urban centres become magnets for global capital, the housing markets shift, pushing out social housing in favour of real estate that facilitates high-income speculation. ${ }^{5}$ In some areas, this has led to increasing protest (such as the Toronto rent strikes of 2018), while in others 'tiny houses' or other downsized living environments are gaining traction. ${ }^{6}$ For now, the urban centres or their directly surrounding rings are still growing, attracting many new occupants, but the question is how long this will continue with rising real estate prices, and particularly in the wake of the 2020 pandemic, when a series of lockdowns recalled the value of greenery and public spaces in urban centres.

While there are many new challenges and developments, there is an undercurrent in the work of Ungers and Koolhaas that continues to hold relevance: the openness to different influences and to a changing profession. Situating architecture at the crossroads of a disciplinary autonomy and a service to society, there are elements in their approach that appeal to long gone days of authority, yet there are also more hopeful aspects, which suggest that the architect might provide some expertise in connecting various systems and needs.

Koolhaas and Ungers's teaching and writing in particular provide a view to other approaches. Some of the earliest work of Koolhaas - the dry observations of the Haagse Post articles - provides a foundation for observing without judgement, for taking on the surroundings with an interest. And while the portrayal of Koolhaas as a visionary may not be the best way forward, the various collaborations in and outside of the office do suggest some 
potential. The work of Ungers stands as an example of a broad intellectual approach with extensive knowledge of historical examples, which he used to illuminate the qualities present in architecture, and the type of knowledge and reflection needed to achieve this. The challenge now may be to face forward with both historical knowledge and a collaborative mindset as standing practice in architecture, rather than as exception. This may require rethinking design curricula as well, fostering a more collaborative and situated approach in the studio.

Two aspects of the twenty-first century seem fairly uncontested: that the global dependencies and interconnections have resulted in an unprecedented complexity, and that climate change presents an urgency that can no longer be ignored. In the face of these issues, architecture might appear to be just a marginal endeavour, but it has some features that make it valuable for addressing future challenges, provided an increased culture of openness and collaboration is fostered. Bringing order to (apparent) chaos: the idea put forward by Ungers in 1976 that our image-work is a manner of structuring the world around us, may help to understand why architecture often maintains such evocative power. Additionally, it synthesizes complex interdependencies; the architect ensures that different systems and structures are brought into a coherent whole. The spatial structuring of these interdependencies requires the ability to understand interfaces and interference. Finally, as a field situated 'between' many others - part engineering, part creative endeavour, part social analysis - architecture reveals the ambiguous nature of knowledge, and in so doing can help to more fundamentally grasp the mutual benefits of different perspectives.

In a lecture given online in 2020 , Anna Tsing noted that the contemporary to her is about teasing out lines of thought that both show the patchiness of current developments and push back at the singular narratives of modernity. ${ }^{7}$ More to the point in addressing the projects presented here, she noted how the central 'designers' of the current age (referring mainly to an engineering mindset, but the comment may equally hold for the visionary architect) have rarely looked beyond the boundaries of their project to the unforeseen and unintended consequences. This approach to the world at large, seeking out the unexpected and the unpredictable entanglements of people, animals, things, holds great promise for rethinking the role of architecture in the twenty-first century. 


\section{Sources}

Albrecht, Donald, Designing Dreams: Modern Architecture in the Movies (Santa Monica, CA: Hennessy + Ingalls, 2000 [1986])

Barthes, Roland, Mythologies, translated by Annette Lavers (New York: Hill and Wang, 1972)

Böck, Ingrid, Six Canonical Projects by Rem Koolhaas: Essays on the History of Ideas (Berlin: Jovis, 2015)

Bollerey, Franziska, ‘ . . immer wieder eine Mischung von Verführung und Ungenießbarkeit ins Spiel bringen: Conversation with Rem Koolhaas', Bauwelt, 17/18 (1987), 627-633

Calinescu, Matei, Faces of Modernity: Avant-Garde, Decadence, Kitsch (Bloomington: Indiana University Press, 1977)

Caragonne, Alexander, The Texas Rangers: Notes from an Architectural Underground (Cambridge, MA: MIT Press, 1995)

Cepl, Jasper, 'Ungers und seine Bücher: Die Bibliothek als Sammlung der Ideen', in: Andres Lepik (ed.), O.M. Ungers: Kosmos der Architektur (Ostfildern: Hatje Cantz, 2006), 31-40

Cepl, Jasper, Oswald Mathias Ungers: Eine intellektuelle Biografie (Cologne: Walther König, 2007)

Cohen, Jean-Louis, The Future of Architecture since 1889: A Worldwide History (London: Phaidon, 2012)

Colquhoun, Alan, 'Form and Figure', Oppositions 12 (1978), 29-37

Dovey, Kim and Scott Dickson, 'Architecture and Freedom? Programmatic Innovation in the Work of Koolhaas/OMA', Journal of Architectural Education 56/1 (2002), 5-13

Drexler, Arthur, 'Preface', in: Five Architects (New York: Oxford University Press, 1975), 1

Dijk, Hans van, 'Interview met Rem Koolhaas', Wonen-TABK 11 (1978), 17-20 
Eisenman, Peter, The Formal Basis of Modern Architecture (Zurich: Lars Müller, 2006 [1963])

Eyck, Aldo van, 'Message to Mathias Ungers from Another World', in: Francis Strauven and Vincent Ligtelijn (eds.), Aldo van Eyck: Writings, Vol. 2 (Amsterdam: Sun, 2008 [1979]), 530-532

Foucault, Michel, 'Des Espaces Autres: Hétérotopies' (1967), Architecture Mouvement Continuité 5 (1984), 46-49

Gargiani, Roberto, OMA/Rem Koolhaas: The Construction of Merveilles (Lausanne: EPFL Press, 2011)

Gerrewey, Christophe Van (ed.), OMA Koolhaas: A Critical Reader (Basel: Birkhäuser, 2019)

Gieselmann, Reinhard and Oswald Mathias Ungers, 'Towards a New Architecture', in: Ulrich Conrads (ed.), Programs and Manifestoes in $20^{\text {th }}$-Century Architecture, translated by Michael Bullock (Cambridge, MA: MIT Press, 1970 [1964]), 165-166.

Glazer, Nathan, 'The Schools of the Minor Professions', Minerva 12/3 (1974), 346-364

Goulet, Patrice, 'Interview with Rem Koolhaas', L'Architecture d'Aujourd'hui 238 (1985)

Graaf, Reinier de, On Hold, exhibition catalogue (Rome: The British School at Rome, 2010)

Greenberg, Clement, 'Modernist Painting', in: Charles Harrison and Paul Wood (eds.), Art in Theory 1900-1990: An Anthology of Changing Ideas (Oxford: Blackwell, 1992 [1960]), 754-760

Gutman, Robert, 'Architecture: The Entrepreneurial Profession', Progressive Architecture 5 (1977), 55-58

Harries, Karsten, The Ethical Function of Architecture (Cambridge, MA: MIT Press, 1997)

Hassenewert, Frank, 'Lehren des Entwerfens', PhD dissertation (TU Berlin, 2006)

Hays, K. Michael, 'Critical Architecture: Between Culture and Form', Perspecta 21 (1984), 14-29

Heron, Katrina, 'From Bauhaus to Koolhaas, Interview with Rem Koolhaas', Wired (1996), available online at wired.com/wired/archive/4.07/koolhaas. html (accessed I July 2020)

Hertweck, Florian and Sébastien Marot (eds.), The City in the City: Berlin, a Green Archipelago (Zurich: Lars Mueller, 2013) 
Heynen, Hilde, 'The Antinomies of Utopia: Superstudio in Context', in: Valentijn Byvanck (ed.), Superstudio: The Middelburg Lectures (Middelburg: De Vleeshal and Zeeuws Museum, 2005), 61-74

Hollein, Hans (ed.), MAN transFORMS, exhibition catalogue (New York: Smithsonian Institution, 1976)

Huyssen, Andreas, After the Great Divide: Modernism, Mass Culture, Postmodernism (Bloomington: Indiana University Press, 1986)

Jacoby, Russell, Picture Imperfect: Utopian Thought for an Anti-Utopian Age (New York: Columbia University Press, 2005)

Fredric Jameson, 'Postmodernism, Or, The Cultural Logic of Late Capitalism', New Left Review 146 (1984), 59-92

Kieren, Martin, Oswald Mathias Ungers (Zurich: Artemis, 1994)

Kieren, Martin, 'Der Architekt als Bauherr: Ungers's eigene Häuser als Ergebnis einer monologischen Kunst', in: Andres Lepik (ed.), O.M. Ungers: Kosmos der Architektur (Ostfildern: Hatje Cantz, 2006), 31-40

Klotz, Heinrich (ed.), O.M. Ungers: 1951-1984: Bauten und Projekte (Braunschweig: Vieweg, 1985)

Koolhaas, Rem, Elia Zenghelis, Madelon Vriesendorp and Zoe Zenghelis, 'OMA', Lotus International 11 (1976), 34-41

Koolhaas, Rem and OMA, 'The Discovery of Manhattanism', Architectural Design 17 (1977), 330

Koolhaas, Rem, 'Bigness: The Problem of LARGE', Wiederhall 17 (1994), 32-33

Koolhaas, Rem, 'Dali, the Critical Method and Le Corbusier', transcript of 1976 lecture, in: Brett Steele (ed.), Supercritical: Peter Eisenman and Rem Koolhaas, series Architecture Words I (London: Architectural Association, 2009), 88-93 Koolhaas, Rem, 'Exodus, or the Voluntary Prisoners of Architecture', in: OMA/Rem Koolhaas and Bruce Mau, SMLXL (Rotterdam: 010, 1995), 2-21 Koolhaas, Rem, 'Urban Operations', Columbia Documents 3 (1992), edited transcript of lecture given by Koolhaas at Columbia University (19 October 1992), 25

Koolhaas, Rem, 'Field Trip, A(A) Memoir', in: OMA/Rem Koolhaas and Bruce Mau, SMLXL (Rotterdam: 010, 1995), 212-233

Koolhaas, Rem, 'Weird Science: Excerpts from a Diary', in: OMA/Rem Koolhaas and Bruce Mau, SMLXL (Rotterdam: 010, 1995), 604-661

Koolhaas, Rem, 'Interview', Wired (1996), see https://wired.com/wired/archiv e/4.07/koolhaas.html

Koolhaas, Rem, 'Generic City', in: OMA/Rem Koolhaas and Bruce Mau, SMLXL (Rotterdam: 010, 1995), 1238-1264 
Koolhaas, Rem, in conversation with Sarah Whiting, 'Spot Check', Assemblage 40 (1999), 36-55

Koolhaas, Rem and Brendan McGetrick (eds.), Content (Cologne, Taschen, 2004)

Koolhaas, Rem, 'Visual Language: Architect's Notes', in: Rem Koolhaas and Kayoko Ota (eds.), Domus d'Autore I (Milan: Domus, 2006)

Koolhaas, Rem and Hans Ulrich Obrist, 'In Gespräch mit O.M. Ungers', Archt 179 (2006), 6-11

Kuhnert, Nikolaus, 'Die erschreckende Schönheit des 20. Jahrhunderts', excerpts of a conversation with Rem Koolhaas and Patrice Goulet, Arch+ 86 (1986), 34-43

Kuhnert, Nikolaus, 'Vorbemerkung: Auf dem Weg zu einer neuen Architektur', Arch 237 (2019), 3-4

Latour, Bruno, 'En tapotant légèrement sur l'architecture de Koolhaas avec un baton d'aveugle', L'Architecture d'Aujourd'hui 361 (2005), 70-79

Leupen, Bernard, Wouter Deen and Christoph Grafe (eds.), Hoe modern is de Nederlandse architectuur? (Rotterdam: 010, 1990)

Loth, David, The City within a City: The Romance of Rockefeller Center (New York: William Morrow, 1966)

Love, Timothy, 'Kit-of-Parts Conceptualism: Abstracting Architecture in the American Academy', Harvard Design Magazine 19 (2003)

Mannheim, Karl, 'The Problem of Generations', in: Karl Mannheim, Essays on the Sociology of Knowledge, edited by Paul Kecsemeti (London: Routledge and Kegan Paul, 1952 [1927]), 276-320

Marot, Sébastien and Florian Hertweck (eds.), The City in the City: Berlin, a Green Archipelago (Zurich: Lars Müller, 2013)

Marwick, Arthur, The Sixties: Cultural Revolution in Britain, France, Italy and the United States, c.1958-c.1974 (Oxford: Oxford University Press, 1998)

McLeod, Mary, 'Architecture and Politics in the Reagan Era: From Postmodernism to Deconstructivism', reprinted in: K. Michael Hays (ed.), Architecture Theory since 1968 (Cambridge, MA: MIT Press, 1998 [1989]), 678703

Miller, Wallis, 'Circling the Square', in: Andres Lepik (ed.), O.M. Ungers: Kosmos der Architektur (Ostfildern: Hatje Cantz, 2006), 31-40

Mühlthaler, Erika, 'Lernen von O.M. Ungers: Die Berliner Lehrzeit 1963-1969', in: Erika Mühlthaler (ed.), Lernen von O.M. Ungers (Berlin: TU Berlin and Arch+, 2006), 23-29 
Mühlthaler, Erika (ed.), O.M. Ungers: Grossformen im Wohnungsbau, revised, German-English edition of the original Veröffentlichungen zur Architektur 5 (Berlin: Universitätsverlag der TU Berlin, 2007)

Neumeyer, Fritz and Francesca Rogier, 'OMA's Berlin: The Polemic Island In The City', Assemblage 11 (1990), 36-53

Obrist, Hans Ulrich, Rem Koolhaas, The Conversation Series 4 (Cologne: Walther König, 2006)

Obrist, Hans Ulrich, 'Oswald Mathias Ungers im Gespräch mit Rem Koolhaas und Hans Ulrich Obrist', Arch+ 179 (2006), 6-11

Poggioli, Renato, The Theory of the Avant-Garde (Cambridge, MA: Belknap/Harvard University Press, 1968)

Riemann, Peter, 'OMU and the Magritte Man', in: Erika Mühlthaler (ed.), Lernen von O.M. Ungers (Berlin: TU Berlin and Arch+, 2006), 176-177

Robertson, Jaquelin T. (ed.), The Charlottesville Tapes (New York: Rizzoli, 1985)

Rowe, Colin, The Mathematics of the Ideal Villa and Other Essays (Cambridge, MA: MIT Press, 1976)

Rowe, Colin and Fred Koetter, Collage City (Cambridge, MA: MIT Press, 1978)

Rowe, Colin, As I was Saying: Recollections and Miscellaneous Essays, Vol. 2 'Cornelliana', edited by Alexander Caragonne (Cambridge, MA: MIT Press, 1995)

Rykwert, Joseph, On Adam's House in Paradise (New York: Museum of Modern Architecture Papers, 1972)

Ryle, Gilbert, 'Knowing How and Knowing That', Proceedings of the Aristotelian Society (1946)

Saffron, Inga, 'The Latest Indulgence of the Architect and Self-Proclaimed Visionary', Dezeen, 17 March 2020, https://dezeen.com/2020/03/17/countrys ide-the-future-exhibition-guggenheim-museum-inga-saffron/, accessed 6 July 2020

Sassen, Saskia, Expulsions: Brutality and Complexity in the Global Economy (Cambridge, MA: Harvard University Press, 2014)

Schrijver, Lara, 'The Archipelago City: Piecing together Collectivities', OASE 71 (2006), 18-36

Schröder, Uwe, Drei Lehrer: Vom Wert der Theorie für den architektonischen Entwurf (Cologne: Walther König, 2019)

Schumacher, Thomas, 'Contextualism', Casabella 359-360 (1971), 79-86

Scott Brown, Denise, 'On Architectural Formalism and Social Concern: A Discourse for Social Planners and Radical Chic Architects', reprinted in: 
K. Michael Hays, Oppositions Reader: Selected Essays 1973-1984 (New York: Princeton Architectural Press, 1998 [1976]), 317-330

Simmel, Georg, 'The Metropolis and Mental Life', in: Neil Leach (ed.), Rethinking Architecture: A Reader in Cultural Theory (London: Routledge, 1997), 69-79

Somol, Robert E., '12 Reasons to Get Back in Shape', in: Rem Koolhaas andBrendan McGetrick (eds.), Content (Cologne, Taschen, 2004)

Sörgel, Herman, Einführung in die Architektur-Ästhetik: Prolegomena zu einer Theorie der Baukunst (Munich: Piloty \& Loehle, 1918)

Stern, Robert, 'Stomping at the Savoye: Five on Five', Architectural Forum 138/4 (1973), 49-53

Stern, Robert, 'Gray Architecture as Post-Modernism, or, Up and Down from Orthodoxy', in: K. Michael Hays, Architecture Theory since 1968 (Cambridge, MA: MIT Press, 1998 [1976]), 240-245

Swenarton, Mark, Dirk van den Heuvel and Tom Avermaete (eds.), The Architecture of the Welfare State (London: Routledge, 2014)

Tafuri, Manfredo, 'Toward a Critique of Architectural Ideology', in: K. Michael Hays (ed.), Architecture Theory since 1968 (Cambridge, MA: MIT Press, 1998), 6-35

Till, Jeremy, Architecture Depends (Cambridge, MA: MIT Press, 2009)

Tönnies, Ferdinand, Gemeinschaft und Gesellschaft (Leipzig: Fues's Verlag, 1887)

Toorn, Roemer van, 'Architecture against Architecture', CTheory (1997)

Toorn, Roemer van and Ole Bouman (eds.), The Invisible in Architecture (London: Academy Editions, 1994)

Trentin, Annalisa (ed.), Oswald Mathias Ungers: una scuola (Milan: Mondadori Electa, 2004)

Ungers, Liselotte and Oswald Mathias Ungers, Kommunen in der Neuen Welt 1740-1972 (Cologne: Kiepenheuer \& Witzsch, 1972)

Ungers, Oswald Mathias, Shadrach Woods and Stefan Wewerka (eds.), 'Team $\mathrm{X}$ Treffen', in: Veröffentlichungen zur Architektur 3 (Berlin: Lehrstuhl für Entwerfen VI, TU Berlin, 1965)

Ungers, Oswald Mathias, 'Grossformen im Wohnungsbau', in: Veröffentlichungen zur Architektur 5 (Berlin: Lehrstuhl für Entwerfen VI, TU Berlin, 1966)

Ungers, Oswald Mathias and Liselotte Ungers, 'Early Communes in the U.S.A.', Architectural Design 42 (1972), 505-512

Ungers, Oswald Mathias and OMA, 'Roosevelt Island Housing Competition', Lotus International 11 (1976), 37-41 
Ungers, Oswald Mathias. Die Stadt in der Stadt: Berlin das grüne Stadtarchipel (Cologne: Studio Verlag für Architektur, 1977)

Ungers, Oswald Mathias, Hans Kollhoff and Arthur Ovaska, The Urban Villa: A Multi-Family Dwelling Type (Cologne: Studio Verlag für Architektur, 1977)

Ungers, Oswald Mathias, Rem Koolhaas, Peter Riemann, Hans Kollhoff and Arthur Ovaska, 'Cities within the City', Lotus International 19 (1978), 82-97

Ungers, Oswald Mathias, 'Architecture's Right to an Autonomous Language', in: Paolo Portoghesi (ed.), The Presence of the Past (New York: Academy Editions, 1980), 319-323

Ungers, Oswald Mathias, Morphologie/City Metaphors (Cologne: Walther König, 1982)

Ungers, Oswald Mathias, Architecture as Theme/Architettura come tema, Quaderni di Lotus 1 (Milan: Electa, 1982)

Ungers, Oswald Mathias, 'The Janus Face of Architecture', Architectural Design 6 (1986), 9-11

Ungers, Oswald Mathias, 'Aphorisms on Buildings Houses', Lotus 90 (1996), 7-35

Ungers, Oswald Mathias and Stefan Vieths, The Dialectic City (Milan: Skira, 1997)

Ungers, Oswald Mathias, 'Ordo, fondo et mensura', in: Henry A. Millon (ed.), The Renaissance from Brunelleschi to Michelangelo: The Representation of Architecture (London: Thames and Hudson, 1994), 306-317

Verschaffel, Bart, 'De overlevingsethiek van Rem Koolhaas: De eerste huizen van OMA', in: Véronique Patteeuw (ed.), Wat is OMA: Betreffende Rem Koolhaas en het Office for Metropolitan Architecture (Rotterdam: NAi publishers, 2003), 153-163

Wensing, Thomas, 'It's the Economy, Stupid!' Archined, 4 May 2020, https://ar chined.nl/2020/05/its-the-economy-stupid/, accessed 6 July 2020

Wortmann, Arthur, 'Un paradis artificial: A House by OMA in Floirac', Archis 11 (1998), 46-53

Zenghelis, Elia, 'Text and Architecture: Architecture as Text', in: Martin van Schaik and Otakar Máčel (eds.), Exit Utopia: Architectural Provocations 195676 (Munich: Prestel, 2005), 255-262 



\section{Notes}

\section{Preface: Architecture and Disciplinary Crises}

1 Reinier de Graaf, On Hold exhibition catalogue (Rome: The British School at Rome, 2010).

2 One notable article documents Ungers's seriousness in his studies of architecture history, addressing his library as a space for intellectual labour, and thus implicitly providing a counterfoil to the breadth of Koolhaas's often pop-culture references. Jasper Cepl, 'Ungers under seine Bücher: Die Bibliothek als Sammlung der Ideen', in: Andres Lepik (ed.), O.M. Ungers: Kosmos der Architektur (Ostfildern: Hatje Cantz, 2006), 38.

3 For a general overview of OMA in terms of design and ideas, two highlights worth mentioning are: Christophe Van Gerrewey (ed.), OMA /Rem Koolhaas: A Critical Reader from 'Delirious New York' to 'S, M, L,XL' (Basel: Birkhäuser, 2019) and Ingrid Böck, Six Canonical Projects by Rem Koolhaas: Essays on the History of Ideas (Berlin: Jovis, 2015).

4 On Dutch television, the programme College Tour showed how Koolhaas became flustered after a question on manifestoes. NOVA College Tour, 'Rem Koolhaas', presented by Twan Huys (Vara/NPS, 22 April 2009).

5 Projecting a slide of an architect with his back turned to the project and examining blueprints, he notes the seriousness and necessity that emanates from the architect's stance, while observing that this is a type of building practice that has nearly disappeared from the current state of the profession. Rem Koolhaas, 'Navigating Modernization', American University Beirut, 17 May 2010. Available online at oma.eu/lectures/navi gating-modernization (accessed 3 July 2020).

6 Thomas Wensing, 'It's the Economy, Stupid!' Archined, 4 May 2020. Available online at archined.nl/2020/05/its-the-economy-stupid/ (accessed 6 July 2020); Inga Saffron, 'The Latest Indulgence of the Architect and Self-Proclaimed Visionary', Dezeen, 17 March 2020. Available online 
at dezeen.com/2020/03/17/countryside-the-future-exhibition-guggenhe im-museum-inga-saffron/ (accessed 6 July 2020).

7 Bruno Latour, 'En tapotant légèrement sur l'architecture de Koolhaas avec un baton d'aveugle', L'Architecture d'Aujourd'hui 361 (NovemberDecember 2005), 76-77.

8 Richard Lacayo, 'Rem Koolhaas', The 2008 Time 100, Time, 12 May 2008. Available online at content.time.com/time/specials/2007/article/0,2880 4,1733748_1733752_1735981,00.html (accessed 5 July 2020).

9 An overview of note is Jasper Cepl, Oswald Mathias Ungers: Eine intellektuelle Autobiografie (Cologne: Walther König, 2007). Here, Cepl particularly brought to light the mutual respect between Ungers and Koolhaas, 312315 .

10 Oswald Mathias Ungers, Shadrach Woods and Stefan Wewerka (eds.), 'Team X Treffen', Veröffentlichungen zur Architektur 3 (June 1966); Team 10 seminar Cornell 1971-1972, team1oonline.org/team1o/meetings/1970-71-c ornell.htm; Jaquelin T. Robertson (ed.), The Charlottesville Tapes (New York: Rizzoli Books, 1985).

11 Oswald Mathias Ungers, 'Grossformen im Wohnungsbau', Veröffentlichungen zur Architektur 5 (December 1966); Rem Koolhaas, 'Bigness: The Problem of LARGE', Wiederhall 17 (1994), 32-33. The history of 'Bigness' is slightly more complex; as the notion is present in some of the retrospective texts on three big competitions from 1989 (library Jussieu, ZKM Karlsruhe and Zeebrugge terminal), I here use 1989 as the delimiting date. Rem Koolhaas, 'Weird Science', in: OMA/Rem Koolhaas and Bruce Mau, SMLXL (Rotterdam: 010 publishers, 1995), 604-661.

12 Rem Koolhaas, letter to Fonds BK Amsterdam, funding proposal (Het Nieuwe Instituut (HNI) Rotterdam, archive Office for Metropolitan Architecture (OMAR), clippings archive).

13 Oswald Mathias Ungers and OMA, 'Roosevelt Island Housing Competition', Lotus International 11 (1976), 37-41.

14 Hans Ulrich Obrist, Rem Koolhaas (Cologne: Walther König, 2006), 83-84.

15 Sanford Kwinter (ed.), Rem Koolhaas: Conversations with Students (Houston: Rice University School of Architecture and New York: Princeton Architectural Press, 1996), 11. 


\section{Chapter 1. The 1970s: Reclaiming Autonomy for the Fait Social}

1 Rem Koolhaas in conversation with Sarah Whiting 'Spot Check', Assemblage 40 (1999), 36-55: 50.

2 This also calls to mind various revisions of criticality, perhaps best summarized in George Baird, "Criticality" and Its Discontents', Harvard Design Magazine 21 (2004/2005), 16-21. For an earlier exploration of architecture's complicated relation to criticism, see: Roemer van Toorn, 'Architecture against Architecture: Radical Criticism within the Society of the Spectacle', catalogue Film + Arc 2 (Graz, 1993). Available online: roemervantoorn.nl/architectureagai.html.

3 Oswald Mathias Ungers, 'Architecture's Right to an Autonomous Language', in: Paolo Portoghesi (ed.), The Presence of the Past (New York: Academy Editions, 1980), 319-323.

4 As will be discussed further in Chapter 4, Koolhaas wrote Delirious New York (London: Oxford University Press, 1978) without using any typical architectural terms - this was an experimental side to the book: the desire, in a sense, to redefine how we speak and think about architecture. Rem Koolhaas in conversation with Franziska Bollerey, Bauwelt 17/18 (1987), 627-633. Similarly, the notion of 'Bigness' revolves around an urban condition of scale that transcends formal tools, it is about a condition that creates something new.

5 Reinhold Martin suggests that many projects of the 1970s and 1980s can be read with the spectre of Utopia hovering in the background. Reinhold Martin, Utopia's Ghost (Minneapolis: University of Minnesota Press, 2010). While he proposes that a social Utopia may be extracted from these projects to inform a present in desperate need of ideals, my suggestion here is that the turn to an autonomous discourse that remains informed by societal and cultural conditions acknowledges the limits of what architecture can do without concluding that architecture is irrelevant.

6 Peter Eisenman, The Formal Basis of Modern Architecture (Zurich: Lars Müller, 2006 [1963]).

7 Manfredo Tafuri, 'Toward a Critique of Architectural Ideology', in: K. Michael Hays (ed.), Architecture Theory since 1968 (Cambridge, MA: MIT Press, 1998 [1969]), 6-35. 
8 Clement Greenberg, 'Modernist Painting', in: Charles Harrison and Paul Wood (eds.), Art in Theory 1900-1990: An Anthology of Changing Ideas (Oxford: Blackwell, 1992 [1960]), 754-760.

9 Alexander Caragonne, The Texas Rangers: Notes from an Architectural Underground (Cambridge, MA: MIT Press, 1995); Timothy Love, 'Kit-of-Parts Conceptualism: Abstracting Architecture in the American Academy', Harvard Design Magazine 19 (2003).

10 The legacy of Dutch modernism plays an important role both in this presence of the social and in the work of Koolhaas, as will be discussed further in Chapters 2 and 4.

11 With gratitude for the discussions and apologies for my reduction, I am indebted to Christine Boyer for the conversations we have had on this topic. Particular moments have brought this problem to centre stage in past decades, such as the urban renewal after the 2005 destruction of New Orleans by hurricane Katrina, followed by the silence of many urban thinkers on the topic. M. Christine Boyer, 'Projective Mappings', paper presented at 'The Projective Landscape' conference, 16-17 March 2006, Delft University of Technology, courtesy of author. While these immediate issues of social concern demand attention, this book is concerned with the manners of thinking that are embedded in architecture discourse, particularly in the opposition between social concern and formalism.

12 Charles Jencks identifies the advent of postmodernism as coinciding with the demolition of the Pruitt-Igoe housing complex in St Louis in 1972. Although this is a reductive synopsis of a contested debate in architecture, the topic of this book is directed at its effects more than its (ideological) nametag - so whether we choose to consider contemporary discourse as 'modern', albeit exacerbated (Habermas), 'postmodern' (Lyotard), or to give it any other label, the defining features of complexity, interconnectedness and speed are more or less uncontested.

13 Colin Rowe, 'The Architecture of Utopia', in: Colin Rowe, The Mathematics of the Ideal Villa and Other Essays (Cambridge, MA: MIT Press, 1976 [1959]), 205-223.

14 Colin Rowe and Fred Koetter, Collage City (Cambridge, MA: MIT Press, 1978).

15 Both 'The Welfare Palace Hotel' and 'The Story of the Pool' are included as a fictional appendix in: Koolhaas, Delirious New York, 304-311. The MoMA devoted an exhibition to many of these images, noting: "The 1970s saw an 
explosion of architectural thought and experimentation - with the city, and New York especially, becoming a screen for the projection of architectural fantasies and utopias.' 'Dreamland: Architectural Experiments since the 1970s', MoMA, 23 July 2008 - 16 March 2009. Jeremy Till, Architecture Depends (Cambridge, MA: MIT Press, 2009); 'Dreamland: Architectural Experiments since the 1970s', MoMA, 23 July 2008 - 16 March 2009.

17 Erika Mühlthaler, 'Lernen von O.M. Ungers: Die Berliner Lehrzeit 19631969', in: Erika Mühlthaler (ed.), Lernen von O.M. Ungers (Berlin: TU Berlin and Arch+, 2006), 23-29; Jasper Cepl, Oswald Mathias Ungers: Eine intellektuelle Biografie (Cologne: Walther König, 2007), 223-228.

18 Excerpt from fellowship application, Rockefeller Archive Center, Commonwealth Fund Archives, Harkness Fellowship Files, Series 20.2, Box 115, Folder 941.

19 Colin Rowe, As I was Saying: Recollections and Miscellaneous Essays, Vol. 2 'Cornelliana', edited by Alexander Caragonne (Cambridge, MA: MIT Press, 1995), 75-78.

20 See, for example, the reminiscences of Koolhaas on the shared ideas and vehement animosity between Rowe and Ungers in 'Die erschreckende Schönheit des 20. Jahrhunderts', Arch+ 86 (1986), 34-43.

21 By his own account, he found the publications during his study trip to the Berlin Wall in 1971. Rem Koolhaas, 'Visual Language: Architect's notes', in: Rem Koolhaas and Kayoko Ota (eds.), Domus d'Autore 1 (Milan: Domus, 2006). According to Jasper Cepl, copies were likely circulating in London, either via James Stirling or Léon Krier. Cepl, Oswald Mathias Ungers, 295296.

22 Hans van Dijk, 'Interview met Rem Koolhaas', Wonen-TABK 11 (1978), 1720.

23 Ibid.; Aldo van Eyck, 'Message to Mathias Ungers from Another World', in: Francis Strauven and Vincent Ligtelijn (eds.), Aldo van Eyck: Writings, Vol. 2 (Amsterdam: Sun, 2008 [1979]), 530-532.

24 In the introduction to Five Architects, this specific understanding of autonomy is identified as American, in contrast to the belief in architecture as a social instrument of the younger generation of European architects. Arthur Drexler, 'Preface', in: Five Architects (New York: Oxford University Press, 1975), 1. In a similar polemic, Robert Stern situates European idealism in opposition to the broad field of American architecture. 
Robert Stern, 'Stomping at the Savoye: Five on Five', Architectural Forum 138/4 (1973), 49-53.

25 Arthur Marwick, The Sixties: Cultural Revolution in Britain, France, Italy and the United States, c.1958-c.1974 (Oxford: Oxford University Press, 1998), 2638, 217-229, 584-586.

26 See also: Donald Albrecht, Designing Dreams: Modern Architecture in the Movies (Santa Monica, CA: Hennessy + Ingalls, 2000 [1986]), 56-74; Andreas Huyssen, After the Great Divide: Modernism, Mass Culture, Postmodernism (Bloomington, IN: Indiana University Press, 1986).

27 For an extensive treatment of the role of architecture in shaping the European welfare state, see Mark Swenarton, Dirk van den Heuvel and Tom Avermaete (eds.), The Architecture of the Welfare State (London: Routledge, 2014).

28 Mary McLeod, 'Architecture and Politics in the Reagan Era: From Postmodernism to Deconstructivism', reprinted in: K. Michael Hays (ed.), Architecture Theory since 1968 (Cambridge, MA: MIT Press, 1998 [1989]), 678703.

29 In his dissertation, Sébastien Marot argued that Ithaca and its surrounding landscape was also crucial to the development of these ideas. Sébastien Marot, 'Palimpsestuous Ithaca: Un manifeste relatif du SubUrbanisme', PhD dissertation, École des Hautes Études en Sciences Sociales (EHESS), July 2008, courtesy of author.

30 Denise Scott Brown, 'On Architectural Formalism and Social Concern: A Discourse for Social Planners and Radical Chic Architects', reprinted in: K. Michael Hays (ed.), Oppositions Reader: Selected essays 1973-1984 (New York: Princeton Architectural Press, 1998 [1976]), 317-330: 320. The article was in part a response to criticisms of Learning from Las Vegas, such as that by Fred Koetter, 'On Robert Venturi, Denise Scott Brown, and Steven Izenour's Learning from Las Vegas', Oppositions 3 (May 1974), 98-104.

31 Ibid., 320.

32 Drexler, 'Preface', 1.

33 Colin Rowe, The Mathematics of the Ideal Villa and Other Essays (Cambridge, MA: MIT Press, 1976), 1-28.

34 Koolhaas, Delirious New York; Bollerey, 'Conversation with Rem Koolhaas', 627-633.

35 Rowe and Koetter, Collage City, 50-85, 118-150.

36 Hanno Walter-Kruft, A History of Architectural Theory from Vitruvius to the Present (New York: Princeton Architectural Press, 1994), 327-334. 
37 Ungers, 'Architecture's Right to an Autonomous Language', 320.

38 Hermann Sörgel, Einführung in die Architektur-Ästhetik: Prolegomena zu einer Theorie der Baukunst (Munich: Piloty \& Loehle, 1918).

39 Kim Dovey and Scott Dickson, 'Architecture and Freedom? Programmatic Innovation in the Work of Koolhaas/OMA', Journal of Architectural Education 56/1 (2002), 4-13.

40 Many insightful studies have been published on the logic of the avantgarde, and its relation to modernism. Particular books of note are, in chronological order: Renato Poggioli, The Theory of the Avant-Garde (Cambridge, MA: Belknap/Harvard University Press, 1968); Matei Calinescu, Faces of Modernity: Avant-Garde, Decadence, Kitsch (Bloomington: Indiana University Press, 1977); Andreas Huyssen, After the Great Divide: Modernism, Mass Culture, Postmodernism (Bloomington: Indiana University Press, 1986).

41 Vitruvius, The Ten Books on Architecture, translated by Morris Hicky Morgan (New York: Dover, 1960), 181-182; John Ruskin, The Seven Lamps of Architecture (New York: John Wiley, 1849), 25-56, 123-145.

42 While architecture has often - even in the 1970s - laid claim to the status of avant-garde, its practices typically require a mode of operation within the dominant culture, which contradicts the main principles of avantgarde practice.

43 An interesting book in this context is one that Ungers co-authored with his wife Liselotte, Kommunen in der Neuen Welt 1740-1972 (Cologne: Kiepenheuer \& Witsch, 1972). The book is a study of various communes in the United States, from the late 1800s to the 1970s. It examines the conditions of smaller collective societies, and the social parameters that define them. It also includes urban plans of each commune and some notes on specific buildings. An article was published in English as 'Early Communes in the U.S.A.', Architectural Design 42 (1972), 505-512.

44 Reinier de Graaf, Four Walls and a Roof (Cambridge, MA: Harvard University Press, 2017).

45 Karl Mannheim, 'The Problem of Generations', in: Karl Mannheim, Essays on the Sociology of Knowledge, edited by Paul Kecsemeti (London: Routledge and Kegan Paul, 1952 [1927]), 276-320.

46 Robert Gutman, 'Architecture: The Entrepreneurial Profession', Progressive Architecture 5 (1977), 55-58.

47 Jean-Louis Cohen, The Future of Architecture since 1889: A Worldwide History (London: Phaidon, 2012). 
48 Rem Koolhaas, 'Exodus, or the Voluntary Prisoners of Architecture', in: OMA/Rem Koolhaas and Bruce Mau, SMLXL (Rotterdam: o10 publishers, 1995), 2-21.

49 Thomas A. Harris, I'm OK-You're OK (New York: Harper \& Row, 1967). A popular self-help book of the 1960s, its title became a common phrase to refer to an overly permissive culture.

50 Lara Schrijver, Radical Games (Rotterdam: NAi Publishers, 2009), 107-117.

51 Kim Dovey and Scott Dickson, 'Architecture and Freedom? Programmatic Innovation in the Work of Koolhaas/OMA', Journal of Architectural Education 56/1 (2002), 4-13.

52 My thinking on this is influenced by Crimson Architectural Historians, Too Blessed to be Depressed (Rotterdam: 010, 2002). Another architect famously disparaged by Van Eyck for producing 'fascist' architecture was Rotterdam architect Hugh Maaskant. See Michelle Provoost, Hugh Maaskant: Architect of Progress (Rotterdam: naio1o, 2014).

53 The desire of Team 10 to find social value in architecture, combined with the aversion of Aldo van Eyck to the rationalism and formal interest of Oswald Mathias Ungers, came to a head in 1979 in Van Eyck's published fulmination against more or less everything Ungers stood for, with a particular emphasis on formalism. Van Eyck. 'Message to Mathias Ungers from Another World'. Ironically, both Ungers and Van Eyck showed a predilection for the 'spiritual content' of architecture in the 1960 s.

54 Ungers, 'Architecture's Right to an Autonomous Language'.

55 Ibid., 319.

56 Over time, the spiritual or intellectual content of architecture - its transcendent qualities - have remained central. From the manifesto 'Towards a New Architecture' with Reinhard Gieselmann (1960) to 'Architecture's Right to an Autonomous Language' (1980) to 'Ordo, Fondo et Mensura' (1994), the best architecture is seen to embody a content beyond the strictly functional, technical or even strictly aesthetic, a quality that appeals to essential qualities of form.

57 Ungers, 'Architecture's Right to an Autonomous Language', 319.

58 Reinhard Gieselmann and Oswald Mathias Ungers, 'Towards a New Architecture', in: Ulrich Conrads (ed.), Programs and Manifestoes in $20^{\text {th }}$. Century Architecture, translated by Michael Bullock (Cambridge, MA: MIT Press, 1970 [1964]), 165-166.

59 Mühlthaler, 'Lernen von O.M. Ungers'. 
60 Ungers, 'Architecture's Right to an Autonomous Language', 321.

61 Joseph Rykwert, On Adam's House in Paradise (New York: The Museum of Modern Art papers, 1972). Koolhaas appears to have been familiar with this work.

62 Oswald Mathias Ungers, 'Das Recht der Architektur auf eine autonome Sprache', as cited in Martin Kieren, Oswald Mathias Ungers (Zurich: Artemis, 1994), 21. Kieren notes the prominence of form in the work of Ungers, which is unmistakably central. Kieren's citation differs slightly from the English version of 'Architecture's Right to an Autonomous Language'.

63 Koolhaas, Delirious New York, 100.

64 Ibid., 173.

65 Kieren, Oswald Mathias Ungers, 22.

66 Rem Koolhaas, lecture 19 October 2012, at receiving an honorary doctorate from the VU Amsterdam. A number of lectures have incorporated a retrospective gaze towards his own biography as formative for his architectural approach.

67 Years later, in the Harvard Guide to Shopping, Koolhaas reminisces on the impact of a study of Las Vegas. The study on Levittown offered a different view of the value of pre-packaged symbolism, while Koolhaas's interest in Rockefeller Center may well have suggested the name 'City within the City' for the Berlin studios of 1977. David Loth, The City within a City: The Romance of Rockefeller Center (New York: William Morrow \& Company, 1966).

68 'Koolhaas: Und eigentlich sagen Sie auch in jeder Arbeit, dass es für diese Dinge formal und morphologisch Lösungen gibt, aber nicht sozial. . . . Ungers: Ich bin der Meinung, dass die sozialen Probleme von Architektur nicht gelöst werden können. Wir haben keine Mittel dazu. Sie können architektonische Probleme lösen. Genauso kann Kunst die gesellschaftlichen Fragen nicht lösen.' 'Oswald Mathias Ungers im Gespräch mit Rem Koolhaas und Hans Ulrich Obrist', Arch+ 179 (2006), 10 , author's translation.

69 Oswald Mathias Ungers, City Metaphors (Cologne: Walther König, 1982), 11-12.

70 For an overview of what is becoming known as 'new materialisms', see: Diana Coole and Samantha Frost (eds.), New Materialisms: Ontology, Agency, and Politics (Durham, NC: Duke University Press, 2010). 
71 Ungers, 'Das Recht der Architektur auf eine autonome Sprache', as cited in Kieren, Oswald Mathias Ungers, 21.

72 Veröffentlichungen zur Architektur issues 8 'Plätze und Strassen' (1967), 21 'Snellbahn und Gebäude' (1968) and 27 'Berliner Brandwände' (1969).

73 A case in point is the IJplein project, which Koolhaas himself notes as a moment in which the project was overtaken by a full transformation of the reality around it. From an underwriting of the socialist principles underlying it, the new references became private/corporate developments in Baltimore and San Francisco's Bay Area. Rem Koolhaas, untitled contribution, in: Bernard Leupen, Wouter Deen and Christoph Grafe (eds.), Hoe modern is de Nederlandse architectuur? (Rotterdam: o10 publishers, 1990), 13. See also Christophe Van Gerrewey, 'A Weissenhofsiedlung for Amsterdam: OMA's IJplein', LOG 44 (2018), 82-93.

74 Interview Rem Koolhaas, Radical Philosophy, 47.

75 Koolhaas, Delirious New York, 152.

76 Alan Colquhoun, 'Form and Figure', Oppositions 12 (1978), 29-37.

77 Ungers, 'Architecture's Right to an Autonomous Language', 320.

78 Robert E. Somol, '12 Reasons to Get Back in Shape', in: Rem Koolhaas and Brendan McGetrick (eds.), Content (Cologne: Taschen, 2004), 86-87.

79 Madelon Vriesendorp also comments that she could not 'read' people by their clothing in America in the same way she could in the Netherlands. Beatriz Colomina, interview with Madelon Vriesendorp part II 'Disaster Follows Ecstasy Like Form Follows Function', in: Shumon Basar and Stephan Trüby (eds.), The World of Madelon Vriesendorp (London: AA Publications, 2008), 40-59: 49.

80 Colquhoun, 'Form and Figure'.

81 Rem Koolhaas, 'Dali, the Critical Method and Le Corbusier', lecture 1976, in: Brett Steele (ed.), Supercritical: Peter Eisenman and Rem Koolhaas, 'Architecture Words I' series (London: AA Publications, 2009), 88-93.

82 John Seabrooks, NoBrow: The Culture of Marketing the Marketing of Culture (London: Methuen, 2000).

83 David Cunningham and Jon Goodbun, 'Interview Rem Koolhaas and Reinier de Graaf', Radical Philosophy 154 (2009), 35-47. Available online at https://staging.radicalphilosophy.com/interview/rem-koolhaas-andreinier-de-graaf (accessed 9 November 2020).

84 Koolhaas states: 'I doubt I would have written [Delirious New York] had I not met him or read Mythologies.' Ibid., 39. 
85 Roland Barthes, Mythologies, translated by Annette Lavers (New York: Hill and Wang, 1972), 109, note 1.

86 Katrina Heron, 'From Bauhaus to Koolhaas', interview with Rem Koolhaas, Wired (July 1996), available online at https:/wired.com/wired/arch ive/4.07/koolhaas.html (accessed I July 2020).

87 Vittorio Lampugnani, 'Tolerant Normality', in: Arie Graafland and Leslie Jay Kavanaugh (eds.), Crossover (Rotterdam: 010, 2006), 294-311.

88 Kieren, Oswald Mathias Ungers, 16.

\section{Chapter 2. From Delirium to Archipelago, the Postmodern Collective in the City}

1 Oswald Mathias Ungers et al., 'Cities within the City', Lotus 19 (1977), 86.

2 Hans Ulrich Obrist, Rem Koolhaas, The Conversation Series 4 (Cologne: Walther König, 2006), 52.

3 Georg Simmel, 'The Metropolis and Mental Life', in: Neil Leach (ed.), Rethinking Architecture: A Reader in Cultural Theory (London: Routledge, 1997 [1903]), 69-79. As I argue in Radical Games, the city is not only the locus of architecture, it is also one of its primary conceptual issues. This remains so even today, notwithstanding Koolhaas's recent turn to the countryside with the 2020 exhibition at MoMA.

4 Simmel, 'The Metropolis and Mental Life', 78-79; Robert Park, The Crowd and the Public and other Essays (Chicago: University of Chicago Press, 1972 [1904]).

5 Rem Koolhaas, 'The Terrifying Beauty of the Twentieth Century', in: OMA/Rem Koolhaas and Bruce Mau, SMLXL (Rotterdam: o1o publishers, 1995), 204-209.

6 Rem Koolhaas, 'Generic City 6.1', in: OMA/Koolhaas and Mau, SMLXL, 1238.

7 Patrice Goulet, 'Interview with Rem Koolhaas', L'Architecture d'Aujourd'hui 238 (1985), 1-14.

8 Aldo Rossi and Vittorio Gregotti travelled to Cologne to visit the house in 1960, which led to the first Italian publication on Ungers. Aldo Rossi, 'Una giovane architetto tedesco: Oswald Mathias Ungers', Casabella 244 (1960), 22-35. 
9 'Maelstrom' is the word that Marshall Berman uses to characterize the modern experience, which Koolhaas regularly refers to. Marshall Berman, All that Is Solid Melts into Air (New York: Simon \& Schuster, 1982).

10 Simmel, 'The Metropolis and Mental Life', Ferdinand Tönnies, Gemeinschaft und Gesellschaft (Leipzig: Fues's Verlag, 1887). Robert Park's work remained less widely known until its translation into English in 1972.

11 The interest of Koolhaas in the theories and practice of urbanism are reflected in his course selection at Cornell, which was primarily in the field of urban design, as proposed in his initial application. He also took (and did not complete) an introductory reading course in Russian. Rockefeller Archive Center, Commonwealth Fund Archives, Harkness Fellowship Files, Series 20.2, Box 115, Folder 941. Item: Transcript Cornell, academic year 1972-1973.

12 Ungers won first place in the 1974 competition for the area of BerlinLichterfelde, which was never realized. OMA's 1994 master plan for Lille was perhaps the first on such a great scale. The city centre for Almere (also 1994) is more architectural in scale but is based on ideas of congestion.

13 Thomas Schumacher, 'Contextualism', Casabella 359-360 (1971), 79-86; according to Gargiani, this is the first use of contextualism. Roberto Gargiani, OMA/Rem Koolhaas: The Construction of Merveilles (Lausanne: EPFL Press, 2011), 88, ff. 33.

14 Rem Koolhaas, 'Imagining Nothingness', in: OMA/Koolhaas and Mau, $S M L X L, 198-203$. The notion arguably also relates to OMA/AMO's Venice Biennale exhibition of 2010, Cronocaos, which addresses the problem of heritage and transformation. While the 'City within the City' was concerned with the decreasing need for architecture due to the population drop, Cronocaos suggests a different problem: that increasing preservation diminishes the space for new buildings, causing architecture to lose its relevance.

15 While the mutual influence of Ungers and Koolhaas in terms of urban thinking was noted as 'overlooked' in 2006 by Peter Eisenman in Supercritical (London: AA Publications, 2010), 31, this no longer holds. Between the writings of Jasper Cepl, Roberto Gargiani, Pier Vittorio Aureli, Sébastien Marot and my own work, this collaboration can no longer qualify as overlooked. At the same time, this book is an attempt to situate their particular contribution as a key to understanding today's transitions in architecture. 
Koolhaas, Delirious New York (London: Oxford University Press, 1978), 100, 173.

17 Ungers et al., 'Cities within the City', 82, 84.

18 For an analysis of the developmental stages of the text, see the critical edition of the 'City within the City': Florian Hertweck and Sébastien Marot (eds.), The City in the City: Berlin, a Green Archipelago (Zurich: Lars Mueller, 2013).

19 Ungers later bears the brunt of Van Eyck's anger at neo-rationalism. Van Eyck, 'Message to Mathias Ungers from Another World'. Grossform was originally received with interest by Team 10 and translated as 'megaform'.

20 Rem Koolhaas, untitled contribution in Bernard Leupen, Wouter Deen and Christoph Grafe (eds.), Hoe modern is de Nederlandse architectuur? (Rotterdam: 010, 1990), 11-22. The text sharply criticizes the nostalgia for the historical core as well as what he sees as nondescript Dutch modernism.

21 As will be discussed later in Chapter 4, perception and Gestalt theory are important touchstones in the work of Ungers, and in this period likely also contribute to his conversations with Koolhaas.

22 As noted earlier, there are varying accounts of how Koolhaas came to be familiar with these publications (Chapter 1, note 21).

23 The series, comprising 27 issues, also included publications of guest lectures, symposium proceedings and other architectural studies. Some of the highlights in the series include a report on the Team 10 meeting in Berlin of 1965, Ungers's Moscow lecture on 'Grossformen im Wohnungsbau' in 1966, the proceedings of the architecture theory conference organized by Ungers at the TU Berlin in 1967, and the 'Berlin 1995' studio at Cornell in 1969. An overview of the issues is published in: Erika Mühlthaler (ed.), Lernen von O.M. Ungers (Berlin: TU Berlin and Arch+, 2006), 82-169.

24 Harkness Fellowship Files, Series 20.2, Transcript Cornell (note 11).

25 Subtitle of: David Loth, The City within a City: The Romance of Rockefeller Center (New York: William Morrow \& Company, 1966). The book is an ode to the construction of Rockefeller Center and the manner in which it was run, singing the particular praise of the role of the Rockefeller family in upholding a level of quality and maintaining a large percentage of public space within the complex (more than was typically deemed financially profitable). As the book was listed as a source for Delirious New York, the phrase 'City within the City' may have derived from Loth's work as an 
apt description for the urban concepts already circulating in the work of Ungers and Koolhaas.

26 The City of the Captive Globe was initially developed in 1972, published in Lotus International 11 (1976) and Architectural Design 5 (1977), and republished in an adapted form in Delirious New York in 1978. The City within the City was originally proposed in 1977 during the Cornell summer studio of the same name. Rotterdam also recurs in the texts of Koolhaas as a city without character, but it does not seem to have generated a specific concept, unless it is in the notion of 'nothingness', also based on Berlin.

27 'Roma Interrotta', Architectural Design 49/3-4 (1979).

28 Koolhaas, 'Imagining Nothingness'. The studio he refers to incorporated the work of many different people, including himself and Ungers, but also Hans Kollhoff.

29 The 'City within the City' was first published as Die Stadt in der Stadt, (summer academy 1977), in German only. It was subsequently published in Italian and English in Lotus, bringing it to a broader audience. Much of the work of Ungers follows this trajectory of a German language publication with an English translation about a year later. Koolhaas even now refers to this work as important and relevant. For example, in an interview with Hans Ulrich Obrist, he points out how Ungers understood the artificiality of Berlin and consequently used it as a laboratory, setting up a number of design seminars that systematically explored various dimensions of its urban and architectural condition, artnode.se/artorbi t/issue4/i_koolhaas/i_koolhaas.html (accessed 11 April 2006).

30 Koolhaas, 'Imagining Nothingness', 201.

31 Koolhaas, Delirious New York, 294-296.

32 Oswald Mathias Ungers, Die Stadt in der Stadt: Berlin das grüne Stadtarchipel (Cologne: Studio Verlag für Architektur, 1977). The publication was completed in collaboration with Rem Koolhaas, Peter Riemann, Hans Kollhoff and Arthur Ovaska, and republished entirely in Lotus 19 (1978), extending its audience with this bilingual (Italian/English) publication. Oswald Mathias Ungers, Hans Kollhoff and Arthur Ovaska, The Urban Villa: A Multi-Family Dwelling Type (Cologne: Studio Verlag für Architektur, 1977). The summer academies were set up like the earlier TU Berlin studios, isolating specific conditions of the Berlin 'laboratory'.

33 Fritz Neumeyer and Francesca Rogier, 'OMA's Berlin: The Polemic Island In The City', Assemblage 11 (1990), 36-53. 
34 Aldo Rossi, The Architecture of the City (New York: Rizzoli, 1984 [1966]).

35 Ungers, Die Stadt in der Stadt, these 6. The references in this passage are translated from the original German publication, which in some cases diverges from the English translation in Lotus 19 (1977); 'design knowledge' here refers to the original 'Gestaltungerkenntnisse'.

36 Ungers, Die Stadt in der Stadt, these 4 (author's translation).

37 Ibid., schlussfolgerung.

38 Ungers, Die Stadt in der Stadt, these 5 (author's translation).

39 Ibid., schlussfolgerung.

40 The condition of heterogeneity is a general issue in reflections on postmodernity, most notably in David Harvey's The Condition of Postmodernity (1989) and Jean-Francois Lyotard's La Condition Postmoderne (1979). It appears that the most direct philosophical influence on Koolhaas in this area is Michel Foucault, however. M. Christine Boyer, 'Projective Mappings', courtesy of author.

41 George Baird, 'Les Extrêmes qui se Touchent', Architectural Design 5 (1977), 326-328.

42 It seems fair to say that both ideas were developed during a period of regular discussions on architecture between Koolhaas and Ungers. The available evidence suggests that the City within the City was developed primarily by Ungers, with input from Koolhaas, although Peter Riemann suggestively notes that Koolhaas got off the plane with the idea of Berlin as a green archipelago. Peter Riemann, 'OMU and the Magritte Man', in: Mühlthaler, Lernen von O.M. Ungers, 176.

43 Koolhaas left for Manhattan in the fall of 1973. At the IAUS, there was a continual stream of lectures and visiting scholars.

44 In this sense, the work itself resonates with what Venturi and Scott Brown did in Learning from Las Vegas (also published in 1972), examining the environment that was already there in order to reassess the tools and vocabulary of the discipline.

45 Koolhaas, Delirious New York, 296.

46 Following his time at Cornell, Koolhaas also worked on two competition entries for Ungers in 1974 and would on occasion assist with the Cornell summer studios through 1977. It is not surprising that the strongest resonance between the ideas of Koolhaas and Ungers are to be found in the mid-1970s.

47 Ungers, 'Die Stadt als Kunstwerk'. An important observation is made by Jasper Cepl in his extensive study of Ungers, where he notes that 
Ungers was so driven to morphology that he in essence considered everything scalable. Jasper Cepl, Oswald Mathias Ungers: Eine intellektuelle Biografie (Cologne: Walther König, 2007). This point forms a crucial distinction with the approach of Koolhaas. Ungers's morphological focus on architecture is notably visible in the Berlin lectures from 1964-1965, published in Arch+ 179 (2006).

48 Reinhard Gieselmann and Oswald Mathias Ungers, 'Towards a New Architecture', in: Ulrich Conrads (ed.), Programs and Manifestoes in $20^{\text {th }}$. Century Architecture, translated by Michael Bullock (Cambridge, MA: MIT Press, 1970 [1964]), 165-166.

49 Schweizer taught at the TH Karlsruhe when Ungers was studying there, from 1947 to 1950. Schweizer was invited to the CIAM meeting 1951 in Hoddesdon - this may have been why Ungers was present at the CIAM meeting in Aix-en-Provence.

50 Otto Ernst Schweizer, Die Architektonische Grossform: Gebautes und Gedachtes (Karlsruhe: G. Braun, 1957). Ungers's lecture 'Grossformen im Wohnungsbau' was originally given in Moscow and published as the fifth issue of his TU-Berlin series Veröffentlichungen zur Architektur. Its propositions are present in: Alison Smithson, Team 1o Primer (Cambridge, MA: MIT Press, 1973), where it was translated into 'megaform'; in this book I retain the original German term for its specific connotations.

51 Kollhoff identifies Egon Eiermann and Otto Schweizer as the two main influences on Ungers. Hans Kollhoff, 'Die Sache mit den Quadraten', Die Welt, 12 July 2006.

52 Kollhoff, 'Die Sache mit den Quadraten', identifies the distinction between the two as a focus on typology (Schweizer) versus the visual (Ungers).

53 Schweizer, Die Architektonische Grossform, 56. He sees the development as a shift from the 'architektonische Bedeutung des einzelne bauten to the Grossordnung des Gebauten'.

54 Schweizer, Die Architektonische Grossform, 55 (my italics).

55 Ibid.

56 Ungers, 'Grossformen im Wohnungsbau', 4.

57 Koolhaas, 'Bigness: The Problem of LARGE', Wiederhall 17 (1994), 32-33.

58 Otto Ernst Schweizer, 'Über das Wesen des Architektonischen', in: Schweizer, Die Architektonische Grossform, 183. Schweizer specifically refers to considerations of society, technology and economics (Gesellschaft, Technologie, Wirtschaft) as foundations for a modern approach to ar- 
chitecture. His appeal to modern architectural unity (zeitentsprechenden architektonische Einheit) is founded on historical examples, appealing specifically to the qualities of the Gothic for its structural solutions (the dematerialization of the inside, shifting support to outside), and the Baroque for its spatial forms (open spaces).

Schweizer, Die Architektonische Grossform, introduction.

60 Michel Foucault, 'Des Espaces Autres: Hétérotopies' (1967), Architecture Mouvement Continuité 5 (1984), 46-49.

61 Ungers, Die Stadt in der Stadt; Ungers, Kollhoff and Ovaska, The Urban Villa; Oswald Mathias Ungers, Hans Kollhoff and Arthur Ovaska, The Urban Garden: Student Projects for the Südliche Friedrichstadt (Cologne: Studio Verlag für Architektur, 1978) (see also note 32).

62 For a more specific elaboration on the idea of the City within the City, see my article 'The Archipelago City: Piecing together Collectivities', OASE 71 (2006), 18-36.

63 Neumeyer and Rogier, 'OMA's Berlin: The Polemic Island In The City'. In this article, Neumeyer and Rogier are attuned to the encompassing ambivalence that is expressed in pairs of oppositions, noting the references to the 'shocking beauty of the 2oth century', the 'minimal architectural interventions' (with reference to Leonidov) combined with the 'absolute sensual delight' in OMA's early projects.

64 For Ungers, exploring form is fundamental to architecture. According to Heinrich Klotz, his interest in form is situated between autonomy and a more embedded position, which allows him to transcend mere formal experimentation: 'Die Gefahr der Formbeliebigkeit schwindet; an deren Stelle tritt ein Formprinzip.' From: Heinrich Klotz (ed.), O.M. Ungers: 19511984: Bauten und Projekte (Braunschweig: Vieweg, 1985), 29.

65 As Zenghelis notes, Exodus should have been concerned with 'pure architecture and its autonomy' instead of its underlying social programme. Koolhaas himself remarks on the 'overwrought insistence on collectivity'. Hilde Heynen, 'The Antinomies of Utopia: Superstudio in Context', in: Valentijn Byvanck (ed.), Superstudio: The Middelburg Lectures (Middelburg: De Vleeshal and Zeeuws Museum, 2005), 61-74.

66 Koolhaas, 'Bigness: The Problem of LARGE'.

67 Ibid.

68 Although many of these studies no doubt arise from the need to find new clients, one might argue that the full cultural significance of architecture does not necessarily derive from its intentions - whether that is building 
on a tight budget, client acquisition or any other 'banal' motivation - but in its reception and reproduction in the realms of media. In other words, in its accruing cultural significance after the fact.

69 Philipp Oehmke and Tobias Rapp, 'Und immer ein Atrium!', Der Spiegel 50 (2011), 136-139. The liberation Koolhaas here suggested as inherent to the generic may have reached its limits, which is perhaps why OMA has now turned to the countryside as an object of inquiry that escapes urban logic.

70 OMA/AMO, 'Cronocaos', Venice Biennale 2010, exhibition text.

71 Russell Jacoby, Picture Imperfect: Utopian Thought for an Anti-Utopian Age (New York: Columbia University Press, 2005). Central to Jacoby's argument is that Utopian proposals often fail when they try to provide a 'blueprint' for their ideal, which includes a hyper-definition of features, rather than a 'sketched' ideal that allows for adaptation.

72 Oswald Mathias Ungers and Liselotte Ungers, Kommunen in der Neuen Welt 1740-1972 (Cologne: Kiepenheuer \& Witsch, 1972). This project, though co-authored, was primarily Liselotte's research and work (conversation with Sophia Ungers, May 9, 2007).

73 Fredric Jameson, 'Postmodernism, Or, the Cultural Logic of Late Capitalism', New Left Review 146 (1984), 59-92.

74 Ungers and Rossi are likely the architects in mind as examples. Goulet, 'Interview with Rem Koolhaas'.

75 Ibid.

\section{Chapter 3. The House: Crystallized Architecture Thinking}

1 Hans Ulrich Obrist, Rem Koolhaas, The Conversation Series 4 (Cologne: Walther König, 2006), 93. In the interview, this is positioned as little more than an offhand comment.

2 Alan Colquhoun, 'Symbolic and Literal Aspects of Technology', AD 32/8 (1962), 508-509.

3 Reinhard Bentmann and Michael Müller, Die Villa als Herrschaftsarchitektur: Versuch einer kunst- und sozialgeschichtlichen Analyse (Frankfurt am Main: Suhrkamp, 1970).

4 Bart Verschaffel notes this striking reticence about the houses, in combination with their extensive documentation in 'De overlevingsethiek van Rem Koolhaas: De eerste huizen van OMA'. in: Véronique Patteeuw (ed.), 
Wat is OMA: Betreffende Rem Koolhaas en het Office for Metropolitan Architecture (Rotterdam: NAi publishers, 2003), 153-163. Ungers, in contrast, is remarkably candid about the houses he built for himself in the article 'Aphorisms on Building Houses', Lotus 90 (1996), 7-35.

5 While mass housing was significant to the ideological programme of modern architecture, it was in the villas that many of the ideas of modernism were elaborated. Colquhoun, 'Symbolic and Literal Aspects of Technology'. Joseph Rykwert, On Adam's House in Paradise (New York: Museum of Modern Architecture papers, 1972); Gaston Bachelard, The Poetics of Space (Boston: Beacon Press, 1994 [1958]); Reinhard Bentmann and Michael Müller, The Villa as Hegemonic Architecture (Atlantic Highlands, NJ: Humanities Press, 1992 [1970]); Witold Rybcynski, Home: A Short History of an Idea (New York: Penguin, 1987).

7 The Farnsworth House by Mies van der Rohe stands as testimony to the vulnerability of the architect-client relationship, culminating in a wellknown lawsuit over budget overruns and the general frustration of Edith Farnsworth that the house was not liveable.

8 Koolhaas, 'Obstacles', in: OMA/Rem Koolhaas and Bruce Mau, SMLXL (Rotterdam: O10 publishers, 1995), 133-193. The piece is a constellation of brief statements that together mythologize the process, from the desperation of the client to find the 'right' architect to the contradictions within the brief, naturally exacerbated in the design.

9 The 1998 Maison à Bordeaux by OMA provides an interesting example in relation to the developments over time of the programme: the arrangement of the children's rooms was conceived when they were rather young, and their separation from the parents' part of the house provided space to create their own world. By the time they moved in, they were adolescents, at which point the internal continuity between the rooms may have posed some challenges, as they seem to lack the privacy one would imagine to be preferable during adolescence. Again, the Maison à Bordeaux provides some interesting details that show an ambivalence in Koolhaas's position: according to the owner, even many years after its completion Koolhaas would be irritated by the disconnection in the tile seams between inside and outside. At the same time, he seemed to care less about the more mundane facts of use, such as the crumbling concrete at the edge of the elevator (conversation with the author, May 2010). 
11 'Small' is used in this case as a reference to the categorization in SMLXL, which does exclude some projects.

12 Distinct omissions from this section are the design for the Spear Villa in Miami (1974), the competition design for the Irish Prime Minister's Residence (1979), and the Dutch House (1995). The Maison à Bordeaux (1998) was completed after the publication of SMLXL. Other more recent projects that would fall under the category 'small' include the addition to the Chemosphere for Benedikt Taschen (2000), the Distributed House in the Bahamas (2000), and the Ascot Residence (2003).

13 Koolhaas, 'The Terrifying Beauty of the Twentieth Century', in: OMA/Koolhaas and Mau, SMLXL, 204-209. Koolhaas regularly refers to the clinical and factual description of the journalists at the Haagse Post in retrospective conversations. Bart Lootsma also refers to the influence of the Nul movement in art in the Netherlands and the artists' interest in the registration of reality without commentary. Bart Lootsma, 'Koolhaas, Constant und die Niederländische Kultur der 6oer Jahre', disko 1 (2006), 7-41. See in particular his reference to John Jansen van Galen and Hendrik Spiering: Rare Jaren, Nederland en de Haagse Post 1914-1990 (Amsterdam, 1993), $17 \mathrm{ff}$.

14 Ungers, 'Das Recht der Architektur auf eine autonome Sprache', as quoted in Martin Kieren, Oswald Mathias Ungers (Zurich: Artemis, 1994), 21.

15 Ungers, 'Aphorisms on Building Houses'. Here, Ungers notably advises all architects against building their own house, speaking of his intellectual rather than financial ruin (see pages 15-16).

16 These two types were articulated in corrugated iron, rough wood, sand (in the patio) and a collage of pictures. As such, they subverted the modern references they made use of. See also Ben Highmore, 'Rough Poetry: Patio and Pavilion Revisited', Oxford Art Journal 29/2 (2006), 269290. For a fuller account of the Smithsons' projects for modern houses, see Dirk van den Heuvel and Max Risselada, From the House of the Future to a House for Today (Rotterdam: 010, 2004).

17 HNI Rotterdam, OMA archive (OMAR), inv.no. 2120.

18 The archive shows that the original design intended to include marble for the stairs, but that budget constraints required amendments. Design development 1984-1986, sketches and memos, HNI Rotterdam, OMAR inv.nos. 1079, 2120, 2124. 
19 Walter Benjamin, 'Experience and Poverty' in: Michael W. Jennings, Howard Eiland and Gary Smith (eds.), Walter Benjamin: Selected Writings vol.2, 1927-1934, transl. Rodney Livingstone et al., (Cambridge, MA: Belknap Press, 1999), 731-736. 'It is no coincidence that glass is such a hard, smooth material to which nothing can be fixed. A cold and sober material into the bargain. Objects made of glass have no "aura."

20 HNI Rotterdam, OMAR inv.no. 2124. Notes to this effect are to be found in numerous places in the archive, such as a memo on an early sketch in this folder, noting: 'basics as cheap as possible, finishing as good as possible'.

21 Oswald Mathias Ungers, 'Ordo, Fondo et Mensura: The Criteria of Architecture', in: Henry A. Millon (ed.), The Renaissance from Brunelleschi to Michelangelo: The Representation of Architecture (London: Thames and Hudson, 1994), 306-317. The title refers to a biblical passage that suggests everything is determined by weight, order and measure, typically referred to with 'ordo, pondo et mensura'.

22 Sörgel: 'Architecture, in a general sense, is the formation of our entire spatial environment; from the vastness of space in nature right down to the smallest spatial unit of furniture.' from Architekturaesthetik (1918), as quoted in Oswald Mathias Ungers, 'The Janus Face of Architecture', Architectural Design 6 (1986), 11.

23 Ungers, 'Aphorisms on Building Houses', 13.

24 Oswald Mathias Ungers, Sieben Variationen der Leuchter der Baukunst von John Ruskin (Stuttgart: Gerd Hatje, 1985).

25 Ibid.

26 Oswald Mathias Ungers, 'Designing and Thinking in Images, Metaphors and Analogies,' in: Hans Hollein (ed.), Man TransFORMS (New York: Smithsonian Institution, 1976), 96-113.

27 Kieren, Oswald Mathias Ungers, 33.

28 Oswald Mathias Ungers, Quadratische Häuser (Stuttgart: Gerd Hatje, 1986), based on: Bruno Munari, Discovery of the Square (New York: George Wittenborn, 1962).

29 Munari, Discovery of the Square, 80.

30 Ibid., 51.

31 Kieren, Oswald Mathias Ungers, 90 (italics in original).

32 Jasper Cepl, 'Ungers und seine Bücher: Die Bibliothek als Sammlung der Ideen', in: Andres Lepik (ed.), O.M. Ungers: Kosmos der Architektur 
(Ostfildern: Hatje Cantz, 2006), 31-40: 34. 'Auch in seiner Anlage ist die Bibliothek der Pol der Konzentration und der geistigen Ordnung.'

33 Ibid.

34 'Zwischen Ordnung und Konflikt: Oswald Mathias Ungers im Gespräch mit Klaus-Dieter Weiss', Werk, Bauen + Wohnen 76/9 (1989), 4-11: 4-5.

35 Ungers, 'Aphorisms on Building Houses', 12.

36 It is tempting to follow Koolhaas's own suggestion that this sensitivity is related to his early childhood in Indonesia, where the domains of adults and children were quite separate in his recollection. Rem Koolhaas, lecture 19 October 2012, at receiving honorary doctorate from the VU Amsterdam.

37 Kim Dovey and Scott Dickson, 'Architecture and Freedom? Programmatic Innovation in the Work of Koolhaas/OMA', Journal of Architectural Education 56/1 (2002), 4-13. In the case of the Maison à Bordeaux, the later emptiness of the elevator platform required a change of the habitus in the house, rethinking the form of the habitat.

38 In 2010, the platform was filled with beanbag chairs and pillows as a space for reading books and viewing films.

39 Ungers, 'Aphorisms on Building Houses', 17. Here, Ungers not only positions the three houses as specific explorations of architectural ideas, but also implies the relation with the social, not as a political construct, but as an individual quest.

40 Lepik, O.M. Ungers: Kosmos der Architektur, introduction. Lepik also makes note of the fact that in both cases, the architect is both client and user, the central point in his self-constructed world.

41 Ibid., 15.

42 It was primarily its sculptural quality and its materialization that suggested a relation to Banham's idea of the New Brutalist architecture. This view was not shared by Ungers, who was more engaged with the house as a small city.

43 Ungers, 'Aphorisms on Building Houses', 13.

44 The importance of 'how we conceive the world' to the building of a house is prominent in the Belvederestrasse house and forms the foundation for Ungers's ideas on the 'spirit' of architecture. He makes reference to a manifesto 'written in that house after it was finished'. This seems most likely to be the 1960 'Towards a New Architecture', co-authored with Reinhard Gieselmann, in which the spirit of a new architecture is central, regardless of its scale. Ungers, 'Aphorisms on Building Houses', 7. 
45 There were two apartments available for rent. Notes in the archive show that at least one was rented out. See also Cepl, Oswald Mathias Ungers, 52-53.

46 'als die beiden Einliegerwohnungen im Haus aufgelöst wurden', in: Cepl, 'Ungers und seine Bücher', 34.

47 The most salient feature of the client in this story is his passion for architecture. The story comprises a number of anecdotes, including his argument with a policeman while waiting for Koolhaas to arrive at the airport, and fights with neighbours over the design of their house. This version of the facts emphasizes the mythical proportions of architecture as a battleground.

48 Conversation with Hélène Lemoine, May 2010. She recalled that Jacques Herzog, also in the running for the commission, was focused on designing the most beautiful one-storey home with no obstacles. Around the same time, Koolhaas in a phone conversation stated that he was actually more interested in the commission now, as it offered a more challenging programme.

49 From the OMA website: 'Contrary to what you would expect,' he told the architect, 'I do not want a simple house. I want a complex house, because the house will define my world. . .' The Lemoine family bought land on a hill with panoramic views over the city. See: oma.eu/projects/1998/maison-à-bordeaux (accessed 8 December 2011).

50 Ungers, 'Aphorisms on Building Houses', 12.

51 Again recalling the argument by Alan Colquhoun that the modernist focus on standardization is contradicted by its actual production of unique objects. Alan Colquhoun, 'Symbolic and Literal Aspects of Technology'.

52 Munari, Discovery of the Square.

53 Paul von Naredi-Rainer, 'Introduction', in: Ungers, Quadratische Häuser, unpaginated, first page.

54 Sophia Ungers, 'Afterword', in: Ungers, Sieben Variationen. 'Eine Zelle als Mikrokosmos des Lebens, in der Jede Funktion eines Lebewesens existiert - eine beschützende Haut, innere Strukturen, ein Nukleus. Ein Mikrokosmos, der das Leben widerspiegelt, der in der Reduktion ein Symbol des Lebenden wird. So auch ein Hotel als Zelle, als Archetyp einer Stadt - mit einer beschützenden Mauer, inneren Elementen, einem Mittelpunkt. Ein Gebäude, ein Hotel als Stadt: als Mikrokosmos im Makrokosmos.' There is a striking resemblance to the work of Charles 
and Ray Eames in this analogical function - the manner in which they make scale and space tangible in their film Powers of Ten.

55 Peter Blake, No Place Like Utopia: Modern Architecture and the Company We Kept (New York: W.W. Norton \& Company, 1996).

56 Bachelard, Poetics of Space (Boston: Beacon Press, 1994 [1958]). Bachelard also discusses the safety and warmth of the home that is expressed through the lamp at the window in a hut in the woods - which may in this case be applicable to the patio itself, glowing at the heart of the patio villa.

57 Michel Jacques (ed.), OMA Rem Koolhaas: Living (Bordeaux: arc en rêve centre d'architecture and Basel: Birkhäuser, 1998), 6. The catalogue largely gathers material that is known, but draws interesting comparisons between the houses.

58 Jacques Lucan, 'The Pleasures of Dissymmetry', in: ibid., 18-21.

59 François Chaslin, 'The Gay Disenchantment', in: ibid., 12-16.

60 The iterations of the Rotterdam Patio Houses confirm this in showing both canonical infills like those of Mies, as well as more light-hearted versions of pop-culture houses and California modern. HNI Rotterdam, OMAR, inv.nos. 2120, 2123, sketches and typological diagrams.

61 Chaslin, 'The Gay Disenchantment', 15-16.

62 Does it also suggest the potential to break away from the house, swimming elsewhere, as described in Delirious New York's 'Story of the Pool'?

\section{Chapter 4. Elements, Rules and Conventions: Architecture as Material Knowledge}

1 Oswald Mathias Ungers, 'Aphorisms on Building Houses', Lotus 90 (1996), 7-35: 12 .

2 Jeremy Till, Architecture Depends (Cambridge, MA: MIT Press, 2009).

3 Jean-Louis Cohen, The Future of Architecture Since 1889: A Worldwide History (London: Phaidon, 2012), 321, Cohen notes that modernism is the only historical period to engage with mass housing; Robert Gutman, 'Architecture: The Entrepreneurial Profession', Progressive Architecture 5 (1977), 55-58.

4 See also Léa-Catherine Szacka, Exhibiting the Postmodern: Venice 1980 Architecture Biennale (Venice: Marsilio, 2017). 
5 Stanford Anderson, 'Rational Reconstructions and Architectural Knowledge', in: Architecture in the Age of Empire, 11th International Bauhaus Colloquium Weimar (Verlag der Bauhaus-Universität Weimar, 2011), 160173. Anderson's argument is founded on the ideas of Imre Lakatos. In 2002, Robert Somol and Sarah Whiting provide a diagram that depicts architecture as a fluid field between and overlapping with economy, technology and other areas, while also arguing that there is some kind of core related to the projective capacities of architecture. Robert Somol and Sarah Whiting, 'Notes around the Doppler Effect, and the Many Moods of Modernism', Perspecta 33 (2002), 72-77.

6 Nathan Glazer, 'The Schools of the Minor Professions', Minerva 12/3 (1974), 346-364.

7 Kazys Varnelis, 'Is There Research in the Studio?', Journal of Architectural Education 61/1 (2007), 11-14.

8 Vittorio Lampugnani, 'Tolerant Normality', in: Arie Graafland and Leslie Jay Kavanaugh (eds.), Crossover (Rotterdam: 010, 2006), 294-311.

9 Reinhard Gieselmann and Oswald Mathias Ungers, "Towards a New Architecture', in: Ulrich Conrads (ed.), Programs and Manifestoes in $20^{\text {th }}$ Century Architecture, translated by Michael Bullock (Cambridge, MA: MIT Press, 1970 [1964]), 165-166.

10 K. Michael Hays, 'Critical Architecture: Between Culture and Form', Perspecta 21 (1984), 14-29.

11 Till, Architecture Depends.

12 Karsten Harries, The Ethical Function of Architecture (Cambridge, MA: MIT Press, 1997).

13 Gilbert Ryle, 'Knowing How and Knowing That', Proceedings of the Aristotelian Society (1946).

14 Michael Polanyi, The Tacit Dimension (Chicago: University of Chicago Press, 1966). The notion was presented in his article 'Tacit Knowing: Its Bearing on Some Problems of Philosophy', Rev.Mod.Phys. 34/4 (1962), 601616 , and further developed in the book.

15 Bruno Latour in particular notes the irreducibility of reality to models and argues that reality is worth treating with care. Bruno Latour, 'Why has Critique Run out of Steam? From Matters of Fact to Matters of Concern', Critical Inquiry 30 (2004), 225-248.

16 Nikolaus Kuhnert, 'Vorbemerkung: Auf dem Weg zu einer neuen Architektur', Arch+ 237 (2019), 3-4.

17 Martin Kieren, Oswald Mathias Ungers (Zurich: Artemis, 1994), 16. 
18 M. Christine Boyer, Not Quite Architecture: Writing around Alison and Peter Smithson (Cambridge, MA: MIT Press, 2017).

19 Adrian Forty, Words and Buildings: A Vocabulary of Modern Architecture (London: Thames \& Hudson, 2004).

20 Christof Thoenes, 'Introduction', in: Architectural Theory from the Renaissance to the Present (Cologne: Taschen, 2003), 8-19.

21 Rem Koolhaas, 'Learning Japanese', in: OMA/Rem Koolhaas and Bruce Mau, SMLXL (Rotterdam: 010 publishers, 1995), 88-125.

22 While some of this might now be attributed to Koolhaas's celebrity status, it is also visible in early receptions of his work. One of the evaluations of the work done for the Harkness fellowship of 19711972 clearly articulates an uncertainty on how to appraise the work. Evaluation letter by Sir Frederick Dainton, January 1975. Rockefeller Archive Center, Commonwealth Fund Archives, Harkness Fellowship Files, Series 20.2, Box 115, Folder 941.

23 As Andres Lepik notes in a retrospective on his work: 'Kein anderer Architekt Deutschlands hat nach dem Zweiten Weltkrieg das Nachdenken über die Grundlagen der Architektur so gründlich und so grundsätzlich betrieben wie Oswald Mathias Ungers.' Andres Lepik (ed.), O.M. Ungers: Kosmos der Architektur (Ostfildern: Hatje Cantz, 2006), 17. Lepik also makes a point of his resistance to fashions and trends.

24 In particular, 'Oswald Mathias Ungers Architekturlehre: Berliner Vorlesungen 1964-65', Arch+ 179 (2006), and an overview of the Veröffentlichungen zur Architektur and the summer academies in: Erika Mühlthaler (ed.), Lernen von O.M. Ungers (Berlin: TU Berlin and Arch+, 2006). The summer academies have drawn attention for some time already, as Koolhaas has often referred to the City within the City summer academy of 1977.

25 Kieren, Oswald Mathias Ungers, 25.

26 Marot, 'Palimpsestuous Ithaca', 451.

27 Herbert Simon, The Sciences of the Artificial (Cambridge, MA: MIT Press, 1969).

28 Marot, 'Palimpsestuous Ithaca', 453.

29 Rem Koolhaas, 'Less Is More', in: OMA/Koolhaas and Mau, SMLXL, 46-51: 49.

30 The book was a German-English publication with the German title simply Morphologie, which does more justice to its intellectual premise. Oswald Mathias Ungers, Morphologie / City Metaphors (Cologne: Walther König, 1982). 
31 See especially the Gebäudelehre of the TU Berlin lectures, 1964-1965, republished in Arch+ 179 (2006).

32 Oswald Mathias Ungers, Architecture as Theme/Architettura come tema, Quaderni di Lotus I (Milan: Electa, 1982), 57. This theme frequently recurs in the work of Ungers and is to be found in many different sources.

33 For a full history of the institute, see Kim Foerster, The Institute for Architecture and Urban Studies, New York (1967-1985): A Cultural Project in the Field of Architecture (PhD dissertation, ETH Zurich, 2011). For an insider's perspective, see Suzanne Frank, IAUS: An Insider's Memoir (New York: Author House, 2010). Two important legacies from the Institute are the Oppositions journal, and the ANY conferences.

34 Turpin C. Bannister, "The Research Heritage of the Architectural Profession,' Journal of Architectural Education 1 (1947), 5-12.

35 Robert Gutman, 'Architecture: The Entrepreneurial Profession', Progressive Architecture 5 (1977), 55-58.

36 Koolhaas, 'Less Is More', 49.

37 A number of remarkable teaching experiments in architecture in the 1960 s and 1970s are presented online at radical-pedagogies.com (accessed Dec. 18, 2020). The website is the result of an extended collaborative project with PhD students supervised by Beatriz Colomina.

38 Elia Zenghelis, 'Text as Architecture and Architecture as Text', in: Martin van Schaik and Otakar Màčel (eds.), Exit Utopia: Architectural Provocations 1956-76 (Munich: Prestel, 2005), 262.

39 Ungers, 'Aphorisms on Building houses', 7.

40 Rem Koolhaas, 'Visual Language: Architect's Notes', in: Rem Koolhaas and Kayoko Ota (eds.),Domus d'Autore 1 (Milan: Domus, 2006).

41 Rem Koolhaas, 'Urban Operations', Columbia Documents 3 (1992). Edited transcript of lecture given by Koolhaas at Columbia University on 19 October 1992, 25.

42 Koolhaas at Festival of Architecture in Cagliari, 2007. Fragment 'writing vs architecture', youtube.com/watch?v=P35DRxgIz8M (accessed 15 October 2014). His conclusion is that fewer architects write, and they now simply make shapes.

43 Koolhaas at Festival of Architecture in Cagliari, 2007. Fragment 'very few architects write these days', youtube.com/watch?v=eKzek_DijeI (accessed 15 October 2014).

44 See, for example, Oswald Mathias Ungers, 'Ordo, Fondo et Mensura: The Criteria of Architecture', in: Henry A. Millon (ed.), The Renaissance 
from Brunelleschi to Michelangelo: The Representation of Architecture (London: Thames and Hudson, 1994), 306-317.

45 For an extensive discussion on the tension between the sciences and the crafts, see Paola Bertucci, Artisanal Enlightenment: Science and the Mechanical Arts in Old Regime France (New Haven, CT: Yale University Press, 2017).

46 See, for example: Bryan Lawson and Kees Dorst, Design Expertise (London: Taylor and Francis, 2009).

47 Andrea Deplazes, Architektur Entwerfen, 3rd edition [2010], 11. Translation from the German by Stefan Koller. Deplazes goes on to position his book as a guideline not meant as clear rules, but rather as a springboard for students to develop their own position in architecture: 'Many of the themes in the current book are theses that aren't true simply because they are written "black on white" in a handbook. Rather, the handbook is better perceived as a tentative accumulation of known and contemporary questions, both architectural and technological - as a platform one can use to reflect on the complex métier of architecture.'

48 Kazys Varnelis offers a brief overview of research questions in various studios in his article 'Is There Research in the Studio?'.

49 Robert Venturi, Denise Scott Brown and Steven Izenour, Learning from Las Vegas (Cambridge, MA: MIT Press, 1972); Robert Venturi and Denise Scott Brown, Venturi Scott Brown $\&$ Associates on Houses and Housing (London: Academy Editions, 1992).

50 A full study of how the two offices work would require further research, but there are a number of notable details to be found in the archives and the publications.

51 The less hierarchical structure also presented problems at times. Matthias Sauerbruch remarked in a letter to Koolhaas that the office had 'too many colonels, not enough foot soldiers!' HNI Rotterdam, archive OMAR, clippings.

52 Robert Kloosterman, 'Walls and Bridges: Knowledge Spillover between Superdutch Architectural Firms', Journal of Economical Geography 8/4 (2008), 545-563.

53 Oswald Mathias Ungers, 'Architekturtheorie', Veröffentlichungen zur Architektur 14 (1968).

54 Rem Koolhaas in conversation with Franziska Bollerey, Bauwelt 17-18 (1987), 627-633. 
55 Ungers, 'Ordo, Fondo et Mensura', in: Henry A. Millon (ed.),The Renaissance from Brunelleschi to Michelangelo: The Representation of Architecture (London: Thames and Hudson, 1994), 306-317.

56 Rem Koolhaas and Brendan McGetrick (eds.), Content (Cologne: Taschen, 2004).

57 Ibid.; Koolhaas, Delirious New York (postcard illustrations); OMA/Koolhaas and Mau, SMLXL, Villa dall'Ava/'The Void' (Japanese porn).

58 Cepl refers to the intellectual weight of the reading material in Ungers's library, from an unpublished interview, noting that Ungers does not read comic books, but that they can also be read anywhere. Jasper Cepl, 'Ungers under seine Bücher: Die Bibliothek als Sammlung der Ideen', in: Andres Lepik (ed.), O.M. Ungers: Kosmos der Architektur (Ostfildern: Hatje Cantz, 2006), 38.

59 Charles Jencks, 'Pop - Non Pop', Architectural Association Quarterly, 1/1 (1969), 48-64. Patricia Phillips, 'Why is pop so unpopular?' in: Lawrence Alloway (ed.), Modern Dreams: The Rise and Fall and Rise of Pop. (Cambridge, MA: MIT Press, 1988). At the same time, the cryptic texts make some of these references seem more self-enclosed than those of Pop Art.

60 During the stay in Ithaca, Vriesendorp had a well-received exhibition of her work, where the sensual elements were explicitly referenced in a review, as well the explosion of color. Review, exhibition Madelon Vriesendorp, newspaper clipping, Rockefeller Archive Center, Commonwealth Fund Archives, Harkness Fellowship Files, Series 20.2, Box 115, Folder 941.

61 Albena Yaneva, OMA: An Ethnography of Design (Rotterdam: 010, 2009), 85.

62 Ungers, Architecture as Theme.

63 Andres Lepik, 'Vorwort', in: O.M. Ungers: Kosmos der Architektur, 16-17. Especially the specific reference to the multiplicity not only recalls the Cusanus idea of the Coincidentia Oppositorum that Ungers sets stock by, but also recalls one of the early statements by OMA, in which the 'permissive melting pot' of Manhattanism is identified in contrast to the 'puritanical dogma' of the Modern Movement. OMA, 'The Discovery of Manhattanism', Lotus 11, 34.

64 Robert Venturi, Complexity and Contradiction in Architecture (New York: Museum of Modern Art Papers, 1966).

65 Aside from Venturi, Rowe, Ungers and Rossi, a notable contribution is Alan Colquhoun's article 'From Bricolage to Myth, or How to Put Humpty-Dumpty Together Again', Oppositions 12 (Spring 1978). 
66 Ungers, Architecture as Theme, 33.

67 Ibid., 31.

68 Ibid., 31, my italics.

69 F. Scott Fitzgerald, 'The Crack-Up', Esquire, February, March and April 1936.

70 Freudian connotations were set squarely centre stage in Anthony Vidler, The Architectural Uncanny (Cambridge, MA: MIT Press, 1992).

71 Cepl, 'Ungers under seine Bücher', 34. He refers to a 'geistigen Ordnung' as a determining feature of Ungers's library.

72 Ungers, Architecture as Theme, 75.

73 Ibid., 77.

74 The projection of possible futures is one of the standard approaches of OMA/AMO, as visible for example in the project Europe 2050, where Europe becomes a continent of energy generation, addressing sustainability issues by becoming self-sufficient with wind parks and solar farms.

75 Kieren, Oswald Mathias Ungers, 11.

76 Chaslin, 'The Gay Disenchantment', 14.

77 See for example Christopher Alexander, Sara Ishikawa and Murray Silverstein, A Pattern Language: Towns, Buildings, Construction (London: Oxford University Press 1977); Donald A. Schön, The Reflective Practitioner: How Professionals Think In Action (New York: Basic Books, 1984).

78 Denise Scott Brown, 'On Architectural Formalism and Social Concern: A Discourse for Social Planners and Radical Chic Architects', Oppositions 5 (1976), 99-112.

79 Koolhaas acknowledges the influence of Barthes' Mythologies in an interview with Radical Philosophy. Jon Goodbun and David Cunningham, Interview with Rem Koolhaas and Reinier De Graaf, Radical Philosophy 154 (2009), available online: staging.radicalphilosophy.com/interview/re $\mathrm{m}$-koolhaas-and-reinier-de-graaf

80 Ibid.

81 In terms of 'contributing factors', this argument is indebted to Polanyi's argument on tacit knowledge - particularly the part resting on the Gestalt theory of perception, where the individual characteristics are not apprehended as attributes in themselves, but for how they contribute to the whole. Michael Polanyi, The Tacit Dimension (Chicago: University of Chicago Press, 1966).

82 Ungers, Quadratische Häuser, author's translation. 
83 Koolhaas, 'Less Is More'.

84 Rem Koolhaas in conversation with Sarah Whiting, 'Spot Check', Assemblage 40 (1999), 36-55: 49.

85 This is also indebted to Polanyi's argument on contributing features that are understood by their relation to the whole.

86 This not only picks up a typical argument along the lines of biological (Darwinian) metaphor, but also appeals strongly to Ludwig Wittgenstein's suggestion that certain categories are identified more by virtue of family resemblances than by clear rules. He develops this notion in relation to games, which are defined by various overlapping similarities, but include no single feature that is common to all. This idea shares a number of elements with Polanyi's idea on the apprehension of contributing features.

87 M. Christine Boyer, Le Corbusier: Homme de Lettres (New York: Princeton Architectural Press, 2011).

88 Bernard Leupen, 'Interview Koolhaas', in: Bernard Leupen (ed.), IJplein Amsterdam (Rotterdam: 010, 1992), 67; Lara Schrijver, 'Stubborn Modernity: IJ-Plein Amsterdam', OASE 94 (2015), 109-115.

89 Viollet-le-Duc, Entretiens sur l'Architecture (1863).

90 'Man transForms', exhibition at Cooper-Hewitt 1976. Later, Ungers published his installation with an accompanying essay on images and metaphors, as Morphologie / City Metaphors.

91 'People can inhabit anything. And they can be miserable in anything and ecstatic in anything. More and more I think architecture has nothing to do with it. Of course that's both liberating and alarming.' Interview in Wired magazine, July 1996, see: wired.com/wired/archive/4.07/koolhaas. html.

\section{Epilogue: Recalibrating the Profession}

1 Bernard Tschumi, 'Advertisements for Architecture', project, 1976-1977.

2 While the age difference between Koolhaas and Ungers was nearly 20 years, they can be considered to share a sociological generation as defined by Karl Mannheim, who argues that substantial societal shifts or experiences can equally define a generation. Karl Mannheim, 'The Problem of Generations', in: Karl Mannheim, Essays on the Sociology of 
Knowledge, edited by Paul Kecsemeti (London: Routledge and Kegan Paul, 1952 [1927]), 276-320.

3 The full report and the summary for policymakers, which lays out the main conclusions, are available online at https://www.ipcc.ch/sr15/ The reports since have underscored the further intensification of these issues.

4 Reinier de Graaf, Four Walls and a Roof (Cambridge, MA: Harvard University Press, 2018).

5 Saskia Sassen, Expulsions: Brutality and Complexity in the Global Economy (Cambridge, MA: Harvard University Press, 2014); Fredrik Gertten, Push (documentary film, 2019); Reinier de Graaf, Four Walls and a Roof (Cambridge, MA: Harvard University Press, 2018).

6 The Toronto rent strikes in the Parkdale neighbourhood are shown in Fredrik Gertten's documentary Push (2019). A variety of television series and documentaries show individual approaches to housing security, such as Living Mortgage-Free, and Tiny House Nation.

7 Anna Tsing, lecture UCSC Center for Cultural Studies, 28 October 2020, culturalstudies.ucsc.edu/2020/09/23/october-28-2020-anna-tsing -feral-atlas-the-more-than-human-anthropocene/. 


\section{Cultural Studies}

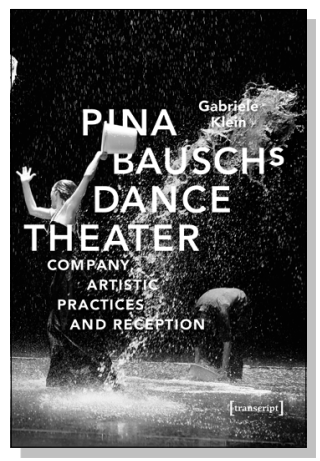

Gabriele Klein

Pina Bausch's Dance Theater

Company, Artistic Practices and Reception

2020, 440 p., pb., col. ill.

29,99€ (DE), 978-3-8376-5055-6

E-Book:

PDF: 29,99 € (DE), ISBN 978-3-8394-5055-0

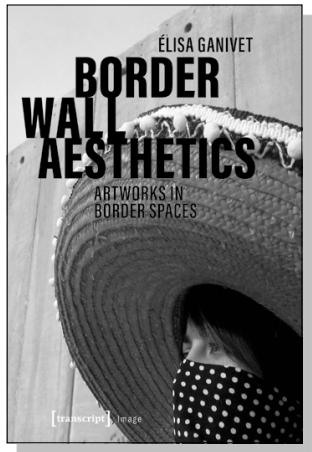

Elisa Ganivet

\section{Border Wall Aesthetics}

Artworks in Border Spaces

2019, 250 p., hardcover, ill.

79,99€ (DE), 978-3-8376-4777-8

E-Book:

PDF: 79,99€ (DE), ISBN 978-3-8394-4777-2

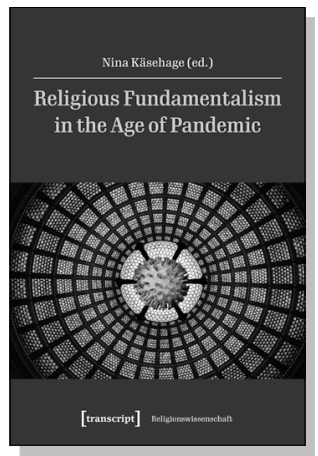

Nina Käsehage (ed.)

\section{Religious Fundamentalism} in the Age of Pandemic

April 2021, 278 p., pb., col. ill. 37,00 € (DE), 978-3-8376-5485-1

E-Book: available as free open access publication PDF: ISBN 978-3-8394-5485-5 


\section{Cultural Studies}
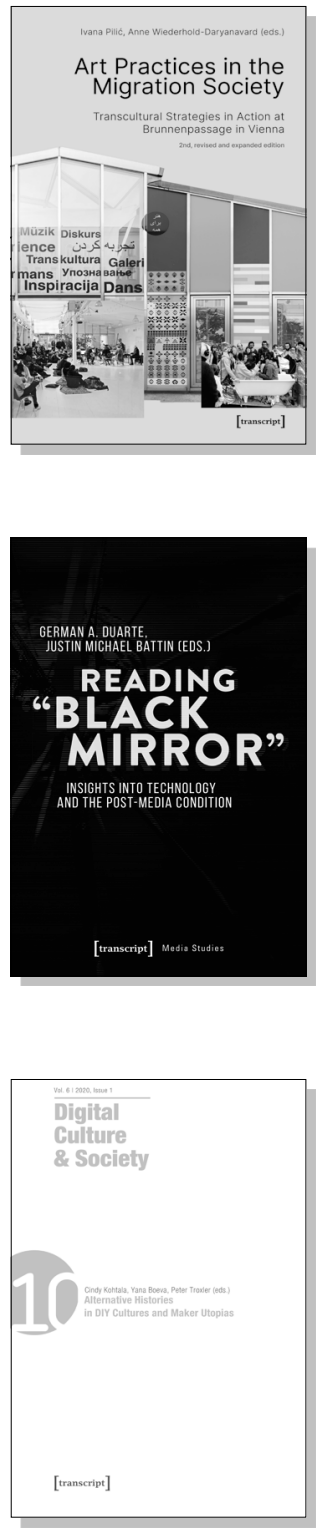

Ivana Pilic, Anne Wiederhold-Daryanavard (eds.) Art Practices in the Migration Society Transcultural Strategies in Action at Brunnenpassage in Vienna

March 2021, 244 p., pb.

29,00€ (DE), 978-3-8376-5620-6

E-Book:

PDF: 25,99€ (DE), ISBN 978-3-8394-5620-0

German A. Duarte, Justin Michael Battin (eds.)

\section{Reading "Black Mirror"}

Insights into Technology and the Post-Media Condition

January 2021, 334 p., pb.

32,00€ (DE), 978-3-8376-5232-1

E-Book:

PDF: 31,99 € (DE), ISBN 978-3-8394-5232-5

Cindy Kohtala, Yana Boeva, Peter Troxler (eds.)

\section{Digital Culture \& Society (DCS)}

Vol. 6, Issue 1/2020 -

Alternative Histories in DIY Cultures and Maker Utopias

February 2021, 214 p., pb., ill.

29,99€ (DE), 978-3-8376-4955-0

E-Book:

PDF: 29,99€ (DE), ISBN 978-3-8394-4955-4 